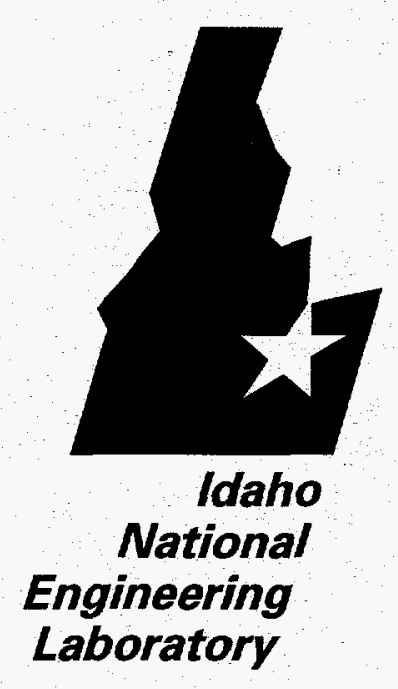

INEL-95/0494

November, 1995

JA1 101905

OSTI

\title{
ATR NEUTRON SPECTRAL CHARACTERIZATION
}

JW Rogers and R. A. Anderl 


\section{DISCLAIMER}

This report was prepared as an account of work sponsored by an agency of the United States Covemment. Noither the United States Govemment nor any agency thereof, nor any of their employees, makes amy warranty, express or implied, or assumes any lopel liablity or responsibility for the accuracy, completenoss, or usefuineses of any intormation, apparatus, proctuct or process disclosed. of represents that its use would not infinge privately owned rights. References herein to any specific commercial product, process, or service by trade name, trademark. manufacturer, or othenvise, does not necessarity constituto or imply its endorsement, recommendation, or favoring by the United States Covemment or amy agency thereof. The views and opinions of authors expressed herein do not necessarily state of reflect those of the United States Govemment or any agenoy thereot. 


\title{
ATR NEUTRON SPECTRAL CHARACTERIZATION*
}

JW Rogers and R. A. Anderl

\author{
Idaho National Engineering Laboratory \\ Lockheed Idaho Technologies Company \\ P. 0. Box 1625 \\ Idaho Falls, Idaho USA 83415-7111
}

November, 1995

*Work supported by U. S. Department of Energy, Office of Nuclear Energy, Idaho Operations Office, under Contract No. DE-AC07-94ID13223. 
-

.

$i i$ 


\section{DISCLAMMER}

Portions of this document may be illegible in electronic image products. Images are produced from the best available original document. 


\section{SUMMARY}

This report documents the results of a detailed characterization of neutron fields in the ATR. The results are based on both the more historical, routine neutron dosimetry measurements and on a comprehensive dosimetry experiment that involved dosimeter irradiation during Cycle 73A-8, neutronics calculations and least-squares-adjustment analyses.

Routine neutron dosimetry has focused on measurements to determine integral fluence rates for three spectral regions: thermal, epithermal and fast. Historically, bare and "Cd-covered" cobalt have been used to monitor the thermal and epithermal neutron regions via the ${ }^{59} \mathrm{Co}(\mathrm{n}, \gamma)^{60} \mathrm{Co}$ reaction. In some cases $\mathrm{Ag}$ and ${ }^{6} \mathrm{Li}$ dosimeters have been used to complement the thermal and epithermal monitoring via the ${ }^{109} \mathrm{Ag}(\mathrm{n}, \gamma)^{110 \mathrm{~m}} \mathrm{Ag}$ and ${ }^{6} \mathrm{Li}(\mathrm{n}, \alpha)^{3} \mathrm{H}$ reactions. The fast-neutron region (neutrons with energies greater than $1 \mathrm{MeV}$ ) has historically been monitored with $\mathrm{Ni}$ dosimeters via the ${ }^{58} \mathrm{Ni}(\mathrm{n}, \mathrm{p})^{58} \mathrm{Co}$ reaction. In this report we summarize the results of these spectral measurements for the following irradiation locations: A-holes, B(inner and outer)-holes, $\mathrm{H}$-holes, SR-holes, I(small, medium and large)-holes and in the small and large inpile tubes. This characterization is in terms of the usual spectral indices: $2200 \mathrm{~m} / \mathrm{s}$ thermal neutron fluence rates, greater than $1-\mathrm{MeV}$ neutron fluence rates, thermal/fast ratio, ${ }^{59} \mathrm{Co}(\mathrm{n}, \gamma)$-cadmium ratio and thermal response fraction.

More detailed characterization of the epithermal and fast neutron energy ranges has been done for the following irradiation locations: A-1, A-10, A-12, B-4, B-8, B-11, H-2, H-10, H-14, I-6, I-8, I$22, \mathrm{SE}(\mathrm{SR})-1, \mathrm{SE}(\mathrm{SR})-3$, and OS-5. These studies required irradiation of Cd-covered dosimeter packages at core-midplane of the reactor during Cycle73A-8 in 1986. During this Cycle the reactor was operated at a total power level of $10 \mathrm{MW}$ for 8 hours. Five dosimeter reactions, $\left[{ }^{45} \mathrm{Sc}(\mathrm{n}, \gamma){ }^{46} \mathrm{Sc},{ }^{197} \mathrm{Au}(\mathrm{n}, \gamma){ }^{198} \mathrm{Au},{ }^{235} \mathrm{U}(\mathrm{n}, \mathrm{f}),{ }^{59} \mathrm{Co}(\mathrm{n}, \gamma){ }^{60} \mathrm{Co}\right.$, and ${ }^{58} \mathrm{Fe}(\mathrm{n}, \gamma){ }^{39} \mathrm{Fe}$ ], were used to monitor the intermediate energy region from $0.4 \mathrm{eV}$ to $\sim 10 \mathrm{keV}$. Nine dosimeter reactions, $\left[{ }^{237} \mathrm{~Np}(\mathrm{n}, \mathrm{f}),{ }^{238} \mathrm{U}(\mathrm{n}, \mathrm{f}),{ }^{47} \mathrm{Ti}(\mathrm{n}, \mathrm{p}){ }^{47} \mathrm{Sc},{ }^{58} \mathrm{Ni}(\mathrm{n}, \mathrm{p}){ }^{58} \mathrm{Co},{ }^{54} \mathrm{Fe}(\mathrm{n}, \mathrm{p}){ }^{54} \mathrm{Mn},{ }^{46} \mathrm{Ti}(\mathrm{n}, \mathrm{p}){ }^{46} \mathrm{Sc},{ }^{63} \mathrm{Cu}(\mathrm{n}, \alpha){ }^{60} \mathrm{Co}\right.$, ${ }^{48} \mathrm{Ti}(\mathrm{n}, \mathrm{p}){ }^{48} \mathrm{Sc}$, and ${ }^{27} \mathrm{Al}(\mathrm{n}, \alpha){ }^{24} \mathrm{Na}$ ], were used to monitor the fast-neutron region from $0.1 \mathrm{MeV}$ to $\sim 10 \mathrm{MeV}$. Reaction rates for each of the dosimeters were determined in post-irradiation measurements and analyses based on the use of calibrated germanium detectors to measure gamma-rays from the dosimeter activation products. These reaction-rate data were subsequently used in least-squares-adjustment analyses with the FERRET data analysis code to establish a more accurate and detailed characterization of the neutron spectra in the irradiation locations.

The FERRET analyses required the following input data: measured reaction rates and uncertainties, 51-group representations of the neutron spectra and corresponding covariance descriptions, 51-group representations of the dosimeter cross sections and corresponding covariances, and a 51-group histogram to represent neutron absorption in the $\mathrm{Cd}$ cover. A significant amount of data processing was required to generate this input data. The input 51group spectra were derived from neutronics calculations using the SCAMP and PDQ-7 codes and an interpolation code to convert the 73-group SCAMP result into the 51-group analysis group structure. This energy structure was selected to best represent spectral structure and the regions of dosimeter response. Reactor-spectrum weighting, using a 620-group representation of the 
ATR H-2 irradiation location, was used to prepare a 51-group library of dosimeter cross sections from the 620-group dosimetry file on ENDF/B-V. Covariance descriptions for the input fluxes were based on two uncertainty components, one a normalization uncertainty and secondly, groupwise uncertainties that were correlated with a Gaussian parametric formulation. Covariance matrices for the dosimeter cross sections were derived from covariance files on ENDF/B-V. Finally, the Cd-cover correction factor was derived from 51-group calculated spectra corresponding to bare and $\mathrm{Cd}$-covered dosimeters in the $\mathrm{H}-2$ hole. A somewhat detailed description of this analysis methodology is given in this report.

Individual FERRET analyses were made for the reaction-rate data corresponding to the various reactor regions, namely, A, H, SR, B, I, and OS-5. For each region this meant a simultaneous adjustment of group-fluence rates corresponding to the input spectra and the respective reactionrate data for each location in that region, e.g., A-1, A-10 and A-12 locations for region A. The results of these analyses are compiled in the Appendix of this report. For each irradiation location, the compilation includes the following: a table that compares measured reaction-rate data to calculated reaction-rate data, both before adjustment and after FERRET adjustment; a figure that compares the unadjusted (input) and FERRET-adjusted 51-group neutron spectra along with a plot of uncertainties for each; a table of the 51-group fluence-rate values and uncertainties; and a table of cumulative group fluence values that were derived from the adjusted group fluences. A cumulative group fluence rate value corresponds to the sum of all neutrons above the lower energy boundary of the group. The results show a high degree of consistency between the measured reaction rates and the reaction rates calculated using the adjusted spectra. Significant reductions in the uncertainty specifications were obtained for the group and cumulative fluence rates. These tables of adjusted group fluence rates and cumulative fluence values are available from the authors on electronic files, either as EXCEL worksheets or as ASC-II files. Information is also provided such that this fluence-rate information can be scaled to other power levels of operation for the ATR.

In addition to an extensive spectral characterization, this work also generated spectrum-averaged cross sections that can be used for neutron spectrum monitoring and for damage-production calculations for materials irradiated in the ATR. The spectrum-averaged cross sections correspond to the dosimeter reactions identified above for the detailed dosimetry experiment. Spectrum-averaged, damage production cross sections were generated using multigroup representations of the displacement-damage cross sections for $\mathrm{Fe}, \mathrm{Cr}$ and $\mathrm{Ni}$, as given in the 1985 International Reactor Dosimetry File, and 51-group adjusted fluence rate spectra from the FERRET analyses. In both cases, the resultant spectrum-averaged cross sections and associated uncertainties provide more accurate information that can be used for better monitoring of neutron fluence rates and displacement damage rates for materials irradiation testing in the ATR.. 


\section{ACKNOWLEDGMENTS}

Several people and groups were instrumental in contributing to this work. We would like to acknowledge the early support of J. T. Parks and more recent support of D. C. Mecham and D. L. Batt for this effort. The Radiation Measurements Laboratory staff provided the radioactivity measurements for the activated dosimeters. J. D. Abrashoff performed the neutronics calculations that served as the basis for input spectra for the FERRET analyses. M. H. Putnam provided much computer software support for the FERRET analyses. 


\section{CONTENTS}

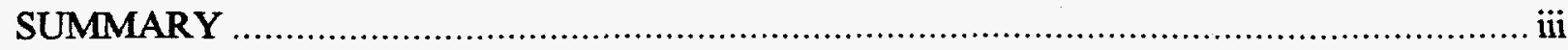

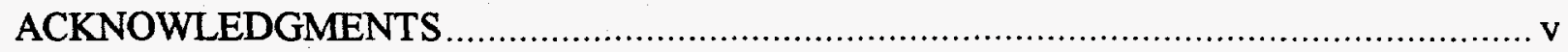

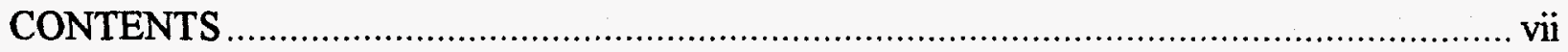

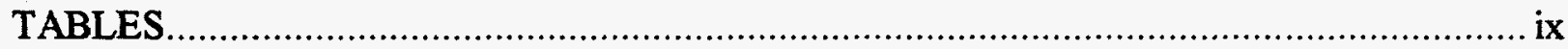

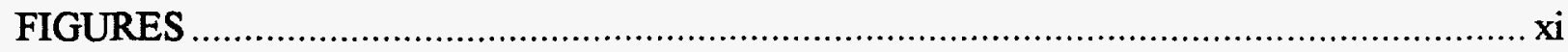

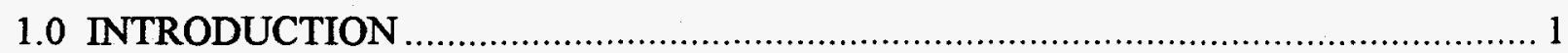

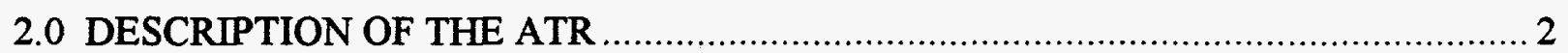

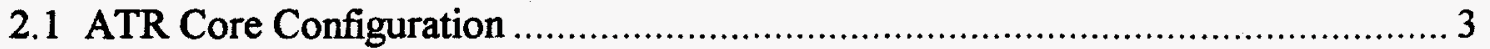

2.2 General Characterization of Neutron Irradiation Locations................................. 3

3.0 MULTIGROUP NEUTRON SPECTRAL CHARACTERIZATION .......................... 7

3.1 Dosimeter Irradiation and Analysis ...................................................... 7

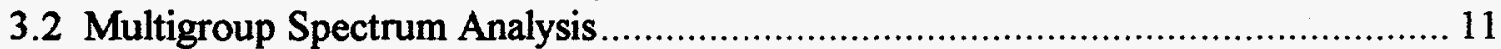

3.2.1 Analysis Methodology ........................................................ 11

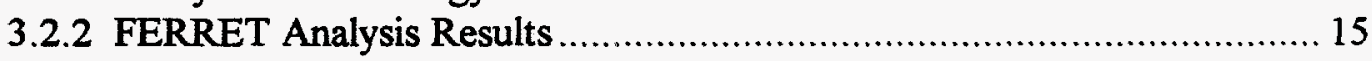

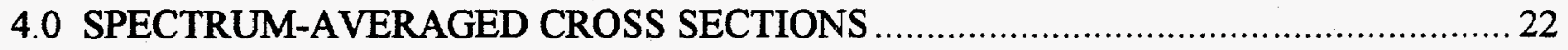

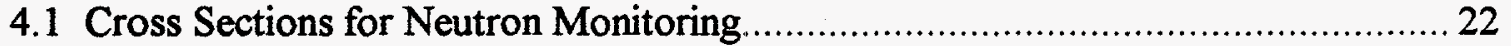

4.2 Neutron Damage Production in ATR Irradiation Locations ............................ 23

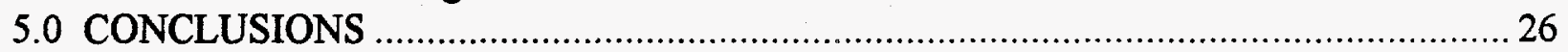

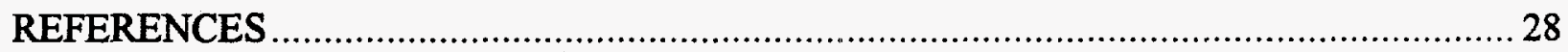

APPENDIX. DETAILED SUMMARY OF RESUILTS FROM FERRET ANALYSES ........ 29 



\section{TABLES}

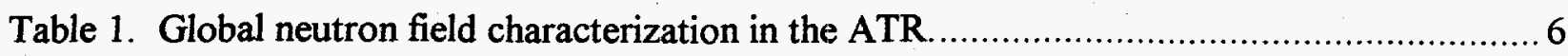

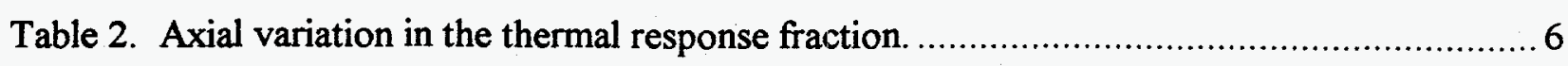

Table 3. Dosimeter materials for detailed characterization of ATR spectra ............................... 8

Table 4. Neutron energy response ranges for the dosimeter reactions in an $\mathrm{H}-2$ location. ............ 8

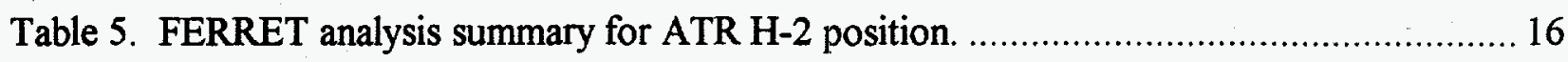

Table 6. Comparison of adjusted and input group fluxes for H-2 ….................................. 19

Table 7. Comparison of adjusted and input cumulative group fluxes for $\mathrm{H}-2$............................ 20

Table 8. Spectrum-averaged cross sections (barns) for neutron dosimeters. ..............................2

Table 9. Damage production in selected ATR irradiation locations. ....................................... 24

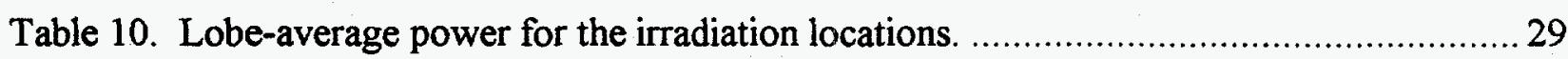

Table A. FERRET analysis summary for ATR A positions. ................................................. 32

Table A1. Adjusted group fluence rates for A-1 irradiation location.......................................... 34

Table A2. Cumulative adjusted group fluence rates for A-1 irradiation location. .......................35

Table A3. Adjusted group fluence rates for A-10 irradiation location...................................... 37

Table A4. Cumulative adjusted group fluence rates for A-10 irradiation location. ......................38

Table A5. Adjusted group fluence rates for A-12 irradiation location................................... 40

Table A6. Cumulative Adjusted group fluence rates for A-12 irradiation location. .................... 41

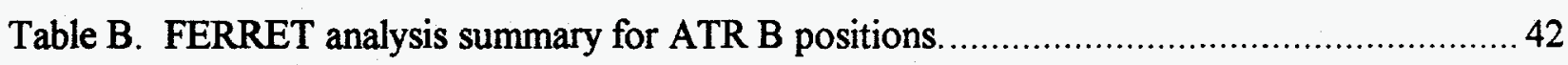

Table B1. Adjusted group fluence rates for B-1 irradiation location. ...................................... 44

Table B2. Cumulative adjusted group fluence rates for B-1 irradiation location. ...................... 45

Table B3. Adjusted group fluence rates for B-8 irradiation location .................................... 47

Table B4. Cumulative adjusted group fluence rates for B-8 irradiation location. ....................... 48

Table B5. Adjusted group fluence rates for B-11 irradiation location. ..................................... 50 
Table B6. Cumulative Adjusted group fluence rates for B-11 irradiation location.

Table $H$. FERRET analysis summary for ATR $H$ positions. ................................................. 52

Table H1. Adjusted group fluence rates for H-2 irradiation location. ....................................5 54

Table H2. Cumulative adjusted group fluence rates for H-2 irradiation location. ......................55

Table H3. Adjusted group fluence rates for H-10 irradiation location.................................57

Table H4. Cumulative adjusted group fluence rates for H-10 irradiation location. ....................58

Table H5. Adjusted group fluence rates for H-14 irradiation location......................................60

Table H6. Cumulative Adjusted group fluence rates for H-14 irradiation location. ....................61

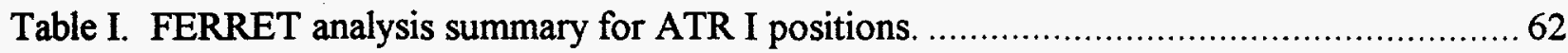

Table I1. Adjusted group fluence rates for I-6 irradiation location. ........................................64

Table I2. Cumulative adjusted group fluence rates for I- 6 irradiation location. ........................65

Table I3. Adjusted group fluence rates for I-8 irradiation location. ....................................67

Table 14. Cumulative adjusted group fluence rates for I-8 irradiation location. ........................68

Table 15. Adjusted group fluence rates for I-22 irradiation location. .................................... 70

Table 16. Cumulative Adjusted group fluence rates for I-22 irradiation location. .....................71

Table OS. FERRET analysis summary for ATR OS-5 position. …….................................... 72

Table OS1. Adjusted group fluence rates for OS-5 irradiation location. ….............................74

Table OS2. Cumulative adjusted group fluence rates for OS-5 irradiation location................... 75

Table SE. FERRET analysis summary for ATR SE positions.................................................76

Table SE1. Adjusted group fluence rates for SE-1 irradiation location................................. 78

Table SE2. Cumulative adjusted group fluence rates for SE-1 irradiation location. …...............79

Table SE3. Adjusted group fluence rates for SE-3 irradiation location.................................. 81

Table SE4. Cumulative adjusted group fluence rates for SE-3 irradiation location. …...............82 82 


\section{FIGURES}

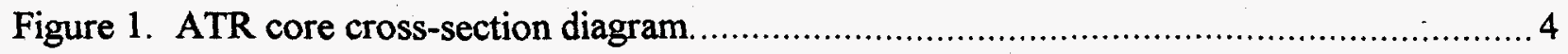

Figure 2. Multigroup response for low-energy dosimeter reactions in the H-2 location. 10

Figure 3. Multigroup response for high-energy threshold dosimeter reactions in the H-2 location. 10

Figure 4. Comparison of calculated 73-group fluxes and the interpolated, smoothed 51-group fluxes for the $\mathrm{H}-2$ location with "no Cd".

Figure 5. Comparison of calculated 73-group fluxes and interpolated, smoothed, 51-group fluxes for a "Cd-covered" $\mathrm{H}-2$ location.

Figure 6. Multigroup cadmium shielding factors for the H-2 location.

Figure 7. Comparison of calculated 73-group fluxes and the interpolated, smoothed 620-group fluxes for the $\mathrm{H}-2$ location with "no-Cd".

Figure 8. Upper part of figure compares adjusted and unadjusted (input) group fluence rates for H-2 location and lower part displays the ratio of adjusted-to-unadjusted group values with input uncertainty bounds and final uncertainty error bars.

Figure 9. Comparison of final adjusted spectra for ATR locations characterized in this work. ... 21

Figure 10. Comparison of multigroup damage response for Fe using adjusted ATR spectra. .... 25

Figure 11. Comparison of multigroup damage response for $\mathrm{Cr}$ using adjusted ATR spectra. .... 25

Figure 12. Comparison of multigroup damage response for Ni using adjusted ATR spectra. .... 26

Figure A1. Upper part of figure compares adjusted and unadjusted (input) group fluence rates for A-1 location and lower part displays the ratio of adjusted-to-unadjusted group values with input uncertainty bounds and final uncertainty error bars....

Figure A2. Upper part of figure compares adjusted and unadjusted (input) group fluence rates for A-10 location and lower part displays the ratio of adjusted-to-unadjusted group values with input uncertainty bounds and final uncertainty error bars. 36

Figure A3. Upper part of figure compares adjusted and unadjusted (input) group fluence rates for A-12 location and lower part displays the ratio of adjusted-to-unadjusted group values with input uncertainty bounds and final uncertainty error bars.

Figure B1. Upper part of figure compares adjusted and unadjusted (input) group fluence rates for B-1 location and lower part displays the ratio of adjusted-to-unadjusted group values with input uncertainty bounds and final uncertainty error bars. 
Figure B2. Upper part of figure compares adjusted and unadjusted (input) group fluence rates for B-8 location and lower part displays the ratio of adjusted-to-unadjusted group values with input uncertainty bounds and final uncertainty error bars.

Figure B3. Upper part of figure compares adjusted and unadjusted (input) group fluence rates for B-11 location and lower part displays the ratio of adjusted-to-unadjusted group values with input uncertainty bounds and final uncertainty error bars.

Figure H1. Upper part of figure compares adjusted and unadjusted (input) group fluence rates for H-2 location and lower part displays the ratio of adjusted-to-unadjusted group values with input uncertainty bounds and final uncertainty error bars.

Figure H2. Upper part of figure compares adjusted and unadjusted (input) group fluence rates for H-10 location and lower part displays the ratio of adjusted-to-unadjusted group values with input uncertainty bounds and final uncertainty error bars.

Figure H3. Upper part of figure compares adjusted and unadjusted (input) group fluence rates for H-14 location and lower part displays the ratio of adjusted-to-unadjusted group values with input uncertainty bounds and final uncertainty error bars.

Figure I1. Upper part of figure compares adjusted and unadjusted (input) group fluence rates for I-6 location and lower part displays the ratio of adjusted-to-unadjusted group values with input uncertainty bounds and final uncertainty error bars.

Figure I2. Upper part of figure compares adjusted and unadjusted (input) group fluence rates for I-8 location and lower part displays the ratio of adjusted-to-unadjusted group values with input uncertainty bounds and final uncertainty error bars.

Figure 13. Upper part of figure compares adjusted and unadjusted (input) group fluence rates for I-22 location and lower part displays the ratio of adjusted-to-unadjusted group values with input uncertainty bounds and final uncertainty error bars.

Figure OS1. Upper part of figure compares adjusted and unadjusted (input) group fluence rates for OS-5 location and lower part displays the ratio of adjusted-to-unadjusted group values with input uncertainty bounds and final uncertainty error bars.

Figure SE1. Upper part of figure compares adjusted and unadjusted (input) group fluence rates for SE-1 location and lower part displays the ratio of adjusted-to-unadjusted group values with input uncertainty bounds and final uncertainty error bars.

Figure SE2. Upper part of figure compares adjusted and unadjusted (input) group fluence rates for SE-3 location and lower part displays the ratio of adjusted-to-unadjusted group values with input uncertainty bounds and final uncertainty error bars. 


\subsection{INTRODUCTION}

The Advanced Test Reactor (ATR) at the Idaho National Engineering Laboratory (INEL) provides intense neutron fields for irradiation-effects testing of reactor material samples (fuel, cladding, control and structural materials) and for production of radionuclides used in industrial and medical applications as well as for scientific research. To quantify the influence of intense neutron exposure on materials and the production of radionuclides, an accurate knowledge of the neutron environment is required. Characterization of the neutron environments in the irradiation locations of the ATR has been done by means of neutronics calculations and by means of neutron dosimetry based on the use of neutron activation monitors that are placed in the various irradiation locations. The primary purpose of this report is to present the results of an extensive characterization of several ATR irradiation locations based on neutron dosimetry measurements and on least-squares-adjustment analyses that utilize both neutron dosimetry measurements and neutronics calculations.

In general, neutrons in the core of a light-water moderated reactor like the ATR have energies ranging from thermal energies, represented by a Maxwellian distribution with a most probable energy of $0.0253 \mathrm{eV}$ if the reactor coolant temperature is $20.4^{\circ} \mathrm{C}$, to fast neutrons with energies greater than $2.2 \mathrm{MeV}$, the most probable energy in the energy distribution for ${ }^{235} \mathrm{U}$ fission neutrons. Although the neutron energy distribution is continuous over the energy range, it is often described in terms of three regions: (1) thermal region with neutrons of energies from 0 to $0.4 \mathrm{eV},(2)$ intermediate (also referred to as resonance or epithermal) region with neutron energies from $0.4 \mathrm{eV}$ to $0.1 \mathrm{MeV}$, and (3) fast region with neutron energies greater than $0.1 \mathrm{MeV}$. The first region consists primarily of the Maxwellian thermal distribution. Neutrons generated by inelastic scattering processes in the moderator comprise the second region, often referred to as the $1 / \mathrm{E}$ region, where $\mathrm{E}$ is the neutron energy. The ${ }^{235} \mathrm{U}$ fission-spectrum distribution is the primary component in the fast region.

Historically, neutron activation monitors with characteristic cross-section responses in the various regions have been used to quantify the neutron fluence rates or fluxes in these regions. For example, activation of bare cobalt and cadmium-covered cobalt wires via the ${ }^{59} \mathrm{Co}(\mathrm{n}, \gamma)^{60} \mathrm{Co}$ reaction has been historically used to determine the thermal and intermediate-energy components of the neutron spectrum. The $(n, \gamma)$ cross section for ${ }^{59} \mathrm{Co}$ has a $1 / \mathrm{v}$ component that responds to thermal neutrons, where $v$ is the velocity of the neutron, and a large resonance at $132 \mathrm{eV}$ that responds to intermediate-energy neutrons. The use of a $0.0505-\mathrm{cm}$ thick cadmium cover essentially removes all neutrons with energies less than $0.414 \mathrm{eV}$. Hence, the Cd-covered monitor responds only to the intermediate-energy component and the bare wire responds to the thermal plus intermediate-energy neutrons. The difference in activation between the bare and $\mathrm{Cd}$-covered cobalt then corresponds to the response only to the thermal component. In addition, activation of nickel wires via the ${ }^{58} \mathrm{Ni}(\mathrm{n}, \mathrm{p})^{58} \mathrm{Co}$ threshold reaction has been used to determine the fast neutron component of a reactor spectrum. The cross section for this $(n, p)$ reaction has an effective threshold of $\sim 1.2 \mathrm{MeV}$, hence it provides a measure of the fluence rate for neutrons above this 
energy. Reference 1 provides a detailed description of the various techniques for measuring neutron fluences that correspond to the three neutron spectral regions identified above. Routine monitoring of the "thermal" and "fast" neutron levels has been conducted in the ATR during every operational cycle since its startup in 1970. This routine neutron dosimetry has been primarily accomplished using the ${ }^{59} \mathrm{Co}(\mathrm{n}, \gamma){ }^{60} \mathrm{Co}$ reaction for "thermal" neutrons and the ${ }^{58} \mathrm{Ni}(\mathrm{n}, \mathrm{p}){ }^{58} \mathrm{Co}$ reaction for "fast" neutrons as described in ASTM standard methods E 261, E 262 and $\mathrm{E} 26$ [2].

In 1986, more detailed neutron spectrum studies were initiated for various irradiation locations in the ATR, namely, A-1, A-10, A-12, B-4, B-8, B-11, H-2, H-10, H-14, I-6, I-8, I-22, OS-5, SE(SR)-1, and SE(SR)-3. These studies entailed irradiation of cadmium-covered neutron activation monitors during cycle $73 \mathrm{~A}-8$, post-irradiation measurements of the induced radioactivity, a determination of the dosimeter reaction rates, transport and diffusion-theory calculations of representative reactor neutron spectra, and, finally, least-squares-adjustment analyses to improve the characterization of the various neutron spectra. The primary purpose of this work was to obtain a better characterization of the intermediate energy and fast neutron spectral regions for the various irradiation locations. Hence, the neutron activation monitor sets included a variety of reactions that provided a more detailed response in the intermediate-energy and fast-neutron regions. Early results of this work have been reported previously $[3,4]$. Reference 3 provides a description of the measurements and analyses made for the $\mathrm{H}$-hole locations. That report also discusses in some detail aspects of the least-squares-adjustment analysis methodology that was adopted for these spectrum-characterization studies. Reference 4 provides a summary report of the least-squares-adjustment analyses for all irradiation locations, as prepared for presentation at a technical meeting on reactor dosimetry.

This report builds upon the previous publications, especially the reference 4 paper. Section 2 provides a brief description of the ATR and it tabulates neutron spectral information for typical irradiation locations, as derived from the more historical neutron dosimetry measurements. Relevant details that pertain to the multigroup neutron spectral characterization are covered in section 3. This discussion includes a presentation on the dosimeter irradiation and analyses and a development of the least-squares adjustment methodology, along with a summary of the results of these analyses. Spectrum-averaged cross sections for neutron monitoring and for displacementdamage prediction in $\mathrm{Fe}, \mathrm{Cr}$, and $\mathrm{Ni}$ are given in section 4 . In addition, section 4 includes estimates of damage generation rates for these materials in selected ATR irradiation locations. In section 5, we present a brief discussion of the most significant conclusions of this work and comment on its relevance to the present ATR core configuration. Finally, detailed numerical and graphical results for the spectrum-characterization analyses in each irradiation location are provided in the Appendix.

\subsection{DESCRIPTION OF THE ATR}

This section includes a brief description of the ATR core configuration at the time of Cycle 73A-8 and provides a summary description of the neutron environment, as derived from the historical neutron dosimetry measurements. 


\subsection{ATR Core Configuration}

Figure 1 provides a cross-sectional view of the uniquely designed ATR core that consists of a serpentine fuel-assembly arrangement (four lobes) to allow instrumented, inpile loop experiments, irradiation holes for capsule experiments, and safety and control device locations. Fueled with forty plate-type assemblies (enriched uranium in an aluminum cladding and matrix), the core has an active length of 1.22 meters and it is cooled with light water $\left(75^{\circ} \mathrm{C}\right.$ at a nominal power of $\sim 150 \mathrm{MW}$ ). The core is surrounded by a beryllium reflector and by hafnium control cylinders that are used primarily to adjust individual core lobe power. Hafnium fixed (neck) shims, located inside the fuel arrangement (in the neck shim-rod housing), are also used primarily to compensate for fuel burnup. The safety rod followers have holes (SR) in them where the neutron monitors are positioned during routine operation. Capsule irradiation holes (A, H, B, SR) located in the corestructural and reflector regions provide for sample irradiations at high neutron levels. Lower neutron level irradiations are provided by the I-holes and capsule irradiation tanks located outside the core-reflector tank on the north (ON) and south (OS) sides.

\subsection{General Characterization of Neutron Irradiation Locations}

A general characterization of the neutron irradiation locations has been achieved since the startup of ATR by means of neutron activation dosimetry. The objective of these measurements was to obtain effective fluence rate values that correspond to the three regions defined previously as thermal, intermediate and fast.

Three approaches have been used to determine the thermal neutron fluence rates: (1) activation of Co and Cd-covered Co, ASTM Standard E 262 [2], (2) activation of Co and Ag, ASTM Standard E 481 [2], and (3) transmutation of ${ }^{6} \mathrm{Li}$, ASTM Standard E 910 [2]. These approaches utilize the following neutron capture reactions: ${ }^{59} \mathrm{Co}(\mathrm{n}, \gamma)^{60} \mathrm{Co},{ }^{109} \mathrm{Ag}(\mathrm{n}, \gamma)^{110 \mathrm{~m}} \mathrm{Ag}$, and ${ }^{6} \mathrm{Li}(\mathrm{n}, \alpha)^{3} \mathrm{H}$. The $(\mathrm{n}, \gamma)$ cross section for ${ }^{59} \mathrm{Co}$ includes both a $1 / \mathrm{v}$ component and a resonance response primarily at 132 $\mathrm{eV}$. The use of a $0.0505-\mathrm{cm}$ thick cadmium cover essentially removes all neutrons with energies less than $0.414 \mathrm{eV}$. Hence, the Cd-covered monitor responds only to the epithermal component and the bare monitor responds to the thermal plus epithermal neutrons. The $(n, \gamma)$ cross section for ${ }^{109} \mathrm{Ag}$ has a resonance response that is similar to that for ${ }^{59} \mathrm{Co}$, but it has a $1 / \mathrm{v}$ component that is $\sim 8$ times lower than that for ${ }^{59} \mathrm{Co}$. The $(n, \alpha)$ cross section for ${ }^{6} \mathrm{Li}$ is effectively pure $1 / \mathrm{v}$. Postirradiation measurements of the radioactive activation products using gamma-spectrometric or ion-chamber techniques provide the $(\mathrm{n}, \gamma)$ reaction rates for the $\mathrm{Co}$ and $\mathrm{Ag}$ monitors. For ${ }^{6} \mathrm{Li}$, a determination of the $(n, \alpha)$ reaction rate is usually done by a mass-spectrometric measurement of ${ }^{4} \mathrm{He}$ or ${ }^{3} \mathrm{He}$ resulting from the reaction-product alpha particles and beta decay of the tritium, respectively. As we discussed briefly in the introduction, the thermal fluence rate is derived from the difference between bare $\mathrm{Co}$ and $\mathrm{Cd}$-covered $\mathrm{Co}$ activation results. Similarly, the thermal neutron fluence rate can be obtained from the bare $\mathrm{Co}$ activation value corrected by the $\mathrm{Ag}$ activation value that is appropriately scaled to account for differences in the absolute magnitudes of the resonance contributions for ${ }^{59} \mathrm{Co}(\mathrm{n}, \gamma)$ and ${ }^{109} \mathrm{Ag}(\mathrm{n}, \gamma)$. Finally, the thermal neutron fluence can be obtained directly from a measurement of the ${ }^{4} \mathrm{He}$ or ${ }^{3} \mathrm{He}$ resulting from the ${ }^{6} \mathrm{Li}$ irradiation. 


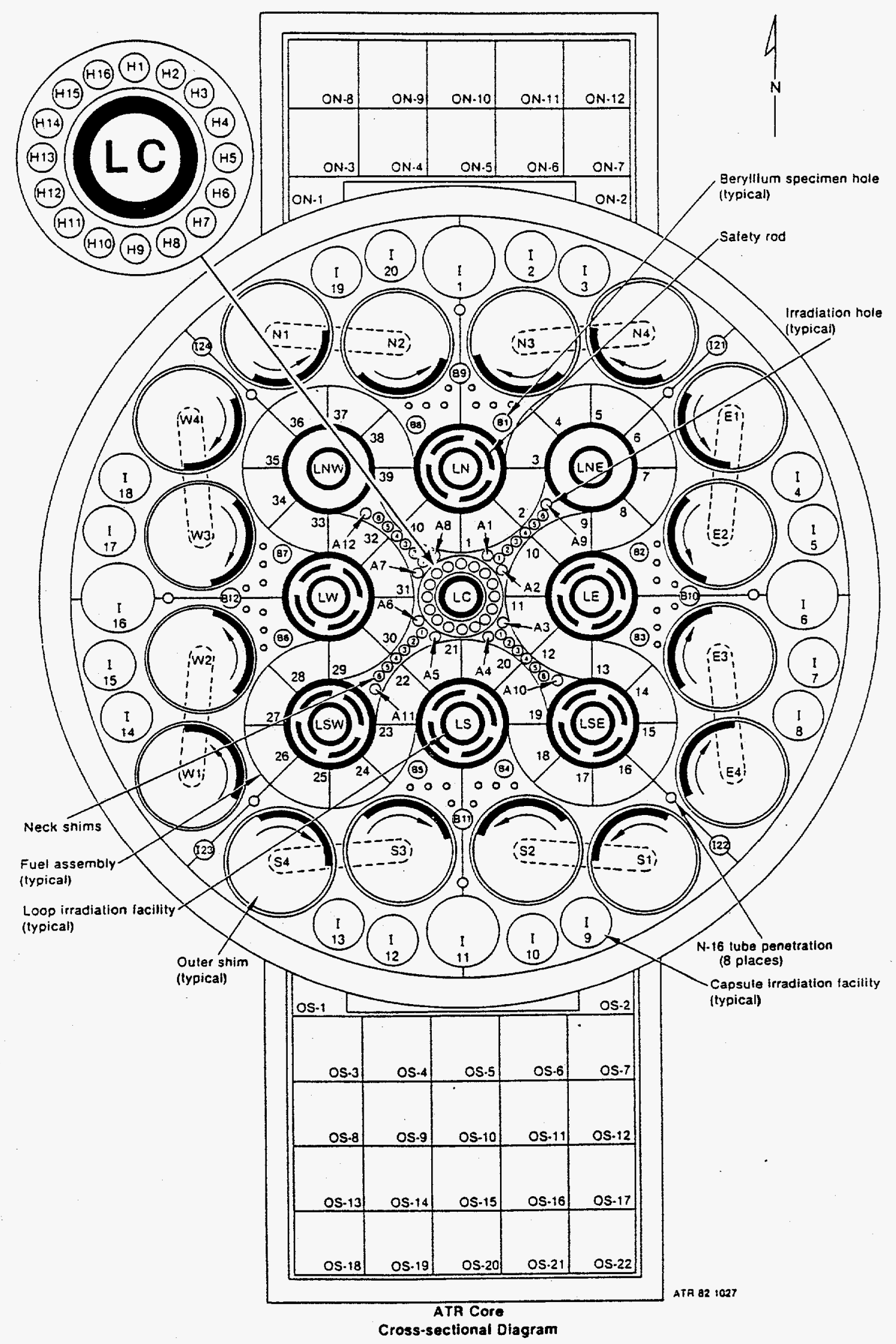

Figure 1. ATR core cross-section diagram. 
For exposure of these neutron monitors in the same irradiation location, under the same irradiation conditions, the derived thermal fluence rates agree very well, within a couple of percent or better, the accuracy of the measurement approach. Systematic studies have also been done to determine whether dosimeter exposure at different power levels and for different irradiation times affected the thermal fluence rates. These studies included irradiation of pure Co at low power and at high power for a short time and irradiation of dilute $\mathrm{Co}$ (Co in $\mathrm{Al}$ matrix) at full power for a typical ATR cycle. These studies indicated no significant variation in the derived thermal neutron fluence rates normalized to a common power level.

Two approaches typically used to determine epithermal neutron fluence rates are : (1) activation of $\mathrm{Co}$ and $\mathrm{Cd}$-covered $\mathrm{Co}$ and (2) activation of $\mathrm{Co}$ and $\mathrm{Ag}$. As discussed previously, the $\mathrm{Cd}-$ covered $\mathrm{Co}$ monitor and the $\mathrm{Ag}$ monitor respond primarily to epithermal neutrons, providing intermediate-energy neutron fluence rates. Both approaches yield consistent fluence-rate values.

Historically, the fast neutron fluence rates for the ATR irradiation locations have been determined from $\mathrm{Ni}$ monitors via the ${ }^{58} \mathrm{Ni}(\mathrm{n}, \mathrm{p}){ }^{58} \mathrm{Co}$ threshold reaction that responds primarily to neutrons greater than $\sim 1.2 \mathrm{MeV}$. Gamma-spectrometric or ion-chamber measurements of the induced ${ }^{58} \mathrm{Co}$ radioactivity were used to determine the $(\mathrm{n}, \mathrm{p})$ reaction rate, and a spectrum-averaged cross section of 133 millibarns was used to determine the greater than $1 \mathrm{MeV}$ neutron fluence rates.

In addition, $\mathrm{Fe}$ and $\mathrm{Ti}$ monitors have been used simultaneously with $\mathrm{Ni}$ monitors for tests to evaluate burnout correction factors and neutron-spectral response range differences in fastneutron fluence rate determinations. The ${ }^{54} \mathrm{Fe}(\mathrm{n}, \mathrm{p})^{54} \mathrm{Mn}$ threshold reaction has an energy response similar to that of ${ }^{58} \mathrm{Ni}(\mathrm{n}, \mathrm{p})^{58} \mathrm{Co}$. However, the reactions have significantly different cross-section levels and decay characteristics. Fast fluence rates derived from the measurements were consistent, providing verification that the ${ }^{58} \mathrm{Co}$ isomer burnout corrections were accurately applied and that the cross-section and decay data were consistent. This monitor comparison test demonstrated that $\mathrm{Ni}$ monitors could be used for accurate fast fluence-rate measurements for both low fluence and high fluence irradiation applications. Finally, the ${ }^{46} \mathrm{Ti}(\mathrm{n}, \mathrm{p}){ }^{46} \mathrm{Sc}$ threshold reaction, with a higher energy response range than that for ${ }^{58} \mathrm{Ni}(\mathrm{n}, \mathrm{p})$, was used to verify spectral-sensitivity assumptions associated with these fast neutron dosimetry approaches

Neutron characterization results for various ATR irradiation locations are summarized in Tables 1 and 2. This information was derived from neutron dosimetry measurements as described in the previous three paragraphs. Table 1 provides a global neutron field characterization in terms of neutron fluence rates and conventional spectral indices. The neutron fluence-rate values correspond to nominal peak values per lobe $\mathrm{MW}$. In this case thermal corresponds to equivalent $2200 \mathrm{~m} / \mathrm{s}$ neutrons and fast corresponds to neutrons with energies greater than $1 \mathrm{MeV}$. The last three columns tabulate conventional spectral indices for these locations. The Thermal/Fast Ratio corresponds to the $2200 \mathrm{~m} / \mathrm{s}$ neutron fluence rate divided by the $>1 \mathrm{MeV}$ neutron fluence rate. The ${ }^{59} \mathrm{Co}(\mathrm{n}, \gamma)$-Cadmium Ratio corresponds to the ratio of induced radioactivities for bare Co to $\mathrm{Cd}$-covered Co. Finally, the thermal response fraction is the fraction of the ${ }^{59} \mathrm{Co}(\mathrm{n}, \gamma)$ reaction rate that is due to subcadmium $(<0.414 \mathrm{eV})$ neutrons. Table 2 provides an indication of the variation in the axial ${ }^{59} \mathrm{Co}(\mathrm{n}, \gamma)$ thermal fraction for three irradiation locations in the ATR. 
Table 1. Global neutron field characterization in the ATR.

\begin{tabular}{|c|c|c|c|c|c|}
\hline $\begin{array}{c}\text { ATR } \\
\text { Location }\end{array}$ & $\begin{array}{c}\text { Thermal* } \\
\text { Fluence Rate } \\
\left(\mathrm{n} / \mathrm{cm}^{2}-\mathrm{s}\right)\end{array}$ & $\begin{array}{c}\text { Fast* }^{*} \\
\text { Fluence Rate } \\
\left(\mathrm{n} / \mathrm{cm}^{2}-\mathrm{s}\right)\end{array}$ & $\begin{array}{c}\text { Thermal/ } \\
\text { Fast } \\
\text { Ratio }^{+}\end{array}$ & $\begin{array}{c}{ }^{59} \mathrm{Co}(\mathrm{n}, \gamma) \\
\text { Cadmium } \\
\text { Ratio } \\
\end{array}$ & $\begin{array}{l}\text { Thermal } \\
\text { Response } \\
\text { Fraction" }\end{array}$ \\
\hline H-holes & $7.5 \mathrm{E} 12$ & $6.5 \mathrm{E} 12$ & 1.1 & 4.0 & 0.75 \\
\hline $\begin{array}{l}\text { A-holes } \\
\text { B-holes }\end{array}$ & $7.5 \mathrm{E} 12$ & $8.0 \mathrm{E} 12$ & 0.9 & 4.0 & 0.75 \\
\hline Inner B & $1.5 \mathrm{E} 13$ & $5.0 \mathrm{E} 12$ & 3.0 & 6.2 & 0.84 \\
\hline Outer B & $4.0 \mathrm{E} 12$ & 7.0E11 & 6.0 & 11 & 0.91 \\
\hline SR-holes & $9.0 \mathrm{E} 12$ & $6.0 \mathrm{E} 12$ & 1.5 & 4.2 & 0.76 \\
\hline $\begin{array}{r}\text { Small Inpile } \\
\text { Tube }\end{array}$ & 7.0E12 & $6.0 \mathrm{E} 12$ & $1.1-2.0$ & & \\
\hline $\begin{array}{r}\text { Large Inpile } \\
\text { Tube }\end{array}$ & 8.5E12 & 4.0E 12 & $2.0-3.5$ & & \\
\hline $\begin{array}{l}\text { I-holes } \\
\text { Small I }\end{array}$ & $4.0 \mathrm{E} 12$ & $1.5 \mathrm{E} 11$ & 30 & 50 & 0.98 \\
\hline Medium I & $1.0 \mathrm{E} 12$ & $6.0 \mathrm{E} 10$ & $20-40$ & & \\
\hline Large I & $6.5 \mathrm{E} 11$ & $6.0 \mathrm{E} 10$ & $10-25$ & & \\
\hline OS-holes & $\begin{array}{c}2.0 \mathrm{E} 11 \text { to } \\
1.0 \mathrm{E} 10\end{array}$ & $\begin{array}{c}5.0 \mathrm{E} 09 \text { to } \\
2.0 \mathrm{E} 08\end{array}$ & $30-70$ & 50 & 0.98 \\
\hline
\end{tabular}

* Nominal peak fluence rates per lobe MW

+ Ratio of $2200 \mathrm{~m} / \mathrm{s}$ flux divided by the greater than $1 \mathrm{MeV}$ flux, I hole values depend on Hf drum position

\# Fraction of the ${ }^{59} \mathrm{Co}(\mathrm{n}, \gamma){ }^{60} \mathrm{Co}$ reaction rate due to subcadmium $(<0.414 \mathrm{eV})$ neutrons

Table 2. Axial variation in the thermal response fraction.

\begin{tabular}{|c|c|c|}
\hline ATR Location & Elevation (inches) & Thermal Response Fraction \\
\hline H-holes & Centerline & 0.75 \\
& +21.5 & 0.75 \\
& +24.0 & 0.80 \\
N-SR & +32.0 & 0.92 \\
& Centerline & 0.81 \\
& +16.5 & 0.81 \\
& +24.0 & 0.58 \\
SW-SR & +31.0 & 0.58 \\
& Centerline & 0.76 \\
& +16.5 & 0.76 \\
& +24.0 & 0.58 \\
& +31.0 & 0.64 \\
\hline
\end{tabular}




\subsection{MULTIGROUP NEUTRON SPECTRAL CHARACTERIZATION}

In contrast to the characterization measurements discussed in the previous section, the measurements and analyses described in this section provide a more detailed characterization of the neutron spectra in the ATR. This work resulted from the irradiation of multiple neutron activation dosimeters during Cycle 73A-8. Subsection 3.1 presents the details of the neutron dosimetry package, the irradiation conditions and reaction-rate determinations. The analysis methodology and multigroup spectral results are presented in Subsection 3.2.

\subsection{Dosimeter Irradiation and Analysis}

Neutron dosimeter packages were irradiated at the core midplane of the various irradiation locations during reactor Cycle 73A-8, immediately following the core internals changeout that took place in 1986. Because the ATR normal operational cycles were too high in power and too long in duration to allow optimum exposure and measurement of the neutron monitors desirable for a detailed spectral analyses, a 10-MW, 8-hour irradiation was performed. The lobe powers were divided as follows: $\mathrm{LNW}=1.81 \mathrm{MW}, \mathrm{LNE}=1.82 \mathrm{MW}, \mathrm{LC}=2.17 \mathrm{MW}, \mathrm{LSW}=2.15 \mathrm{MW}$, LSE $=2.05 \mathrm{MW}$ based on the ${ }^{16} \mathrm{~N}$ lobe power monitors. No interruptions or shifts in the nominal power level occurred during the irradiation and the power-level uncertainty was estimated to be $+/-5 \%$. Neutron monitors were centered at the reactor midplane elevation in the following locations (see Figure 1): [H-2, H-10, H-14], [A-1, A-10, A-12], [SE(SR)-1, SE(SR)-3], [B-4, B-8, B-11], [I-6, I-8, I-22], and OS-5.

Each neutron monitor package consisted of a set of sensor materials encapsulated in a cadmium tube with 7.2-cm outside length, $0.24-\mathrm{cm}$ outside diameter, $0.14-\mathrm{cm}$ inside diameter, $6.0-\mathrm{cm}$ inside length and 0.6-cm crimped ends. Cadmium encapsulation was used because the emphasis of this neutron spectral characterization effort was on the intermediate and fast-neutron energy regions. The $\mathrm{Cd}$ filter eliminated most of the thermal neutron response for the monitors, response that would result in interference activation or burnout if not removed. Table 3 summarizes the sensor materials used, their physical characteristics and the neutron activation reactions. The selection, design, irradiation and handling of the sensor materials and encapsulations were based on the standard guidelines as described in ASTM E 844 [2]. The sensor materials were ${ }^{235} \mathrm{U}, \mathrm{Sc}$, $\mathrm{Au}, \mathrm{Co},{ }^{237} \mathrm{~Np},{ }^{238} \mathrm{U}, \mathrm{Ni}, \mathrm{Fe}, \mathrm{Ti}, \mathrm{Cu}$ and $\mathrm{Al}$ with the fission monitors encapsulated in vanadium.

Based on the cross sections of the various reactions listed in Table 3, this set of neutron dosimeters provided an extensive coverage of the neutron energy spectrum, especially in the fastneutron energy region. Table 4 summarizes the response ranges for each of these reactions. The information listed in this table is arranged according to increasing response energy. For example, the ${ }^{45} \mathrm{Sc}(\mathrm{n}, \gamma)$ reaction has its primary response at low neutron energy and the ${ }^{27} \mathrm{Al}(\mathrm{n}, \alpha)$ reaction has its response at the high neutron energies. Definitions of the response characteristic terms is as follows: resonance or threshold refers to the primary resonance energy or cross-section energy range for each reaction, median is that energy for which $50 \%$ of the response is above and below, 
Table 3. Dosimeter materials for detailed characterization of ATR spectra.

\begin{tabular}{|c|c|c|c|c|}
\hline Sensor Material & Form & $\begin{array}{l}\text { Size } \\
(\mathrm{cm})\end{array}$ & $\begin{array}{c}\text { Concentration } \\
(\%)\end{array}$ & Reaction \\
\hline $\begin{array}{l}\text { Titanium } \\
\text { Iron }\end{array}$ & $\begin{array}{l}\text { pure wire } \\
\text { pure wire }\end{array}$ & $\begin{array}{l}0.051 \times 2.2 \\
0.051 \times 2.2\end{array}$ & $\begin{array}{c}99.9+ \\
99.99+\end{array}$ & $\begin{array}{c}6,47,48 \mathrm{Ti}(\mathrm{n}, \mathrm{p}) \\
{ }^{54} \mathrm{Fe}(\mathrm{n}, \mathrm{p}) \\
{ }^{58} \mathrm{Fe}(\mathrm{n}, \gamma)\end{array}$ \\
\hline Nickel & pure wire & $0.051 \times 2.2$ & $99.9+$ & ${ }^{58} \mathrm{Ni}(\mathrm{n}, \mathrm{p})$ \\
\hline Cobalt-Al. & alloy wire & $0.051 \times 2.2$ & $\begin{array}{c}0.116 \% \text { Co } \\
(99.999 \text { Co\&Al })\end{array}$ & $\begin{array}{l}{ }^{59} \mathrm{Co}(\mathrm{n}, \gamma) \\
{ }^{27} \mathrm{Al}(\mathrm{n}, \alpha)\end{array}$ \\
\hline $\mathbf{2 3 8 U}$ & oxide wire & $0.051 \times 0.63$ & 99.999 & ${ }^{238} U(n, f)$ \\
\hline 235U & oxide wire & $0.051 \times 0.63$ & 99.89 & ${ }^{235} \mathrm{U}(\mathrm{n}, \mathrm{f})$ \\
\hline $237 \mathrm{~Np}$ & oxide wire & $0.051 \times 0.63$ & 99.999 & ${ }^{237} \mathrm{~Np}(\mathrm{n}, \mathrm{f})$ \\
\hline Gold-Al. & alloy wire & $0.051 \times 2.2$ & $\begin{array}{c}0.135 \% \mathrm{Au} \\
(99.99 \mathrm{Au} \& \mathrm{Al})\end{array}$ & $\begin{array}{l}{ }^{197} \mathrm{Au}(\mathrm{n}, \gamma) \\
{ }^{27} \mathrm{Al}(\mathrm{n}, \alpha)\end{array}$ \\
\hline Copper & pure wire & $0.051 \times 2.2$ & $99.999+$ & ${ }^{63} \mathrm{Cu}(\mathrm{n}, \alpha)$ \\
\hline Scandium & pure wire & $0.10 \times 2.2$ & $99.99+$ & ${ }^{45} \mathrm{Sc}(\mathrm{n}, \gamma)$ \\
\hline
\end{tabular}

Table 4. Neutron energy response ranges for the dosimeter reactions in an H-2 location.

\begin{tabular}{|c|c|c|c|c|c|}
\hline Reaction & $\begin{array}{c}\text { Resonance or } \\
\text { Threshold Energy } \\
(\mathrm{MeV})\end{array}$ & $\begin{array}{l}\text { Median } \\
\text { Energy } \\
(\mathrm{MeV}) \\
\end{array}$ & $\begin{array}{l}\text { Mean } \\
\text { Energy } \\
\text { (MeV) }\end{array}$ & $\begin{array}{c}\text { 95\% Response } \\
\text { Lower Energy } \\
(\mathrm{MeV})\end{array}$ & $\begin{array}{c}\text { 95\% Response } \\
\text { Upper Energy } \\
(\mathrm{MeV})\end{array}$ \\
\hline${ }^{45} \operatorname{Sc}(n, \gamma)$ & 1 to $3700 \mathrm{E}-06$ & $1.46 \mathrm{E}-06$ & $6.8 \mathrm{E}-03$ & $5.6 \mathrm{E}-08$ & $2.1 \mathrm{E}-02$ \\
\hline${ }^{197} \mathrm{Au}(\mathrm{n}, \gamma)$ & 4.9E-06 & 3.7E-06 & 7.8E-04 & $1.5 \mathrm{E}-06$ & 2.5E-04 \\
\hline${ }^{235} U(n, f)$ & 1 to $100 \mathrm{E}-06$ & 5.9E-06 & 8.6E-02 & $1.4 \mathrm{E}-07$ & $1.7 \mathrm{E}+00$ \\
\hline${ }^{59} \mathrm{Co}(\mathrm{n}, \gamma)$ & 1.32E-04 & $5.6 \mathrm{E}-05$ & $1.5 \mathrm{E}-03$ & 4.5E-07 & $2.6 \mathrm{E}-04$ \\
\hline${ }^{58} \mathrm{Fe}(\mathrm{n}, \gamma)$ & $2.2,3.4 \mathrm{E}-04$ & $2.2 \mathrm{E}-04$ & 2.3E-02 & $3.6 \mathrm{E}-07$ & $1.0 \mathrm{E}-01$ \\
\hline${ }^{237} \mathrm{~Np}(\mathrm{n}, \mathrm{f})$ & 0.10 & 1.1 & 2.0 & 0.1 & 6.5 \\
\hline${ }^{238} \mathrm{U}(\mathbf{n}, \mathbf{n})$ & 0.30 & 2.0 & 2.9 & 0.9 & 7.8 \\
\hline${ }^{47} \mathrm{Ti}(\mathrm{n}, \mathrm{p})$ & 1.0 & 3.0 & 3.9 & 1.0 & 8.7 \\
\hline${ }^{58} \mathrm{Ni}(\mathrm{n}, \mathrm{p})$ & 1.0 & 3.4 & 4.2 & 1.2 & 8.7 \\
\hline${ }^{54} \mathrm{Fe}(\mathrm{n}, \mathrm{p})$ & 0.5 & 3.5 & 4.3 & 1.5 & 8.8 \\
\hline${ }^{46} T i(n, p)$ & 2.0 & 5.1 & 5.9 & 3.0 & 10.7 \\
\hline${ }^{63} \mathrm{Cu}(\mathrm{n}, \alpha)$ & 2.0 & 6.8 & 7.5 & 3.8 & 12.4 \\
\hline${ }^{48} \mathbf{T i}(n, p)$ & 3.0 & 7.6 & 8.4 & 5.1 & 13.5 \\
\hline${ }^{27} \mathrm{Al}(\mathbf{n}, \boldsymbol{\alpha})$ & 5.0 & 7.9 & 8.7 & 5.7 & 13.3 \\
\hline
\end{tabular}


mean is the response-weighted average energy, and $95 \%$ response indicates the energy range over which $95 \%$ of the response occurs. This response-range characterization was based on numerical analysis of the response plots shown in Figures 2 and 3. These histogram distributions were computed by multiplying 51-group representations of reaction cross sections with a 51 -group representation of the "Cd-covered" $\mathrm{H}-2$ neutron spectrum described in section 3.2. The relative group response value, $\mathrm{RP}_{\mathrm{g}}$, for a group cross section , $\sigma_{\mathrm{g}}$, and a group flux, $\phi_{\mathrm{g}}$, was computed using

$$
\mathrm{RP}_{\mathrm{g}}=\phi_{\mathrm{g}} \sigma_{\mathrm{g}} / \Sigma_{\mathrm{g}} \phi_{\mathrm{g}} \sigma_{\mathrm{g}}
$$

where $\Sigma_{\mathrm{g}}$ stands for the sum over all groups. We note from Figure 3 that the threshold dosimeters provide good overlapping response in the energy range from $\sim 0.5 \mathrm{MeV}$ to greater than $10 \mathrm{MeV}$. This means that the least-squares-adjustment analysis should provide an improved characterization of this region of the input neutron spectra, a region of particular significance to accurate prediction of displacement damage production in materials exposed to the fast neutrons. The response information shown in Figure 2 illustrates significant narrow response due to resonances in the ${ }^{197} \mathrm{Au}(\mathrm{n}, \gamma),{ }^{59} \mathrm{Co}(\mathrm{n}, \gamma)$ and ${ }^{58} \mathrm{Fe}(\mathrm{n}, \gamma)$ cross sections and a generally broad response for the ${ }^{45} \mathrm{Sc}(\mathrm{n}, \gamma)$ and ${ }^{235} \mathrm{U}(\mathrm{n}, \mathrm{f})$ reactions. These reactions should provide improved characterization of the input neutron spectra between $0.4 \mathrm{eV}$ and $\sim 10^{-3} \mathrm{MeV}$. The region between $10^{-3} \mathrm{MeV}$ and $0.5 \mathrm{MeV}$ will not, in general, undergo significant improvement because the dosimeters used in this work have almost no response in this region.

Following the irradiation, the neutron monitor packages were retrieved and the sensor materials were removed from the cadmium tubes. Each item was reweighed and compared to the preirradiation weight and, if any losses were incurred due to handling, corrections were made.

Neutron-induced radioactivities for each sensor were measured by gamma-ray spectrometry using germanium-detector-based spectrometry systems standardized and calibrated as described in ASTM Standard E 181 [2]. Spectrometer detection efficiencies were calibrated with an estimated uncertainty of $+/-2$ percent $(l \sigma)$ throughout the energy range of the measurements. Reaction rates were derived from the measured activations using standard methods as described in ASTM E 261 and ASTM E 1005. Where they exist, ASTM standard methods were followed for specific types of monitors and reactions. For the most part, these have been identified in previous paragraphs. The fission reaction rates were determined from the ${ }^{95} \mathrm{Zr},{ }^{103} \mathrm{Ru},{ }^{140} \mathrm{Ba}$ and ${ }^{140} \mathrm{La}$ fission products observed in each fission monitor, as per ASTM Standards E-393, -704, -705. The total estimated uncertainties for the measured reaction rates were a combination of the detection efficiency, counting statistics, gamma-ray emission probability, fission yield and target atom uncertainty components. Uncertainties ranged from about 2 percent to 6 percent. 


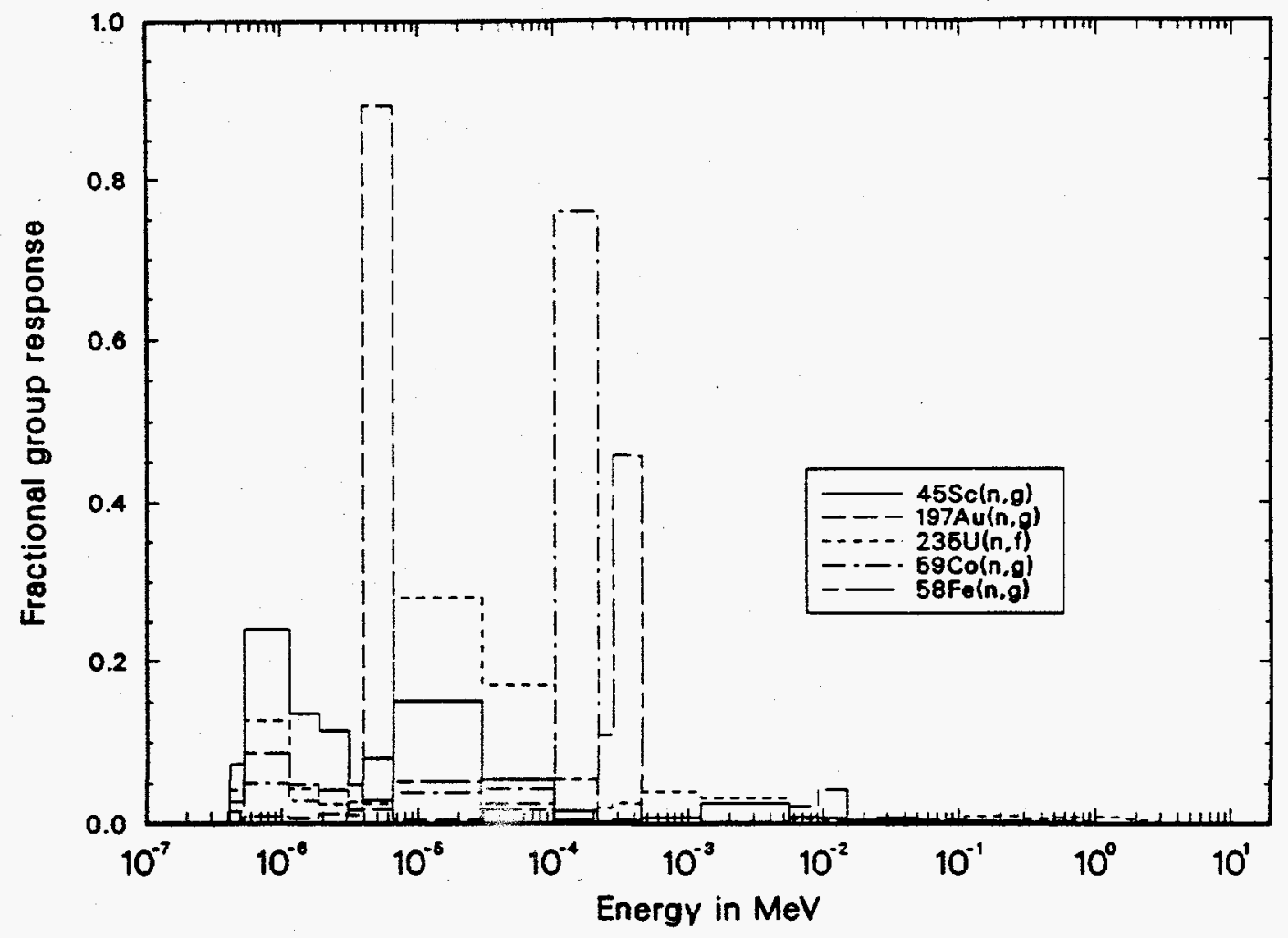

Figure 2. Multigroup response for low-energy dosimeter reactions in the $\mathrm{H}-2$ location.

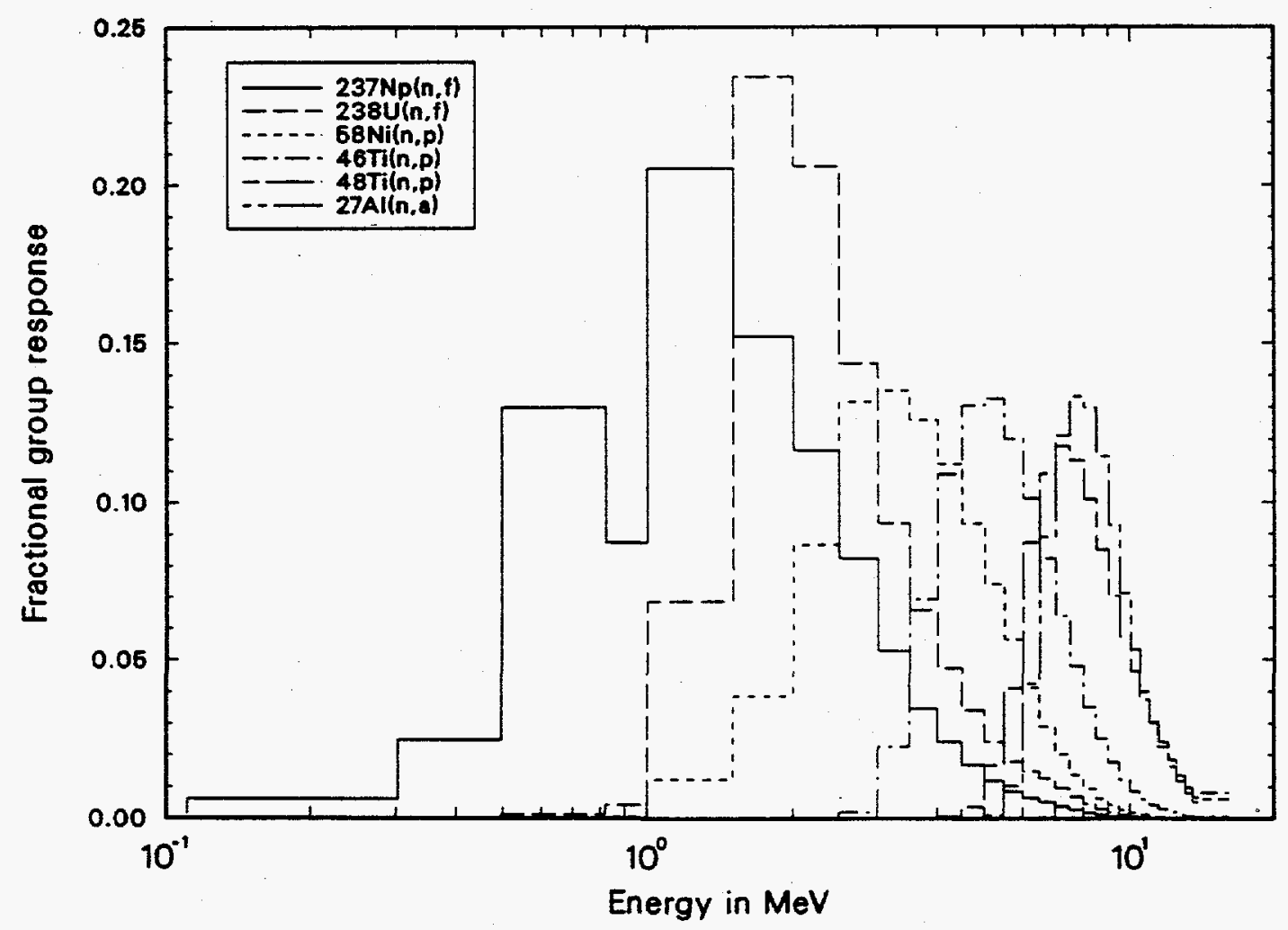

Figure 3. Multigroup response for high-energy threshold dosimeter reactions in the $\mathrm{H}-2$ location. 


\subsection{Multigroup Spectrum Analysis}

\subsubsection{Analysis Methodology}

Multigroup characterization of the neutron spectra in the ATR was obtained by least-squaresadjustment analyses using the FERRET code [5,6] as per ASTM Standard E 944. In these analyses, adjustment of a priori (or input) estimates of the group fluence rates were made to achieve consistency between the measured reaction rates and the reaction rates calculated using the equation:

where

$$
{ }_{j} R_{i}=\Sigma_{g j} C_{g} \sigma_{g} j \phi_{g}
$$

${ }_{j} R_{i}=$ the reaction rate for reaction $i$, spectrum $j$,

${ }_{j} \mathrm{C}_{\mathrm{g}}=$ group correction factor to account for neutron flux depression and shielding effects due to the use of cadmium-covered dosimeters, spectrum $j$,

${ }_{i} \sigma_{\mathrm{g}}=$ infinite-dilute, group cross section for reaction, $\mathrm{i}$,

$\mathrm{j} \phi_{\mathrm{g}}=$ neutron fluence rate group values for the spectrum identified as spectrum $\mathrm{j}$.

The analyses were made in a group structure employing 51 groups, with group-energy boundaries chosen to cover in some detail the major structure in the dosimeter cross sections and in the neutron spectra. Energy boundaries for the 51-group structure are given in Table 6 of Subsection 3.2.2. Input estimates of the 51-group fluence rates, $j \phi_{g}$, for each core location were based on a transport calculation of the neutron spectra in the H-hole region of the ATR. Group correction factors, ${ }_{j} C_{g}$, were obtained from calculated spectra corresponding to "cadmium-covered" and "nocadmium" conditions. Infinite-dilute group cross sections, ${ }_{j} \sigma_{g}$, were obtained by processing 620 group representations of the dosimeter cross sections, as specified in the ENDF/B-V Dosimetry File [7], into 51-group cross sections using reactor-spectrum weighting. Least-squaresadjustment analyses of the type performed here also required a detailed prescription of the covariances for the input fluence rates and cross sections. For all of the dosimeter reactions, except for ${ }^{45} \mathrm{Sc}(\mathrm{n}, \gamma)$ and ${ }^{59} \mathrm{Co}(\mathrm{n}, \gamma)$, the PUFF code [8] was used to process ENDF/B-V covariance files and to generate the appropriate 51-group covariance matrices. Because the ENDF/B-V covariance files for ${ }^{45} \mathrm{Sc}(\mathrm{n}, \gamma)$ and ${ }^{59} \mathrm{Co}(\mathrm{n}, \gamma)$ were incomplete, a covariance prescription provided by Schmittroth [9] was used. The covariance prescription for the input multigroup/neutron spectra consisted of a fractional normalization uncertainty of $10 \%$ and a short-range component in which groupwise uncertainties of $20 \%$ were correlated by a Gaussian distribution $[5,6]$. This prescription assured that the final group fluence rate adjustments were largely determined by the relatively accurate measured dosimeter reaction rates and cross sections. In the following paragraphs, we present additional information regarding the data-processing required to support this analysis method; namely, (1) computation of multigroup reactor spectra for input to this analysis, (2) computation of multigroup cadmium shielding correction factors, (3) processing of infinite-dilute multigroup cross sections for the dosimeter reactions and (4) generation of covariance matrices for the multigroup fluence rates and cross sections. 
Neutron spectra used as input data for these analyses were obtained from neutronics calculations for the H-2 location in the ATR. Although the various spectra are expected to vary somewhat in absolute magnitude and shape from the $\mathrm{H}$-region to others, especially the I- and OS-regions, this approach was deemed appropriate to obtain a relative spectral shape. Calculated neutron spectra for "Cd-covered" and bare or "no-Cd" dosimeters in the H-2 location were obtained using onedimensional $S_{6}$ transport theory and the SCAMP computer code [10]. To obtain these spectra, various parameters in the SCAMP model were adjusted in an attempt to match the 73-group SCAMP spectral results to the 4-group spectra generated from a PDQ-7 two-dimensional diffusion code [11] calculation. The 73-group spectra were smoothed in the regions of structure $\left(10^{-6}\right.$ to $10^{-5} \mathrm{MeV}$ and $10^{-2}$ to $\left.0.2 \mathrm{MeV}\right)$ prior to application of a spline interpolation scheme to generate the 51-group input fluence rate spectra from the 73-group SCAMP calculation. A visual comparison of the unaltered, calculated 73-group fluence rates and the smoothed, 51-group fluence rates are give in Figures 4 and 5 for the "no-Cd" and the "Cd-covered" cases, respectively. The group fluence rates are presented as group flux per unit lethargy. In Figure 5 we observe the "cut-off" in flux values at $0.414 \mathrm{eV}$ due to thermal neutron absorption in the cadmium. Tabular data for the H-2 input group fluence rates, the energy boundaries and the lethargy widths of the groups are given in Table 6 of Subsection 3.2.2. Prior to their use in the FERRET analyses for each irradiation location, the 51-group spectra were modified further by adjusting the spectrum normalization with scale factors based on the ${ }^{235} U$ fission rates in the various measurement locations. The adjustment compensated for the absolute magnitude differences between the actual spectra for the $\mathrm{H}$-hole and other locations.

Group correction factors to account for neutron flux depression and shielding by the cadmium were derived from the 51-group fluxes by dividing the "Cd-covered" group values by the "no-Cd" group values. A visual presentation of the 51-group cadmium correction factors is shown in Figure 6.

Generation of the 51-group cross sections for the FERRET analyses required a 620-group representation of the reactor spectrum to be used as a weighting function with the 620-group cross sections on the ENDF/B-V dosimetry file [7]. The fine-group weighting function was computed using the spline-interpolation scheme and a modification of the 73-group flux calculated as discussed above for the H-2 location with "no Cd". The modified spectrum included a fine-group Maxwellian thermal distribution, with the distribution area equated to that for the thermal group in the 73-group spectrum. Interpolation calculations were made for a modified spectrum with structure and for a spectrum with the structure smoothed out as described earlier. A comparison of the unaltered 73-group fluxes to the interpolated, smoothed 620-group weighting function is shown in Figure 7. The group flux values are plotted as flux per unit lethargy. As discussed in Reference 3, a systematic study was done to evaluate the importance of including or neglecting the spectral structure for cross-section processing and for the FERRET analyses. The evaluation indicated that for the dosimeter set used, there was little response in the regions of the spectral structure. Hence the inclusion of the structure was expected to have little influence on cross section processing or on the FERRET analyses. 


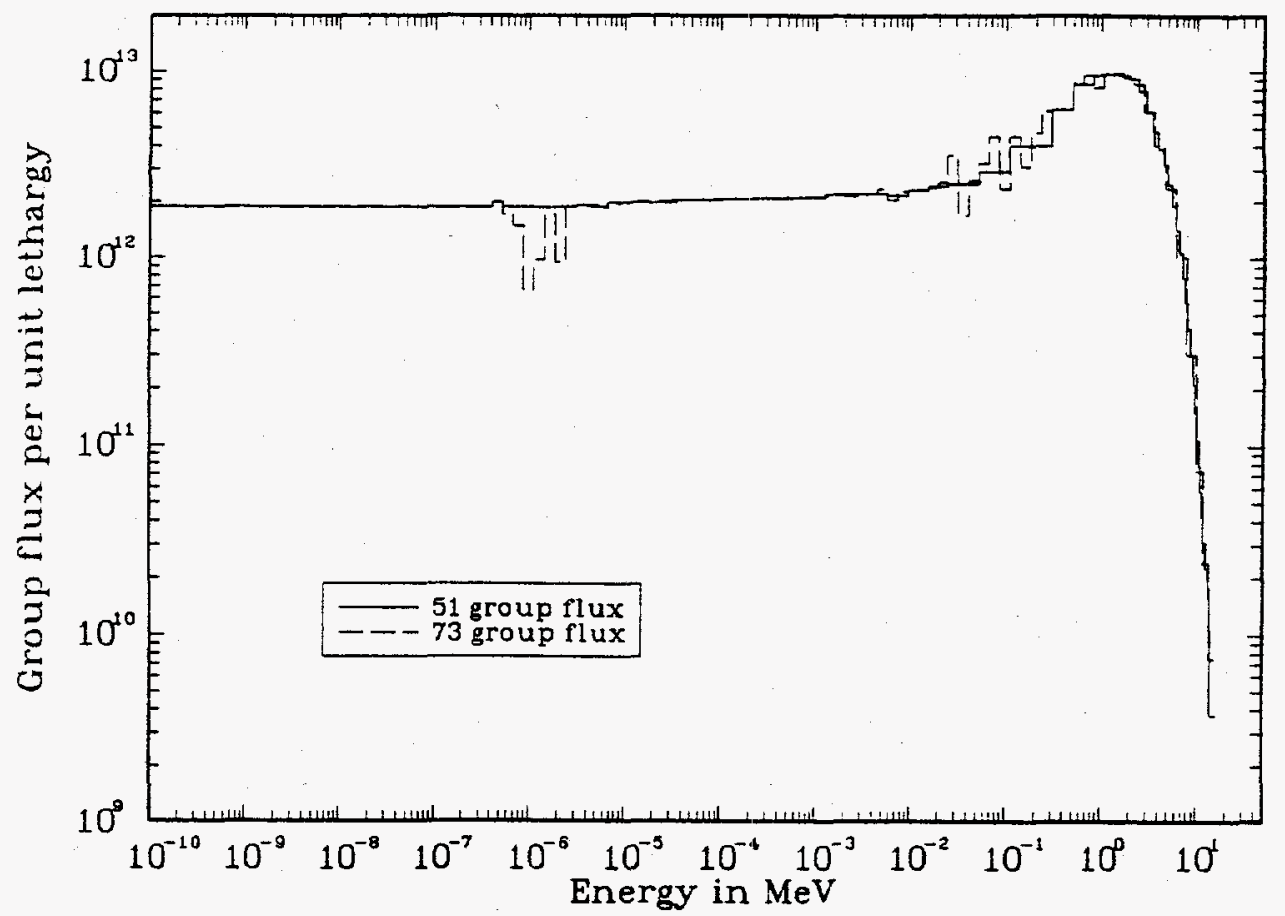

Figure 4. Comparison of calculated 73-group fluxes and the interpolated, smoothed 51-group fluxes for the H-2 location with "no Cd".

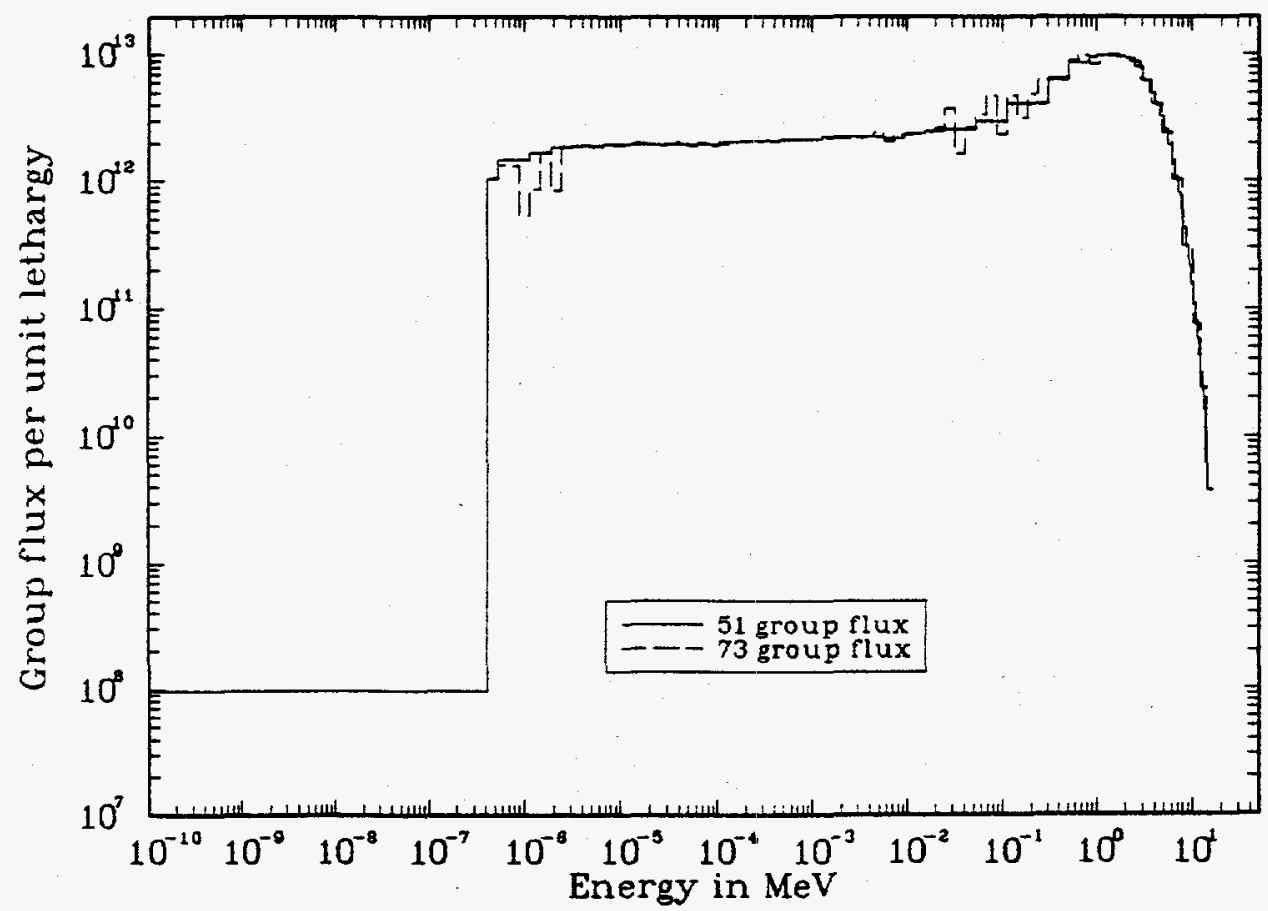

Figure 5. Comparison of calculated 73-group fluxes and interpolated, smoothed, 51-group fluxes for a "Cd-covered" H-2 location. 


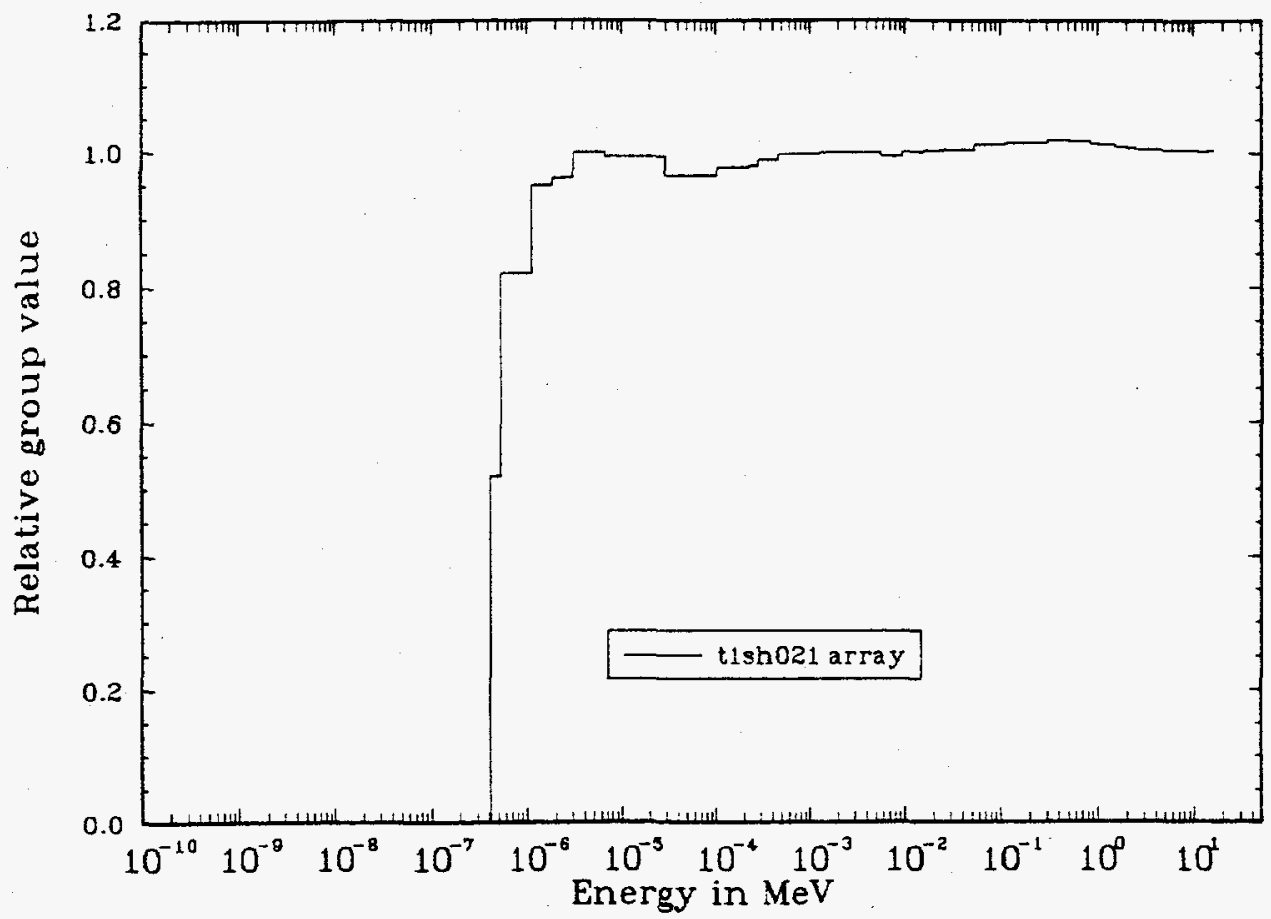

Figure 6. Multigroup cadmium shielding factors for the H-2 location.

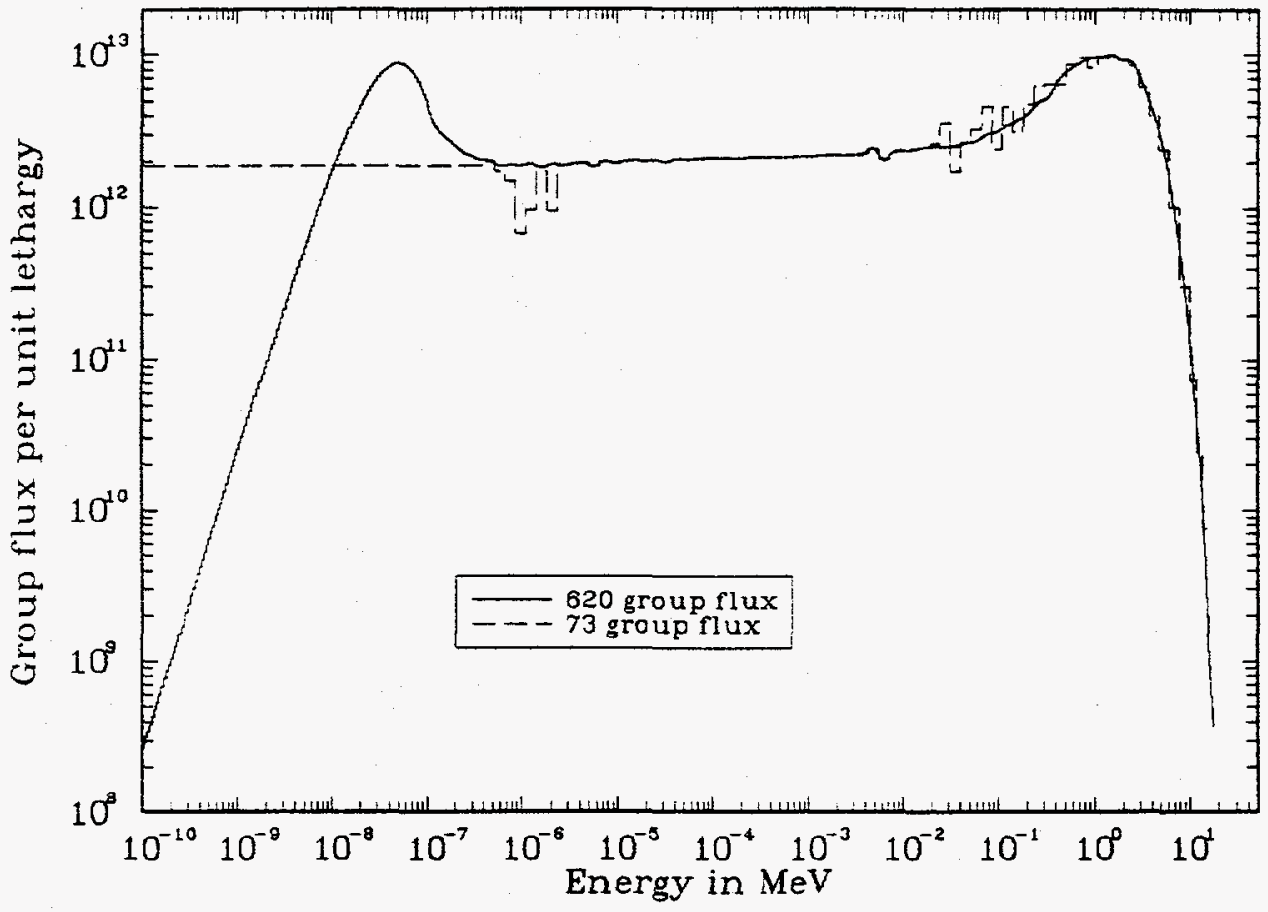

Figure 7. Comparison of calculated 73-group fluxes and the interpolated, smoothed 620-group fluxes for the H-2 location with "no-Cd". 
Covariance matrices were prescribed for the 51-group cross sections and fluence-rate data. The method for obtaining the cross-section covariances was discussed previously. A parametric expression $[5,6]$ was used to generate the fractional covariance elements for the input group flux data according to the following expression

$$
M_{i j}=r_{n}^{2}+r_{i} r_{j} \rho_{i j}
$$

where $r_{n}$ is a fractional normalization uncertainty (independent of groups $i$ and $j$ ), $r_{i}$ and $r_{j}$ represent fractional statistical uncertainties for groups $i$ and $j$, respectively, and $\rho_{i j}$ is the correlation matrix that correlates the group statistical uncertainties. The correlation matrix elements, $\rho_{i j}$, are defined by the following Gaussian expression

$$
\rho_{\mathrm{ij}}=(1-\theta) \delta_{\mathrm{ij}}+\theta \exp \left\{-(\mathrm{i}-\mathrm{j})^{2} / 2 \gamma^{2}\right\}
$$

where the first term represents a purely random component to the correlation $\left(\delta_{i j}=0\right.$ for $i$ not equal to $\mathrm{j}$, and $\delta_{\mathrm{ij}}=1$ for $\mathrm{i}=\mathrm{j}$ ) and the second term represents a short-range correlated component with strength $\theta$ and range $\gamma$. For the present FERRET analyses, the normalization uncertainty, $r_{n}$, was estimated to be $10 \%$ and the groupwise statistical uncertainty, $r_{i}$, was estimated to be $20 \%$, with $\theta=0.8$ indicating a relatively high degree of correlation in the groupwise statistical uncertainty components. Analyses were made for $\gamma$ values of 2 and 4, and the results presented here correspond to the analyses for $\gamma=4$. A selection of $\gamma=2$ enhances local group adjustments in the vicinity of dominant response for a dosimeter cross section, whereas, use of a range parameter of 4 tends to give to smaller adjustments over a broader energy range.

\subsubsection{FERRET Analysis Results}

Individual FERRET analyses were made for the reaction-rate data corresponding to the various reactor regions, namely, A, H, SR, B, I and OS-5. For each region, this meant a simultaneous adjustment of group fluence-rate values corresponding to the input spectra and the respective reaction-rate data for each location in that region, e.g., A-1, A-10 and A-12 locations in region A. Detailed results of these analyses are presented in the Appendix in tabular and graphical form.

However, to establish an understanding of these results and their significant features, we present here representative FERRET results for position $\mathrm{H}-2$. These results consist of the following: Table 5, a summary of input and FERRET-adjusted reaction rates and uncertainties; Figure 8, a graphical comparison of the unadjusted (input) and FERRET-adjusted group fluence rates; Table 6 , a numerical tabulation of the unadjusted (input) and FERRET-adjusted group fluence rates and uncertainties; and Table 7, a numerical tabulation of cumulative flux values and uncertainties that were derived from the unadjusted and adjusted group fluence rates.

Table 5 provides a summary of the input and final reaction-rates and uncertainties calculated in the FERRET analysis, as compared to the measured reaction-rate data. In the table, the reaction 
Table 5. FERRET analysis summary for ATR H-2 position.

\begin{tabular}{|c|c|c|c|c|c|c|c|c|}
\hline $\begin{array}{c}\text { Dosimeter } \\
\text { Reaction }\end{array}$ & $\begin{array}{c}\text { Measured } \\
\text { Rate } \\
\text { (Bq/atom) }\end{array}$ & $\begin{array}{c}\sigma \\
(\%)\end{array}$ & $\begin{array}{c}\text { Calculated } \\
\text { Rate } \\
\text { (Bq/atom) }\end{array}$ & $\begin{array}{c}\sigma \\
(\%)\end{array}$ & $\mathbf{C} / \mathbf{M}$ & $\begin{array}{c}\text { FERRET-Fit } \\
\text { Rate } \\
\text { (Bq/atom) }\end{array}$ & $\begin{array}{c}\sigma \\
(\%)\end{array}$ & FF/M \\
\hline $45 \operatorname{Sc}(n, \gamma)$ & $2.99 \mathrm{E}-11$ & 2 & $2.24 \mathrm{E}-11$ & 19.4 & 0.75 & $2.99 \mathrm{E}-11$ & 5.4 & 1 \\
\hline 197Au(n,y) & $3.66 \mathrm{E}-09$ & 2 & $2.98 \mathrm{E}-09$ & 21.8 & 0.815 & $3.67 \mathrm{E}-09$ & 4.3 & 1 \\
\hline 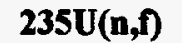 & $7.42 \mathrm{E}-10$ & 2.3 & $5.67 \mathrm{E}-10$ & 17.3 & 0.765 & $7.38 \mathrm{E}-10$ & 3 & 0.99 \\
\hline $59 \mathrm{Co}(\mathrm{n}, \gamma)$ & $1.86 \mathrm{E}-10$ & 2 & $1.48 \mathrm{E}-10$ & 20.9 & 0.798 & $1.86 \mathrm{E}-10$ & 5.4 & 1 \\
\hline $\operatorname{s8Fe}(n, \gamma)$ & $3.43 \mathrm{E}-12$ & 2 & $2.60 \mathrm{E}-12$ & 18 & 0.759 & $3.43 \mathrm{E}-12$ & 4.9 & 1 \\
\hline $237 \mathrm{~Np}(\mathrm{n}, \mathrm{f})$ & $3.40 \mathrm{E}-11$ & 2 & $3.00 \mathrm{E}-11$ & 20.4 & 0.881 & $3.41 \mathrm{E}-11$ & 4.9 & 1 \\
\hline $238 U(n, f)$ & 6.17E-12 & 2 & $5.41 \mathrm{E}-12$ & 18.6 & 0.876 & $6.06 \mathrm{E}-12$ & 2.4 & 0.98 \\
\hline 47Ti(n,p) & $3.23 \mathrm{E}-13$ & 2 & $3.56 \mathrm{E}-13$ & 21.1 & 1.103 & 3.31E-13 & 3 & 1.02 \\
\hline $58 \mathrm{Ni}(\mathbf{n}, \mathbf{p})$ & $1.85 \mathrm{E}-12$ & 2 & $1.61 E-12$ & 19.1 & 0.872 & $1.84 \mathrm{E}-12$ & 3.4 & 1 \\
\hline $54 F e(n, p)$ & $1.35 \mathrm{E}-12$ & 2 & $1.23 \mathrm{E}-12$ & 18.4 & 0.909 & $1.35 \mathrm{E}-12$ & 3.6 & 1 \\
\hline 46Ti(n,p) & $1.81 \mathrm{E}-13$ & 2 & $1.56 \mathrm{E}-13$ & 21.9 & 0.86 & $1.80 \mathrm{E}-13$ & 5.2 & 1 \\
\hline $63 \mathrm{Cu}(\mathrm{n}, \alpha)$ & $8.88 \mathrm{E}-15$ & 3 & 7.55E-15 & 17.9 & 0.85 & $8.63 \mathrm{E}-15$ & 4.8 & 0.97 \\
\hline 48Ti $(n, p)$ & $4.39 \mathrm{E}-15$ & 2 & $3.77 \mathrm{E}-15$ & 20.2 & 0.858 & $4.46 \mathrm{E}-15$ & 5.4 & 1.01 \\
\hline $27 \mathrm{~A} \mid(n, \alpha)$ & $1.05 \mathrm{E}-14$ & 5.6 & $9.54 \mathrm{E}-15$ & 18.7 & 0.909 & $1.03 \mathrm{E}-14$ & 6.1 & 0.98 \\
\hline
\end{tabular}

rates are in units of $\mathrm{Bq} /$ atom, i.e. Bequerel/atom or reactions per second per atom. $\mathrm{C} / \mathrm{M}$ represents the ratio of calculated to measured reaction rates. Similarly, FF/M represents the ratio of calculated (after FERRET adjustment) to measured reaction rates. Initially, that is prior to adjustment, the $\mathrm{C} / \mathrm{M}$ reaction-rate ratios ranged from 0.7 to 0.8 for the low energy dosimeters and from 0.8 to 1.1 for the high energy dosimeters, indicating a systematic discrepancy between the measured reaction-rate data and the calculated reaction rate data. This reaction-rate comparison indicates that the input group fluxes were probably too low by as much as $20 \%$ to $30 \%$ in the low-energy region and they were too low in the fast-neutron region by approximately $10 \%$ to $20 \%$. After the FERRET adjustment analysis, whereby the group fluxes experienced the most significant adjustments, these $\mathrm{C} / \mathrm{M}$ ratios were essentially 1.0 for the low energy dosimeters and between 0.97 and 1.03 for the high energy dosimeters, indicating a high degree of consistency between the measured and FERRET-Fit reaction rates.

Inspection of the uncertainty data, $\sigma$, in Table 5 reveals a feature of the FERRET least-squares adjustment analysis. Initially (before adjustment), the uncertainties for the calculated reaction rates were about $20 \%$, with most of this uncertainty due to the conservative uncertainty estimates placed on the input flux data. The final uncertainties for the FERRET-Fit reaction rates are reduced from the initial values by about a factor of 4 , indicating significant improvement in the uncertainty and correlation specification for the final group fluxes. In addition, these results indicate that the uncertainty specification of the input flux data was not overly conservative in that the final uncertainty values are fairly close to the uncertainties in the measured values. A more conservative input flux uncertainty specification would have resulted in larger final uncertainties for the calculated FERRET-Fit reaction rates.

In the upper part of Figure 8, group flux values are plotted as $\mathrm{n} / \mathrm{cm}^{2}-\mathrm{s}$ per unit lethargy. The lower part of the figure displays the ratio of adjusted-to-unadjusted group flux values, along with 
uncertainty bounds, to indicate the input uncertainty ranges, and error bars at the midpoint of the group values, to indicate the values of the uncertainties in the FERRET-adjusted group fluence rates. This comparison indicates that to achieve consistency between the measured and calculated reaction rates, the input group fluence-rate values were adjusted upward by $15 \%$ to $30 \%$ in the low energy range from $0.4 \mathrm{eV}$ to $0.1 \mathrm{MeV}$ and by $3 \%$ to $5 \%$ in the high energy range above 0.1 $\mathrm{MeV}$. The lower part of Figure 8 indicates a significant reduction in the uncertainty specification for the adjusted group fluence rates, especially in the energy ranges of dominant dosimeter response, e.g., by a factor of 2 to 6 in the energy range between $0.4 \mathrm{eV}$ and $10^{-3} \mathrm{MeV}$ and by as much as a factor of 3 in the fast-neutron energy range 0.1 to $5.0 \mathrm{MeV}$

Numerical values for the adjusted and unadjusted group flux values for the $\mathrm{H}-2$ location along with a tabulation of cumulative flux values are given in Tables 6 and 7, respectively. The symbols used in the tables are defined as follows:

EU: upper energy bound for the group (MeV)

EL: lower energy bound for the group (MeV)

DU: lethargy width for the group $\{\log (10 / \mathrm{EL})-\log (10 / \mathrm{EU})\}$

PHI: unadjusted (input) group fluence rate, CPHI: cumulative group value for $\mathrm{PHI}$ UNCI: \% uncertainty for PHI or for CPHI

FRPHI: \% fractional group value for PHI, FRCPHI: \% fractional group value for CPHI PHA: adjusted group fluence rate, CPHA: cumulative group value for PHA UNCA: \% uncertainty for PHA or for CPHA FRPHA: \% fractional group value for PHA FRCPHA: \% fractional group value for CPHA RPH: ratio of PHA/PHI group values, $\mathbf{R C P H : ~ r a t i o ~ o f ~ C P H A / C P H I ~ g r o u p ~ v a l u e s ~}$

In these tables the \% uncertainties for the group fluence-rate values were derived from the diagonal elements of the covariance matrices corresponding to the respective input and adjusted data. The cumulative group flux values correspond to the total number of neutrons above the low energy bound of the designated group. These values and their associated uncertainties were obtained from additional calculations with the group fluence-rate and covariance data obtained from the FERRET analyses. As a consequence of the uncertainty reduction in the FERRET adjusted group fluence rates, the cumulative fluence rates for the adjusted data manifest uncertainty reductions by factors of 6,3 and 3 for the $>1.0 \mathrm{MeV},>0.1 \mathrm{MeV}$ and $>0.4 \mathrm{eV}$ energy ranges respectively.

Least-squares-adjustment analyses like that made with the FERRET code produce adjustments in all of the input data, namely the group fluence-rate, or flux, values and their corresponding covariances and the group cross sections and their covariances. However, the magnitude of the adjustment is largely determined by the magnitude of the uncertainty specification as prescribed by the covariance matrices. For the case of the present FERRET analyses, the input group fluxes were assigned relatively conservative uncertainties and the dosimeter group cross sections were more tightly defined by their prescribed covariance matrices. Hence, the least-squares-adjustment 

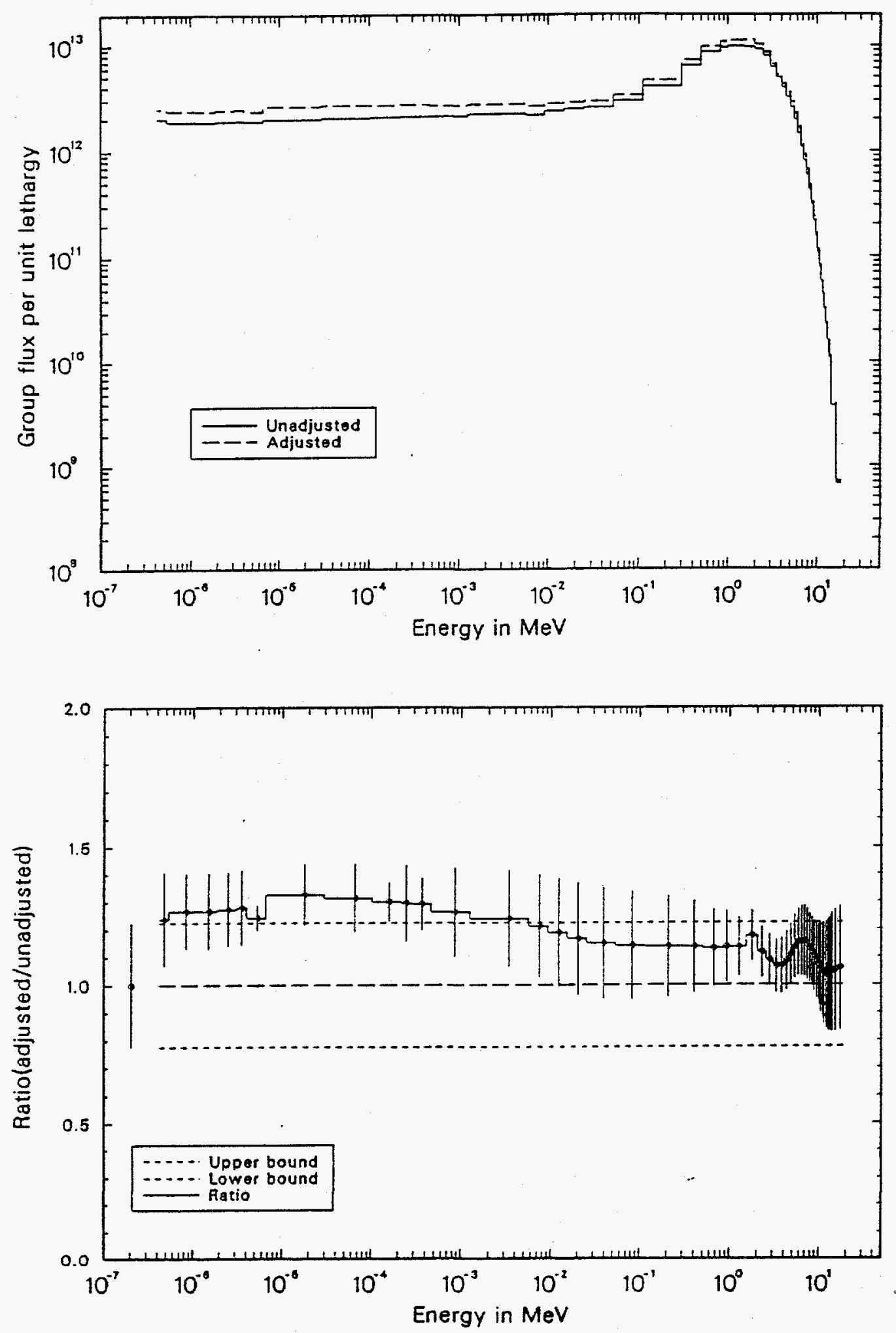

Figure 8. Upper part of figure compares adjusted and unadjusted (input) group fluence rates for H-2 location and lower part displays the ratio of adjusted-to-unadjusted group values with input uncertainty bounds and final uncertainty error bars. 
Table 6. Comparison of adjusted and input group fluxes for $\mathrm{H}-2$.

\begin{tabular}{|c|c|c|c|c|c|c|c|c|c|c|}
\hline Group & EU & EL & DU & PHI & UNCI & FRPHI & PHA & UNCA & FRPHA & RPH \\
\hline 1 & $1.80 E+01$ & $1.60 \mathrm{E}+01$ & $\overline{0.118}$ & $7.90 \mathrm{E}+07$ & 22.4 & 0 & $8.38 E+07$ & 20.8 & 0 & 1.06 \\
\hline 2 & $1.60 E+01$ & $1.40 E+01$ & 0.134 & $5.01 E+08$ & 22.4 & 0 & $5.27 E+08$ & 20.6 & 0 & 1.05 \\
\hline 3 & $1.40 E+01$ & $1.35 E+01$ & 0.036 & $3.92 E+08$ & 22.4 & 0 & $4.11 E+08$ & 20.4 & 0 & 1.05 \\
\hline 4 & 1.35E+01 & $1.30 E+01$ & 0.038 & $6.01 E+08$ & 22.4 & 0 & $6.25 E+08$ & 20.2 & 0 & 1.04 \\
\hline 5 & $1.30 E+01$ & $1.25 E+01$ & 0.039 & $8.83 E+08$ & 22.4 & 0 & $9.17 E+08$ & 19.8 & 0 & 1.04 \\
\hline 6 & $1.25 E+01$ & $1.20 E+01$ & 0.041 & $1.27 E+09$ & 22.4 & 0 & $1.32 E+09$ & 19.2 & 0 & 1.04 \\
\hline 7 & $1.20 E+01$ & $1.15 E+01$ & 0.043 & $1.82 E+09$ & 22.4 & 0 & $1.89 E+\infty 9$ & 18.5 & 0 & 1.04 \\
\hline 8 & $1.15 E+01$ & $1.10 E+01$ & 0.044 & $2.59 E+09$ & 22.4 & 0 & $2.70 E+\infty 9$ & 17.6 & 0 & 1.04 \\
\hline 8 & $1.10 E+01$ & $1.05 E+01$ & 0.047 & $3.68 E+09$ & 22.4 & 0.01 & $3.86 E+\infty 9$ & 16.5 & 0 & 1.05 \\
\hline 10 & $1.05 E+01$ & $1.00 E+01$ & 0.049 & $5.31 E+09$ & 22.4 & 0.01 & $5.63 E+09$ & 15.1 & 0.01 & 1.06 \\
\hline 11 & $1.00 E+01$ & $9.50 E+\infty 0$ & 0.051 & $7.84 E+09$ & 22.4 & 0.01 & $8.40 E+\infty 9$ & 13.7 & 0.01 & 1.07 \\
\hline 12 & $9.50 E+\infty 0$ & $9.00 E+\infty$ & 0.054 & $1.16 E+10$ & 22.4 & 0.02 & $1.27 E+10$ & 12.4 & 0.02 & 1.09 \\
\hline 13 & $9.00 E+\infty 0$ & $8.50 E+\infty$ & 0.057 & $1.73 E+10$ & 22.4 & 0.02 & $1.91 E+10$ & 11.5 & 0.02 & 1.1 \\
\hline 14 & $8.50 E+\infty 0$ & $8.00 E+\infty$ & 0.061 & $2.56 E+10$ & 22.4 & 0.04 & $2.86 \mathrm{E}+10$ & 11 & 0.04 & 1.12 \\
\hline 16 & $8.00 E+\infty 0$ & $7.50 E+\infty 0$ & 0.065 & $3.75 E+10$ & 22.4 & 0.05 & $4.24 E+10$ & 11 & 0.05 & 1.13 \\
\hline 16 & $7.50 E+\infty 0$ & $7.00 E+\infty 0$ & 0.069 & $5.45 E+10$ & 22.4 & 0.08 & $6.25 E+10$ & 11.1 & 0.08 & 1.15 \\
\hline 17 & $7.00 E+\infty$ & $6.50 E+\infty$ & 0.074 & $7.92 E+10$ & 22.4 & 0.11 & $9.15 E+10$ & 11.1 & 0.11 & 1.16 \\
\hline 18 & $6.50 E+\infty$ & $6.00 E+\infty$ & 0.08 & 1.15E+11 & 22.4 & 0.17 & $1.33 E+11$ & 10.9 & 0.17 & 1.15 \\
\hline 19 & $6.00 E+\infty 0$ & $5.50 E+\infty$ & 0.087 & $1.68 E+11$ & 22.4 & 0.24 & $1.93 E+11$ & 10.5 & 0.24 & 1.15 \\
\hline 20 & $5.50 E+\infty 0$ & $5.00 E+\infty 0$ & 0.095 & $2.41 E+11$ & 22.4 & 0.35 & $2.74 E+11$ & 10.1 & 0.34 & 1.14 \\
\hline 21 & $5.00 E+\infty 0$ & $4.50 E+00$ & 0.105 & 3.37E+11 & 22.4 & 0.48 & $3.75 E+11$ & 9.9 & 7 & .11 \\
\hline 22 & $4.50 E+\infty 0$ & $4.00 E+\infty 0$ & 0.118 & $4.63 E+11$ & 22.4 & 0.67 & $5.02 E+11$ & 9.7 & 0.63 & 1.09 \\
\hline 23 & $4.00 E+\infty 0$ & $3.50 E+\infty 0$ & 0.134 & $6.49 E+11$ & 22.4 & 0.93 & $6.94 E+11$ & 9.4 & 0.87 & 1.07 \\
\hline 24 & $3.50 E+\infty 0$ & $3.00 E+\infty 0$ & 0.154 & $9.53 E+11$ & 22.4 & 1.37 & $1.02 E+12$ & 8.9 & 1.28 & 1.07 \\
\hline 25 & $3.00 E+\infty 0$ & $2.50 E+\infty 0$ & 0.182 & 1.45E+12 & 22.4 & 2.08 & $1.58 E+12$ & 8.6 & 1.98 & 1.09 \\
\hline 28 & $2.50 E+\infty 0$ & $2.00 E+\infty 0$ & 0.223 & $2.05 E+12$ & 22.4 & 2.95 & $2.29 E+12$ & 8.2 & 2.87 & 1.12 \\
\hline 27 & $2.00 E+\infty 0$ & $1.50 E+00$ & 0.288 & $2.75 E+12$ & 22.4 & 3.95 & $3.24 E+12$ & 7.7 & 4.06 & 1.18 \\
\hline 28 & $1.50 E+\infty 0$ & $1.00 E+\infty$ & 0.405 & $3.97 E+12$ & 22.4 & 5.71 & $4.51 E+12$ & 9.4 & 5.65 & 1.14 \\
\hline 29 & $1.00 E+\infty 0$ & 8.21E-01 & 0.197 & $1.88 E+12$ & 22.4 & 2.7 & $2.14 E+12$ & 11.4 & 2.68 & 1.14 \\
\hline 30 & 8.21E-01 & 4.98E-01 & 0.5 & $4.30 E+12$ & 22.4 & 6.18 & $4.87 E+12$ & 12.2 & 6.1 & 1.13 \\
\hline 31 & 4.98E-01 & $3.02 E-01$ & 0.5 & 3.17E+12 & 22.4 & 4.56 & $3.61 E+12$ & 14.6 & 4.52 & 1.14 \\
\hline 32 & $3.02 E-01$ & 1.11E-01 & 1 & $4.08 E+12$ & 22.4 & 5.86 & $4.64 E+12$ & 16.1 & 5.82 & 1.14 \\
\hline 33 & $1.11 E-01$ & 5.25E-02 & 0.75 & $2.22 E+12$ & 22.4 & 3.19 & $2.53 E+12$ & 17.1 & 3.17 & 1.14 \\
\hline 34 & 5.25E-02 & 2.48E-02 & 0.75 & $1.91 E+12$ & 22.4 & 2.75 & $2.20 \mathrm{E}+12$ & 17.6 & 2.75 & 1.15 \\
\hline 35 & $2.48 E-02$ & $1.50 E-02$ & 0.5 & $1.23 E+12$ & 22.4 & 1.77 & $1.44 E+12$ & 17.5 & 1.8 & 1.17 \\
\hline 36 & $1.50 \mathrm{E}-02$ & $9.12 E-03$ & 0.5 & $1.18 E+12$ & 22.4 & 1.7 & $1.40 E+12$ & 16.6 & 1.76 & 1.19 \\
\hline 37 & $9.12 E-03$ & $5.53 E-03$ & 0.5 & $1.09 E+12$ & 22.4 & 1.57 & $1.33 E+12$ & 15.5 & 1.66 & 1.21 \\
\hline 38 & $5.53 E-03$ & $1.23 E-03$ & 1.5 & $3.34 E+12$ & 22.4 & 4.81 & $4.15 E+12$ & 14.2 & 5.2 & 1.24 \\
\hline 39 & $1.23 E-03$ & 4.54E-04 & 1 & $2.14 E+12$ & 22.4 & 3.07 & $2.70 E+12$ & 12.8 & 3.38 & 1.26 \\
\hline 40 & 4.54E-04 & 2.75E-04 & 0.5 & $1.06 E+12$ & 22.4 & 1.52 & $1.37 E+12$ & 7.3 & 1.72 & 1.29 \\
\hline 41 & $2.75 E-04$ & $2.14 E-04$ & 0.25 & $5.29 E+11$ & 22.4 & 0.76 & $6.86 E+11$ & 10.6 & 0.86 & 1.3 \\
\hline 42 & $2.14 E-04$ & $1.01 E-04$ & 0.75 & $1.57 E+12$ & 22.4 & 2.25 & $2.04 E+12$ & 5.4 & 2.55 & 1.3 \\
\hline 43 & $1.01 E-04$ & 2.90E-05 & 1.25 & $2.55 E+12$ & 22.4 & 3.67 & $3.36 E+12$ & 9.5 & 4.21 & 1.31 \\
\hline 44 & 2.90E-05 & $6.48 E-06$ & 1.5 & $2.99 E+12$ & 22.4 & 4.3 & $3.96 E+12$ & 8.3 & 4.97 & 1.33 \\
\hline 46 & $6.48 E-06$ & $3.93 E-06$ & 0.5 & $9.50 E+11$ & 22.4 & 1.37 & $1.18 E+12$ & 3.7 & 1.48 & 1.24 \\
\hline 46 & $3.93 E-06$ & $3.06 E-06$ & 0.25 & $4.80 E+11$ & 22.4 & 0.69 & $6.14 E+11$ & 10.6 & 0.77 & 1.28 \\
\hline 47 & $3.06 E-06$ & $1.86 E-06$ & 0.5 & $9.47 E+11$ & 22.4 & 1.36 & $1.21 E+12$ & 10.5 & 1.51 & 1.27 \\
\hline 48 & $1.86 E-06$ & 1.13E-06 & 0.5 & $9.37 E+11$ & 22.4 & 1.35 & $1.19 E+12$ & 10.9 & 1.49 & 1.27 \\
\hline 49 & $1.13 E-06$ & $5.32 E-07$ & 0.75 & $1.41 E+12$ & 22.4 & 2.03 & $1.79 E+12$ & 10.8 & 2.25 & 1.27 \\
\hline 60 & 5.32E-07 & 4.14E-07 & 0.25 & $5.00 E+11$ & 22.4 & 0.72 & $6.18 E+11$ & 13.7 & 0.78 & 1.24 \\
\hline 51 & 4.14E-07 & $1.00 \mathrm{E}-10$ & 8.328 & $1.57 E+13$ & 22.4 & 22.54 & $1.57 \mathrm{E}+13$ & 22.4 & 19.65 & 1 \\
\hline
\end{tabular}


Table 7. Comparison of adjusted and input cumulative group fluxes for H-2.

\begin{tabular}{|c|c|c|c|c|c|c|c|c|c|}
\hline Group & $\mathbf{E U}$ & EL & CPHI & UNCI & FRCPHI & CPHA & UNCA & FRCPHA & RCPH \\
\hline 1 & $1.80 \mathrm{E}+01$ & $1.60 \mathrm{E}+01$ & $7.90 E+07$ & 22.4 & 0 & $8.38 E+07$ & 20.8 & 0 & 1.06 \\
\hline 2 & $1.60 E+01$ & $1.40 E+01$ & $5.80 E+08$ & 21.9 & 0 & $6.11 E+08$ & 20.1 & 0 & 1.05 \\
\hline 3 & $1.40 E+01$ & $1.35 E+01$ & $9.72 E+08$ & 21.2 & 0 & $1.02 E+09$ & 19.3 & 0 & 1.05 \\
\hline 4 & $1.35 E+01$ & $1.30 E+01$ & 1.57E+09 & 20.7 & 0 & $1.65 E+09$ & 18.6 & 0 & 1.05 \\
\hline 5 & $1.30 E+01$ & $1.25 E+01$ & $2.46 \mathrm{E}+09$ & 20.3 & 0 & $2.56 \mathrm{E}+\infty 9$ & 17.9 & 0 & 1.04 \\
\hline 6 & $1.25 E+01$ & $1.20 E+01$ & $3.73 E+09$ & 20 & 0.01 & $3.88 E+09$ & 17.3 & 0 & 1.04 \\
\hline 7 & $1.20 E+01$ & $1.15 E+01$ & $5.55 E+\infty 9$ & 19.8 & 0.01 & $5.77 E+\infty 9$ & 16.5 & 0.01 & 1.04 \\
\hline 8 & 1.15E+01 & $1.10 E+01$ & $8.14 E+\infty 9$ & 19.6 & 0.01 & 8.47E+O9 & 15.6 & 0.01 & 1.04 \\
\hline 9 & $1.10 E+01$ & $1.05 E+01$ & $1.18 E+10$ & 19.4 & 0.02 & $1.23 E+10$ & 14.6 & 0.02 & 1.04 \\
\hline 10 & $1.05 E+01$ & $1.00 E+01$ & $1.71 E+10$ & 19.3 & 0.02 & $1.80 E+10$ & 13.4 & 0.02 & 1.05 \\
\hline 11 & $1.00 E+01$ & $9.50 E+\infty 0$ & $2.50 E+10$ & 19.2 & 0.04 & $2.64 E+10$ & 11.9 & 0.03 & 1.06 \\
\hline 12 & $9.50 E+\infty$ & $9.00 E+\infty$ & $3.66 E+10$ & 19.1 & 0.05 & $3.90 E+10$ & 10.3 & 0.05 & 1.07 \\
\hline 13 & $9.00 E+\infty$ & $8.50 E+\infty 0$ & $5.39 E+10$ & 19.1 & 0.08 & $5.81 E+10$ & 8.7 & 0.07 & 1.08 \\
\hline 14 & $8.50 E+\infty$ & $8.00 E+\infty$ & $7.95 E+10$ & 19.1 & 0.11 & $8.67 E+10$ & 7.2 & 0.11 & 1.09 \\
\hline 15 & $8.00 E+\infty$ & $7.50 E+\infty$ & 1.17E+11 & 19.1 & 0.17 & $1.29 \mathrm{E}+11$ & 6.2 & 0.16 & 1.1 \\
\hline 16 & $7.50 E+\infty$ & $7.00 E+\infty$ & $1.71 E+11$ & 19.1 & 0.25 & $1.92 E+11$ & 5.7 & 0.24 & 1.12 \\
\hline 17 & $7.00 E+\infty$ & $6.50 E+\infty 0$ & $2.51 E+11$ & 19.1 & 0.36 & $2.83 E+11$ & 5.7 & 0.35 & 1.13 \\
\hline 18 & $6.50 E+\infty$ & $6.00 E+\infty 0$ & $3.66 E+11$ & 19.1 & 0.53 & $4.16 E+11$ & 5.8 & 0.52 & 1.14 \\
\hline 18 & $6.00 E+\infty$ & $5.50 E+\infty$ & $5.33 E+11$ & 19.1 & 0.77 & $6.09 E+11$ & 5.8 & 0.76 & 1.14 \\
\hline 20 & $5.50 E+\infty$ & $5.00 E+\infty$ & $7.74 E+11$ & 19.1 & 1.11 & $8.83 E+11$ & 5.5 & 1.11 & 1.14 \\
\hline 21 & $5.00 E+\infty$ & $4.50 E+\infty$ & $1.11 E+12$ & 19.1 & 1.6 & $1.26 E+12$ & 5.2 & 1.58 & 1.13 \\
\hline 22 & $4.50 E+\infty$ & $4.00 E+\infty 0$ & $1.57 E+12$ & 19 & 2.26 & $1.76 E+12$ & 4.8 & 2.21 & 1.12 \\
\hline 23 & $4.00 E+\infty 0$ & $3.50 E+\infty 0$ & $2.22 E+12$ & 19 & 3.2 & $2.45 E+12$ & 4.4 & 3.08 & 1.1 \\
\hline 24 & $3.50 E+\infty$ & $3.00 E+\infty 0$ & $3.18 E+12$ & 18.9 & 4.57 & $3.47 E+12$ & 4 & 4.35 & 1.09 \\
\hline 25 & $3.00 E+\infty$ & $2.50 E+\infty$ & $4.63 E+12$ & 19 & 6.65 & $5.05 E+12$ & 3.5 & 6.33 & 1.09 \\
\hline 26 & $2.50 E+\infty 0$ & $2.00 E+\infty 0$ & $6.67 E+12$ & 19 & 9.6 & $7.34 E+12$ & 3 & 9.2 & 1.1 \\
\hline 27 & $2.00 E+\infty$ & $1.50 E+\infty$ & $9.42 E+12$ & 19 & 13.56 & $1.06 E+13$ & 2.4 & 13.26 & 1.12 \\
\hline 28 & $1.50 E+\infty$ & $1.00 E+\infty 0$ & $1.34 E+13$ & 18.9 & 19.27 & $1.51 E+13$ & 3.1 & 18.91 & 1.13 \\
\hline 29 & $1.00 E+\infty$ & B.21E-01 & $1.53 E+13$ & 18.8 & 21.97 & $1.72 E+13$ & 3.3 & 21.59 & 1.13 \\
\hline 30 & 8.21E-01 & 4.98E-01 & $1.96 E+13$ & 18.6 & 28.15 & $2.21 E+13$ & 4.2 & 27.69 & 1.13 \\
\hline 31 & 4.98E-01 & 3.02E-01 & $2.27 E+13$ & 18.4 & 32.71 & $2.57 E+13$ & 4.9 & 32.22 & 1.13 \\
\hline 32 & $3.02 E-01$ & 1.11E-01 & $2.68 E+13$ & 18.1 & 38.58 & $3.03 E+13$ & 6 & 38.04 & 1.13 \\
\hline 33 & $1.11 \mathrm{E}-01$ & 5.25E-02 & $2.90 E+13$ & 17.9 & 41.76 & $3.29 E+13$ & 6.4 & 41.21 & 1.13 \\
\hline 34 & $5.25 E-02$ & 2.48E-02 & $3.09 E+13$ & 17.7 & 44.51 & $3.51 E+13$ & 6.8 & 43.96 & 1.13 \\
\hline 36 & 2.48E-02 & $1.50 \mathrm{E}-02$ & $3.22 E+13$ & 17.6 & 46.28 & $3.65 E+13$ & 7 & 45.77 & 1.13 \\
\hline 36 & 1.50E-02 & $9.12 E-03$ & $3.34 E+13$ & 17.4 & 47.98 & $3.79 E+13$ & 7 & 47.53 & 1.14 \\
\hline 37 & $9.12 E-03$ & 5.53E-03 & $3.45 E+13$ & 17.2 & 49.55 & $3.92 E+13$ & 7.1 & 49.19 & 1.14 \\
\hline 38 & 5.53E-03 & 1.23E-03 & $3.78 E+13$ & 16.7 & 54.36 & $4.34 E+13$ & 7 & 54.39 & 1.15 \\
\hline 39 & $1.23 E-03$ & 4.54E-04 & $3.99 E+13$ & 16.4 & 57.43 & $4.61 E+13$ & 6.8 & 57.77 & 1.15 \\
\hline 40 & 4.54E-04 & 2.75E-04 & $4.10 E+13$ & 16.2 & 58.96 & $4.75 E+13$ & 6.7 & 59.49 & 1.16 \\
\hline 41 & 2.75E-04 & 2.14E-04 & $4.15 E+13$ & 16.2 & 59.72 & $4.81 E+13$ & 6.6 & 60.35 & 1.16 \\
\hline 42 & $2.14 E-04$ & 1.01E-04 & $4.31 E+13$ & 15.9 & 61.97 & $5.02 E+13$ & 6.3 & 62.9 & 1.16 \\
\hline 43 & 1.01E-04 & 2.90E-05 & $4.56 E+13$ & 15.6 & 65.64 & $5.35 E+13$ & 5.9 & 67.11 & 1.17 \\
\hline 4 & 2.90E-05 & 6.48E-06 & $4.86 E+13$ & 15.3 & 69.94 & $5.75 E+13$ & 5.4 & 72.08 & 1.18 \\
\hline 46 & $6.48 E-06$ & 3.93E-06 & $4.96 E+13$ & 15.2 & 71.31 & $5.87 E+13$ & 5.3 & 73.56 & 1.18 \\
\hline 46 & 3.93E-06 & 3.06E-06 & $5.01 E+13$ & 15.2 & 72 & $5.93 E+13$ & 5.2 & 74.33 & 1.18 \\
\hline 47 & $3.06 E-06$ & $1.86 E-06$ & $5.10 E+13$ & 15.1 & 73.36 & $6.05 E+13$ & 5.1 & 75.84 & 1.19 \\
\hline 48 & $1.86 E-06$ & $1.13 E-06$ & $5.19 E+13$ & 15 & 74.71 & $6.17 E+13$ & 5 & 77.33 & 1.19 \\
\hline 49 & 1.13E-06 & 5.32E-07 & $5.34 E+13$ & 14.8 & 76.74 & $6.35 E+13$ & 4.8 & 79.57 & 1.19 \\
\hline 50 & 5.32E-07 & 4.14E-07 & $5.39 E+13$ & 14.8 & 77.46 & $6.41 E+13$ & 4.8 & 80.35 & 1.19 \\
\hline 51 & 4.14E-07 & 1.00E-10 & $6.95 E+13$ & 12.5 & 100 & $7.98 E+13$ & 5.8 & 100 & 1.15 \\
\hline
\end{tabular}


analyses resulted in major changes in the input group flux values and only minor or insignificant changes in the dosimeter cross-section group values. An important output from the least-squaresadjustment analyses are the covariance matrices generated for the adjusted group fluence rates. In effect, they embody the influence of the precise measured reaction-rate data on the magnitude and correlations in the groupwise uncertainties for the adjusted group values.

A comparison of representative adjusted multigroup spectra from various reactor locations is shown in Figure 9. These spectra show how the high-energy and low-energy spectral regions change in going from an inner position (A-10) to an outer location (OS-5). It should be noted that the relative shape of the input spectrum was identical for all the FERRET analysis. Hence, the initial $\mathrm{C} / \mathrm{M}$ reaction-rate ratios for the high-energy dosimeters were quite large for the B-11, Iholes and OS-5 location (ranging from a 3 to 6 , typically). To achieve consistency between the measured and the calculated reaction rates, the FERRET adjustment resulted in a significant "softening" of the input neutron spectra for these locations as expected. The FERRET-Fit C/M reaction-rate ratios were typically between 0.97 and 1.01 for the low-energy dosimeters and between 0.95 and 1.08 for the high-energy dosimeters for the B, I and OS locations. C/M comparisons and FERRET results for the A, SE, $\mathrm{H}$ and B-4, B-8 locations were very similar to those stated above for the $\mathrm{H}-2$ case.

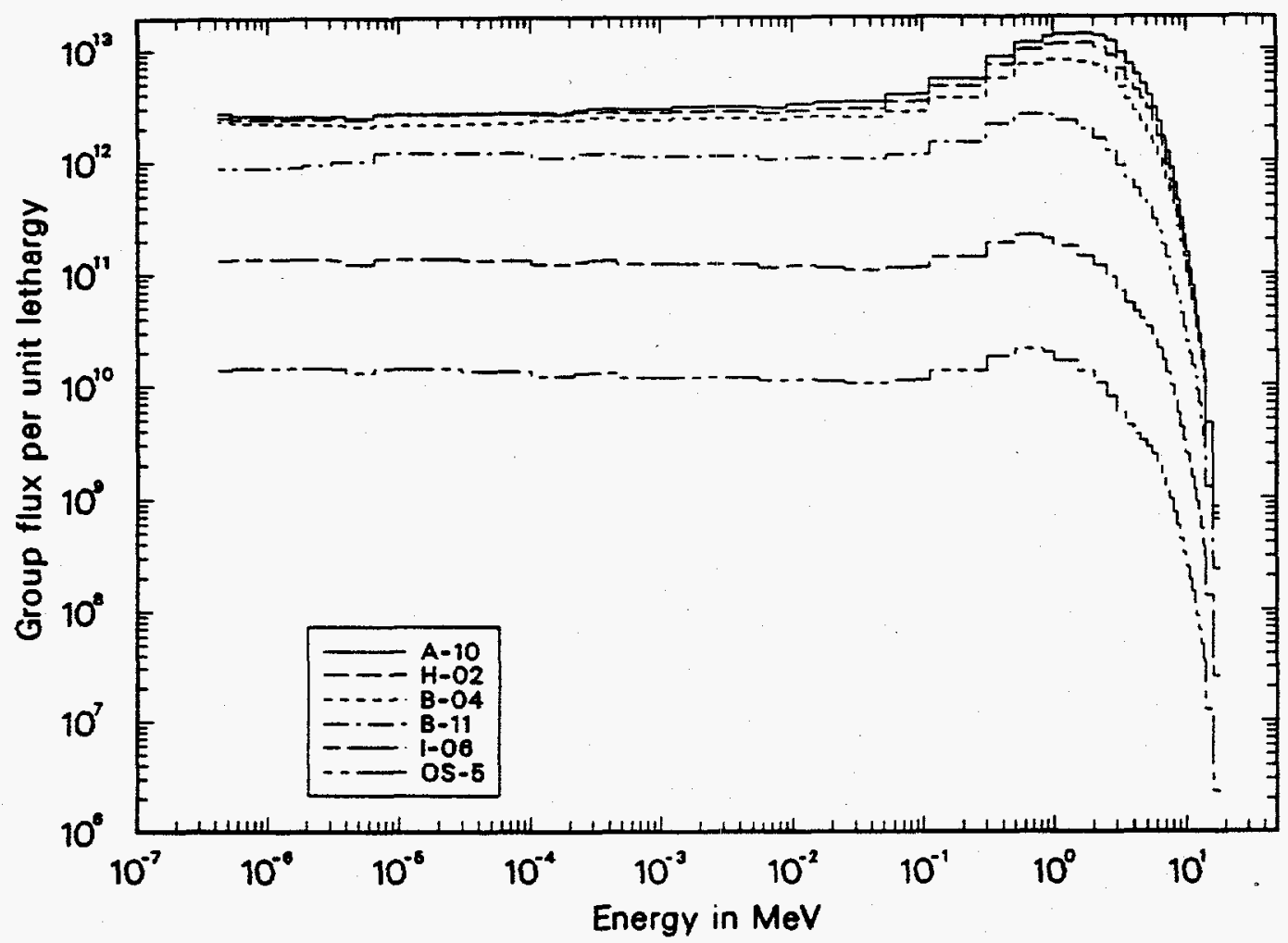

Figure 9. Comparison of final adjusted spectra for ATR locations characterized in this work. 


\subsection{SPECTRUM-AVERAGED CROSS SECTIONS}

\subsection{Cross Sections for Neutron Monitoring}

Historically, neutron flux levels and distributions in reactor environments have been monitored routinely by the use of selected neutron activation monitors with reaction cross sections sensitive to specific neutron energies. For example, since the startup of ATR, the "fast" neutron levels and distributions have been monitored routinely by the ${ }^{58} \mathrm{Ni}(\mathrm{n}, \mathrm{p}){ }^{58} \mathrm{Co}$ reaction. Some occasional monitoring has been done with other reactions, such as ${ }^{54} \mathrm{Fe}(n, p){ }^{54} \mathrm{Mn}$ and ${ }^{46} \mathrm{Ti}(\mathrm{n}, \mathrm{p}){ }^{46} \mathrm{Sc}$, that have energy response ranges similar to that for the ${ }^{58} \mathrm{Ni}(\mathrm{n}, \mathrm{p})$ reaction. Usually the analysis approach for determining the neutron flux levels and distributions from the dosimeter data did not involve the extensive spectrum-adjustment analysis that comprises the major part of this report. Rather, "fast" neutron flux-level predictions for neutrons with energies greater than $1 \mathrm{MeV}$ depended on the use of spectrum-averaged cross sections corresponding to the specific reactor environment. Throughout the past and current "fast" neutron monitoring program for the ATR, spectrumaveraged cross sections of 0.092 barns and 0.133 barns were adopted for the fast and $>1 \mathrm{MeV}$ cross sections, respectively, for the ${ }^{58} \mathrm{Ni}(\mathrm{n}, \mathrm{p})$ reactions.

To verify the applicability of the above spectrum-averaged cross section for ${ }^{58} \mathrm{Ni}(\mathrm{n}, \mathrm{p})$ and to obtain similar spectrum-averaged cross sections for other reactions, we have computed ATR reactor-relevant, spectrum-averaged cross sections using the adjusted spectra from the FERRET analysis. Such values for relevant dosimeter reactions in A-10, H-2, B-4, B-11, I-6 and OS-5 locations are presented in Table 8. The presentation of these selected values is somewhat representative of the variations in the spectrum-averaged cross sections throughout the ATR core. Values for the SE irradiation location are expected to be similar to values for the $A$ and $H$ irradiation locations. Cross sections for the low-energy reactions were computed by dividing the respective measured reaction rates by the $>0.4 \mathrm{eV}$, cumulative adjusted fluence rate values and, for the high-energy reaction rates, by the $>0.1 \mathrm{MeV}$, cumulative adjusted fluence rates. This information is found in the tables in the Appendix for each of the irradiation locations. Estimated uncertainties in these derived spectrum-averaged cross sections range from $\sim 6 \%$ for the lowenergy reactions to $7-10 \%$ for the high-energy reactions. Spectrum-averaged cross sections corresponding to $>1 \mathrm{MeV}$ can be derived for the high-energy reactions listed in Table 8 by multiplying the tabulated $>0.1 \mathrm{MeV}$ values by the factors $1.9,2.0,2.1,2.7,3.0$ and 3.1 for locations A-10, H-2, B-4, B-11, I-6 and OS-5, respectively.

Based on the cross-section results given in Table 8 for the A-10 and H-2 irradiation locations, the $>1 \mathrm{MeV}$ spectrum-averaged, cross section-values derived for the ${ }^{58} \mathrm{Ni}(\mathrm{n}, \mathrm{p})$ reaction in these locations are 0.136 barns and 0.122 barns, respectively. These values bracket the value of 0.133 barns that has been used historically to monitor fast-neutron fluences in the ATR. The estimated uncertainty for the derived cross-section values is $+/-6 \%$, a value considerably lower than the $+/$ $20 \%$ assigned to the historical 0.133 barn value. Based on this information, it appears that the routine $>1 \mathrm{MeV}$ neutron fluence rates are very consistent with the results of this study for the $A$ and $\mathrm{H}$ irradiation locations. We note, however, that the $>1 \mathrm{MeV},{ }^{58} \mathrm{Ni}(\mathrm{n}, \mathrm{p})$ cross-section values derived for the other irradiation locations identified in Table 8 are somewhat less than 0.133 
barns. Therefore, accurate fast-flux predictions for the B, I and OS locations, based on the ${ }^{58} \mathrm{Ni}(\mathrm{n}, \mathrm{p})$ reaction, require spectrum-averaged cross sections that are representative of the specific locations, values such as those reported here.

Table 8. Spectrum-averaged cross sections (barns) for neutron dosimeters.

\begin{tabular}{|c|c|c|c|c|c|c|}
\hline Reaction & $\mathbf{A - 1 0}$ & $\mathbf{H}-2$ & $\mathbf{B}-4$ & $\mathbf{B}-11$ & $\mathbf{I}-6$ & OS-5 \\
\hline${ }^{45} \mathbf{S c}(\mathbf{n}, \boldsymbol{\gamma})^{*}$ & $4.26 \mathrm{E}-1$ & $4.66 \mathrm{E}-1$ & $5.28 \mathrm{E}-1$ & $5.85 \mathrm{E}-1$ & $8.40 \mathrm{E}-1$ & $8.40 \mathrm{E}-1$ \\
${ }^{197} \mathbf{A u}(\mathbf{n}, \boldsymbol{\gamma})^{*}$ & $5.17 \mathrm{E}+1$ & $5.71 \mathrm{E}+1$ & $6.36 \mathrm{E}+1$ & $7.66 \mathrm{E}+1$ & $8.73 \mathrm{E}+1$ & $9.58 \mathrm{E}+1$ \\
${ }^{235} \mathbf{U}(\mathbf{n}, \mathbf{f})^{*}$ & $1.05 \mathrm{E}+1$ & $1.16 \mathrm{E}+1$ & $1.22 \mathrm{E}+1$ & $1.51 \mathrm{E}+1$ & $1.74 \mathrm{E}+1$ & $1.77 \mathrm{E}+1$ \\
${ }^{59} \mathbf{C o}(\mathbf{n}, \boldsymbol{\gamma})^{*}$ & $2.48 \mathrm{E}+0$ & $2.90 \mathrm{E}+0$ & $3.07 \mathrm{E}+0$ & $3.56 \mathrm{E}+0$ & $3.89 \mathrm{E}+0$ & $3.97 \mathrm{E}+0$ \\
${ }^{58} \mathbf{F e}(\mathbf{n}, \boldsymbol{\gamma})^{*}$ & $5.02 \mathrm{E}-2$ & $5.35 \mathrm{E}-2$ & $6.06 \mathrm{E}-2$ & $7.02 \mathrm{E}-2$ & $8.03 \mathrm{E}-2$ & $8.22 \mathrm{E}-2$ \\
${ }^{237} \mathbf{N p}\left(\mathbf{n}, \mathbf{f}^{+}\right.$ & $1.16 \mathrm{E}+0$ & $1.12 \mathrm{E}+0$ & $1.07 \mathrm{E}+0$ & $9.61 \mathrm{E}-1$ & $9.25 \mathrm{E}-1$ & $7.94 \mathrm{E}-1$ \\
${ }^{238} \mathbf{U}\left(\mathbf{n}, \mathbf{f}^{+}\right.$ & $2.13 \mathrm{E}-1$ & $2.04 \mathrm{E}-1$ & $1.89 \mathrm{E}-1$ & $1.38 \mathrm{E}-1$ & $1.24 \mathrm{E}-1$ & $1.05 \mathrm{E}-1$ \\
${ }^{\mathbf{5 8}} \mathbf{N i ( n , p )}$ & $6.80 \mathrm{E}-2$ & $6.10 \mathrm{E}-2$ & $5.43 \mathrm{E}-2$ & $3.64 \mathrm{E}-2$ & $3.37 \mathrm{E}-2$ & $2.46 \mathrm{E}-2$ \\
${ }^{54} \mathbf{F e}(\mathbf{n}, \mathbf{p})^{+}$ & $5.00 \mathrm{E}-2$ & $4.46 \mathrm{E}-2$ & $3.93 \mathrm{E}-2$ & $2.68 \mathrm{E}-2$ & $2.37 \mathrm{E}-2$ & $2.23 \mathrm{E}-2$ \\
${ }^{46} \mathbf{T i}(\mathbf{n}, \mathbf{p})^{+}$ & $6.50 \mathrm{E}-3$ & $5.97 \mathrm{E}-3$ & $5.48 \mathrm{E}-3$ & $3.84 \mathrm{E}-3$ & $4.07 \mathrm{E}-3$ & $3.18 \mathrm{E}-3$ \\
${ }^{48} \mathbf{T i}(\mathbf{n}, \mathbf{p})^{+}$ & $1.71 \mathrm{E}-4$ & $1.45 \mathrm{E}-4$ & $1.43 \mathrm{E}-4$ & $1.06 \mathrm{E}-4$ & $1.29 \mathrm{E}-4$ & $9.91 \mathrm{E}-5$ \\
${ }^{27} \mathbf{A l}(\mathbf{n}, \boldsymbol{\alpha})^{+}$ & $3.63 \mathrm{E}-4$ & $3.47 \mathrm{E}-4$ & $3.58 \mathrm{E}-4$ & $2.53 \mathrm{E}-4$ & $2.62 \mathrm{E}-4$ & $1.93 \mathrm{E}-4$ \\
\hline
\end{tabular}

*For neutrons with $\mathrm{E}>0.4 \mathrm{eV}$.

+For neutrons with $\mathrm{E}>0.1 \mathrm{MeV}$.

\subsection{Neutron Damage Production in ATR Irradiation Locations}

Results of the FERRET analyses, especially the improved characterization of the "fast" neutron region of the neutron spectra, are of particular interest to an accurate prediction of neutroninduced displacement damage for material irradiated in the ATR. To assist in the prediction of damage rates for materials testing applications, we have computed spectrum-averaged damageproduction cross sections for $\mathrm{Fe}, \mathrm{Cr}$ and $\mathrm{Ni}$ in selected irradiation locations that were characterized in this study. These calculations were made using ASTM damage cross-section data obtained from the International Reactor Dosimetry File [12] and spectra of selected adjusted multigroup fluence rates from the FERRET analyses. Table 9 details the results of these calculations, namely, spectrum-averaged damage cross sections, estimates of damage-production rates, and estimates of relative damage response for $>0.1 \mathrm{MeV}$ and $>1.0 \mathrm{MeV}$ neutrons. The cross sections tabulated correspond to $>0.1 \mathrm{MeV}$ neutrons. Cross sections corresponding to $>1.0 \mathrm{MeV}$ neutrons can be easily computed by multiplying the listed values by the following: 1.9 for A-10, 2.0 for H-2, 2.1 for B-4, 2.7 for B-11, 3.0 for I-6 and 3.1 for OS-5. Uncertainties estimated for these damage production reactions range from $7 \%$ to $10 \%$. Estimates of the damage rates given in the second half of the table correspond to the irradiation conditions during the $10 \mathrm{MW}$ Cycle $73 \mathrm{~A}-8$ operation of ATR. These rates were computed using the $>0.1 \mathrm{MeV}$ neutron fluxes that were obtained from the FERRET-adjusted spectra for the various irradiation locations, namely; $3.72 \mathrm{E} 13 \mathrm{n} / \mathrm{cm}^{2}-\mathrm{s}$ for A-10, 3.03E13 n/cm ${ }^{2}$-s for H-2, $2.19 \mathrm{E} 13 \mathrm{n} / \mathrm{cm}^{2}-\mathrm{s}$ for B-4, $6.87 \mathrm{E} 12 \mathrm{n} / \mathrm{cm}^{2}-\mathrm{s}$ for B-11, $5.75 \mathrm{E} 11 \mathrm{n} / \mathrm{cm}^{2}-\mathrm{s}$ for I-6 and $5.48 \mathrm{E} 10 \mathrm{n} / \mathrm{cm}^{2}-\mathrm{s}$ for OS-5. 
Table 9. Damage production in selected ATR irradiation locations.

\begin{tabular}{|c|c|c|c|c|c|c|}
\hline Material & A-10 & H-2 & B-4 & B-11 & I-6 & OS-5 \\
\hline & & & $\begin{array}{c}\text { Cross Section } \\
>0.1 \mathrm{MeV} \\
\text { (barns) }\end{array}$ & & & \\
\hline $\mathbf{F e}$ & 713 & 689 & 673 & 588 & 577 & 566 \\
\hline $\mathrm{Cr}$ & 795 & 769 & 749 & 653 & 636 & 622 \\
\hline $\mathbf{N i}$ & 744 & 725 & $\begin{array}{c}713 \\
\text { Damage Rate } \\
\text { (dpa/s) }\end{array}$ & 648 & 644 & 635 \\
\hline $\mathbf{F e}$ & $2.6 \mathrm{E}-8$ & 2.1E-08 & $1.5 \mathrm{E}-8$ & 4.0E-09 & $3.3 \mathrm{E}-10$ & 3.1E-11 \\
\hline $\mathrm{Cr}$ & $3.0 \mathrm{E}-8$ & 2.3E-08 & $1.6 \mathrm{E}-8$ & $4.5 \mathrm{E}-09$ & 3.7E-10 & $3.4 \mathrm{E}-11$ \\
\hline $\mathbf{N i}$ & $2.8 \mathrm{E}-8$ & 2.2E-08 & $\begin{array}{c}1.6 \mathrm{E}-8 \\
\text { Damage } \\
\text { Response } \\
(\%)\end{array}$ & 4.5E-09 & 3.7E-10 & $3.5 \mathrm{E}-11$ \\
\hline $\mathrm{Fe}(>0.1)$ & 97 & 96 & 95 & 93 & 89 & 90 \\
\hline $\mathrm{Fe}(>1.0)$ & 76 & 74 & 71 & 61 & 56 & 55 \\
\hline $\operatorname{Cr}(>0.1)$ & 97 & 97 & 96 & 94 & 93 & 93 \\
\hline $\operatorname{Cr}(>1.0)$ & 76 & 74 & 72 & 62 & 58 & 56 \\
\hline $\mathrm{Ni}(>0.1)$ & 95 & 95 & 94 & 91 & 88 & 88 \\
\hline $\mathrm{Ni}(>1.0)$ & 70 & 68 & 66 & 54 & 50 & 48 \\
\hline
\end{tabular}

For materials irradiated in the ATR, neutron-induced damage is highly dependent on the irradiation location. In Table 9, we observe approximately a 20\% reduction in the spectrumaveraged cross sections for damage production in $\mathrm{Fe}, \mathrm{Cr}$ and $\mathrm{Ni}$ in going from the $\mathrm{A}-10$ location to the OS-5 location. A much larger reduction in the absolute damage rate is observed in going from the A-10 location to the OS-5 location. The primary reason for the large reduction in absolute damage rate is the significant reduction in fast-neutron flux as one goes from the $\mathrm{A}$ irradiation region to the I and OS regions. The variation in the spectrum-averaged damage cross sections relates to the changes in the shape of the fast-neutron spectral region as evidenced by the adjusted spectra shown in Figure 9. This variation in spectral shape results in significant changes in the damage-response distributions, as illustrated in Figures 10 to 12 and by the \% damageresponse values given in Table 9 for $>0.1 \mathrm{MeV}$ neutrons and $>1.0 \mathrm{MeV}$ neutrons. The same procedure used to compute the dosimeter response distributions, as discussed in section 3.1, was used in the calculations of the damage response distributions. A feature, that is particularly noteworthy in Figures 10 to 12 and in the response values listed in Table 9, is the significant increase in damage response between $0.1 \mathrm{MeV}$ and $1.0 \mathrm{MeV}$ and the reduction in response for neutrons with energies greater than $1 \mathrm{MeV}$, as one goes from the $\mathrm{A}$ region to the $\mathrm{OS}$ region. This feature demonstrates the importance in having accurate measurement of the $>0.1 \mathrm{MeV}$ neutron fluences and accurate spectrum-averaged cross sections if accurate damage-production analyses are to be done. 


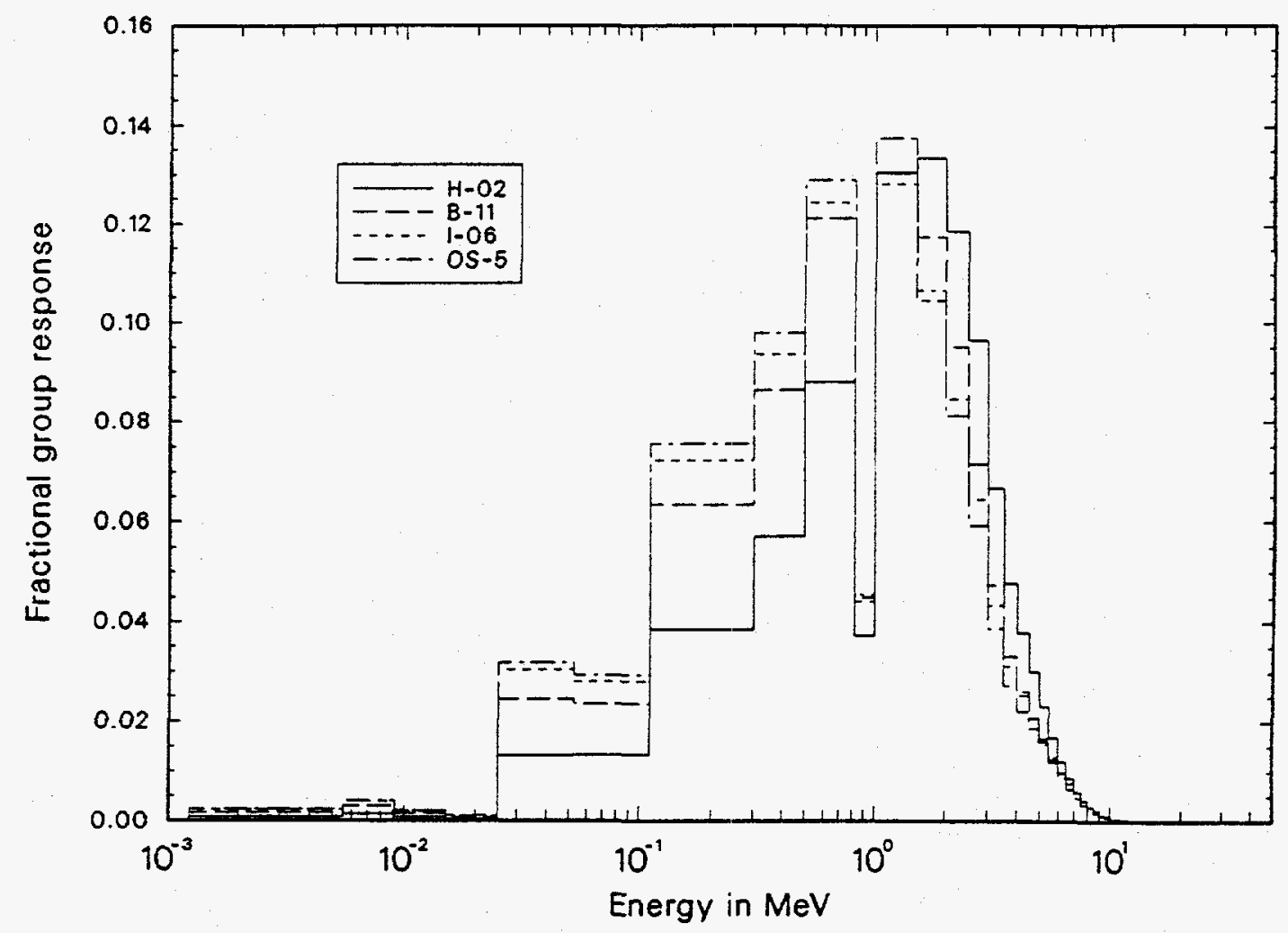

Figure 10. Comparison of multigroup damage response for Fe using adjusted ATR spectra.

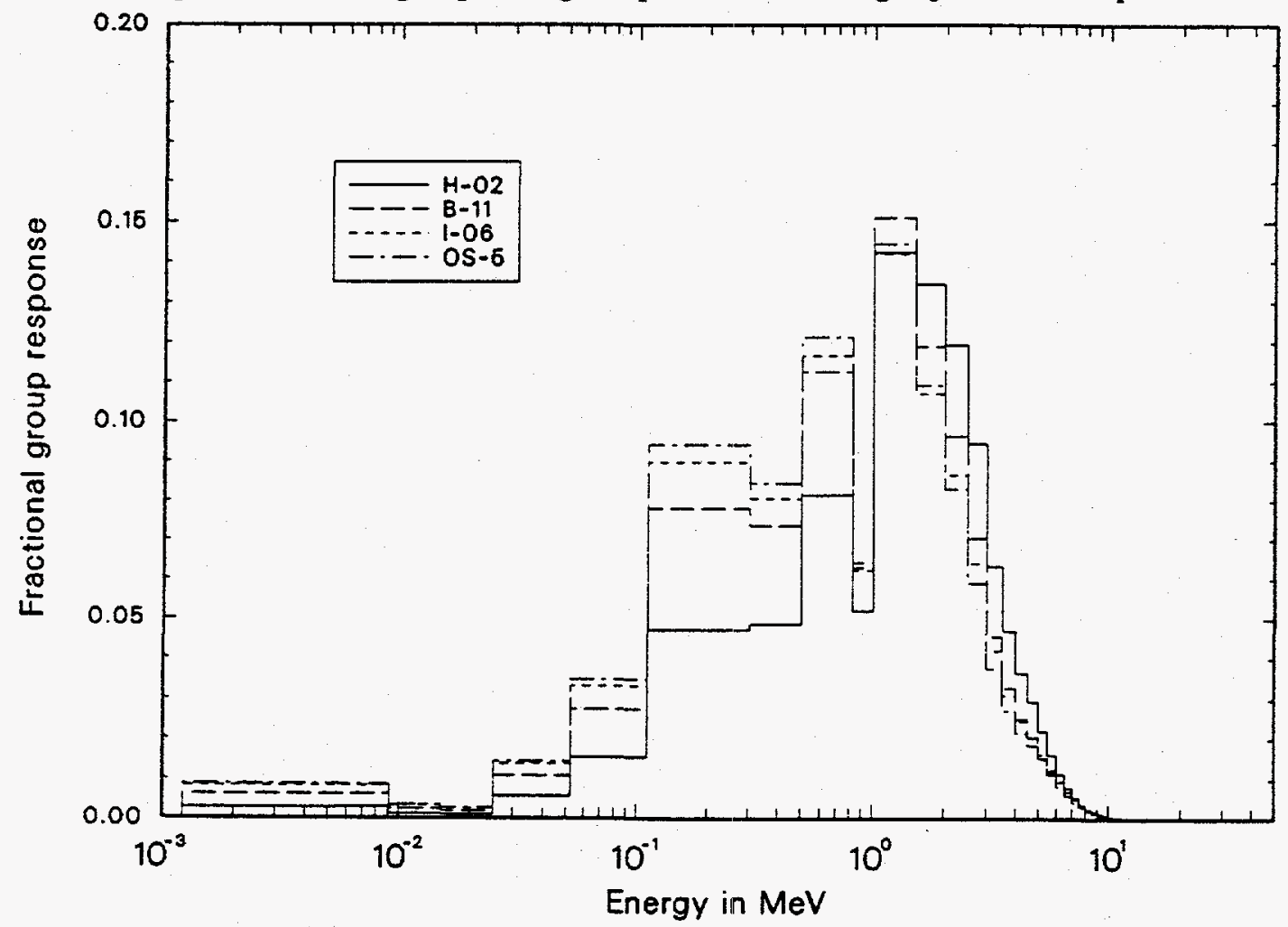

Figure 11. Comparison of multigroup damage response for $\mathrm{Cr}$ using adjusted ATR spectra. 


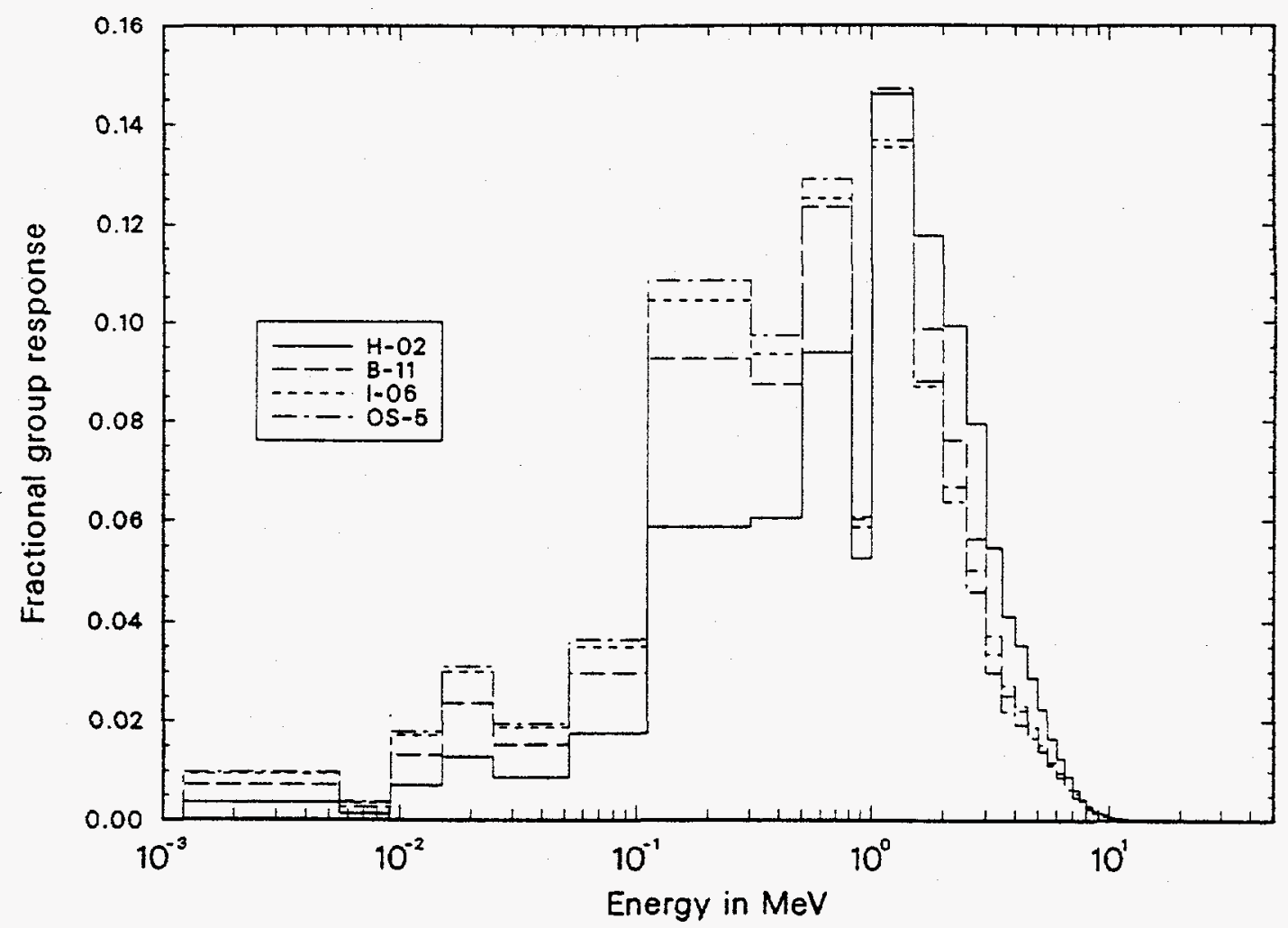

Figure 12. Comparison of multigroup damage response for Ni using adjusted ATR spectra.

\subsection{CONCLUSIONS}

In this report, we have demonstrated the extent to which neutron dosimetry measurements have been used to characterize the neutron environment in the irradiation locations of the ATR. The presentation of materials included a summary of the global spectral characterization based on historical dosimetry measurements to determine the thermal, epithermal and fast-neutron fluence rates. A major component of this report is the documentation of a more detailed characterization of the neutron spectra for selected A, B, H, I OS, and SE irradiation locations. This characterization is based on the use of a dosimeter package that was sensitive to a broader range of the epithermal neutron region from $0.4 \mathrm{eV}$ to $0.001 \mathrm{MeV}$ and was particularly sensitive to fast neutrons in the energy range from $0.5 \mathrm{MeV}$ to $10 \mathrm{MeV}$. Measured reaction-rate data for the lowenergy dosimeter reactions and for the high-energy threshold reactions were used in least-squaresadjustment analyses with the FERRET code to obtain a significant improvement in the neutron spectral characterization for various irradiation locations in the ATR. The methodology for these analyses was described in some detail. Tabulations of spectral results in terms of 51-group fluence rates and cumulative flux distributions are included here in the appendix. These spectral tabulations serve as an important reference for analysis of past and future irradiation experiments in that they represent a significant extension beyond the historical dosimetry-based spectral characterization and they serve as a measurement-based refinement of calculated neutron spectra. In addition to providing a more-detailed spectral characterization, this work generated more 
accurate spectrum-averaged cross sections for several dosimeter reactions that have been used for the more historical spectrum characterization in terms of epithermal, $>0.1 \mathrm{MeV}$, and $>1 \mathrm{MeV}$ neutron fluences. These cross sections have uncertainties in the $6 \%$ to $10 \%$ range for the highenergy response reactions. Finally, displacement damage (dpa) spectrum-averaged cross sections were derived in this work for $\mathrm{Fe}, \mathrm{Cr}$ and $\mathrm{Ni}$ to provide information not previously available for the prediction of damage to materials in the ATR. In conclusion, the results from these studies have produced information which allows neutron monitoring and spectral characterization to be done at a higher accuracy and with more spectral detail than has previously been possible.

The accurate neutron reaction rates that were measured as part of these neutron characterization studies provide measured data that can be used to develop and validate (benchmark) neutronics calculations for the ATR. Neutronics calculations and measurements have been compared for a few locations to examine neutron activation distribution profiles under perturbed conditions. The results have generally been in good agreement.

Finally, the results presented in this report were obtained for the 1986 core configuration and loading of Cycle 73A-8 that is representative of earlier and some later cycles. In the current configuration and loading ( November,1995), where inpile loops have been replaced by flux traps and material loadings are different, some changes in neutron spectral characterization and flux perturbations have occurred, predominantly in the flux trap irradiation facilities (NE, E, C and S). No extensive spectral and perturbation studies have been conducted for the new configuration. However, no significant changes are expected in the A, B, SE, I and OS regions where no major absorber and moderator alterations have been made. 


\section{REFERENCES}

1. Neutron Fluence Measurements, Technical Reports Series No. 107, International Atomic Energy Agency, Vienna, 1970.

2. 1993 Annual Book of ASTM Standards, Volume 12.02, "Nuclear (11), Solar, and Geothermal Energy," American Society for Testing and Materials, Philadelphia, PA (1993).

3. JW Rogers and R. A. Anderl, "Neutron Spectrum Studies in the ATR Center Lobe Positions H-2, H-10 and H-14 ," US DOE Report EGG-CS-8668, INEL, September, 1989.

4. JW Rogers, R. A. Anderl and M. H. Putnam, "Neutron Spectrum Studies in the ATR", Proceedings of the Seventh ASTM-EURATOM Symposium on Reactor Dosimetry, Kluwer Academic Publishers, Dordrecht (1992).

5. F. Schmittroth, "FERRET Data Analysis Code," US DOE Report HEDL-TME 79-40, Hanford Engineering Development Laboratory (September 1979).

6. F. Schmittroth, Nucl. Sci. Eng., $\underline{72}$, (1979) 19-34.

7. R. Kinsey, "ENDF-102 Data Formats and Procedures for the Evaluated Nuclear Data File, ENDF," BNL-NCS-50496, (ENDF-102) 2nd Edition (ENDF/B-V), UC-80, (General Reactor Technology TID-4500), Brookhaven National Laboratory, Upton, NY (October 1979).

8. "PUFF2 Determination of Multigroup Covariance Matrices from ENDF/B-V Uncertainty Files," RSIC Computer Code Collection, PSR-157 (1980).

9. Private Communication from F. Schmittroth, Hanford Engineering Development Laboratory (February 1982).

10. G. E. Putnam, TOPIC - A Fortran Program Calculating Transport of Particles in Cylinders, IDO-16968, April 1964. SCAMP is an undocumented internal $S_{n}$ transport code with onedimensional slab, cylindrical, and spherical capabilities. In cylindrical form, it is a multigroup version of TOPIC.

11. C. J. Pfeifer, PDQ-7 Reference Manual II, WAPD-TM-947(2), 1971.

12. D. E. Cullen and P. K. McLaughlin, "The International Reactor Dosimetry File (IRDF-85)," IAEA-NDS-41, Rev- 1, IAEA Nuclear Data Section, Vienna, Austria (April 1985). 


\section{APPENDIX. DETAILED SUMMARY OF RESULTS FROM FERRET ANALYSES}

In this appendix we summarize the relevant results from the FERRET analyses for all of the ATR irradiation locations that were characterized by neutron dosimeter packages during reactor Cycle 73A-8, immediately following the core internals changeout that took place in 1986 . Dosimeters were placed at core-midplane in the following irradiation locations: A-1, A-10, A-12, B-4, B-8, B-1 1, H-2, H-10, H-14, I-6, I-8, I-22, SE(SR)-1, SE(SR)-3, and OS-5. The data as presented correspond to the reactor operating at a total power level of $10 \mathrm{MW}$ during Cycle $73 \mathrm{~A}-8$, with the lobe-power distribution as follows: $\mathrm{LNW}=1.81 \mathrm{MW}, \mathrm{LNE}=1.82 \mathrm{MW}, \mathrm{LC}=2.17 \mathrm{MW}$, $\mathrm{LSW}=2.15 \mathrm{MW}, \mathrm{LSE}=2.05 \mathrm{MW}$ based on the ${ }^{16} \mathrm{~N}$ lobe power monitors. Scaling the tabulated group fluence-rate data to a higher power level of operation must consider the above power distribution that corresponded to the dosimetry experiment. In addition, scaling of the data to a different power level must consider the relative contributions from the lobes that most influence the selected irradiation location. A reasonable lobe contribution identification is given in Table 9. In this table, estimates are given for the lobe-average power that can be associated with a selected irradiation location for this specific spectral characterization. For the cases in which more than one lobe contributes, each is considered to contribute equally.

Table 10. Lobe-average power for the irradiation locations.

\begin{tabular}{|c|c|c|}
\hline $\begin{array}{c}\text { Irradiation } \\
\text { Location }\end{array}$ & $\begin{array}{c}\text { Applicable } \\
\text { Lobes }\end{array}$ & $\begin{array}{c}\text { Lobe-Average } \\
\text { Power (MW) }\end{array}$ \\
\hline A-1 & C, NE & 2.00 \\
A-10 & SE & 2.05 \\
A-12 & NW & 1.81 \\
B-4 & SE & 2.05 \\
B-8 & NW & 1.81 \\
B-11 & SE, SW, C & 2.12 \\
H-2 & C & 2.17 \\
H-10 & C & 2.17 \\
H-14 & C & 2.17 \\
I-6 & NE, SE, C & 2.01 \\
I-8 & SE & 2.05 \\
I-22 & SE & 2.05 \\
SE-1 & SE & 2.05 \\
SE-3 & SE & 2.05 \\
OS-5 & SE, SW, C & 2.12 \\
\hline
\end{tabular}

The information in this appendix is organized according to the specific type of irradiation location, A, B, H, I, SE, or OS location. For each of these irradiation type locations, we provide the following: a table comparing the measured dosimetry reaction-rate data to the calculated and FERRET-Fit reaction-rate data, figures that compare the unadjusted (or FERRET-input) and 
FERRET-adjusted group fluence rates for each irradiation location of the type specified, tables that compare the unadjusted and FERRET-adjusted group fluence rates for each irradiation location and tables that list the cumulative group fluence rates for the unadjusted and FERRETadjusted group fluence rates for each irradiation location. Fluence rate and flux are used interchangeably in this document. Both the table headings and the figure captions include letter identifiers that relate the information to the specific irradiation type locations. For example, Table $B$ summarizes the reaction-rate information for the three type $B$ irradiation locations studied in this work, Figure B1 displays the comparison of the unadjusted and FERRET-adjusted group fluence rates for ATR location B-4, Table B1 summarizes the numerical data for the unadjusted and FERRET-adjusted group fluence rates for location B-4, Table B2 lists the cumulative groupfluence rates for location B-4, Figure B2 compares the unadjusted and FERRET-adjusted group fluence rates for ATR location B-8, etc.

In the upper part of each figure, group-flux values are plotted as $\mathrm{n} / \mathrm{cm}^{2}$-s per unit lethargy. The lower part of each figure displays the ratio of adjusted-to-unadjusted group flux values, along with uncertainty bounds to indicate the input uncertainty ranges and error bars at the midpoint of the group values to indicate the values of the uncertainties in the FERRET-adjusted group fluxes.

Symbols used in the tables are defined as follows:

EU: upper energy bound for the group (MeV)

EL: lower energy bound for the group (MeV)

DU: lethargy width for the group $\{\log (10 / \mathrm{EL})-\log (10 / \mathrm{EU})\}$

PHA: adjusted group fluence rate,

CPHA: cumulative group value for PHA

UNCA: \% uncertainty for PHA or for CPHA

FRPHA: \% fractional group value for PHA

FRCPHA: \% fractional group value for CPHA

RPH: ratio of adjusted-to-unadjusted group fluence rates

RCPH: ratio of adjusted to unadjusted cumulative group values

Group fluence-rate data, PHA, in these tables were obtained directly from the FERRET analyses adjusted spectra. The \% uncertainties for the group fluence-rate values were derived from the diagonal elements of the covariance matrices corresponding to the FERRET adjusted data. The cumulative group flux values correspond to the total number of neutrons above the lower energy bound of the designated group. These values and their associated uncertainties were obtained from additional calculations with the adjusted group fluence-rate and covariance data obtained from the FERRET analyses. No specific tabulation of the input group flux data and corresponding cumulative group values are presented in these tables. However such data can be inferred from the ratio data, RPH and RCPH. In addition, Tables 6 and 7 provide such information for the $\mathrm{H}-2$ location. The input group flux data for the other irradiation locations was scaled to this spectrum based on the measured ${ }^{235} \mathrm{U}(\mathrm{n}, \mathrm{f})$ reaction-rate values. 
Electronic data files of the group fluence rate and cumulative data are available from the authors. Both EXCEL worksheets and ASC-II files are available. This information can be obtained by contacting one of the following:

Robert A. Anderl

JW Rogers

Pamela R. King

Del C. Mecham phone: (208-533-4153)

phone: (208-533-4252)

phone: (208-533-4437)

phone: (208-533-4577) email: raa@inel.gov

email: prk@inel.gov

email: dcm@inel.gov 
Table A. FERRET analysis summary for ATR A positions.

\begin{tabular}{|c|c|c|c|c|c|c|c|c|}
\hline $\begin{array}{c}\text { Dosimeter } \\
\text { Reaction }\end{array}$ & $\begin{array}{c}\text { Measured } \\
\text { Rate } \\
\text { (Bq/atom) }\end{array}$ & $\begin{array}{c}\sigma \\
(\%)\end{array}$ & $\begin{array}{c}\text { Calculated } \\
\text { Rate } \\
\text { (Bg/atom) }\end{array}$ & $\begin{array}{c}\sigma \\
(\%)\end{array}$ & $\mathrm{C} / \mathrm{M}$ & $\begin{array}{c}\text { FERRET-Fit } \\
\text { Rate } \\
\text { (Bq/atom) } \\
\end{array}$ & $\begin{array}{c}\sigma \\
(\%)\end{array}$ & FF/M \\
\hline $45 \operatorname{Se}(n, \gamma)$ & $2.99 \mathrm{E}-11$ & 2 & $\begin{array}{c}\mathbf{A - 1} \\
2.24 \mathrm{E}-11\end{array}$ & 19.4 & 0.75 & $2.99 \mathrm{E}-11$ & 5.3 & 1 \\
\hline 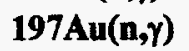 & $3.64 \mathrm{E}-09$ & 2 & $2.98 \mathrm{E}-09$ & 21.8 & 0.82 & $3.65 \mathrm{E}-09$ & 4.3 & 1 \\
\hline $235 \mathrm{U}(\mathrm{n}, \mathrm{f})$ & $7.54 \mathrm{E}-10$ & 2 & $5.67 \mathrm{E}-10$ & 17.3 & 0.753 & $7.49 E-10$ & 2.9 & 0.99 \\
\hline $59 \mathrm{Co}(\mathrm{n}, \gamma)$ & $1.85 \mathrm{E}-10$ & 2.1 & $1.48 \mathrm{E}-10$ & 20.9 & 0.803 & $1.85 \mathrm{E}-10$ & 5.4 & 1 \\
\hline $58 F e(n, \gamma)$ & $3.58 \mathrm{E}-12$ & 2.2 & $2.60 \mathrm{E}-12$ & 18 & 0.727 & $3.57 \mathrm{E}-12$ & 5 & 1 \\
\hline $237 N p(n, f)$ & $4.03 \mathrm{E}-11$ & 2 & $3.00 \mathrm{E}-11$ & 20.4 & 0.744 & $4.03 E-11$ & 4.8 & 1 \\
\hline $238 \mathrm{U}(\mathrm{n}, \mathrm{f})$ & $7.29 \mathrm{E}-12$ & 2.1 & $5.41 \mathrm{E}-12$ & 18.6 & 0.741 & $7.29 \mathrm{E}-12$ & 2.4 & 1 \\
\hline 47Ti(n,p) & $4.36 \mathrm{E}-13$ & 2.2 & $3.56 \mathrm{E}-13$ & 21.1 & 0.817 & $4.34 \mathrm{E}-13$ & 3.1 & 1 \\
\hline $58 N i(n, p)$ & $2.35 \mathrm{E}-12$ & 2 & $1.61 \mathrm{E}-12$ & 19.1 & 0.687 & $2.36 \mathrm{E}-12$ & 3.5 & 1 \\
\hline $54 F e(n, p)$ & $1.74 \mathrm{E}-12$ & 3 & $1.23 \mathrm{E}-12$ & 18.4 & 0.705 & $1.74 \mathrm{E}-12$ & 3.7 & 1 \\
\hline $46 \operatorname{Ti}(n, p)$ & $2.36 \mathrm{E}-13$ & 2.1 & $1.56 \mathrm{E}-13$ & 21.9 & 0.659 & $2.34 \mathrm{E}-13$ & 5.3 & 0.99 \\
\hline $63 \mathrm{Cu}(n, \alpha)$ & $1.09 \mathrm{E}-14$ & 3 & $7.55 \mathrm{E}-15$ & 17.9 & 0.692 & $1.10 E-14$ & 5.1 & 1.01 \\
\hline 48Ti(n,p) & $6.00 \mathrm{E}-15$ & 2.9 & $3.77 \mathrm{E}-15$ & 20.2 & 0.628 & $5.97 \mathrm{E}-15$ & 5.9 & 1 \\
\hline $27 A \mid(n, \alpha)$ & $1.28 \mathrm{E}-14$ & 9.1 & $\begin{array}{c}9.54 \mathrm{E}-15 \\
\mathrm{~A}-10\end{array}$ & 18.7 & 0.746 & $1.29 \mathrm{E}-14$ & 6.7 & 1.01 \\
\hline $45 \operatorname{Sc}(n, \gamma)$ & $3.13 \mathrm{E}-11$ & 2 & 2.24E-11 & 19.4 & 0.717 & $3.13 \mathrm{E}-11$ & 5.3 & 1 \\
\hline 197Au(n,y) & $3.80 \mathrm{E}-09$ & 2 & $2.98 \mathrm{E}-09$ & 21.8 & 0.785 & $3.81 E-09$ & 4.3 & 1 \\
\hline $235 U(n, n)$ & $7.73 \mathrm{E}-10$ & 2 & $5.67 \mathrm{E}-10$ & 17.3 & 0.734 & $7.69 \mathrm{E}-10$ & 2.9 & 1 \\
\hline $59 \mathrm{Co}(\mathbf{n}, \gamma)$ & $1.82 \mathrm{E}-10$ & 2.1 & $1.48 \mathrm{E}-10$ & 20.9 & 0.816 & $1.83 E-10$ & 5.4 & 1 \\
\hline $58 \mathrm{Fe}(\mathrm{n}, \gamma)$ & $3.69 \mathrm{E}-12$ & 2.2 & $2.60 \mathrm{E}-12$ & 18 & 0.705 & $3.68 \mathrm{E}-12$ & 5 & 1 \\
\hline $237 \mathrm{~Np}(\mathrm{n}, \mathrm{n})$ & $4.33 \mathrm{E}-11$ & 2 & $3.00 \mathrm{E}-11$ & 20.4 & 0.692 & 4.33E-11 & 4.8 & 1 \\
\hline $238 U(n, f)$ & $7.93 \mathrm{E}-12$ & 2.1 & $5.41 \mathrm{E}-12$ & 18.6 & 0.682 & $7.90 \mathrm{E}-12$ & 2.4 & 1 \\
\hline 47Ti(n,p) & $4.60 E-13$ & 2.2 & $3.56 \mathrm{E}-13$ & 21.1 & 0.775 & $4.65 \mathrm{E}-13$ & 3.1 & 1.01 \\
\hline $58 N i(n, p)$ & $2.53 E-12$ & 2 & $1.61 E-12$ & 19.1 & 0.638 & $2.51 E-12$ & 3.5 & 0.99 \\
\hline $54 F e(n, p)$ & $1.86 \mathrm{E}-12$ & 3 & $1.23 \mathrm{E}-12$ & 18.4 & 0.66 & $1.85 \mathrm{E}-12$ & 3.7 & 1 \\
\hline $46 \operatorname{Ti}(n, p)$ & $2.42 \mathrm{E}-13$ & 2.1 & $1.56 \mathrm{E}-13$ & 21.9 & 0.643 & $2.43 \mathrm{E}-13$ & 5.3 & 1 \\
\hline $63 \mathrm{Cu}(\mathrm{n}, \alpha)$ & $1.17 \mathrm{E}-14$ & 3 & $7.55 \mathrm{E}-15$ & 17.9 & 0.645 & $1.16 \mathrm{E}-14$ & 5.1 & 0.99 \\
\hline 48Ti(n,p) & $6.37 \mathrm{E}-15$ & 2.9 & $3.77 \mathrm{E}-15$ & 20.2 & 0.591 & $6.35 \mathrm{E}-15$ & 5.9 & 1 \\
\hline $27 A \mid(n, \alpha)$ & $1.35 \mathrm{E}-14$ & 9.1 & $\begin{array}{c}9.54 \mathrm{E}-15 \\
\mathbf{A}-12\end{array}$ & 18.7 & 0.707 & $1.39 \mathrm{E}-14$ & 6.7 & 1.03 \\
\hline $45 \operatorname{Se}(n, y)$ & $2.92 \mathrm{E}-11$ & 2 & $2.24 \mathrm{E}-11$ & 19.4 & 0.768 & $2.91 \mathrm{E}-11$ & 5.3 & 1 \\
\hline $197 A u(n, \gamma)$ & $3.64 \mathrm{E}-09$ & 2 & $2.98 \mathrm{E}-09$ & 21.8 & 0.82 & $3.64 \mathrm{E}-09$ & 4.3 & 1 \\
\hline $235 U(n, f)$ & $7.09 \mathrm{E}-10$ & 2 & $5.67 \mathrm{E}-10$ & 17.3 & 0.8 & $7.12 \mathrm{E}-10$ & 2.9 & 1 \\
\hline $59 \operatorname{Co}(\mathbf{n}, \gamma)$ & $1.83 \mathrm{E}-10$ & 2.1 & $1.48 \mathrm{E}-10$ & 20.9 & 0.811 & $1.83 \mathrm{E}-10$ & 5.4 & 1 \\
\hline $\operatorname{s8Fe}(\mathbf{n}, \gamma)$ & $3.42 E-12$ & 2.2 & $2.60 \mathrm{E}-12$ & 18 & 0.761 & $3.41 \mathrm{E}-12$ & 5 & 1 \\
\hline 237Np(n,f) & $3.96 E-11$ & 2 & $3.00 \mathrm{E}-11$ & 20.4 & 0.757 & $3.95 \mathrm{E}-11$ & 4.8 & 1 \\
\hline $238 U(n, n)$ & $7.12 \mathrm{E}-12$ & 2.1 & $5.41 \mathrm{E}-12$ & 18.6 & 0.759 & $7.13 \mathrm{E}-12$ & 2.4 & 1 \\
\hline 47Ti(n,p) & $4.20 \mathrm{E}-13$ & 2.2 & $3.56 \mathrm{E}-13$ & 21.1 & 0.848 & $4.20 \mathrm{E}-13$ & 3.1 & 1 \\
\hline 58Ni(n,p) & $2.27 \mathrm{E}-12$ & 2.2 & $1.61 \mathrm{E}-12$ & 19.1 & 0.711 & $2.27 \mathrm{E}-12$ & 3.5 & 1 \\
\hline $54 F e(n, p)$ & $1.68 \mathrm{E}-12$ & 3 & $1.23 \mathrm{E}-12$ & 18.4 & 0.73 & $1.67 \mathrm{E}-12$ & 3.7 & 1 \\
\hline 46Ti(n,p) & $2.21 \mathrm{E}-13$ & 2.1 & $1.56 \mathrm{E}-13$ & 21.9 & 0.704 & $2.21 \mathrm{E}-13$ & 5.3 & 1 \\
\hline $63 \mathrm{Cu}(n, \alpha)$ & $1.07 \mathrm{E}-14$ & 3 & $7.55 \mathrm{E}-15$ & 17.9 & 0.705 & $1.06 \mathrm{E}-14$ & 5.1 & 1 \\
\hline 48Ti(n,p) & $5.88 \mathrm{E}-15$ & 2.9 & 3.77E-15 & 20.2 & 0.641 & $5.87 \mathrm{E}-15$ & 5.9 & 1 \\
\hline $27 \mathrm{Al}(\mathbf{n}, \boldsymbol{\alpha})$ & $1.30 \mathrm{E}-14$ & 9.1 & $9.54 \mathrm{E}-15$ & 18.7 & 0.734 & $1.29 \mathrm{E}-14$ & 6.7 & 0.99 \\
\hline
\end{tabular}



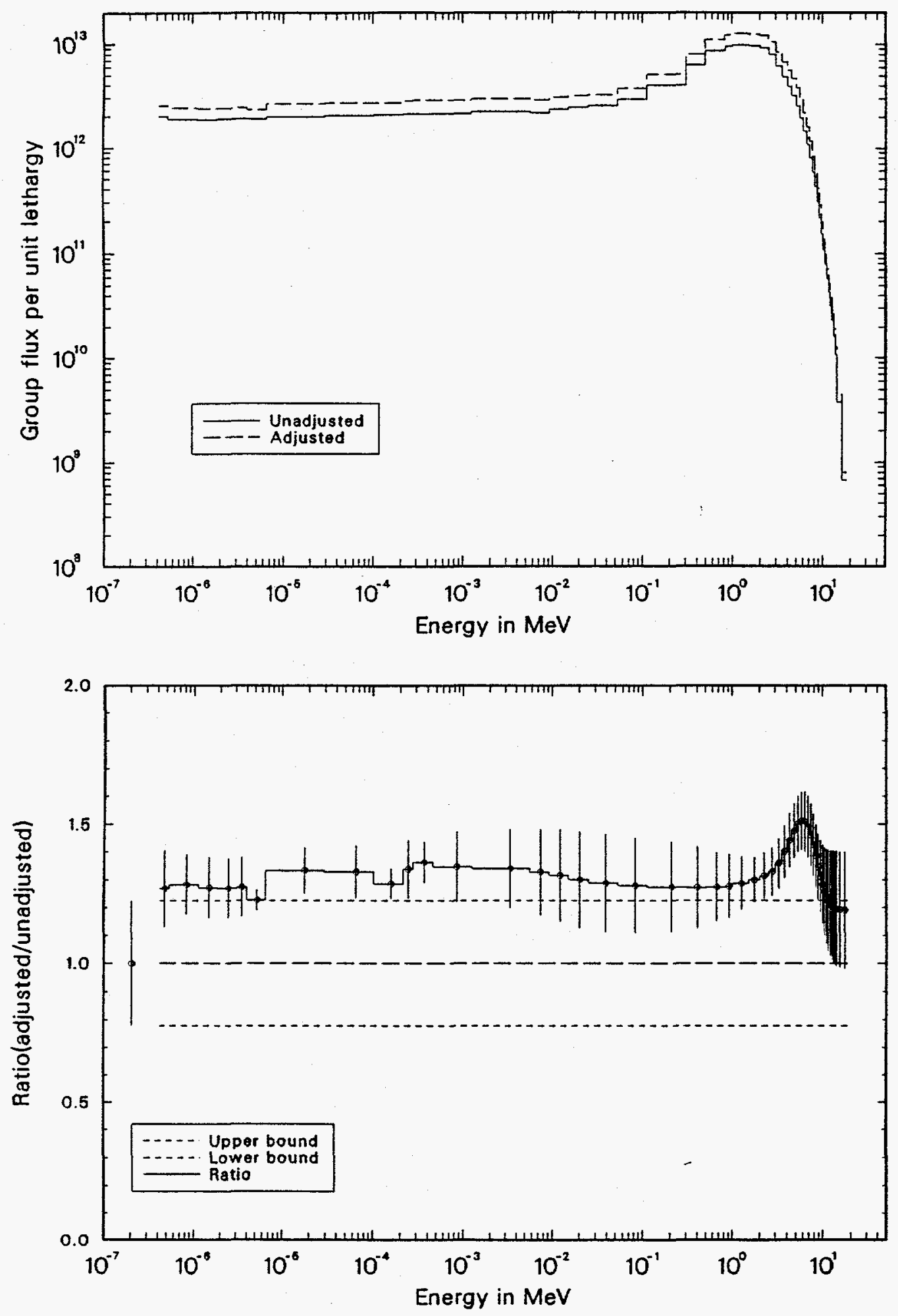

Figure Al. Upper part of figure compares adjusted and unadjusted (input) group fluence rates for A-1 location and lower part displays the ratio of adjusted-to-unadjusted group values with input uncertainty bounds and final uncertainty error bars. 
Table A1. Adjusted group fluence rates for A-1 irradiation location.

\begin{tabular}{|c|c|c|c|c|c|c|c|}
\hline GROUP & EU & EL & DU & PHA & UNCA & FRPHA & RPH \\
\hline 1 & $1.80 \mathrm{E}+01$ & $1.60 \mathrm{E}+01$ & 0.118 & $9.40 \mathrm{E}+07$ & 20.9 & 0 & 1.19 \\
\hline 2 & $1.60 E+01$ & $1.40 E+01$ & 0.134 & $5.97 E+08$ & 20.7 & 0 & 1.19 \\
\hline 3 & $1.40 E+01$ & $1.35 E+01$ & 0.036 & $4.68 E+08$ & 20.6 & 0 & 1.19 \\
\hline 4 & $1.35 E+01$ & $1.30 E+01$ & 0.038 & $7.19 E+08$ & 20.3 & 0 & 1.2 \\
\hline 5 & $1.30 E+01$ & $1.25 E+01$ & 0.039 & $1.06 E+09$ & 20 & 0 & 1.2 \\
\hline 6 & $1.25 E+01$ & $1.20 E+01$ & 0.041 & $1.54 E+09$ & 19.5 & 0 & 1.21 \\
\hline 7 & $1.20 E+01$ & $1.15 E+01$ & 0.043 & $2.21 E+09$ & 18.9 & 0 & 1.22 \\
\hline 8 & 1.15E+01 & 1.10E+01 & 0.044 & $3.17 E+09$ & 18 & 0 & 1.23 \\
\hline 9 & 1.10E+01 & $1.05 E+01$ & 0.047 & $4.56 E+\infty 9$ & 17 & 0.01 & 1.24 \\
\hline 10 & $1.05 E+01$ & $1.00 E+01$ & 0.049 & $6.68 E+09$ & 15.7 & 0.01 & 1.26 \\
\hline 11 & $1.00 E+01$ & $9.50 E+\infty 0$ & 0.051 & $1.00 E+10$ & 14.3 & 0.01 & 1.28 \\
\hline 12 & $9.50 E+\infty 0$ & $9.00 E+\infty$ & 0.054 & $1.53 E+10$ & 13 & 0.02 & 1.31 \\
\hline 13 & $9.00 E+\infty 0$ & $8.50 E+\infty$ & 0.057 & $2.33 E+10$ & 11.9 & 0.03 & 1.35 \\
\hline 14 & $8.50 E+\infty$ & $8.00 E+\infty$ & 0.061 & $3.54 E+10$ & 11.3 & 0.04 & 1.39 \\
\hline 16 & $8.00 E+\infty 0$ & $7.50 E+\infty 0$ & 0.065 & $5.34 E+10$ & 11.1 & 0.06 & 1.43 \\
\hline 16 & $7.50 E+\infty 0$ & $7.00 E+\infty 0$ & 0.069 & $7.97 E+10$ & 11.2 & 0.09 & 1.46 \\
\hline 17 & $7.00 E+\infty$ & $6.50 E+\infty 0$ & 0.074 & $1.18 E+11$ & 11.1 & 0.14 & 1.49 \\
\hline 18 & $6.50 E+\infty 0$ & $6.00 E+\infty 0$ & 0.08 & $1.74 E+11$ & 10.9 & 0.2 & 1.51 \\
\hline 19 & $6.00 E+\infty 0$ & $5.50 E+\infty$ & 0.087 & $2.53 E+11$ & 10.5 & 0.29 & 1.51 \\
\hline 20 & $5.50 E+\infty$ & $5.00 E+\infty 0$ & 0.095 & $3.62 E+11$ & 10.2 & 2 & 1.5 \\
\hline 21 & $5.00 E+\infty$ & $4.50 E+\infty$ & 0.105 & $4.98 E+11$ & 9.9 & 0.58 & 1.48 \\
\hline 22 & $4.50 E+\infty 0$ & $4.00 E+\infty$ & 0.118 & $6.67 E+11$ & 9.7 & 0.78 & 1.44 \\
\hline 23 & $4.00 E+\infty 0$ & $3.50 E+00$ & 0.134 & $9.09 E+11$ & 9.4 & 1.06 & 1.4 \\
\hline 24 & $3.50 E+\infty 0$ & $3.00 E+\infty 0$ & 0.154 & $1.30 E+12$ & 9 & 1.51 & 1.36 \\
\hline 25 & $3.00 E+00$ & $2.50 E+\infty 0$ & 0.182 & $1.93 E+12$ & 8.7 & 2.24 & 1.33 \\
\hline 26 & $2.50 \mathrm{E}+\infty 0$ & $2.00 E+\infty$ & 0.223 & $2.69 E+12$ & 8.3 & 3.13 & 1.31 \\
\hline 27 & $2.00 E+\infty$ & $1.50 E+\infty$ & 0.288 & $3.57 E+12$ & 8.1 & 4.15 & 1.3 \\
\hline 28 & $1.50 E+\infty$ & $1.00 E+\infty$ & 0.405 & $5.11 E+12$ & 9.5 & 5.94 & 1.29 \\
\hline 29 & $1.00 E+\infty$ & 8.21E-01 & 0.197 & $2.40 E+12$ & 11.5 & 2.79 & 1.28 \\
\hline 30 & 8.21E-01 & 4.98E-01 & 0.5 & $5.48 E+12$ & 12.3 & 6.37 & 1.27 \\
\hline 31 & 4.98E-01 & 3.02E-01 & 0.5 & $4.03 E+12$ & 14.7 & 4.69 & 1.27 \\
\hline 32 & 3.02E-01 & $1.11 \mathrm{E}-01$ & 4 & $5.19 E+12$ & 16.1 & 6.04 & 1.27 \\
\hline 33 & 1.11E-01 & $5.25 E-02$ & 0.75 & $2.83 E+12$ & 17.1 & 3.3 & 1.28 \\
\hline 34 & 5.25E-02 & $2.48 E-02$ & 0.75 & $2.46 E+12$ & 17.6 & 2.86 & 1.29 \\
\hline 35 & $2.48 E-02$ & $1.50 \mathrm{E}-02$ & 0.5 & $1.60 \mathrm{E}+12$ & 17.5 & 1.86 & 1.3 \\
\hline 36 & $1.50 E-02$ & 9.12E-03 & 0.5 & $1.55 E+12$ & 16.6 & 1.81 & 1.31 \\
\hline 37 & $9.12 E-03$ & 5.53E-03 & 0.5 & $1.45 E+12$ & 15.5 & 1.69 & 1.33 \\
\hline 38 & $5.53 E-03$ & $1.23 E-03$ & 1.5 & $4.48 E+12$ & 14.2 & 5.21 & 1.34 \\
\hline 39 & $1.23 E-03$ & 4.54E-04 & 1 & $2.87 E+12$ & 12.8 & 3.34 & 1.35 \\
\hline 40 & 4.54E-04 & 2.75E-04 & 0.5 & $1.44 E+12$ & 7.3 & 1.68 & 1.36 \\
\hline 41 & 2.75E-04 & $2.14 E-04$ & 0.25 & $7.08 E+11$ & 10.6 & 0.82 & 1.34 \\
\hline 42 & $2.14 E-04$ & $1.01 E-04$ & 0.75 & $2.01 E+12$ & 5.5 & 2.34 & 1.28 \\
\hline 43 & $1.01 E-04$ & 2.90E-05 & 1.25 & $3.39 \mathrm{E}+12$ & 9.4 & 3.94 & 1.33 \\
\hline 44 & $2.90 E-05$ & $6.48 E-06$ & 1.5 & $3.99 E+12$ & 8.2 & 4.63 & 1.33 \\
\hline 46 & $6.48 E-06$ & 3.93E-06 & 0.5 & $1.17 E+12$ & 3.7 & 1.36 & 1.23 \\
\hline 46 & $3.93 E-06$ & $3.06 \mathrm{E}-06$ & 0.25 & $6.11 E+11$ & 10.6 & 0.71 & 1.27 \\
\hline 47 & $3.06 E-06$ & $1.86 E-06$ & 0.5 & $1.20 \mathrm{E}+12$ & 10.5 & 1.4 & 1.27 \\
\hline 48 & $1.86 E-06$ & $1.13 E-06$ & 0.5 & $1.19 E+12$ & 10.8 & 1.38 & 1.27 \\
\hline 49 & $1.13 E-06$ & 5.32E-07 & 0.75 & $1.81 E+12$ & 10.8 & 2.11 & 1.28 \\
\hline 50 & 5.32E-07 & 4.14E-07 & 0.25 & $6.34 E+11$ & 13.7 & 0.74 & 1.27 \\
\hline 51 & 4.14E-07 & $1.00 \mathrm{E}-10$ & 8.328 & $1.57 E+13$ & 22.4 & 18.23 & 1 \\
\hline
\end{tabular}


Table A2. Cumulative adjusted group fluence rates for A-1 irradiation location.

\begin{tabular}{|c|c|c|c|c|c|c|}
\hline GROUP & $\overline{E U}$ & $\mathbf{E L}$ & CPHA & UNCA & FRCPHA & RCPH \\
\hline 1 & $1.80 \mathrm{E}+01$ & $1.60 \mathrm{E}+01$ & $9.40 E+07$ & 20.9 & 0 & 1.19 \\
\hline 2 & $1.60 E+01$ & $1.40 E+01$ & $6.91 E+08$ & 20.2 & 0 & 1.19 \\
\hline 3 & $1.40 E+01$ & 1.35E+01 & $1.16 E+09$ & 19.4 & 0 & 1.19 \\
\hline 4 & 1.35E+01 & $1.30 \mathrm{E}+01$ & $1.88 \mathrm{E}+09$ & 18.7 & 0 & 1.19 \\
\hline 6 & $1.30 E+01$ & $1.25 E+01$ & $2.94 E+09$ & 18.1 & 0 & 1.2 \\
\hline 6 & $1.25 \mathrm{E}+01$ & $1.20 \mathrm{E}+01$ & $4.48 E+\infty 9$ & 17.5 & 0.01 & 1.2 \\
\hline 7 & $1.20 \mathrm{E}+01$ & $1.15 E+01$ & $6.69 E+\infty 9$ & 16.8 & 0.01 & 1.21 \\
\hline 8 & $1.15 E+01$ & $1.10 E+01$ & $9.86 E+\infty 9$ & 16 & 0.01 & 1.21 \\
\hline 9 & $1.10 E+01$ & $1.05 E+01$ & $1.44 E+10$ & 15 & 0.02 & 1.22 \\
\hline 10 & $1.05 E+01$ & $1.00 E+01$ & $2.11 E+10$ & 13.9 & 0.02 & 1.23 \\
\hline 11 & $1.00 E+01$ & $9.50 E+\infty 0$ & $3.12 E+10$ & 12.5 & 0.04 & 1.25 \\
\hline 12 & $9.50 E+\infty$ & $9.00 E+\infty$ & $4.64 E+10$ & 11 & 0.05 & 1.27 \\
\hline 13 & $9.00 E+\infty$ & $8.50 E+\infty$ & $6.97 E+10$ & 9.4 & 0.08 & 1.29 \\
\hline 14 & $8.50 E+\infty 0$ & $8.00 E+\infty$ & $1.05 E+11$ & 7.9 & 0.12 & 1.32 \\
\hline 15 & $8.00 E+\infty$ & $7.50 E+\infty$ & $1.59 E+11$ & 6.8 & 0.18 & 1.36 \\
\hline 16 & $7.50 E+\infty$ & $7.00 E+\infty$ & $2.38 E+11$ & 6.2 & 0.28 & 1.39 \\
\hline 17 & $7.00 E+\infty$ & $6.50 E+\infty$ & $3.56 E+11$ & 5.9 & 0.41 & 1.42 \\
\hline 18 & $6.50 E+\infty$ & $6.00 \mathrm{E}+\infty$ & $5.30 E+11$ & 5.9 & 0.62 & 1.45 \\
\hline 19 & $6.00 E+\infty$ & $5.50 E+\infty$ & $7.83 E+11$ & 5.9 & 0.91 & 1.47 \\
\hline 20 & $5.50 E+\infty 0$ & $5.00 E+\infty$ & $1.15 E+12$ & 5.6 & 1.33 & 1.48 \\
\hline 21 & $-5.00 E+\infty$ & $4.50 E+\infty$ & $1.64 E+12$ & 5.2 & 1.91 & 1.48 \\
\hline 22 & $4.50 E+\infty$ & $4.00 E+\infty$ & $2.31 E+12$ & 4.8 & 2.69 & 1.47 \\
\hline 23 & $4.00 E+\infty$ & $3.50 E+\infty 0$ & $3.22 E+12$ & 4.5 & 3.74 & 1.45 \\
\hline 24 & $3.50 E+\infty$ & $3.00 E+\infty$ & $4.51 E+12$ & 4 & 5.25 & 1.42 \\
\hline 26 & $3.00 E+\infty$ & $2.50 E+\infty$ & $6.44 E+12$ & 3.5 & 7.49 & 1.39 \\
\hline 26 & $2.50 E+\infty$ & $2.00 E+\infty$ & $9.13 E+12$ & 2.9 & 10.62 & 1.37 \\
\hline 27 & $2.00 E+\infty$ & $1.50 E+\infty$ & $1.27 \mathrm{E}+13$ & 2.4 & 14.77 & 1.35 \\
\hline 28 & $1.50 E+\infty$ & $1.00 E+\infty$ & $1.78 E+13$ & 3 & 20.71 & 1.33 \\
\hline 28 & $1.00 E+\infty$ & $8.21 E-01$ & $2.02 E+13$ & 3.2 & 23.5 & 1.32 \\
\hline 30 & 8.21E-01 & 4.98E-01 & $2.57 E+13$ & 4.1 & 29.87 & 1.31 \\
\hline 31 & 4.98E-01 & $3.02 E-01$ & $2.97 E+13$ & 4.9 & 34.56 & 1.31 \\
\hline 32 & $3.02 E-01$ & $1.11 E-01$ & $3.49 E+13$ & 5.9 & 40.6 & 1.3 \\
\hline 33 & 1.11E-01 & $5.25 E-02$ & 3.77E+13 & 6.3 & 43.89 & 1.3 \\
\hline 34 & 5.25E-02 & $2.48 E-02$ & $4.02 E+13$ & 6.7 & 46.75 & 1.3 \\
\hline 36 & 2.48E-02 & $1.50 E-02$ & $4.18 E+13$ & 6.8 & 48.62 & 1.3 \\
\hline 36 & $1.50 E-02$ & $9.12 E-03$ & $4.34 E+13$ & 6.9 & 50.42 & 1.3 \\
\hline 37 & $9.12 E-03$ & $5.53 E-03$ & $4.48 E+13$ & 6.9 & 52.11 & 1.3 \\
\hline 38 & $5.53 E-03$ & $1.23 E-03$ & $4.93 E+13$ & 6.9 & 57.32 & 1.3 \\
\hline 38 & $1.23 E-03$ & $4.54 E-04$ & $5.22 E+13$ & 6.7 & 60.66 & 1.31 \\
\hline 40 & 4.54E-04 & $2.75 E-04$ & $5.36 E+13$ & 6.6 & 62.34 & 1.31 \\
\hline 41 & 2.75E-04 & $2.14 \mathrm{E}-0.4$ & $5.43 E+13$ & 6.5 & 63.16 & 1.31 \\
\hline 42 & 2.14E-04 & $1.01 E-04$ & $5.63 E+13$ & 6.3 & 65.5 & 1.31 \\
\hline 43 & $1.01 E-04$ & 2.90E-05 & $5.97 E+13$ & 5.9 & 69.44 & 1.31 \\
\hline 44 & 2.90E-05 & $6.48 E-06$ & $6.37 E+13$ & 5.4 & 74.08 & 1.31 \\
\hline 46 & $6.48 E-06$ & $3.93 E-06$ & $6.49 E+13$ & 5.3 & 75.43 & 1.31 \\
\hline 46 & $3.93 E-06$ & $3.06 \mathrm{E}-06$ & $6.55 E+13$ & 5.3 & 76.14 & 1.31 \\
\hline 47 & $3.06 E-06$ & $1.86 E-06$ & $6.67 E+13$ & 5.1 & 77.54 & 1.31 \\
\hline 48 & $1.86 \mathrm{E}-06$ & 1.13E-06 & $6.79 E+13$ & 5 & 78.93 & 1.31 \\
\hline 49 & $1.13 E-06$ & 5.32E-07 & $6.97 E+13$ & 4.9 & 81.03 & 1.31 \\
\hline 50 & 5.32E-07 & 4.14E- 07 & $7.03 E+13$ & 4.8 & 81.77 & 1.31 \\
\hline 51 & $4.14 E-07$ & $1.00 \mathrm{E}-10$ & $8.60 E+13$ & 5.7 & 100 & 1.24 \\
\hline
\end{tabular}



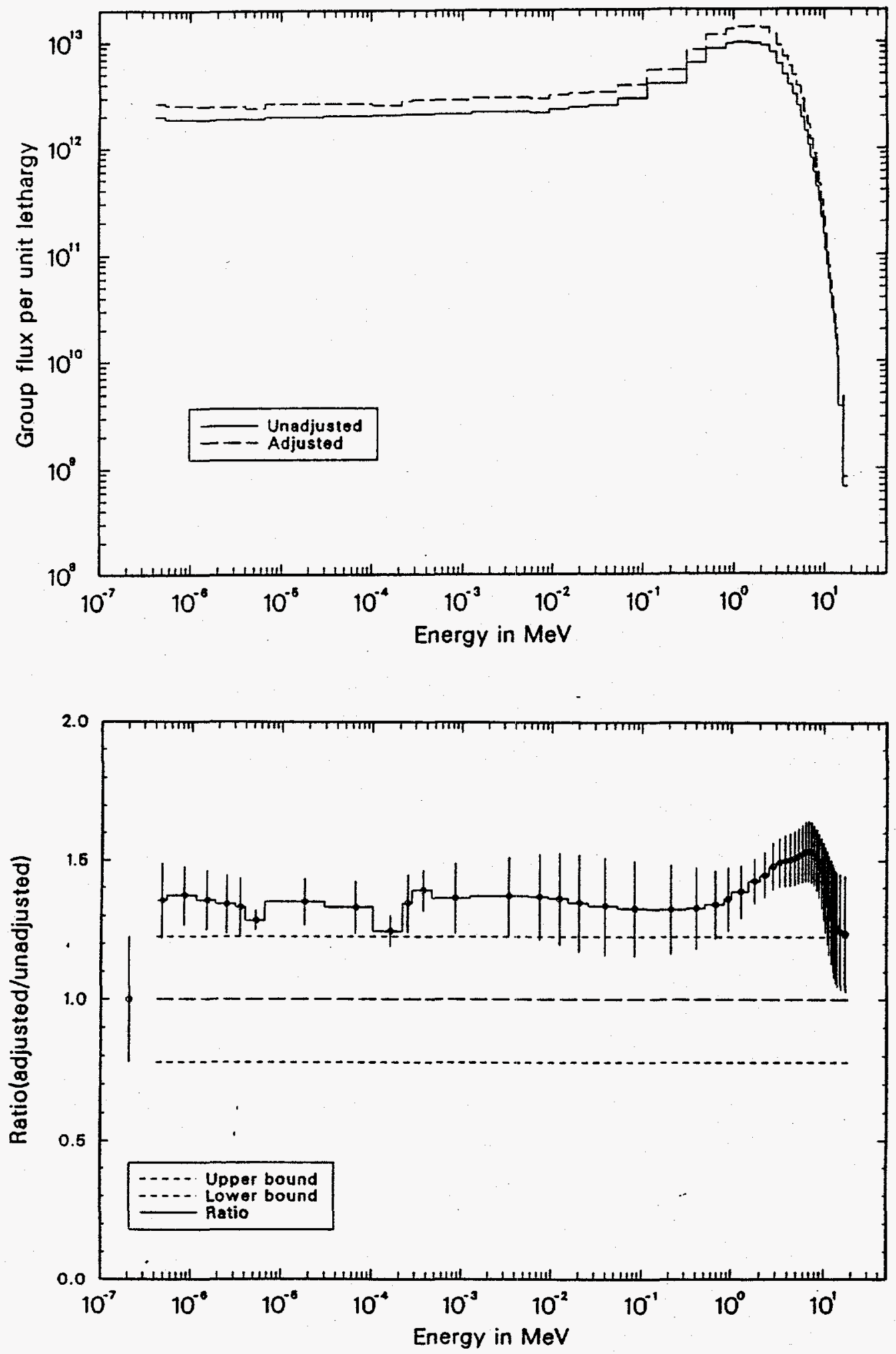

Figure A2. Upper part of figure compares adjusted and unadjusted (input) group fluence rates for A-10 location and lower part displays the ratio of adjusted-to-unadjusted group values with input uncertainty bounds and final uncertainty error bars. 
Table A3. Adjusted group fluence rates for A-10 irradiation location.

\begin{tabular}{|c|c|c|c|c|c|c|c|}
\hline GROUP & EU & EL. & DU & PHA & UNCA & FRPHA & RPH \\
\hline 1 & $1.80 \mathrm{E}+01$ & $1.60 E+01$ & 0.118 & $9.76 E+07$ & 20.9 & 0 & 1.24 \\
\hline 2 & $1.60 E+01$ & $1.40 E+01$ & 0.134 & $6.22 \mathrm{E}+08$ & 20.7 & 0 & 1.24 \\
\hline 3 & $1.40 \mathrm{E}+01$ & $1.35 E+01$ & 0.036 & $4.90 E+08$ & 20.6 & 0 & 1.25 \\
\hline 4 & $1.35 E+01$ & $1.30 E+01$ & 0.038 & $7.58 E+08$ & 20.3 & 0 & 1.26 \\
\hline 5 & $1.30 E+01$ & $1.25 E+01$ & 0.039 & $1.13 E+09$ & 20 & 0 & 1.28 \\
\hline 6 & $1.25 E+01$ & $1.20 E+01$ & 0.041 & $1.65 E+\infty 9$ & 19.5 & 0 & 1.29 \\
\hline 7 & $1.20 E+01$ & $1.15 E+01$ & 0.043 & $2.39 E+\infty 9$ & 18.8 & 0 & 1.31 \\
\hline 8 & $1.15 E+01$ & $1.10 E+01$ & 0.044 & $3.46 E+09$ & 18 & 0 & 1.34 \\
\hline 8 & 1.10E+O1 & $1.05 E+01$ & 0.047 & $5.02 E+09$ & 16.8 & 0.01 & 1.36 \\
\hline 10 & $1.05 E+01$ & $1.00 E+01$ & 0.049 & $7.41 E+\infty 9$ & 15.5 & 0.01 & 1.39 \\
\hline 11 & $1.00 E+01$ & $9.50 E+\infty 0$ & 0.051 & $1.12 E+10$ & 14.1 & 0.01 & 1.42 \\
\hline 12 & $9.50 E+\infty 0$ & $9.00 E+\infty 0$ & 0.054 & $1.69 \mathrm{E}+10$ & 12.8 & 0.02 & 1.45 \\
\hline 13 & $9.00 E+\infty 0$ & $8.50 E+\infty 0$ & 0.057 & $2.56 \mathrm{E}+10$ & 11.8 & 0.03 & 1.48 \\
\hline 14 & $8.50 E+\infty 0$ & $8.00 E+\infty$ & 0.061 & $3.84 E+10$ & 11.3 & 0.04 & 1.5 \\
\hline 16 & $8.00 E+\infty 0$ & $7.50 E+\infty 0$ & 0.065 & $5.69 E+10$ & 11.1 & 0.06 & 1.52 \\
\hline 16 & $7.50 E+\infty$ & $7.00 \mathrm{E}+\infty 0$ & 0.069 & $8.33 E+10$ & 11.2 & 0.09 & 1.53 \\
\hline 17 & $7.00 E+\infty 0$ & $6.50 \mathrm{E}+\infty 0$ & 0.074 & $1.21 \mathrm{E}+11$ & 11.2 & 0.14 & 1.53 \\
\hline 18 & $6.50 E+00$ & $6.00 E+\infty$ & 0.08 & $1.76 E+11$ & 11 & 0.2 & 1.53 \\
\hline 19 & $6.00 E+\infty 0$ & $5.50 E+\infty 0$ & 0.087 & $2.56 E+11$ & 10.6 & 0.29 & 1.52 \\
\hline 20 & $5.50 E+\infty 0$ & $5.00 E+\infty 0$ & 0.095 & $3.66 \mathrm{E}+11$ & 10.2 & 0.41 & 1.52 \\
\hline 21 & $5.00 E+00$ & $4.50 E+\infty$ & 0.105 & $5.09 E+11$ & 10 & 0.57 & 1.51 \\
\hline 22 & $4.50 E+\infty 0$ & $4.00 E+\infty 0$ & 0.118 & $6.96 E+11$ & 9.8 & 0.78 & 1.5 \\
\hline 23 & $4.00 E+\infty 0$ & $3.50 E+\infty$ & 0.134 & $9.73 E+11$ & 9.4 & 1.09 & 1.5 \\
\hline 24 & $3.50 E+\infty 0$ & $3.00 E+\infty$ & 0.154 & $1.42 E+12$ & 8.9 & 1.6 & 1.49 \\
\hline 25 & $3.00 E+\infty$ & $2.50 \mathrm{E}+\infty$ & 0.182 & $2.14 E+12$ & 8.6 & 2.4 & 1.48 \\
\hline 26 & $2.50 E+\infty$ & $2.00 E+\infty$ & 0.223 & 2.97E+12 & 8.2 & 3.32 & 1.45 \\
\hline 27 & $2.00 E+\infty 0$ & $1.50 E+\infty$ & 0.288 & $3.92 E+12$ & 8.1 & 4.39 & 1.43 \\
\hline 28 & $1.50 E+\infty$ & $1.00 E+\infty$ & 0.405 & $5.50 \mathrm{E}+12$ & 9.5 & 6.17 & 1.39 \\
\hline 29 & $1.00 E+\infty$ & 8.21E-01 & 0.197 & $2.56 \mathrm{E}+12$ & 11.5 & 2.87 & 1.36 \\
\hline 30 & 8.21E-01 & 4.98E-01 & 0.5 & $5.76 \mathrm{E}+12$ & 12.4 & 6.45 & 1.34 \\
\hline 31 & 4.98E-01 & $3.02 \mathrm{E}-01$ & 0.5 & $4.21 E+12$ & 14.7 & 4.72 & 1.33 \\
\hline 32 & $3.02 E-01$ & $1.11 E-01$ & 1 & $5.39 E+12$ & 16.2 & 6.05 & 1.32 \\
\hline 33 & 1.11E-01 & 5.25E-02 & 0.75 & $2.94 E+12$ & 17.2 & 3.29 & 1.33 \\
\hline 34 & 5.25E-02 & 2.48E-02 & 0.75 & $2.55 E+12$ & 17.6 & 2.85 & 1.33 \\
\hline 36 & 2.48E-02 & 1.50E-02 & 0.5 & $1.66 E+12$ & 17.5 & 1.86 & 1.35 \\
\hline 36 & $1.50 E-02$ & $9.12 E-03$ & 0.5 & $1.61 E+12$ & 16.6 & 1.8 & 1.36 \\
\hline 37 & $9.12 E-03$ & 5.53E-03 & 0.5 & $1.49 E+12$ & 15.5 & 1.68 & 1.37 \\
\hline 38 & 5.53E-03 & 1.23E-03 & 1.5 & $4.58 E+12$ & 14.2 & 5.13 & 1.37 \\
\hline 39 & 1.23E-03 & 4.54E-04 & 1 & $2.91 E+12$ & 12.8 & 3.26 & 1.36 \\
\hline 40 & 4.54E-04 & 2.75E-04 & 0.5 & $1.47 E+12$ & 7.4 & 1.65 & 1.39 \\
\hline 41 & $2.75 E-04$ & 2.14E-04 & 0.25 & $7.10 E+11$ & 10.6 & 0.8 & 1.34 \\
\hline 42 & 2.14E-04 & $1.01 E-04$ & 0.75 & $1.95 E+12$ & 5.5 & 2.18 & 1.24 \\
\hline 43 & $1.01 E-04$ & 2.90E-05 & 1.25 & $3.40 E+12$ & 9.4 & 3.81 & 1.33 \\
\hline 44 & 2.90E-05 & $6.48 E-06$ & 1.5 & $4.03 E+12$ & 8.3 & 4.52 & 1.35 \\
\hline 46 & $6.48 E-06$ & $3.93 E-06$ & 0.5 & $1.22 E+12$ & 3.7 & 1.37 & 1.28 \\
\hline 46 & $3.93 E-06$ & $3.06 E-06$ & 0.25 & $6.37 E+11$ & 10.6 & 0.71 & 1.33 \\
\hline 47 & $3.06 \mathrm{E}-06$ & $1.86 E-06$ & 0.5 & 1.27E+12 & 10.5 & 1.42 & 1.34 \\
\hline 48 & $1.86 E-06$ & $1.13 E-06$ & 0.5 & 1.27E+12 & 10.8 & 1.42 & 1.35 \\
\hline 49 & 1.13E-06 & 5.32E-07 & 0.75 & $1.94 E+12$ & 10.7 & 2.17 & 1.37 \\
\hline 60 & 5.32E-07 & 4.14E-07 & 0.25 & $6.76 E+11$ & 13.6 & 0.76 & 1.35 \\
\hline 51 & 4.14E-07 & $1.00 E-10$ & 8.328 & $1.57 E+13$ & 22.4 & 17.58 & 1 \\
\hline
\end{tabular}


Table A4. Cumulative adjusted group fluence rates for A-10 irradiation location.

\begin{tabular}{|c|c|c|c|c|c|c|}
\hline GROUP & EU & EL & CPHA & UNCA & FRCPHA & RCPH \\
\hline 1 & $1.80 E+01$ & $1.60 E+01$ & $9.76 E+07$ & 20.9 & 0 & 1.24 \\
\hline 2 & $1.60 E+01$ & $1.40 E+01$ & $7.19 E+08$ & 20.2 & 0 & 1.24 \\
\hline 3 & $1.40 \mathrm{E}+01$ & 1.35E+01 & $1.21 E+09$ & 19.4 & 0 & 1.24 \\
\hline 4 & $1.35 E+01$ & 1.30E+01 & $1.97 E+09$ & 18.7 & 0 & 1.25 \\
\hline 5 & $1.30 E+01$ & $1.25 E+01$ & $3.09 E+09$ & 18.1 & 0 & 1.26 \\
\hline 6 & $1.25 \mathrm{E}+01$ & $1.20 E+01$ & $4.74 E+09$ & 17.5 & 0.01 & 1.27 \\
\hline 7 & $1.20 E+01$ & $1.15 E+01$ & $7.13 E+09$ & 16.8 & 0.01 & 1.29 \\
\hline 8 & $1.15 E+01$ & $1.10 E+01$ & $1.06 E+10$ & 16 & 0.01 & 1.3 \\
\hline 8 & $1.10 E+01$ & $1.05 E+01$ & $1.56 E+10$ & 15 & 0.02 & 1.32 \\
\hline 10 & $1.05 E+01$ & $1.00 E+01$ & $2.30 E+10$ & 13.8 & 0.03 & 1.34 \\
\hline 11 & $1.00 E+01$ & $9.50 E+\infty 0$ & $3.42 E+10$ & 12.4 & 0.04 & 1.37 \\
\hline 12 & $9.50 E+\infty 0$ & $9.00 E+\infty 0$ & $5.11 E+10$ & 10.9 & 0.06 & 1.4 \\
\hline 13 & $9.00 E+00$ & $8.50 E+\infty 0$ & $7.67 E+10$ & 9.3 & 0.09 & 1.42 \\
\hline 14 & $8.50 E+\infty 0$ & $8.00 E+\infty 0$ & $1.15 E+11$ & 7.8 & 0.13 & 1.45 \\
\hline 16 & $8.00 E+\infty 0$ & $7.50 E+\infty 0$ & $1.72 E+11$ & 6.7 & 0.19 & 1.47 \\
\hline 16 & $7.50 E+\infty$ & $7.00 E+\infty 0$ & $2.55 E+11$ & 6.1 & 0.29 & 1.49 \\
\hline 17 & $7.00 E+\infty 0$ & $6.50 E+\infty 0$ & 3.77E+11 & 5.9 & 0.42 & 1.5 \\
\hline 18 & $6.50 E+00$ & $6.00 E+\infty 0$ & $5.53 E+11$ & 5.9 & 0.62 & 1.51 \\
\hline 19 & $6.00 E+\infty 0$ & $5.50 E+\infty 0$ & $8.09 E+11$ & 5.9 & 0.91 & 1.52 \\
\hline 20 & $5.50 E+\infty 0$ & $5.00 E+\infty 0$ & $1.17 E+12$ & 5.6 & 1.32 & 1.52 \\
\hline 21 & $5.00 E+\infty 0$ & $4.50 E+\infty 0$ & $1.68 E+12$ & 5.3 & 1.89 & 1.51 \\
\hline 22 & $4.50 E+\infty 0$ & $4.00 E+\infty 0$ & $2.38 E+12$ & 4.9 & 2.67 & 1.51 \\
\hline 23 & $4.00 E+\infty$ & $3.50 E+\infty 0$ & $3.35 E+12$ & 4.5 & 3.76 & 1.51 \\
\hline 24 & $3.50 E+\infty 0$ & $3.00 E+\infty 0$ & $4.78 E+12$ & 4.1 & 5.35 & 1.5 \\
\hline 26 & $3.00 E+\infty 0$ & $2.50 E+\infty$ & $6.92 \mathrm{E}+12$ & 3.5 & 7.76 & 1.5 \\
\hline 26 & $2.50 E+\infty 0$ & $2.00 E+\infty 0$ & $9.88 E+12$ & 3 & 11.08 & 1.48 \\
\hline 27 & $2.00 E+\infty 0$ & $1.50 E+\infty$ & $1.38 E+13$ & 2.4 & 15.48 & 1.46 \\
\hline 28 & $1.50 \mathrm{E}+\infty$ & $1.00 E+00$ & $1.93 E+13$ & 3 & $21: 65$ & 1.44 \\
\hline 29 & $1.00 E+\infty$ & 8.21E-01 & $2.19 E+13$ & 3.2 & 24.51 & 1.43 \\
\hline 30 & 8.21E-01 & 4.98E-01 & $2.76 E+13$ & 4.1 & 30.96 & 1.41 \\
\hline 31 & 4.98E-01 & $3.02 E-01$ & $3.18 E+13$ & 4.8 & 35.68 & 1.4 \\
\hline 32 & $3.02 E-01$ & $1.11 E-01$ & $3.72 E+13$ & 5.8 & 41.73 & 1.39 \\
\hline 33 & $1.11 E-01$ & 5.25E-02 & $4.02 E+13$ & 6.3 & 45.02 & 1.38 \\
\hline 34 & $5.25 E-02$ & $2.48 E-02$ & $4.27 E+13$ & 6.6 & 47.88 & 1.38 \\
\hline 36 & $2.48 E-02$ & $1.50 \mathrm{E}-02$ & $4.44 E+13$ & 6.8 & 49.74 & 1.38 \\
\hline 36 & $1.50 E-02$ & $9.12 E-03$ & $4.60 E+13$ & 6.9 & 51.54 & 1.38 \\
\hline 37 & $9.12 E-03$ & 5.53E-03 & $4.75 E+13$ & 6.9 & 53.21 & 1.38 \\
\hline 38 & $5.53 E-03$ & $1.23 E-03$ & $5.20 E+13$ & 6.8 & 58.34 & 1.38 \\
\hline 39 & $1.23 E-03$ & 4.54E-04 & $5.49 E+13$ & 6.7 & 61.61 & 1.38 \\
\hline 40 & 4.54E-04 & $2.75 E-04$ & $5.64 E+13$ & 6.5 & 63.26 & 1.38 \\
\hline 41 & 2.75E-04 & $2.14 E-04$ & $5.71 E+13$ & 6.4 & 64.05 & 1.38 \\
\hline 42 & $2.14 E-04$ & 1.01E-04 & $5.91 E+13$ & 6.2 & 66.24 & 1.37 \\
\hline 43 & 1.01E-04 & 2.90E-05 & $6.25 E+13$ & 5.9 & 70.05 & 1.37 \\
\hline 4 & 2.90E-05 & $6.48 E-06$ & $6.65 E+13$ & 5.4 & 74.57 & 1.37 \\
\hline 46 & $6.48 E-06$ & $3.93 E-06$ & $6.77 E+13$ & 5.3 & 75.93 & 1.37 \\
\hline 46 & $3.93 E-06$ & $3.06 E-06$ & $6.84 E+13$ & 5.3 & 76.65 & 1.37 \\
\hline 47 & $3.06 E-06$ & $1.86 E-06$ & $6.96 E+13$ & 5.1 & 78.07 & 1.37 \\
\hline 48 & $1.86 E-06$ & $1.13 E-06$ & $7.09 E+13$ & 5 & 79.49 & 1.36 \\
\hline 49 & 1.13E-06 & 5.32E-07 & $7.28 E+13$ & 4.9 & 81.67 & 1.37 \\
\hline 50 & 5.32E-07 & 4.14E-07 & $7.35 E+13$ & 4.8 & 82.42 & 1.37 \\
\hline 61 & $4.14 E-07$ & $1.00 \mathrm{E}-10$ & $8.92 E+13$ & 5.6 & 100 & 1.28 \\
\hline
\end{tabular}



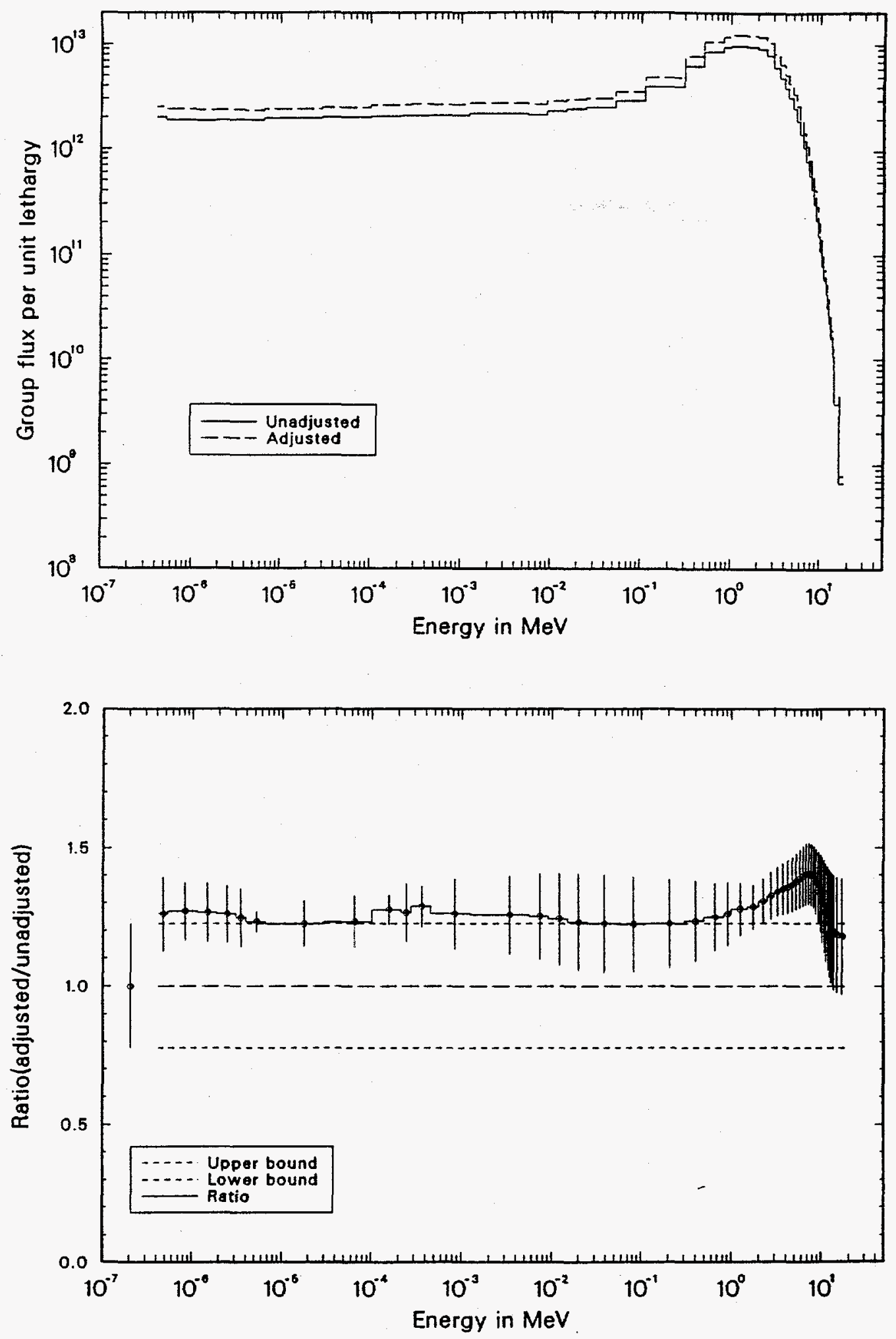

Figure A3. Upper part of figure compares adjusted and unadjusted (input) group fluence rates for A-12 location and lower part displays the ratio of adjusted-to-unadjusted group values with input uncertainty bounds and final uncertainty error bars. 
Table A5. Adjusted group fluence rates for A-12 irradiation location.

\begin{tabular}{|c|c|c|c|c|c|c|c|}
\hline GROUP & $\mathbf{E U}$ & EL & DU & PHA & UNCA & FRPHA & RPH \\
\hline 1 & $1.80 E+01$ & $.60 E+01$ & 0.118 & $9.30 E+07$ & 20.8 & $\overline{0}$ & 1.18 \\
\hline 2 & $1.60 \mathrm{E}+01$ & $1.40 E+01$ & 0.134 & $5.93 E+08$ & 20.7 & 0 & 1.18 \\
\hline 3 & $1.40 E+01$ & $1.35 E+01$ & 0.036 & $4.67 E+08$ & 20.6 & 0 & 1.19 \\
\hline 4 & 1.35E+01 & $1.30 E+01$ & 0.038 & $7.20 E+08$ & 20.3 & 0 & 1.2 \\
\hline 6 & $1.30 E+01$ & $1.25 E+01$ & 0.039 & $1.07 \mathrm{E}+09$ & 20 & 0 & 1.21 \\
\hline 6 & $1.25 E+01$ & $1.20 \mathrm{E}+01$ & 0.041 & $1.56 \mathrm{E}+09$ & 19.5 & 0 & 1.23 \\
\hline 7 & $1.20 E+01$ & $1.15 E+01$ & 0.043 & $2.26 \mathrm{E}+09$ & 18.8 & 0 & 1.24 \\
\hline 8 & 1.15E+01 & $1.10 E+01$ & 0.044 & $3.27 E+09$ & 17.9 & 0 & 1.26 \\
\hline 8 & $1.10 E+01$ & $1.05 E+01$ & 0.047 & $4.73 E+\infty 9$ & 16.8 & 0.01 & 1.29 \\
\hline 10 & $1.05 E+01$ & $1.00 E+01$ & 0.049 & $6.95 E+\infty 9$ & 15.5 & 0.01 & 1.31 \\
\hline 11 & $1.00 E+01$ & $9.50 E+\infty$ & 0.051 & $1.04 E+10$ & 14.1 & 0.01 & 1.33 \\
\hline 12 & $9.50 E+\infty 0$ & $9.00 E+\infty$ & 0.054 & $1.58 E+10$ & 12.8 & 0.02 & 1.36 \\
\hline 13 & $9.00 E+00$ & $8.50 E+\infty 0$ & 0.057 & $2.38 E+10$ & 11.8 & 0.03 & 1.38 \\
\hline 14 & $8.50 E+\infty 0$ & $8.00 E+\infty$ & 0.061 & $3.55 E+10$ & 11.3 & 0.04 & 1.39 \\
\hline 16 & $8.00 \mathrm{E}+00$ & $7.50 E+\infty$ & 0.065 & $5.24 E+10$ & 11.2 & 0.06 & 1.4 \\
\hline 16 & $7.50 \mathrm{E}+\infty 0$ & $7.00 E+\infty$ & 0.069 & $7.65 E+10$ & 11.2 & 0.09 & 1.4 \\
\hline 17 & $7.00 E+00$ & $6.50 E+\infty$ & 0.074 & $1.11 E+11$ & 11.2 & 0.13 & 1.4 \\
\hline 18 & $6.50 E+\infty 0$ & $6.00 E+00$ & 0.08 & $1.61 E+11$ & 11 & 0.19 & 1.4 \\
\hline 19 & $6.00 E+\infty 0$ & $5.50 E+\infty$ & 0.087 & $2.32 E+11$ & 10.6 & 0.28 & 1.39 \\
\hline 20 & $5.50 E+\infty 0$ & $5.00 E+\infty$ & 0.095 & $3.32 E+11$ & 10.2 & 0.4 & 1.38 \\
\hline 21 & $5.00 E+\infty 0$ & $4.50 E+\infty$ & 0.105 & $4.61 E+11$ & 10 & 0.55 & 1.37 \\
\hline 22 & $4.50 E+\infty 0$ & $4.00 E+\infty 0$ & 0.118 & $6.28 E+11$ & 9.8 & 0.75 & 1.36 \\
\hline 23 & $4.00 E+\infty 0$ & $3.50 E+\infty$ & 0.134 & $8.75 E+11$ & 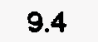 & 1.05 & 1.35 \\
\hline 24 & $3.50 E+\infty 0$ & $3.00 E+\infty$ & 0.154 & $1.28 E+12$ & 8. & 1.53 & 1.34 \\
\hline 25 & $3.00 E+\infty 0$ & $2.50 E+\infty 0$ & 0.182 & $1.92 E+12$ & 8. & 2.3 & 1.32 \\
\hline 26 & $2.50 E+\infty 0$ & $2.00 E+\infty$ & 0.223 & $2.67 E+12$ & & 3.2 & 1.3 \\
\hline 27 & $2.00 E+\infty 0$ & $1.50 E+\infty$ & 0.288 & $3.53 E+12$ & & 4.23 & 1.28 \\
\hline 28 & $1.50 E+\infty$ & $1.00 E+\infty$ & 0.405 & $5.07 E+12$ & 5 & 6.07 & 1.28 \\
\hline 29 & $1.00 E+\infty 0$ & 8.21E-01 & 0.197 & $2.37 E+12$ & 11.5 & 2.83 & 1.26 \\
\hline 30 & 8.21E-01 & 4.98E-01 & 0.5 & $5.36 E+12$ & 12.3 & 6.42 & 1.25 \\
\hline 31 & 4.98E-01 & 3.02E-01 & 0.5 & $3.91 E+12$ & 14.7 & 4.68 & 1.23 \\
\hline 32 & $3.02 E-01$ & 1.11E-01 & 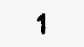 & $4.99 E+12$ & 16.1 & 5.98 & 1.22 \\
\hline 33 & 1.11E-01 & $5.25 \mathrm{E}-02$ & 0.75 & $2.71 E+12$ & 17.1 & 3.24 & 1.22 \\
\hline 34 & $5.25 \mathrm{E}$ & $2.48 E-02$ & 0.75 & 2.34 & 17.6 & 2.8 & 1.22 \\
\hline 36 & $2.48 E-02$ & $1.50 E-02$ & 0.5 & $1.52 E+12$ & 17.5 & 1.82 & 1.23 \\
\hline 36 & $1.50 \mathrm{E}-02$ & $9.12 E-03$ & 0.5 & $1.47 E+12$ & 16.6 & 1.76 & 1.24 \\
\hline 37 & $9.12 E-03$ & $5.53 E-03$ & 0.5 & 1. $37 E+12$ & 15.5 & 1.64 & 1.25 \\
\hline 38 & 5.53E-03 & $1.23 E-03$ & 1.5 & $4.20 E+12$ & 14.2 & 5.03 & 1.26 \\
\hline 39 & $1.23 E-03$ & 4.54E-04 & 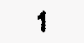 & $2.69 E+12$ & 12.8 & 3.22 & 1.26 \\
\hline 40 & 4.54E-04 & $2.75 E-04$ & 0.5 & $1.36 \mathrm{E}$ & 7.4 & 1.63 & 1.29 \\
\hline 41 & $2.75 E$ & 2.14E-04 & 0.25 & 6.68 & 10.6 & 0.8 & 1.26 \\
\hline 42 & $2.14 E-04$ & 1.01E-04 & 0.75 & $1.99 E+12$ & 55 & 2.39 & 1.27 \\
\hline 43 & 1.01E-04 & 2.90E-05 & 1.25 & $3.14 E+12$ & 9. & 3.77 & 1.23 \\
\hline 4 & $2.90 E-05$ & $6.48 E-06$ & 1.5 & $3.66 E+12$ & 8.3 & 4.38 & 1.22 \\
\hline 46 & $6.48 E-06$ & 3.93E-06 & 0.5 & 1.17E+12 & 3.7 & 1.4 & 1.23 \\
\hline 46 & 3.93E-06 & $3.06 E-06$ & 0.25 & $5.97 E+11$ & 10.6 & 0.72 & 1.24 \\
\hline 47 & $3.06 E-06$ & $1.86 E-\infty 6$ & 0.5 & $1.19 E+12$ & 10.5 & 1.43 & 1.26 \\
\hline 48 & $1.86 E-06$ & $1.13 E-06$ & 0.5 & $1.19 E+12$ & 10.8 & 1.42 & 1.27 \\
\hline 49 & 1.13E-06 & $5.32 E-07$ & 0.75 & $1.80 E+12$ & 10.7 & 2.15 & 1.27 \\
\hline 50 & 5.32E-07 & 4.14E-07 & 0.25 & $6.29 \mathrm{E}+11$ & 13.6 & 0.75 & 1.26 \\
\hline 61 & 4.14E- -07 & $1.00 E-10$ & 8.328 & $1.57 E+13$ & 22.4 & 18.77 & 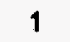 \\
\hline
\end{tabular}


Table A6. Cumulative Adjusted group fluence rates for A-12 irradiation location.

\begin{tabular}{|c|c|c|c|c|c|c|}
\hline GROUP & EU & EL & CPHA & UNCA & FRCPHA & RCPH \\
\hline 1 & $1.80 E+01$ & $1.60 E+01$ & $9.30 \mathrm{E}+07$ & 20.8 & 0 & 1.18 \\
\hline 2 & $1.60 E+01$ & $1.40 E+01$ & $6.86 E+08$ & 20.2 & 0 & 1.18 \\
\hline 3 & $1.40 E+01$ & $1.35 E+01$ & $1.15 E+09$ & 19.4 & 0 & 1.19 \\
\hline 4 & $1.35 E+01$ & $1.30 \mathrm{E}+01$ & $1.87 E+09$ & 18.7 & 0 & 1.19 \\
\hline 5 & $1.30 \mathrm{E}+01$ & $1.25 E+01$ & $2.94 E+09$ & 18.1 & 0 & 1.2 \\
\hline 6 & $1.25 E+01$ & $1.20 E+01$ & 4.51E+09 & 17.5 & 0.01 & 1.21 \\
\hline 7 & $1.20 E+01$ & $1.15 E+01$ & $6.77 E+\infty 9$ & 16.7 & 0.01 & 1.22 \\
\hline 8 & $1.15 E+01$ & $1.10 \mathrm{E}+01$ & $1.00 E+10$ & 15.9 & 0.01 & 1.23 \\
\hline 9 & $1.10 E+01$ & $1.05 E+01$ & $1.48 E+10$ & 14.9 & 0.02 & 1.25 \\
\hline 10 & $1.05 E+01$ & $1.00 E+01$ & $2.17 E+10$ & 13.7 & 0.03 & 1.27 \\
\hline 11 & $1.00 E+01$ & $9.50 E+\infty 0$ & $3.22 E+10$ & 12.3 & 0.04 & 1.29 \\
\hline 12 & $9.50 E+\infty$ & $9.00 E+\infty 0$ & $4.79 E+10$ & 10.8 & 0.06 & 1.31 \\
\hline 13 & $9.00 E+\infty$ & $8.50 E+\infty$ & $7.17 E+10$ & 9.2 & 0.09 & 1.33 \\
\hline 14 & $8.50 E+\infty$ & $8.00 E+00$ & $1.07 E+11$ & 7.7 & 0.13 & 1.35 \\
\hline 15 & $8.00 E+\infty 0$ & $7.50 E+00$ & $1.60 E+11$ & 6.6 & 0.19 & 1.37 \\
\hline 16 & $7.50 E+\infty$ & $7.00 E+00$ & $2.36 E+11$ & 6.1 & 0.28 & 1.38 \\
\hline 17 & $7.00 E+\infty$ & $6.50 \mathrm{E}+00$ & $3.47 E+11$ & 5.9 & 0.42 & 1.39 \\
\hline 18 & $6.50 E+\infty$ & $6.00 E+00$ & $5.08 E+11$ & 5.9 & 0.61 & 1.39 \\
\hline 19 & $6.00 E+\infty$ & $5.50 \mathrm{E}+\infty 0$ & $7.40 E+11$ & 5.8 & 0.89 & 1.39 \\
\hline 20 & $5.50 \mathrm{E}+\infty 0$ & $5.00 E+\infty 0$ & $1.07 E+12$ & 5.6 & 1.28 & 1.38 \\
\hline 21 & $5.00 E+\infty$ & $4.50 E+\infty 0$ & $1.53 E+12$ & 5.3 & 1.84 & 1.38 \\
\hline 22 & $4.50 E+\infty$ & $4.00 E+\infty 0$ & $2.16 E+12$ & 4.9 & 2.59 & 1.37 \\
\hline 23 & $4.00 E+\infty$ & $3.50 \mathrm{E}+\infty 0$ & $3.04 E+12$ & 4.5 & 3.64 & 1.37 \\
\hline 24 & $3.50 E+\infty 0$ & $3.00 E+\infty 0$ & $4.31 E+12$ & 4.1 & 5.17 & 1.36 \\
\hline 25 & $3.00 E+\infty 0$ & $2.50 E+\infty 0$ & $6.23 E+12$ & 3.5 & 7.46 & 1.35 \\
\hline 26 & $2.50 E+\infty 0$ & $2.00 E+\infty 0$ & $8.90 E+12$ & 3 & 10.67 & 1.33 \\
\hline 27 & $2.00 E+\infty$ & $1.50 E+\infty 0$ & $1.24 E+13$ & 2.4 & 14.9 & 1.32 \\
\hline 28 & $1.50 E+\infty$ & $1.00 E+00$ & $1.75 E+13$ & 3 & 20.96 & 1.31 \\
\hline 29 & $1.00 E+\infty$ & 8.21E-01 & $1.99 E+13$ & 3.2 & 23.8 & 1.3 \\
\hline 30 & 8.21E-01 & 4.98E-01 & $2.52 E+13$ & 4.1 & 30.22 & 1.29 \\
\hline 31 & 4.98E-01 & $3.02 E-01$ & $2.91 E+13$ & 4.9 & 34.9 & 1.28 \\
\hline 32 & $3.02 E-01$ & 1.11E-01 & $3.41 E+13$ & 5.8 & 40.88 & 1.27 \\
\hline 33 & 1.11E-01 & 5.25E-02 & $3.68 E+13$ & 6.3 & 44.13 & 1.27 \\
\hline 34 & $5.25 E-02$ & 2.48E-02 & $3.92 E+13$ & 6.6 & 46.93 & 1.27 \\
\hline 36 & $2.48 E-02$ & $1.50 \mathrm{E}-02$ & $4.07 E+13$ & 6.8 & 48.74 & 1.26 \\
\hline 36 & $1.50 E-02$ & $9.12 E-03$ & $4.22 \mathrm{E}+13$ & 6.9 & 50.5 & 1.26 \\
\hline 37 & $9.12 E-03$ & 5.53E-03 & 4.35E+13 & 6.9 & 52.14 & 1.26 \\
\hline 38 & $5.53 E-03$ & $1.23 E-03$ & $4.77 E+13$ & 6.8 & 57.17 & 1.26 \\
\hline 39 & $1.23 E-03$ & 4.54E-0.4 & $5.04 E+13$ & 6.7 & 60.39 & 1.26 \\
\hline 40 & 4.54E-0.4 & $2.75 E-04$ & $5.18 E+13$ & 6.5 & 62.03 & 1.26 \\
\hline 41 & $2.75 E-04$ & $2.14 E-04$ & $5.24 E+13$ & 6.4 & 62.83 & 1.26 \\
\hline 42 & 2.14E-04 & $1.01 E-04$ & $5.44 E+13$ & 6.2 & 65.22 & 1.26 \\
\hline 43 & $1.01 E-04$ & $2.90 E-05$ & $5.76 E+13$ & 5.8 & 68.98 & 1.26 \\
\hline 44 & 2.90E-05 & $6.48 E-06$ & $6.12 E+13$ & 5.4 & 73.36 & 1.26 \\
\hline 45 & $6.48 E-06$ & 3.93E-06 & $6.24 E+13$ & 5.3 & 74.76 & 1.26 \\
\hline 46 & $3.93 E-06$ & $3.06 E-06$ & $6.30 E+13$ & 5.2 & 75.48 & 1.26 \\
\hline 47 & $3.06 E-06$ & $1.86 E-06$ & $6.42 E+13$ & 5.1 & 76.9 & 1.26 \\
\hline 48 & $1.86 \mathrm{E}-\infty 6$ & 1.13E-06 & $6.54 E+13$ & 5 & 78.32 & 1.26 \\
\hline 49 & $1.13 E-\infty 6$ & 5.32E-07 & $6.72 E+13$ & 4.8 & 80.47 & 1.26 \\
\hline 50 & 5.32E-07 & 4.14E-07 & $6.78 E+13$ & 4.8 & 81.23 & 1.26 \\
\hline 51 & 4.14E-07 & $1.00 E-10$ & $8.35 E+13$ & 5.7 & 100 & 1.2 \\
\hline
\end{tabular}


Table B. FERRET analysis summary for ATR B positions.

\begin{tabular}{|c|c|c|c|c|c|c|c|c|}
\hline $\begin{array}{l}\text { Dosimeter } \\
\text { Reaction }\end{array}$ & $\begin{array}{c}\text { Measured } \\
\text { Rate } \\
\text { (Bq/atom) }\end{array}$ & $\begin{array}{c}\sigma \\
(\%)\end{array}$ & $\begin{array}{c}\text { Calculated } \\
\text { Rate } \\
\text { (Bq/atom) }\end{array}$ & $\begin{array}{c}\sigma \\
(\%)\end{array}$ & $\mathbf{C} / \mathbf{M}$ & $\begin{array}{c}\text { FERRET-Fit } \\
\text { Rate } \\
\text { (Bq/atom) }\end{array}$ & $\begin{array}{c}\sigma \\
(\%)\end{array}$ & $\mathbf{F F} / \mathbf{M}$ \\
\hline $45 \operatorname{Sc}(n, \gamma)$ & $2.68 \mathrm{E}-11$ & 2.2 & $\begin{array}{c}\text { B-4 } \\
2.24 \mathrm{E}-11\end{array}$ & .19 .4 & 0.837 & $2.66 \mathrm{E}-11$ & 5.4 & 0.99 \\
\hline $197 \mathrm{Au}(\mathrm{n}, \gamma)$ & $3.23 E-09$ & 2 & $2.98 \mathrm{E}-09$ & 21.8 & 0.924 & $3.23 E-09$ & 4.3 & 1 \\
\hline $235 U(n, f)$ & $6.18 \mathrm{E}-10$ & 2.2 & $5.67 \mathrm{E}-10$ & 17.3 & 0.918 & $6.24 \mathrm{E}-10$ & 3 & 1.01 \\
\hline $59 \mathrm{Co}(\mathrm{n}, \gamma)$ & $1.56 \mathrm{E}-10$ & 2.5 & $1.48 \mathrm{E}-10$ & 20.9 & 0.952 & $1.56 \mathrm{E}-10$ & 5.4 & 1 \\
\hline $\operatorname{s8Fe}(\mathbf{n}, \gamma)$ & $3.08 \mathrm{E}-12$ & 2.1 & $2.60 \mathrm{E}-12$ & 18 & 0.845 & $3.06 \mathrm{E}-12$ & 5 & 0.99 \\
\hline $237 \mathrm{~Np}(\mathrm{n}, \mathrm{f})$ & $2.35 \mathrm{E}-11$ & 2 & $3.00 \mathrm{E}-11$ & 20.4 & 1.275 & $2.36 \mathrm{E}-11$ & 5.1 & 1 \\
\hline $238 U(n, f)$ & $4.14 \mathrm{E}-12$ & 2 & $5.41 \mathrm{E}-12$ & 18.6 & 1.306 & $4.13 \mathrm{E}-12$ & 2.4 & 1 \\
\hline 47Ti(n,p) & $2.24 \mathrm{E}-13$ & 2.2 & $3.56 \mathrm{E}-13$ & 21.1 & 1.591 & $2.23 \mathrm{E}-13$ & 3.1 & 1 \\
\hline $58 N i(n, p)$ & $1.19 \mathrm{E}-12$ & 2 & $1.61 \mathrm{E}-12$ & 19.1 & 1.356 & $1.18 \mathrm{E}-12$ & 3.5 & 1 \\
\hline $54 \mathrm{Fe}(\mathrm{n}, \mathrm{p})$ & $8.61 \mathrm{E}-13$ & 2.5 & $1.23 \mathrm{E}-12$ & 18.4 & 1.425 & $8.71 \mathrm{E}-13$ & 3.7 & 1.01 \\
\hline $46 \mathrm{Ti}(\mathrm{n}, \mathrm{p})$ & $1.20 E-13$ & 2.1 & $1.56 \mathrm{E}-13$ & 21.9 & 1.297 & $1.20 \mathrm{E}-13$ & 5.3 & 1 \\
\hline $63 \mathrm{Cu}(\mathrm{n}, \alpha)$ & $5.76 \mathrm{E}-15$ & 4.2 & $7.55 \mathrm{E}-15$ & 17.9 & 1.31 & $5.81 \mathrm{E}-15$ & 5.1 & 1.01 \\
\hline $48 T i(n, p)$ & $3.13 \mathrm{E}-15$ & 2.8 & $3.77 \mathrm{E}-15$ & 20.2 & 1.204 & $3.12 \mathrm{E}-15$ & 5.8 & 1 \\
\hline $27 A \mid(n, \alpha)$ & $7.84 \mathrm{E}-15$ & 7.7 & $\begin{array}{c}9.54 \mathrm{E}-15 \\
\mathrm{~B}-8\end{array}$ & 18.7 & 1.217 & $7.78 E-15$ & 6.4 & 0.99 \\
\hline $45 \operatorname{Se}(n, y)$ & $2.46 \mathrm{E}-11$ & 2.2 & $2.24 \mathrm{E}-11$ & 19.4 & 0.912 & $2.46 \mathrm{E}-11$ & 5.4 & 1 \\
\hline 197Au(n,y) & $2.93 \mathrm{E}-09$ & 2 & $2.98 \mathrm{E}-09$ & 21.8 & 1.019 & $2.94 \mathrm{E}-09$ & 4.3 & 1 \\
\hline $235 U(n, f)$ & $5.83 \mathrm{E}-10$ & 2.2 & $5.67 \mathrm{E}-10$ & 17.3 & 0.973 & $5.79 \mathrm{E}-10$ & 3 & 0.99 \\
\hline $59 \mathrm{Co}(\mathrm{n}, \gamma)$ & $1.37 \mathrm{E}-10$ & 2.2 & $1.48 \mathrm{E}-10$ & 20.9 & 1.084 & $1.37 \mathrm{E}-10$ & 5.3 & 1 \\
\hline $\operatorname{s8Fe}(\mathbf{n}, \gamma)$ & $2.68 \mathrm{E}-12$ & 2.1 & $2.60 \mathrm{E}-12$ & 18 & 0.971 & $2.68 \mathrm{E}-12$ & 4.9 & 1 \\
\hline $237 \mathrm{~Np}(\mathrm{n}, \mathrm{n})$ & $2.13 \mathrm{E}-11$ & 2 & $3.00 \mathrm{E}-11$ & 20.4 & 1.407 & $2.13 \mathrm{E}-11$ & 5.1 & 1 \\
\hline $238 U(n, f)$ & $3.62 \mathrm{E}-12$ & 2 & $5.41 E-12$ & 18.6 & 1.493 & $3.64 \mathrm{E}-12$ & 2.4 & 1 \\
\hline 47Ti(n,p) & $1.97 \mathrm{E}-13$ & 2.2 & $3.56 \mathrm{E}-13$ & 21.1 & 1.809 & $1.98 \mathrm{E}-13$ & 3.1 & 1 \\
\hline $58 \mathrm{Ni}(\mathrm{n}, \mathrm{p})$ & $1.07 \mathrm{E}-12$ & 2 & $1.61 \mathrm{E}-12$ & 19.1 & 1.508 & $1.06 \mathrm{E}-12$ & 3.5 & 0.99 \\
\hline $54 \mathrm{Fe}(\mathrm{n}, \mathrm{p})$ & $7.70 \mathrm{E}-13$ & 2.5 & $1.23 E-12$ & 18.4 & 1.593 & $7.77 \mathrm{E}-13$ & 3.7 & 1.01 \\
\hline $46 \mathrm{Ti}(\mathrm{n}, \mathrm{p})$ & $1.08 \mathrm{E}-13$ & 2.1 & $1.56 \mathrm{E}-13$ & 21.9 & 1.441 & $1.09 \mathrm{E}-13$ & 5.3 & 1.01 \\
\hline $63 \mathrm{Cu}(\mathrm{n}, \alpha)$ & 5.30E-15 & 4.2 & $7.55 \mathrm{E}-15$ & 17.9 & 1.424 & $5.16 \mathrm{E}-15$ & 5.1 & 0.97 \\
\hline $48 T i(n, p)$ & $2.74 E-15$ & 2.8 & 3.77E-15 & 20.2 & 1.375 & $2.75 E-15$ & 5.8 & 1 \\
\hline $27 \mathrm{Al}(\mathrm{n}, \alpha)$ & $6.49 \mathrm{E}-15$ & 7.7 & $\begin{array}{c}9.54 \mathrm{E}-15 \\
\text { B-11 }\end{array}$ & 18.7 & 1.471 & $6.81 E-15$ & 6.4 & 1.05 \\
\hline $\operatorname{45Sc}(\mathrm{n}, \gamma)$ & $1.20 \mathrm{E}-11$ & 2 & $1.12 \mathrm{E}-11$ & 19.4 & 0.935 & $1.20 \mathrm{E}-11$ & 5.4 & 1 \\
\hline $197 \mathrm{Au}(\mathrm{n}, \gamma)$ & $1.57 \mathrm{E}-09$ & 2 & $1.49 \mathrm{E}-09$ & 21.8 & 0.95 & $1.57 \mathrm{E}-09$ & 4.3 & 1 \\
\hline $235 \mathrm{U}(\mathrm{n}, \mathrm{f})$ & $3.09 E-10$ & 2.2 & $2.84 \mathrm{E}-10$ & 17.3 & 0.918 & $3.03 \mathrm{E}-10$ & 3.1 & 0.98 \\
\hline $59 \mathrm{Co}(\mathrm{n}, \gamma)$ & $7.29 \mathrm{E}-11$ & 2.2 & $7.42 \mathrm{E}-11$ & 20.9 & 1.018 & $7.34 \mathrm{E}-11$ & 5.4 & 1.01 \\
\hline $58 \mathrm{Fe}(\mathrm{n}, \gamma)$ & $1.44 \mathrm{E}-12$ & 2.1 & $1.30 \mathrm{E}-12$ & 18 & 0.904 & $1.43 \mathrm{E}-12$ & 5.2 & 1 \\
\hline $237 N p(n, f)$ & $6.60 \mathrm{E}-12$ & 2 & $1.50 \mathrm{E}-11$ & 20.4 & 2.27 & $6.58 \mathrm{E}-12$ & 5.2 & 1 \\
\hline $238 U(n, f)$ & $9.46 \mathrm{E}-13$ & 2 & $2.70 \mathrm{E}-12$ & 18.6 & 2.857 & $9.45 \mathrm{E}-13$ & 2.5 & 1 \\
\hline 47Ti(n,p) & $4.77 \mathrm{E}-14$ & 2.2 & $1.78 \mathrm{E}-13$ & 21.1 & 3.735 & $4.81 \mathrm{E}-14$ & 3.1 & 1.01 \\
\hline $58 \mathrm{Ni}(\mathrm{n}, \mathrm{p})$ & $2.50 \mathrm{E}-13$ & 2 & 8.07E-13 & 19.1 & 3.228 & $2.53 \mathrm{E}-13$ & 3.5 & 1.01 \\
\hline $54 F e(n, p)$ & $1.84 \mathrm{E}-13$ & 2.5 & 6.13E-13 & 18.4 & 3.334 & $1.84 \mathrm{E}-13$ & 3.7 & 1 \\
\hline $46 \mathrm{Ti}(\mathrm{n}, \mathrm{p})$ & $2.64 \mathrm{E}-14$ & 2.1 & $7.78 E-14$ & 21.9 & 2.948 & $2.61 \mathrm{E}-14$ & 5.3 & 0.99 \\
\hline $63 \mathrm{Cu}(\mathrm{n}, \alpha)$ & $1.26 \mathrm{E}-15$ & 4.2 & 3.77E-15 & 17.9 & 2.994 & $1.32 \mathrm{E}-15$ & 5.1 & 1.05 \\
\hline $48 \mathrm{Ti}(\mathrm{n}, \mathrm{p})$ & $7.31 \mathrm{E}-16$ & 2.8 & $1.88 \mathrm{E}-15$ & 15.8 & 2.577 & $7.31 \mathrm{E}-16$ & 5.7 & 1 \\
\hline $27 \mathrm{Al}(\mathrm{n}, \alpha)$ & $1.74 \mathrm{E}-15$ & 7.7 & 4.77E-15 & 17.4 & 2.742 & $1.82 \mathrm{E}-15$ & 6.3 & 1.04 \\
\hline
\end{tabular}



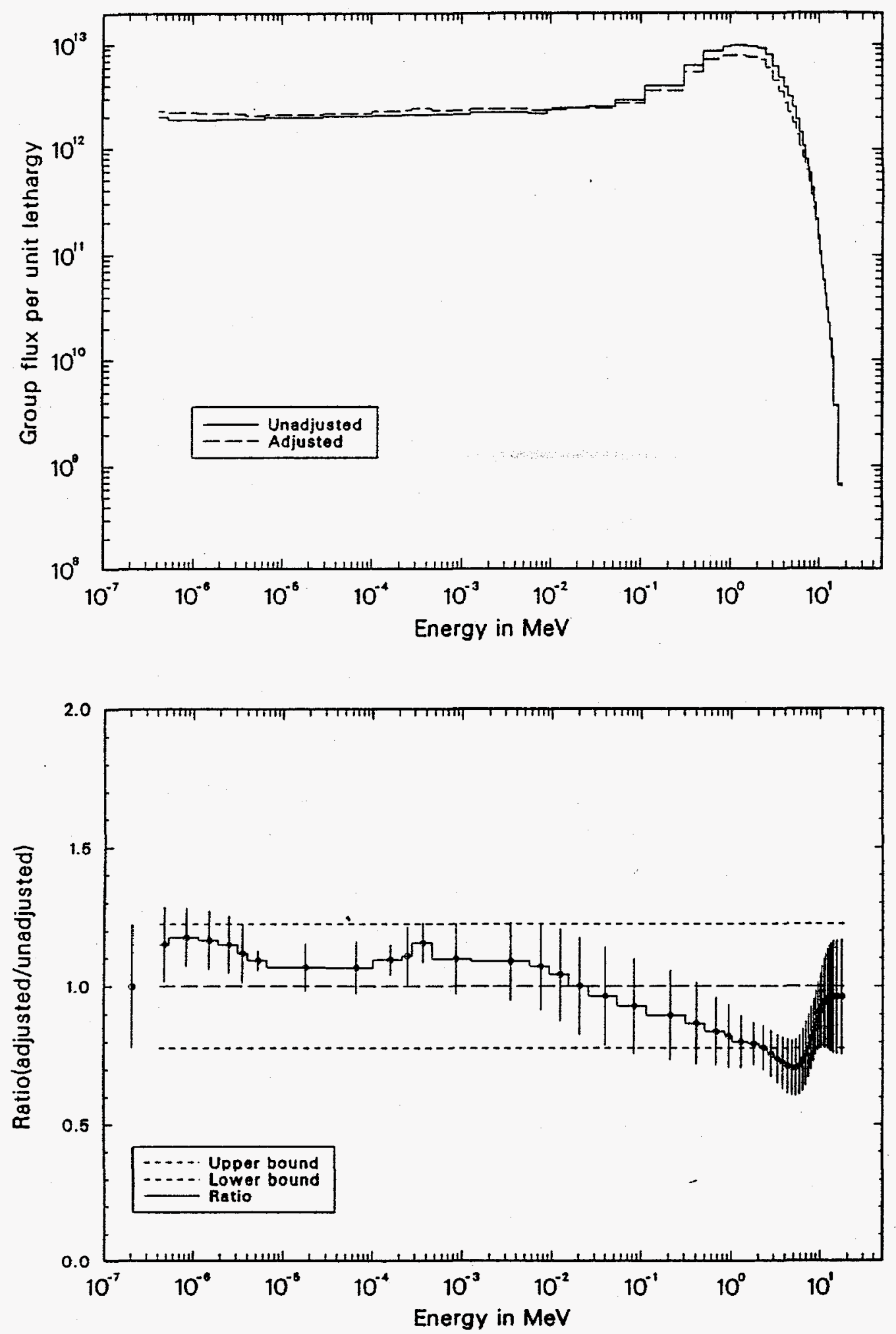

Figure B1. Upper part of figure compares adjusted and unadjusted (input) group fluence rates for B-1 location and lower part displays the ratio of adjusted-to-unadjusted group values with input uncertainty bounds and final uncertainty error bars. 
Table B1. Adjusted group fluence rates for B-1 irradiation location.

\begin{tabular}{|c|c|c|c|c|c|c|c|}
\hline GROUP & EU & EL & DU & $\overline{\text { PHA }}$ & UNCA & FRPHA & RPH \\
\hline 1 & $1.80 E+01$ & $1.60 E+01$ & 0.118 & $7.59 E+07$ & 20.7 & 0 & 0.96 \\
\hline 2 & $1.60 \mathrm{E}+01$ & $1.40 E+01$ & 0.134 & $4.81 E+08$ & 20.6 & 0 & 0.96 \\
\hline 3 & $1.40 E+01$ & $1.35 E+01$ & 0.036 & $3.77 E+08$ & 20.3 & 0 & 0.96 \\
\hline 4 & $1.35 \mathrm{E}+01$ & $1.30 E+01$ & 0.038 & $5.77 E+08$ & 20 & 0 & 0.96 \\
\hline 5 & $1.30 E+01$ & $1.25 E+01$ & 0.039 & $8.48 E+08$ & 19.5 & 0 & 0.96 \\
\hline 6 & $1.25 E+01$ & $1.20 E+01$ & 0.041 & $1.22 E+09$ & 18.9 & 0 & 0.96 \\
\hline 7 & $1.20 E+01$ & $1.15 E+01$ & 0.043 & $1.74 E+09$ & 18.2 & 0 & 0.95 \\
\hline 8 & 1.15E+01 & $1.10 E+01$ & 0.044 & $2.45 E+09$ & 17.2 & 0 & 0.95 \\
\hline 9 & $1.10 E+01$ & $1.05 E+01$ & 0.047 & $3.46 E+09$ & 16 & 0.01 & 0.94 \\
\hline 10 & $1.05 E+01$ & $1.00 E+01$ & 0.049 & $4.93 E+09$ & 14.7 & 0.01 & 0.93 \\
\hline 11 & $1.00 E+01$ & $9.50 E+\infty 0$ & 0.051 & $7.14 E+09$ & 13.4 & 0.01 & 0.91 \\
\hline 12 & $9.50 \mathrm{E}+\infty 0$ & $9.00 E+\infty 0$ & 0.054 & $1.04 E+10$ & 12.3 & 0.02 & 0.89 \\
\hline 13 & $9.00 E+\infty 0$ & $8.50 E+\infty$ & 0.057 & $1.50 E+10$ & 11.6 & 0.02 & 0.87 \\
\hline 14 & $8.50 E+00$ & $8.00 E+\infty$ & 0.061 & $2.16 E+10$ & 11.4 & 0.03 & 0.84 \\
\hline 16 & $8.00 E+00$ & $7.50 E+\infty$ & 0.065 & $3.05 E+10$ & 11.5 & 0.05 & 0.81 \\
\hline 16 & $7.50 E+\infty 0$ & $7.00 E+\infty$ & 0.069 & $4.28 E+10$ & 11.6 & 0.06 & 0.79 \\
\hline 17 & $7.00 E+\infty$ & $6.50 E+\infty$ & 0.074 & $6.00 E+10$ & 11.6 & 0.09 & 0.76 \\
\hline 18 & $6.50 E+\infty 0$ & $6.00 E+\infty$ & 0.08 & $8.46 E+10$ & 11.3 & 0.13 & 0.73 \\
\hline 19 & $6.00 E+\infty 0$ & $5.50 E+\infty$ & 0.087 & $1.20 \mathrm{E}+11$ & 10.8 & 0.18 & 0.72 \\
\hline 20 & $5.50 E+\infty 0$ & $5.00 E+\infty$ & 0.095 & $1.70 E+11$ & 10.4 & 0.26 & 0.71 \\
\hline 21 & $5.00 E+00$ & $4.50 E+\infty$ & 0.105 & $2.38 E+11$ & 10.1 & 0.36 & 0.71 \\
\hline 22 & $4.50 E+\infty 0$ & $4.00 E+\infty$ & 0.118 & $3.29 E+11$ & 9.9 & 0.49 & 0.71 \\
\hline 23 & $4.00 E+\infty 0$ & $3.50 E+\infty 0$ & 0.134 & $4.70 E+11$ & 9.5 & 0.71 & 0.72 \\
\hline 24 & $3.50 E+\infty 0$ & $3.00 E+\infty 0$ & 0.154 & $7.03 E+11$ & 9 & 1.06 & 0.74 \\
\hline 25 & $3.00 E+\infty 0$ & $2.50 E+\infty$ & 0.182 & $1.10 \mathrm{E}+12$ & 8.6 & 1.65 & 0.76 \\
\hline 26 & $2.50 E+00$ & $2.00 E+\infty 0$ & 0.223 & $1.60 E+12$ & 8.2 & 2.4 & 0.78 \\
\hline 27 & $2.00 E+\infty 0$ & $1.50 E+\infty$ & 0.288 & $2.18 \mathrm{E}+12$ & 7.8 & 3.28 & 0.79 \\
\hline 28 & $1.50 E+\infty 0$ & $1.00 E+\infty$ & 0.405 & $3.18 E+12$ & 9.5 & 4.78 & 0.8 \\
\hline 29 & $1.00 E+\infty 0$ & 8.21E-01 & 0.197 & $1.54 E+12$ & 11.5 & 2.32 & 0.82 \\
\hline 30 & 8.21E-01 & $4.98 E-01$ & 0.5 & 3.60E+12 & 12.3 & 5.41 & 0.84 \\
\hline 31 & 4.98E-01 & 3.02E-01 & 0.5 & $2.75 E+12$ & 14.6 & 4.13 & 0.87 \\
\hline 32 & 3.02E-01 & 1.11E-01 & 1 & $3.65 E+12$ & 16.1 & 5.49 & 0.9 \\
\hline 33 & 1.11E-01 & $5.25 E-02$ & 0.75 & $2.06 E+12$ & 17.1 & 3.09 & 0.93 \\
\hline 34 & $5.25 E-02$ & 2.48E-02 & 0.75 & $1.84 E+12$ & 17.6 & 2.77 & 0.96 \\
\hline 36 & $2.48 E-02$ & $1.50 E-02$ & 0.5 & $1.23 E+12$ & 17.5 & 1.86 & 1 \\
\hline 36 & $1.50 E-02$ & 9.12E-03 & 0.5 & $1.23 E+12$ & 16.7 & 1.85 & 1.04 \\
\hline 37 & $9.12 E-03$ & $5.53 E-03$ & 0.5 & $1.17 E+12$ & 15.5 & 1.76 & 1.07 \\
\hline 38 & $5.53 E-03$ & $1.23 E-03$ & 1.5 & $3.64 E+12$ & 14.2 & 5.47 & 1.09 \\
\hline 39 & $1.23 E-03$ & 4.54E-04 & 1 & $2.34 E+12$ & 12.8 & 3.52 & 1.1 \\
\hline 40 & 4.54E-04 & 2.75E-04 & 0.5 & $1.22 E+12$ & 7.3 & 1.84 & 1.16 \\
\hline 41 & 2.75E-04 & $2.14 E-04$ & 0.25 & $5.86 E+11$ & 10.6 & 0.88 & 1.11 \\
\hline 42 & $2.14 E-04$ & $1.01 E-04$ & 0.75 & $1.71 E+12$ & 5.5 & 2.58 & 1.09 \\
\hline 43 & $1.01 E-04$ & 2.90E-05 & 1.25 & $2.72 E+12$ & 9.5 & 4.09 & 1.07 \\
\hline 4 & 2.90E-05 & $6.48 E-06$ & 1.5 & $3.19 E+12$ & 8.5 & 4.8 & 1.07 \\
\hline 46 & $6.48 E-06$ & $3.93 E-06$ & 0.5 & $1.04 E+12$ & 3.7 & 1.56 & 1.09 \\
\hline 46 & $3.93 E-06$ & $3.06 \mathrm{E}-06$ & 0.25 & $5.36 E+11$ & 10.6 & 0.81 & 1.12 \\
\hline 47 & 3.06E-06 & $1.86 E-06$ & 0.5 & $1.09 E+12$ & 10.4 & 1.64 & 1.15 \\
\hline 48 & $1.86 E-06$ & $1.13 E-06$ & 0.5 & $1.09 E+12$ & 10.7 & 1.64 & 1.16 \\
\hline 49 & 1.13E-06 & 5.32E-07 & 0.75 & $1.66 E+12$ & 10.5 & 2.5 & 1.17 \\
\hline 60 & 5.32E-07 & 4.14E-07 & 0.25 & $5.75 E+11$ & 13.5 & 0.86 & 1.15 \\
\hline 51 & 4.14E-07 & $1.00 E-10$ & 8.328 & $1.57 E+13$ & 22.4 & 23.56 & 1 \\
\hline
\end{tabular}


Table B2. Cumulative adjusted group fluence rates for B-1 irradiation location.

\begin{tabular}{|c|c|c|c|c|c|c|}
\hline GROUP & $\mathbf{E U}$ & EL & CPHA & UNCA & FRCPHA & RCPH \\
\hline 1 & $1.80 \mathrm{E}+01$ & $1.60 \mathrm{E}+01$ & $7.59 E+07$ & 20.7 & 0 & 0.96 \\
\hline 2 & $1.60 \mathrm{E}+01$ & $1.40 E+01$ & $5.57 E+08$ & 20.1 & 0 & 0.96 \\
\hline 3 & $1.40 E+01$ & $1.35 E+01$ & $9.34 E+08$ & 19.2 & 0 & 0.96 \\
\hline 4 & $1.35 E+01$ & 1.30E+01 & $1.51 E+\infty 9$ & 18.5 & 0 & 0.96 \\
\hline 5 & $1.30 E+01$ & $1.25 E+01$ & $2.36 E+\infty 9$ & 17.8 & 0 & 0.96 \\
\hline 6 & $1.25 E+01$ & $1.20 E+01$ & $3.58 E+09$ & 17 & 0.01 & 0.96 \\
\hline 7 & $1.20 E+01$ & 1.15E+01 & $5.32 E+\infty 9$ & 16.2 & 0.01 & 0.96 \\
\hline 8 & $1.15 E+01$ & $1.10 E+01$ & $7.77 E+\infty 9$ & 15.3 & 0.01 & 0.95 \\
\hline 8 & $1.10 E+01$ & $1.05 E+01$ & $1.12 E+10$ & 14.2 & 0.02 & 0.95 \\
\hline 10 & $1.05 E+01$ & $1.00 E+01$ & $1.62 E+10$ & 12.9 & 0.02 & 0.94 \\
\hline 11 & $1.00 E+01$ & $9.50 E+\infty 0$ & $2.33 E+10$ & 11.5 & 0.04 & 0.93 \\
\hline 12 & $9.50 E+\infty 0$ & $9.00 E+\infty 0$ & $3.37 E+10$ & 9.9 & 0.05 & 0.92 \\
\hline 13 & $9.00 E+\infty 0$ & $8.50 E+\infty 0$ & $4.87 E+10$ & 8.4 & 0.07 & 0.9 \\
\hline 14 & $8.50 E+\infty 0$ & $8.00 E+00$ & $7.02 E+10$ & 7.1 & 0.11 & 0.88 \\
\hline 16 & $8.00 E+\infty$ & $7.50 E+\infty 0$ & $1.01 E+11$ & 6.3 & 0.15 & 0.86 \\
\hline 16 & $7.50 E+\infty 0$ & $7.00 E+\infty 0$ & $1.44 E+11$ & 5.9 & 0.22 & 0.84 \\
\hline 17 & $7.00 E+\infty 0$ & $6.50 E+\infty 0$ & $2.04 E+11$ & 5.9 & 0.31 & 0.81 \\
\hline 18 & $6.50 E+\infty$ & $6.00 E+\infty 0$ & $2.88 E+11$ & 6 & 0.43 & 0.79 \\
\hline 19 & $6.00 E+\infty 0$ & $5.50 E+\infty 0$ & $4.08 E+11$ & 5.9 & 0.61 & 0.77 \\
\hline 20 & $5.50 E+00$ & $5.00 E+\infty 0$ & $5.79 E+11$ & 5.7 & 0.87 & 0.75 \\
\hline 21 & $5.00 E+\infty 0$ & $4.50 E+\infty 0$ & $8.16 E+11$ & 5.3 & 1.23 & 0.73 \\
\hline 22 & $4.50 E+\infty 0$ & $4.00 E+\infty$ & 1.15E+12 & 5 & 1.72 & 0.73 \\
\hline 23 & $4.00 E+00$ & $3.50 E+\infty 0$ & $1.62 E+12$ & 4.6 & 2.43 & 0.73 \\
\hline 24 & $3.50 E+\infty 0$ & $3.00 E+\infty$ & $2.32 E+12$ & 4.1 & 3.48 & 0.73 \\
\hline 26 & $3.00 E+\infty 0$ & $2.50 E+\infty 0$ & $3.41 E+12$ & 3.6 & 5.13 & 0.74 \\
\hline 26 & $2.50 E+\infty 0$ & $2.00 E+\infty 0$ & $5.01 E+12$ & 3 & 7.53 & 0.75 \\
\hline 27 & $2.00 E+\infty 0$ & $1.50 E+\infty$ & $7.19 E+12$ & 2.4 & 10.81 & 0.76 \\
\hline 28 & $1.50 E+\infty$ & $1.00 E+\infty$ & $1.04 E+13$ & 3.1 & 15.58 & 0.77 \\
\hline 29 & $1.00 E+\infty 0$ & 8.21E-01 & $1.19 E+13$ & 3.4 & 17.9 & 0.78 \\
\hline 30 & $8.21 E-01$ & 4.98E-01 & $1.55 E+13$ & 4.4 & 23.31 & 0.79 \\
\hline 31 & 4.98E-01 & 3.02E-01 & $1.83 E+13$ & 5.2 & 27.45 & 0.8 \\
\hline 32 & $3.02 E-01$ & 1.11E-01 & $2.19 E+13$ & 6.3 & 32.93 & 0.82 \\
\hline 33 & 1.11E-01 & $5.25 E-02$ & $2.40 E+13$ & 6.8 & 36.03 & 0.83 \\
\hline 34 & $5.25 E-02$ & $2.48 E-02$ & $2.58 E+13$ & 7.2 & 38.79 & 0.83 \\
\hline 35 & $2.48 E-02$ & $1.50 \mathrm{E}-02$ & $2.70 E+13$ & 7.4 & 40.65 & 0.84 \\
\hline 36 & $1.50 E-02$ & $9.12 E-03$ & $2.83 E+13$ & 7.5 & 42.5 & 0.85 \\
\hline 37 & $9.12 E-03$ & 5.53E-03 & $2.94 E+13$ & 7.5 & 44.26 & 0.85 \\
\hline 38 & 5.53E-03 & $1.23 E-03$ & $3.31 E+13$ & 7.4 & 49.73 & 0.88 \\
\hline 39 & $1.23 E-03$ & $4.54 E-04$ & $3.54 E+13$ & 7.2 & 53.25 & 0.89 \\
\hline 40 & 4.54E-04 & 2.75E-04 & $3.66 E+13$ & 7 & 55.09 & 0.89 \\
\hline 41 & 2.75E-04 & 2.14E-04 & $3.72 E+13$ & 6.9 & 55.97 & 0.9 \\
\hline 42 & $2.14 E-04$ & $1.01 E-04$ & $3.89 E+13$ & 6.6 & 58.55 & 0.9 \\
\hline 43 & $1.01 E-04$ & 2.90E-05 & $4.17 E+13$ & 6.1 & 62.64 & 0.91 \\
\hline 44 & 2.90E-05 & 6.48E-06 & $4.49 E+13$ & 5.6 & 67.44 & 0.92 \\
\hline 46 & $6.48 E-06$ & $3.93 E-06$ & $4.59 E+13$ & 5.5 & 69 & 0.93 \\
\hline 46 & $3.93 E-06$ & $3.06 E-06$ & $4.64 E+13$ & 5.4 & 69.8 & 0.93 \\
\hline 47 & $3.06 E-06$ & $1.86 E-06$ & $4.75 E+13$ & 5.3 & 71.44 & 0.93 \\
\hline 48 & $1.86 E-06$ & $1.13 E-06$ & $4.86 E+13$ & 5.1 & 73.08 & 0.94 \\
\hline 49 & 1.13E-06 & 5.32E-07 & $5.03 E+13$ & 4.9 & 75.57 & 0.94 \\
\hline 50 & 5.32E-07 & $4.14 E-07$ & $5.08 E+13$ & 4.9 & 76.44 & 0.94 \\
\hline 81 & 4.14E-07 & $1.00 E-10$ & $6.65 E+13$ & 6.4 & 100 & 0.96 \\
\hline
\end{tabular}



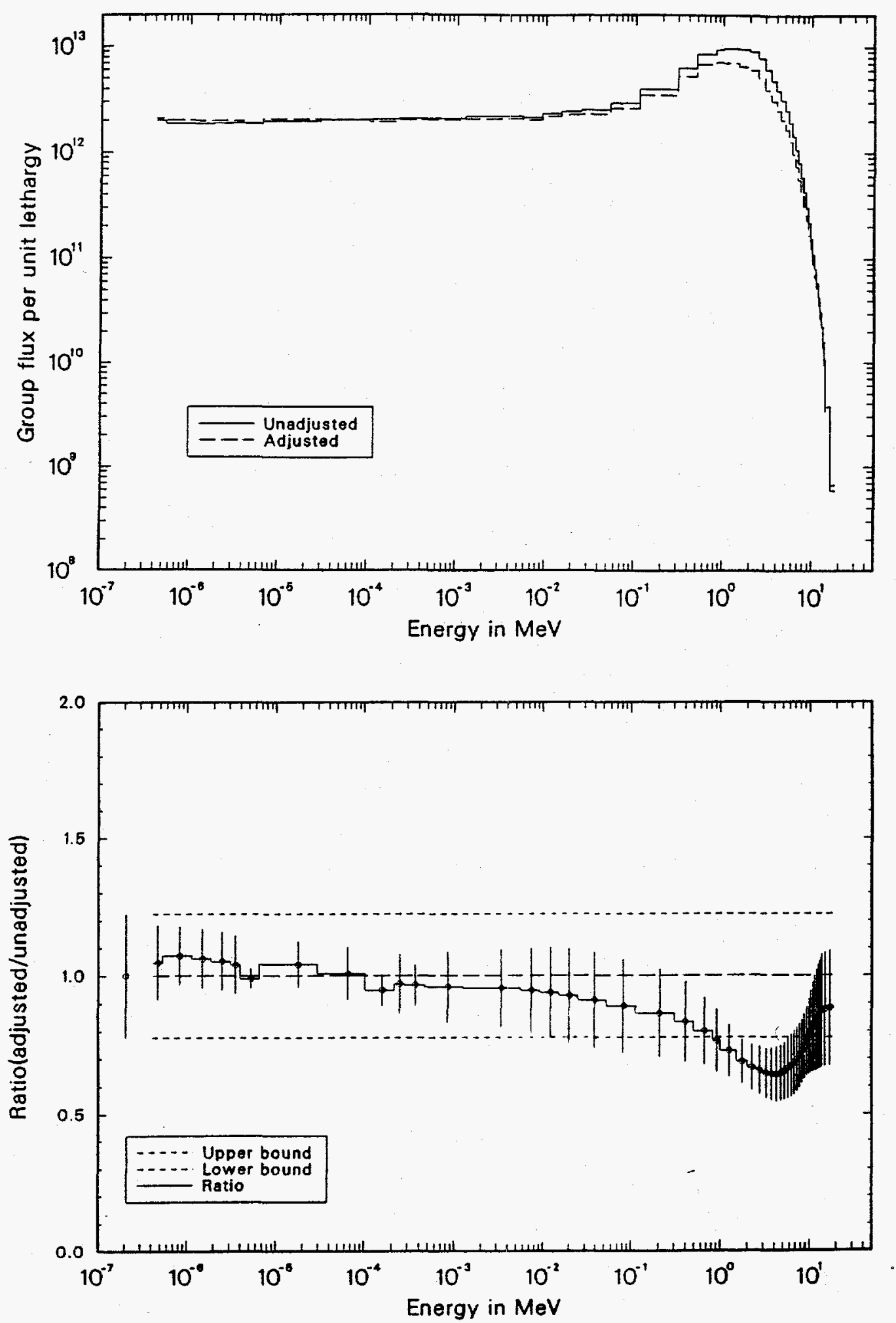

Figure B2. Upper part of figure compares adjusted and unadjusted (input) group fluence rates for B-8 location and lower part displays the ratio of adjusted-to-unadjusted group values with input uncertainty bounds and final uncertainty error bars. 
Table B3. Adjusted group fluence rates for B-8 irradiation location.

\begin{tabular}{|c|c|c|c|c|c|c|c|}
\hline GROUP & $\mathbf{E U}$ & $\mathbf{E L}$ & DU & PHA & UNCA & FRPHA & RPH \\
\hline 1 & $1.80 E+01$ & $1.60 \mathrm{E}+01$ & 0.118 & $6.98 E+07$ & 20.7 & 0 & 0.88 \\
\hline 2 & $1.60 E+01$ & $1.40 E+01$ & 0.134 & $4.40 E+08$ & 20.6 & 0 & 0.88 \\
\hline 3 & $1.40 E+01$ & $1.35 E+01$ & 0.036 & $3.42 E+08$ & 20.3 & 0 & 0.87 \\
\hline 4 & 1.35E+01 & $1.30 E+01$ & 0.038 & $5.21 E+08$ & 20 & 0 & 0.87 \\
\hline 5 & $1.30 E+01$ & $1.25 E+01$ & 0.039 & $7.59 E+08$ & 19.5 & 0 & 0.86 \\
\hline 6 & $1.25 E+01$ & 1.20E+01 & 0.041 & $1.08 E+\infty 9$ & 18.9 & 0 & 0.85 \\
\hline 7 & $1.20 E+01$ & $1.15 E+01$ & 0.043 & $1.53 E+\infty 9$ & 18.2 & 0 & 0.84 \\
\hline 8 & $1.15 E+01$ & $1.10 E+01$ & 0.044 & $2.14 E+09$ & 17.2 & 0 & 0.83 \\
\hline 9 & $1.10 E+01$ & $1.05 E+01$ & 0.047 & $3.00 E+09$ & 16 & 0 & 0.81 \\
\hline 10 & $1.05 E+01$ & $1.00 E+01$ & 0.049 & $4.24 E+09$ & 14.8 & 0.01 & 0.8 \\
\hline 11 & $1.00 E+01$ & $9.50 E+\infty 0$ & 0.051 & $6.12 E+09$ & 13.5 & 0.01 & 0.78 \\
\hline 12 & $9.50 E+\infty 0$ & $9.00 E+\infty$ & 0.054 & $8.89 E+09$ & 12.4 & 0.01 & 0.76 \\
\hline 13 & $9.00 E+\infty$ & $8.50 E+\infty 0$ & 0.057 & $1.29 E+10$ & 11.7 & 0.02 & 0.75 \\
\hline 14 & $8.50 E+\infty 0$ & $8.00 E+\infty$ & 0.061 & $1.86 E+10$ & 11.4 & 0.03 & 0.73 \\
\hline 15 & $8.00 E+\infty 0$ & $7.50 E+\infty$ & 0.065 & $2.67 E+10$ & 11.5 & 0.04 & 0.71 \\
\hline 16 & $7.50 \mathrm{E}+\infty 0$ & $7,00 \mathrm{E}+\infty$ & 0.069 & $3.80 E+10$ & 11.6 & 0.06 & 0.7 \\
\hline 17 & $7.00 E+\infty$ & $6.50 E+\infty$ & 0.074 & $5.43 E+10$ & 11.5 & 0.09 & 0.69 \\
\hline 18 & $6.50 E+\infty 0$ & $6.00 E+\infty$ & 0.08 & $7.78 E+10$ & 11.2 & 0.12 & 0.68 \\
\hline 18 & $6.00 E+\infty$ & $5.50 E+\infty$ & 0.087 & $1.12 E+11$ & 10.8 & 0.18 & 0.67 \\
\hline 20 & $5.50 \mathrm{E}+\infty 0$ & $5.00 E+\infty$ & 0.095 & $1.58 \mathrm{E}+11$ & 10.3 & 0.25 & 0.66 \\
\hline 21 & $5.00 E+\infty 0$ & $4.50 E+\infty 0$ & 0.105 & $2.18 E+11$ & 10.1 & 0.35 & 0.65 \\
\hline 22 & $4.50 \mathrm{E}+\infty 0$ & $4.00 E+\infty$ & 0.118 & $2.97 E+11$ & 9.8 & 0.48 & 0.64 \\
\hline 23 & $4.00 E+\infty 0$ & $3.50 E+\infty 0$ & 0.134 & $4.18 E+11$ & 9.5 & 0.67 & 0.64 \\
\hline 24 & $3.50 E+\infty 0$ & $3.00 E+\infty$ & 0.154 & $6.17 E+11$ & 9 & 0.99 & 0.65 \\
\hline 25 & $3.00 E+\infty 0$ & $2.50 E+\infty$ & 0.182 & $9.53 E+11$ & 8.7 & 1.53 & 0.66 \\
\hline 26 & $2.50 E+\infty 0$ & $2.00 E+\infty 0$ & 0.223 & $1.37 E+12$ & 8.2 & 2.2 & 0.67 \\
\hline 27 & $2.00 E+\infty 0$ & $1.50 E+\infty 0$ & 0.288 & $1.90 E+12$ & 7.9 & 3.04 & 0.69 \\
\hline 28 & $1.50 \mathrm{E}+\infty 0$ & $1.00 E+\infty$ & 0.405 & $2.90 \mathrm{E}+12$ & 9.4 & 4.64 & 0.73 \\
\hline 29 & $1.00 E+\infty 0$ & 8.21E-01 & 0.197 & $1.44 E+12$ & 11.3 & 2.31 & 0.77 \\
\hline 30 & 8.21E-01 & 4.98E-01 & 0.5 & $3.44 E+12$ & 12 & 5.52 & 0.8 \\
\hline 31 & 4.98E-01 & $3.02 E-01$ & 0.5 & $2.64 E+12$ & 14.5 & 4.24 & 0.83 \\
\hline 32 & 3.02E-01 & 1.11E-01 & 1 & $3.52 E+12$ & 15.9 & 5.65 & 0.86 \\
\hline 33 & 1.11E-01 & 5.25E-02 & 0.75 & $1.97 E+12$ & 17 & 3.16 & 0.89 \\
\hline 34 & $5.25 E-02$ & $2.48 E-02$ & 0.75 & $1.74 E+12$ & 17.5 & 2.79 & 0.91 \\
\hline 36 & $2.48 E-02$ & $1.50 \mathrm{E}-02$ & 0.5 & $1.14 E+12$ & 17.5 & 1.83 & 0.93 \\
\hline 36 & $1.50 E-02$ & $9.12 E-03$ & 0.5 & $1.11 E+12$ & 16.6 & 1.78 & 0.94 \\
\hline 37 & $9.12 E-03$ & 5.53E-03 & 0.5 & $1.04 E+12$ & 15.5 & 1.66 & 0.95 \\
\hline 38 & $5.53 E-03$ & $1.23 E-03$ & 1.5 & $3.19 E+12$ & 14.2 & 5.12 & 0.95 \\
\hline 39 & 1.23E-03 & 4.54E-04 & 1 & $2.05 E+12$ & 12.8 & 3.29 & 0.96 \\
\hline 40 & 4.54E-04 & 2.75E-04 & 0.5 & $1.02 E+12$ & 7.4 & 1.64 & 0.97 \\
\hline 41 & 2.75E-04 & 2.14E-04 & 0.25 & $5.14 E+11$ & 10.6 & 0.82 & 0.97 \\
\hline 42 & 2.14E-04 & $1.01 E-04$ & 0.75 & $1.48 E+12$ & 5.6 & 2.38 & 0.95 \\
\hline 43 & 1.01E-04 & 2.90E-05 & 1.25 & $2.58 E+12$ & 9.5 & 4.13 & 1.01 \\
\hline 4 & 2.90E-05 & $6.48 E-06$ & 1.5 & $3.11 E+12$ & 8.3 & 4.99 & 1.04 \\
\hline 46 & $6.48 E-06$ & $3.93 E-06$ & 0.5 & $9.40 E+11$ & 3.7 & 1.51 & 0.99 \\
\hline 46 & 3.93E-06 & $3.06 E-06$ & 0.25 & $4.99 E+11$ & 10.6 & 0.8 & 1.04 \\
\hline 47 & $3.06 E-06$ & $1.86 E-06$ & 0.5 & $9.97 E+11$ & 10.5 & 1.6 & 1.05 \\
\hline 48 & $1.86 E-06$ & 1.13E-06 & 0.5 & $9.94 E+11$ & 10.7 & 1.6 & 1.06 \\
\hline 49 & 1.13E-06 & 5.32E-07 & 0.75 & $1.52 E+12$ & 10.6 & 2.43 & 1.07 \\
\hline 50 & 5.32E-07 & 4.14E-07 & 0.25 & $5.23 E+11$ & 13.5 & 0.84 & 1.05 \\
\hline 51 & 4.14E-07 & $1.00 E-10$ & 8.328 & $1.57 E+13$ & 22.4 & 25.15 & 1 \\
\hline
\end{tabular}


Table B4. Cumulative adjusted group fluence rates for B-8 irradiation location.

\begin{tabular}{|c|c|c|c|c|c|c|}
\hline GROUP & EU & EL & CPHA & UNCA & FRCPHA & RCPH \\
\hline 1 & $1.80 E+01$ & $1.60 E+01$ & $6.98 E+07$ & 20.7 & 0 & 0.88 \\
\hline 2 & $1.60 E+01$ & $1.40 E+01$ & $5.10 E+08$ & 20.1 & 0 & 0.88 \\
\hline 3 & $1.40 \mathrm{E}+01$ & $1.35 E+01$ & $8.52 E+08$ & 19.2 & 0 & 0.88 \\
\hline 4 & $1.35 E+01$ & $1.30 E+01$ & $1.37 E+\infty 9$ & 18.5 & 0 & 0.87 \\
\hline 5 & $1.30 E+01$ & $1.25 E+01$ & $2.13 E+\infty 9$ & 17.8 & 0 & 0.87 \\
\hline 6 & $1.25 E+01$ & $1.20 E+01$ & $3.22 \mathrm{E}+\infty 9$ & 17 & 0.01 & 0.86 \\
\hline 7 & $1.20 E+01$ & $1.15 E+01$ & $4.75 E+\infty 9$ & 16.2 & 0.01 & 0.86 \\
\hline 8 & $1.15 E+01$ & $1.10 E+01$ & $6.89 E+\infty 9$ & 15.3 & 0.01 & 0.85 \\
\hline 9 & 1.10E+Ot & $1.05 E+01$ & $9.89 E+09$ & 14.2 & 0.02 & 0.84 \\
\hline 10 & $1.05 E+01$ & $1.00 E+01$ & $1.41 E+10$ & 12.9 & 0.02 & 0.82 \\
\hline 11 & $1.00 E+01$ & $9.50 E+\infty 0$ & $2.03 E+10$ & 11.5 & 0.03 & 0.81 \\
\hline 12 & $9.50 E+\infty 0$ & $9.00 E+\infty$ & $2.91 E+10$ & 10 & 0.05 & 0.8 \\
\hline 13 & $9.00 E+\infty$ & $8.50 E+\infty$ & $4.20 \mathrm{E}+10$ & 8.5 & 0.07 & 0.78 \\
\hline 14 & $8.50 E+\infty 0$ & $8.00 E+\infty$ & $6.06 E+10$ & 7.2 & 0.1 & 0.76 \\
\hline 16 & $8.00 E+00$ & $7.50 E+\infty$ & $8.73 E+10$ & 6.4 & 0.14 & 0.75 \\
\hline 16 & $7.50 E+\infty 0$ & $7.00 E+\infty$ & $1.25 E+11$ & 6 & 0.2 & 0.73 \\
\hline 17 & $7.00 E+\infty$ & $6.50 E+\infty$ & $1.80 E+11$ & 6 & 0.29 & 0.72 \\
\hline 18 & $6.50 E+\infty 0$ & $6.00 E+\infty 0$ & $2.57 E+11$ & 6 & 0.41 & 0.7 \\
\hline 19 & $6.00 E+\infty 0$ & $5.50 E+\infty$ & $3.69 E+11$ & 5.9 & 0.59 & 0.69 \\
\hline 20 & $5.50 \mathrm{E}+\infty 0$ & $5.00 E+\infty 0$ & $5.27 E+11$ & 5.7 & 0.85 & 0.68 \\
\hline 21 & $5.00 \mathrm{E}+\infty 0$ & $4.50 E+\infty$ & $7.45 E+11$ & 5.3 & 1.2 & 0.67 \\
\hline 22 & $4.50 E+\infty 0$ & $4.00 E+\infty 0$ & $1.04 E+12$ & 4.9 & 1.67 & 0.66 \\
\hline 23 & $4.00 E+\infty 0$ & $3.50 E+\infty 0$ & $1.46 E+12$ & 4.5 & 2.34 & 0.66 \\
\hline 24 & $3.50 E+\infty 0$ & $3.00 E+\infty$ & $2.08 E+12$ & 4.1 & 3.33 & 0.65 \\
\hline 26 & $3.00 E+\infty 0$ & $2.50 E+\infty$ & $3.03 E+12$ & 3.6 & 4.86 & 0.66 \\
\hline 26 & $2.50 \mathrm{E}+\infty 0$ & $2.00 E+\infty$ & $4.40 E+12$ & 3 & 7.06 & 0.66 \\
\hline 27 & $2.00 E+\infty$ & $1.50 E+\infty$ & $6.30 E+12$ & 2.4 & 10.1 & 0.67 \\
\hline 28 & $1.50 E+\infty 0$ & $1.00 E+\infty$ & $9.19 E+12$ & 3.2 & 14.75 & 0.69 \\
\hline 28 & $1.00 E+\infty$ & 8.21E-01 & $1.06 E+13$ & 3.4 & 17.06 & 0.7 \\
\hline 30 & 8.21E-01 & 4.98E-01 & $1.41 E+13$ & 4.4 & 22.58 & 0.72 \\
\hline 31 & 4.98E-01 & $3.02 E-01$ & $1.67 E+13$ & 5.2 & 26.81 & 0.73 \\
\hline 32 & $3.02 E-01$ & 1.11E-01 & $2.02 E+13$ & 6.4 & 32.47 & 0.75 \\
\hline 33 & 1.11E-01 & 5.25E-02 & $2.22 E+13$ & 6.9 & 35.63 & 0.76 \\
\hline 34 & 5.25E-02 & $2.48 E-02$ & $2.40 E+13$ & 7.3 & 38.42 & 0.77 \\
\hline 36 & $2.48 E-02$ & $1.50 E-02$ & $2.51 E+13$ & 7.4 & 40.25 & 0.78 \\
\hline 36 & $1.50 E-02$ & $9.12 E-03$ & $2.62 E+13$ & 7.5 & 42.03 & 0.79 \\
\hline 37 & $9.12 E-03$ & $5.53 E-03$ & $2.72 E+13$ & 7.5 & 43.69 & 0.79 \\
\hline 38 & 5.53E-03 & $1.23 E-03$ & $3.04 E+13$ & 7.4 & 48.81 & 0.81 \\
\hline 39 & $1.23 E-03$ & 4.54E-O4 & $3.25 E+13$ & 7.3 & 52.1 & 0.81 \\
\hline 40 & 4.54E-04 & 2.75E-04 & $3.35 E+13$ & 7.1 & 53.74 & 0.82 \\
\hline 41 & 2.75E-04 & 2.14E-04 & $3.40 E+13$ & 7 & 54.56 & 0.82 \\
\hline 42 & 2.14E-04 & 1.01E-04 & 3.55E+13 & 6.7 & 56.95 & 0.82 \\
\hline 43 & $1.01 E-04$ & 2.90E-05 & $3.81 E+13$ & 6.2 & 61.08 & 0.83 \\
\hline 4 & 2.90E-05 & $6.48 E-06$ & $4.12 E+13$ & 5.6 & 66.07 & 0.85 \\
\hline 46 & $6.48 E-06$ & 3.93E-06 & $4.21 E+13$ & 5.5 & 67.58 & 0.85 \\
\hline 46 & $3.93 E-06$ & $3.06 E-06$ & $4.26 E+13$ & 5.4 & 68.38 & 0.85 \\
\hline 47 & $3.06 E-06$ & $1.86 E-06$ & $4.36 E+13$ & 5.3 & 69.98 & 0.86 \\
\hline 48 & $1.86 E-06$ & $1.13 E-06$ & $4.46 E+13$ & 5.2 & 71.57 & 0.86 \\
\hline 49 & 1.13E-06 & 5.32E-07 & $4.61 E+13$ & 4.9 & 74.01 & 0.86 \\
\hline 60 & 5.32E-07 & 4.14E-07 & $4.67 E+13$ & 4.9 & 74.85 & 0.87 \\
\hline 61 & 4.14E-07 & 1.00E-10 & $6.23 E+13$ & 6.7 & 100 & 0.9 \\
\hline
\end{tabular}



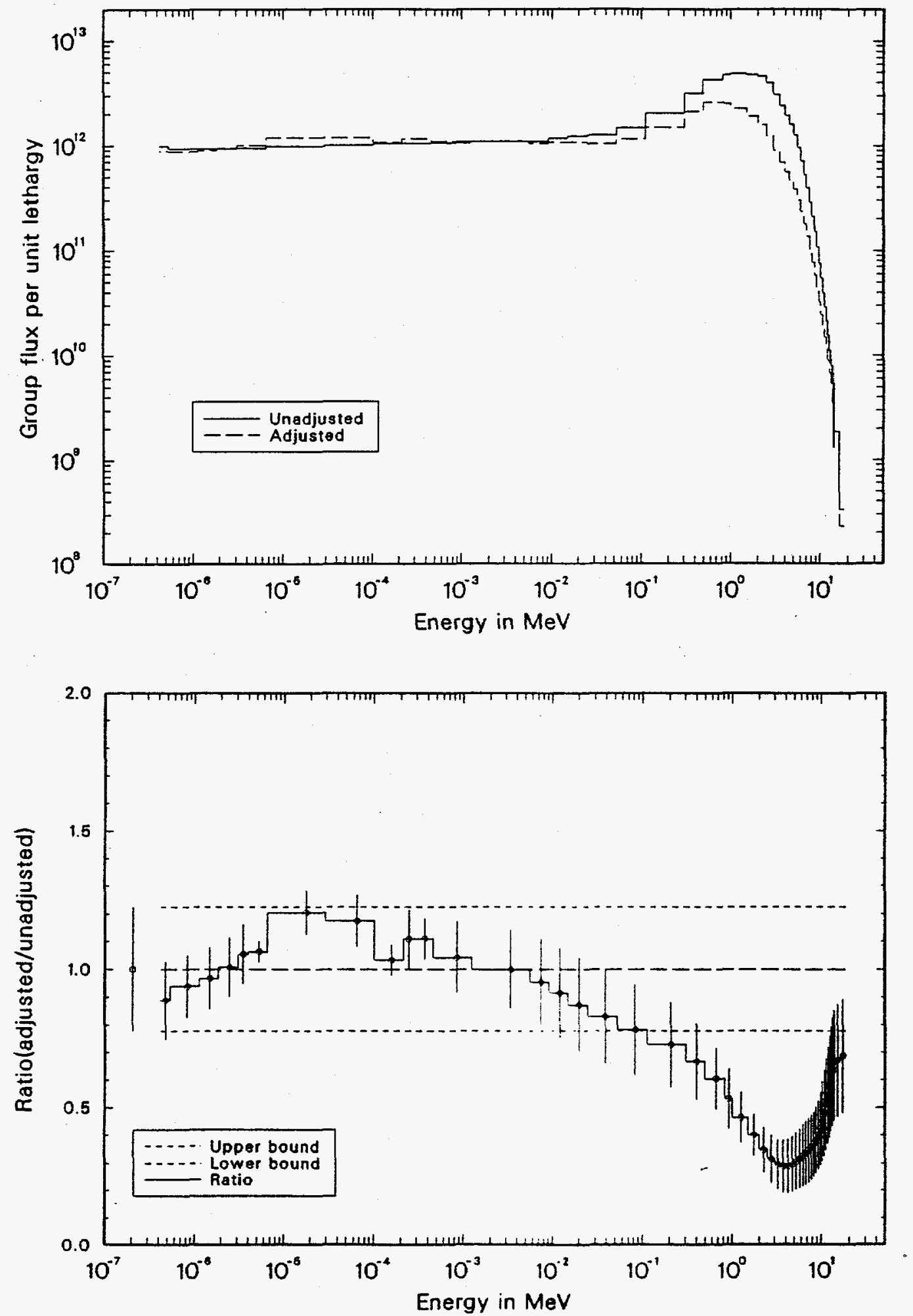

Figure B3. Upper part of figure compares adjusted and unadjusted (input) group fluence rates for B-11 location and lower part displays the ratio of adjusted-to-unadjusted group values with input uncertainty bounds and final uncertainty error bars. 
Table B5. Adjusted group fluence rates for B-11 irradiation location.

\begin{tabular}{|c|c|c|c|c|c|c|c|}
\hline GROUP & $\mathbf{E U}$ & EL & DU & PHA & UNCA & FRPHA & RPH \\
\hline 1 & $1.80 E+01$ & $1.60 E+01$ & 0.118 & $2.71 E+07$ & 20.6 & 0 & 0.69 \\
\hline 2 & $1.60 \mathrm{E}+01$ & $1.40 E+01$ & 0.134 & $1.68 \mathrm{E}+08$ & 20.3 & 0 & 0.67 \\
\hline 3 & $1.40 E+01$ & 1.35E+01 & 0.036 & $1.28 E+08$ & 20 & 0 & 0.65 \\
\hline 4 & 1.35E+01 & $1.30 E+01$ & 0.038 & $1.89 E+08$ & 19.6 & 0 & 0.63 \\
\hline 5 & 1.30E+01 & $1.25 E+01$ & 0.039 & $2.67 E+08$ & 19.1 & 0 & 0.6 \\
\hline 6 & $1.25 E+01$ & $1.20 E+01$ & 0.041 & $3.66 \mathrm{E}+08$ & 18.4 & 0 & 0.58 \\
\hline 7 & $1.20 \mathrm{E}+01$ & $1.15 E+01$ & 0.043 & $4.95 E+08$ & 17.6 & 0 & 0.54 \\
\hline 8 & $1.15 E+01$ & $1.10 E+01$ & 0.044 & $6.63 E+08$ & 16.6 & 0 & 0.51 \\
\hline 8 & $1.10 E+01$ & $1.05 E+01$ & 0.047 & $8.86 E+08$ & 15.5 & 0 & 0.48 \\
\hline 10 & $1.05 E+01$ & $1.00 E+01$ & 0.049 & $1.20 E+09$ & 14.3 & 0 & 0.45 \\
\hline 11 & $1.00 E+01$ & $9.50 E+\infty 0$ & 0.051 & 1.67E+09 & 13.2 & 0.01 & 0.43 \\
\hline 12 & $9.50 E+\infty 0$ & $9.00 E+00$ & 0.054 & $2.34 E+09$ & 12.4 & 0.01 & 0.4 \\
\hline 13 & $9.00 E+\infty 0$ & $8.50 E+\infty 0$ & 0.057 & $3.31 E+09$ & 11.9 & 0.01 & 0.38 \\
\hline 14 & $8.50 E+\infty 0$ & $8.00 E+\infty$ & 0.061 & $4.71 E+09$ & 11.7 & 0.02 & 0.37 \\
\hline 16 & $8.00 E+\infty 0$ & $7.50 \mathrm{E}+\infty 0$ & 0.065 & $6.68 E+09$ & 11.8 & 0.02 & 0.36 \\
\hline 16 & $7.50 E+\infty 0$ & $7.00 E+\infty 0$ & 0.069 & $9.42 E+\infty 9$ & 11.8 & 0.03 & 0.35 \\
\hline 17 & $7.00 E+\infty 0$ & $6.50 E+\infty 0$ & 0.074 & $1.33 E+10$ & 11.6 & 0.05 & 0.34 \\
\hline 18 & $6.50 E+\infty$ & $6.00 E+\infty$ & 0.08 & $1.88 E+10$ & 11.3 & 0.07 & 0.33 \\
\hline 19 & $6.00 E+\infty$ & $5.50 E+\infty 0$ & 0.087 & $2.65 E+10$ & 10.8 & 0.09 & 0.32 \\
\hline 20 & $5.50 E+\infty$ & $5.00 E+00$ & 0.095 & $3.68 E+10$ & 10.4 & 0.13 & 0.31 \\
\hline 21 & $5.00 E+\infty$ & $4.50 E+00$ & 0.105 & $4.99 E+10$ & 10.2 & 0.18 & 0.3 \\
\hline 22 & $4.50 \mathrm{E}+\infty$ & $4.00 E+\infty 0$ & 0.118 & $6.69 E+10$ & 10 & 0.24 & 0.29 \\
\hline 23 & $4.00 E+\infty$ & $3.50 E+\infty 0$ & 0.134 & $9.34 E+10$ & 9.6 & 0.33 & 0.29 \\
\hline 24 & $3.50 E+\infty$ & $3.00 E+\infty 0$ & 0.154 & $1.40 E+11$ & 9.1 & 0.5 & 0.29 \\
\hline 26 & $3.00 E+\infty$ & $2.50 E+\infty 0$ & 0.182 & $2.27 E+11$ & 8.7 & 0.8 & 0.31 \\
\hline 26 & $2.50 E+\infty 0$ & $2.00 E+\infty 0$ & 0.223 & $3.56 E+11$ & 8.2 & 1.26 & 0.35 \\
\hline 27 & $2.00 E+\infty 0$ & $1.50 E+\infty 0$ & 0.288 & $5.51 E+11$ & 7.5 & 1.95 & 0.4 \\
\hline 28 & $1.50 E+\infty 0$ & $1.00 E+\infty$ & 0.405 & $9.22 E+11$ & 9.1 & 3.26 & 0.46 \\
\hline 29 & $1.00 E+\infty 0$ & 8.21E-01 & 0.197 & $4.99 E+11$ & 10.8 & 1.76 & 0.53 \\
\hline 30 & 8.21E-01 & 4.98E-01 & 0.5 & $1.30 E+12$ & 11.1 & 4.58 & 0.6 \\
\hline 31 & 4.98E-01 & $3.02 E-01$ & 0.5 & $1.06 E+12$ & 13.8 & 3.73 & 0.67 \\
\hline 32 & $3.02 E-01$ & 1.11E-01 & 1 & $1.48 E+12$ & 15.4 & 5.24 & 0.73 \\
\hline 33 & 1.11E-01 & $5.25 E-02$ & 0.75 & $8.65 E+11$ & 16.6 & 3.06 & 0.78 \\
\hline 34 & $5.25 E-02$ & $2.48 E-02$ & 0.75 & $7.91 E+11$ & 17.3 & 2.79 & 0.83 \\
\hline 36 & $2.48 E-02$ & $1.50 E-02$ & 0.5 & 5.37E+11 & 17.4 & 1.9 & 0.87 \\
\hline 36 & $1.50 E-02$ & $9.12 \mathrm{E}-03$ & 0.5 & $5.40 E+11$ & 16.6 & 1.91 & 0.91 \\
\hline 37 & $9.12 E-03$ & $5.53 E-03$ & 0.5 & $5.22 \mathrm{E}+11$ & 15.6 & 1.84 & 0.95 \\
\hline 38 & $5.53 E-03$ & $1.23 E-03$ & 1.5 & $1.67 E+12$ & 14.3 & 5.9 & 1 \\
\hline 39 & $1.23 E-03$ & $4.54 E-04$ & 1 & $1.11 E+12$ & 12.9 & 3.93 & 1.04 \\
\hline 40 & 4.54E-04 & 2.75E-04 & 0.5 & $5.88 E+11$ & 7.3 & 2.08 & 1.11 \\
\hline 41 & 2.75E-04 & $2.14 E-04$ & 0.25 & $2.93 E+11$ & 10.5 & 1.04 & 1.11 \\
\hline 42 & $2.14 E-04$ & $1.01 E-04$ & 0.75 & $8.09 E+11$ & 5.5 & 2.86 & 1.03 \\
\hline 43 & $1.01 E-04$ & 2.90E-05 & 1.25 & $1.50 E+12$ & 9.3 & 5.29 & 1.17 \\
\hline 4 & 2.90E-05 & $6.48 E-06$ & 1.5 & $1.80 E+12$ & 7.9 & 6.36 & 1.2 \\
\hline 46 & $6.48 E-06$ & $3.93 E-06$ & 0.5 & $5.05 E+11$ & 3.7 & 1.78 & 1.06 \\
\hline 46 & $3.93 E-06$ & $3.06 E-06$ & 0.25 & $2.53 E+11$ & 10.6 & 0.89 & 1.06 \\
\hline 47 & $3.06 E-06$ & $1.86 E-06$ & 0.5 & 4.77E+11 & 10.6 & 1.69 & 1.01 \\
\hline 48 & $1.86 E-06$ & $1.13 E-06$ & 0.5 & $4.53 E+11$ & 11.1 & 1.6 & 0.97 \\
\hline 49 & $1.13 E-06$ & 5.32E-07 & 0.75 & $6.64 E+11$ & 11.3 & 2.34 & 0.94 \\
\hline 50 & 5.32E-07 & 4.14E-07 & 0.25 & $2.22 E+11$ & 14 & 0.78 & 0.89 \\
\hline 51 & 4.14E-07 & $1.00 \mathrm{E}-10$ & 8.328 & $7.84 E+12$ & 22.4 & 27.7 & 1 \\
\hline
\end{tabular}


Table B6. Cumulative Adjusted group fluence rates for B-11 irradiation location.

\begin{tabular}{|c|c|c|c|c|c|c|}
\hline GROUP & $\mathbf{E U}$ & EL & CPHA & UNCA & FRCPHA & RCPH \\
\hline 1 & $1.80 \mathrm{E}+01$ & $1.60 \mathrm{E}+01$ & $2.71 E+07$ & 20.6 & 0 & 0.69 \\
\hline 2 & $1.60 \mathrm{E}+01$ & $1.40 E+01$ & $1.95 E+08$ & 19.8 & 0 & 0.67 \\
\hline 3 & $1.40 E+01$ & $1.35 E+01$ & $3.23 E+08$ & 18.9 & 0 & 0.66 \\
\hline 4 & 1.35E+01 & $1.30 \mathrm{E}+01$ & $5.12 E+08$ & 18.1 & 0 & 0.65 \\
\hline 5 & $1.30 E+01$ & $1.25 E+01$ & $7.79 E+08$ & 17.4 & 0 & 0.63 \\
\hline 6 & $1.25 E+01$ & $1.20 \mathrm{E}+01$ & $1.15 E+09$ & 16.6 & 0 & 0.61 \\
\hline 7 & $1.20 E+01$ & $1.15 E+01$ & $1.64 E+09$ & 15.7 & 0.01 & 0.59 \\
\hline 8 & $1.15 E+01$ & $1.10 E+01$ & 2.30E+09 & 14.7 & 0.01 & 0.57 \\
\hline 8 & $1.10 E+01$ & $1.05 E+01$ & $3.19 E+09$ & 13.5 & 0.01 & 0.54 \\
\hline 10 & $1.05 E+01$ & $1.00 E+01$ & $4.39 E+09$ & 12.3 & 0.02 & 0.51 \\
\hline 11 & $1.00 E+01$ & $9.50 \mathrm{E}+\infty 0$ & $6.05 E+09$ & 10.9 & 0.02 & 0.49 \\
\hline 12 & $9.50 E+\infty 0$ & $9.00 E+\infty 0$ & $8.40 E+\infty 9$ & 9.4 & 0.03 & 0.46 \\
\hline 13 & $9.00 E+\infty$ & $8.50 E+\infty 0$ & $1.17 E+10$ & 8 & 0.04 & 0.43 \\
\hline 14 & $8.50 E+\infty$ & $8.00 E+\infty 0$ & $1.64 E+10$ & 6.9 & 0.06 & 0.41 \\
\hline 16 & $8.00 E+\infty$ & $7.50 E+\infty 0$ & 2.31E+10 & 6.2 & 0.08 & 0.39 \\
\hline 16 & $7.50 E+\infty$ & $7.00 E+\infty 0$ & $3.25 E+10$ & 6 & 0.11 & 0.38 \\
\hline 17 & $7.00 E+\infty 0$ & $6.50 \mathrm{E}+\infty 0$ & $4.58 E+10$ & 6 & 0.16 & 0.37 \\
\hline 18 & $6.50 E+\infty$ & $6.00 E+\infty 0$ & $6.46 E+10$ & 6 & 0.23 & 0.35 \\
\hline 19 & $6.00 E+\infty$ & $5.50 \mathrm{E}+\infty 0$ & $9.11 E+10$ & 5.9 & 0.32 & 0.34 \\
\hline 20 & $5.50 E+\infty$ & $5.00 E+\infty 0$ & $1.28 E+11$ & 5.6 & 0.45 & 0.33 \\
\hline 21 & $5.00 E+\infty$ & $4.50 E+\infty 0$ & $1.78 \mathrm{E}+11$ & 5.2 & 0.63 & 0.32 \\
\hline 22 & $4.50 E+\infty$ & $4.00 E+\infty 0$ & $2.45 E+11$ & 4.9 & 0.86 & 0.31 \\
\hline 23 & $4.00 E+\infty$ & $3.50 E+\infty 0$ & $3.38 E+11$ & 4.6 & 1.19 & 0.3 \\
\hline 24 & $3.50 E+\infty$ & $3.00 E+\infty$ & $4.78 E+11$ & 4.1 & 1.69 & 0.3 \\
\hline 25 & $3.00 E+00$ & $2.50 E+\infty 0$ & $7.05 E+11$ & 3.7 & 2.49 & 0.3 \\
\hline 26 & $2.50 E+\infty 0$ & $2.00 E+\infty 0$ & $1.06 \mathrm{E}+12$ & 3.2 & 3.75 & 0.32 \\
\hline 27 & $2.00 E+00$ & $1.50 E+\infty 0$ & $1.61 E+12$ & 2.5 & 5.69 & 0.34 \\
\hline 28 & $1.50 \mathrm{E}+\infty$ & $1.00 E+\infty$ & $2.53 E+12$ & 3.4 & 8.95 & 0.38 \\
\hline 29 & $1.00 E+\infty$ & 8.21E-01 & $3.03 E+12$ & 3.6 & 10.71 & 0.4 \\
\hline 30 & 8.21E-01 & $4.98 E-01$ & $4.33 E+12$ & 4.6 & 15.29 & 0.44 \\
\hline 31 & 4.98E-01 & $3.02 E-01$ & $5.39 E+12$ & 5.5 & 19.03 & 0.47 \\
\hline 32 & $3.02 E-01$ & 1.11E-01 & $6.87 E+12$ & 6.8 & 24.26 & 0.51 \\
\hline 33 & $1.11 E-01$ & $5.25 E-02$ & $7.74 E+12$ & 7.4 & 27.32 & 0.53 \\
\hline 34 & $5.25 E-02$ & $2.48 E-02$ & $8.53 E+12$ & 7.8 & 30.11 & 0.55 \\
\hline 36 & $2.48 E-02$ & $1.50 \mathrm{E}-02$ & $9.06 E+12$ & 8 & 32.01 & 0.56 \\
\hline 36 & $1.50 \mathrm{E}-02$ & $9.12 E-03$ & $9.60 E+12$ & 8.2 & 33.92 & 0.58 \\
\hline 37 & $9.12 E-03$ & 5.53E-03 & $1.01 E+13$ & 8.2 & 35.76 & 0.59 \\
\hline 38 & $5.53 E-03$ & $1.23 E-03$ & $1.18 E+13$ & 8.1 & 41.66 & 0.62 \\
\hline 39 & $1.23 E-03$ & 4.54E-04 & $1.29 \mathrm{E}+13$ & 7.8 & 45.59 & 0.65 \\
\hline 40 & $4.54 E-04$ & $2.75 E-04$ & $1.35 E+13$ & 7.5 & 47.67 & 0.66 \\
\hline 41 & $2.75 E-04$ & $2.14 E-04$ & $1.38 \mathrm{E}+13$ & 7.4 & 48.7 & 0.66 \\
\hline 42 & $2.14 E-04$ & $1.01 E-04$ & $1.46 E+13$ & 7 & 51.56 & 0.68 \\
\hline 43 & $1.01 E-04$ & 2.90E-05 & $1.61 E+13$ & 6.3 & 56.86 & 0.71 \\
\hline 44 & $2.90 E-05$ & $6.48 E-06$ & $1.79 E+13$ & 5.6 & 63.21 & 0.74 \\
\hline 45 & $6.48 E-06$ & $3.93 E-06$ & $1.84 E+13$ & 5.4 & 65 & 0.74 \\
\hline 46 & $3.93 E-06$ & $3.06 E-06$ & $1.87 E+13$ & 5.3 & 65.89 & 0.75 \\
\hline 47 & $3.06 E-06$ & $1.86 E-06$ & $1.91 E+13$ & 5.2 & 67.57 & 0.75 \\
\hline 48 & $1.86 \mathrm{E}-06$ & $1.13 E-06$ & $1.96 E+13$ & 5 & 69.18 & 0.75 \\
\hline 49 & 1.13E-06 & 5.32E-07 & $2.03 E+13$ & 4.8 & 71.52 & 0.76 \\
\hline 50 & $5.32 E-07$ & 4.14E-07 & $2.05 E+13$ & 4.8 & 72.3 & 0.76 \\
\hline 51 & $4.14 \mathrm{E}-07$ & $1.00 E-10$ & $2.83 E+13$ & 7.1 & 100 & 0.81 \\
\hline
\end{tabular}


Table H. FERRET analysis summary for ATR $H$ positions.

\begin{tabular}{|c|c|c|c|c|c|c|c|c|}
\hline $\begin{array}{c}\text { Dosimeter } \\
\text { Reaction }\end{array}$ & $\begin{array}{c}\text { Measured } \\
\text { Rate } \\
\text { (Bq/atom) }\end{array}$ & $\begin{array}{c}\sigma \\
(\%)\end{array}$ & $\begin{array}{c}\text { Calculated } \\
\text { Rate } \\
\text { (Bq/atom) }\end{array}$ & $\begin{array}{c}\sigma \\
(\%)\end{array}$ & $\mathbf{C} / \mathbf{M}$ & $\begin{array}{c}\text { FERRET-Fit } \\
\text { Rate } \\
\text { (Bq/atom) } \\
\end{array}$ & $\begin{array}{c}\sigma \\
(\%)\end{array}$ & FF/M \\
\hline $45 \operatorname{Sc}(n, \gamma)$ & $2.99 \mathrm{E}-11$ & 2 & $\begin{array}{c}\text { H-2 } \\
2.24 \mathrm{E}-11\end{array}$ & 19.4 & 0.75 & $2.99 \mathrm{E}-11$ & 5.4 & 1 \\
\hline 197Au(n,y) & $3.66 \mathrm{E}-09$ & 2 & $2.98 \mathrm{E}-09$ & 21.8 & 0.815 & $3.67 \mathrm{E}-09$ & 4.3 & 1 \\
\hline $235 U(n, f)$ & $7.42 \mathrm{E}-10$ & 2.3 & $5.67 \mathrm{E}-10$ & 17.3 & 0.765 & $7.38 \mathrm{E}-10$ & 3 & 0.99 \\
\hline $59 \operatorname{Co}(n, \gamma)$ & $1.86 \mathrm{E}-10$ & 2 & $1.48 \mathrm{E}-10$ & 20.9 & 0.798 & $1.86 \mathrm{E}-10$ & 5.4 & 1 \\
\hline $\operatorname{s8Fe}(n, \gamma)$ & $3.43 \mathrm{E}-12$ & 2 & $2.60 \mathrm{E}-12$ & 18 & 0.759 & $3.43 E-12$ & 4.9 & 1 \\
\hline $237 \mathrm{~Np}(\mathrm{n}, \mathrm{f})$ & $3.40 \mathrm{E}-11$ & 2 & $3.00 \mathrm{E}-11$ & 20.4 & 0.881 & $3.41 \mathrm{E}-11$ & 4.9 & 1 \\
\hline $238 U(n, f)$ & 6.17E-12 & 2 & $5.41 \mathrm{E}-12$ & 18.6 & 0.876 & $6.06 \mathrm{E}-12$ & 2.4 & 0.98 \\
\hline 47Ti(n,p) & $3.23 E-13$ & 2 & $3.56 E-13$ & 21.1 & 1.103 & $3.31 \mathrm{E}-13$ & 3 & 1.02 \\
\hline 58Ni(n,p) & $1.85 \mathrm{E}-12$ & 2 & $1.61 \mathrm{E}-12$ & 19.1 & 0.872 & $1.84 \mathrm{E}-12$ & 3.4 & 1 \\
\hline $54 F e(n, p)$ & 1.35E-12 & 2 & $1.23 \mathrm{E}-12$ & 18.4 & 0.909 & $1.35 \mathrm{E}-12$ & 3.6 & 1 \\
\hline 46Ti(n,p) & $1.81 \mathrm{E}-13$ & 2 & $1.56 \mathrm{E}-13$ & 21.9 & 0.86 & $1.80 \mathrm{E}-13$ & 5.2 & 1 \\
\hline $63 \mathrm{Cu}(\mathrm{n}, \alpha)$ & $8.88 \mathrm{E}-15$ & 3 & $7.55 \mathrm{E}-15$ & 17.9 & 0.85 & $8.63 E-15$ & 4.8 & 0.97 \\
\hline 48Ti(n,p) & $4.39 \mathrm{E}-15$ & 2 & $3.77 \mathrm{E}-15$ & 20.2 & 0.858 & $4.46 \mathrm{E}-15$ & 5.4 & 1.01 \\
\hline $27 \mathrm{Al}(\mathrm{n}, \alpha)$ & $1.05 \mathrm{E}-14$ & 5.6 & $\begin{array}{c}\text { 9.54E-15 } \\
\text { H-10 }\end{array}$ & 18.7 & 0.909 & $1.03 \mathrm{E}-14$ & 6.1 & 0.98 \\
\hline $45 \operatorname{Sc}(n, \gamma)$ & $3.20 \mathrm{E}-11$ & 2 & $2.24 E-11$ & 19.4 & 0.701 & $3.20 \mathrm{E}-11$ & 5.4 & 1 \\
\hline 197Au(n,y) & $3.80 \mathrm{E}-09$ & 2 & $2.98 \mathrm{E}-09$ & 21.8 & 0.785 & $3.81 E-09$ & 4.3 & 1 \\
\hline $235 U(n, f)$ & $7.78 \mathrm{E}-10$ & 2.3 & $5.67 \mathrm{E}-10$ & 17.3 & 0.729 & $7.71 \mathrm{E}-10$ & 3 & 0.99 \\
\hline $59 \mathrm{Co}(\mathrm{n}, \gamma)$ & $1.81 \mathrm{E}-10$ & 2 & $1.48 \mathrm{E}-10$ & 20.9 & 0.82 & $1.82 \mathrm{E}-10$ & 5.3 & 1 \\
\hline $\operatorname{s8Fe}(n, \gamma)$ & $3.65 E-12$ & 2 & $2.60 \mathrm{E}-12$ & 18 & 0.713 & $3.64 E-12$ & 4.9 & 1 \\
\hline $237 \mathrm{~Np}(\mathrm{n}, \mathrm{f})$ & $3.44 \mathrm{E}-11$ & 2 & $3.00 \mathrm{E}-11$ & 20.4 & 0.871 & $3.45 \mathrm{E}-11$ & 4.9 & 1 \\
\hline $238 U(n, f)$ & $6.18 E-12$ & 2 & $5.41 \mathrm{E}-12$ & 18.6 & 0.875 & $6.24 \mathrm{E}-12$ & 2.3 & 1.01 \\
\hline 47Ti(n,p) & $3.60 \mathrm{E}-13$ & 2 & $3.56 \mathrm{E}-13$ & 21.1 & 0.99 & $3.48 \mathrm{E}-13$ & 3 & 0.97 \\
\hline $58 \mathrm{Ni}(\mathrm{n}, p)$ & $1.94 \mathrm{E}-12$ & 2 & $1.61 \mathrm{E}-12$ & 19.1 & 0.832 & $1.95 E-12$ & 3.5 & 1 \\
\hline $54 F e(n, p)$ & $1.41 \mathrm{E}-12$ & 2 & $1.23 \mathrm{E}-12$ & 18.4 & 0.87 & $1.43 \mathrm{E}-12$ & 3.6 & 1.01 \\
\hline 46Ti(n,p) & $1.87 \mathrm{E}-13$ & 2 & $1.56 \mathrm{E}-13$ & 21.9 & 0.832 & $1.88 \mathrm{E}-13$ & 5.2 & 1 \\
\hline $63 \mathrm{Cu}(\mathrm{n}, \alpha)$ & $9.09 \mathrm{E}-15$ & 3 & $7.55 \mathrm{E}-15$ & 17.9 & 0.83 & $9.05 \mathrm{E}-15$ & 4.8 & 1 \\
\hline $48 T i(n, p)$ & $4.76 \mathrm{E}-15$ & 2 & 3.77E-15 & 20.2 & 0.791 & $4.71 \mathrm{E}-15$ & 5.4 & 0.99 \\
\hline $27 \mathrm{~A}(n, \alpha)$ & $1.02 \mathrm{E}-14$ & 5.6 & $\begin{array}{c}\text { 9.54E-15 } \\
\text { H-14 }\end{array}$ & 18.7 & 0.936 & $1.09 \mathrm{E}-14$ & 6.1 & 1.07 \\
\hline $45 \operatorname{Se}(n, \gamma)$ & $2.98 \mathrm{E}-11$ & 2 & $2.24 \mathrm{E}-11$ & 19.4 & 0.753 & $2.98 \mathrm{E}-11$ & 5.4 & 1 \\
\hline $197 A u(n, \gamma)$ & $3.59 \mathrm{E}-09$ & 2 & $2.98 \mathrm{E}-09$ & 21.8 & 0.831 & $3.60 E-09$ & 4.3 & 1 \\
\hline $235 U(n, f)$ & $7.41 \mathrm{E}-10$ & 2.3 & $5.67 \mathrm{E}-10$ & 17.3 & 0.766 & $7.37 \mathrm{E}-10$ & 3 & 1 \\
\hline $59 \mathrm{Co}(\mathrm{n}, \gamma)$ & $1.83 \mathrm{E}-10$ & 2 & $1.48 \mathrm{E}-10$ & 20.9 & 0.811 & $1.83 \mathrm{E}-10$ & 5.4 & 1 \\
\hline $\operatorname{s8Fe}(n, \gamma)$ & $3.50 \mathrm{E}-12$ & 2 & $2.60 \mathrm{E}-12$ & 18 & 0.744 & $3.49 \mathrm{E}-12$ & 5 & 1 \\
\hline $237 N p(n, f)$ & $3.49 E-11$ & 2 & $3.00 \mathrm{E}-11$ & 20.4 & 0.859 & $3.47 E-11$ & 4.9 & 0.99 \\
\hline $238 \mathrm{U}(\mathrm{n}, \mathrm{f})$ & $6.01 \mathrm{E}-12$ & 2 & $5.41 \mathrm{E}-12$ & 18.6 & 0.899 & $6.04 \mathrm{E}-12$ & 2.4 & 1 \\
\hline 47Ti(n,p) & $3.29 \mathrm{E}-13$ & 2 & $3.56 \mathrm{E}-13$ & 21.1 & 1.083 & $3.34 \mathrm{E}-13$ & 3 & 1.02 \\
\hline $58 \mathrm{Ni}(\mathrm{n}, \mathrm{p})$ & $1.88 \mathrm{E}-12$ & 2 & $1.61 \mathrm{E}-12$ & 19.1 & 0.858 & $1.87 \mathrm{E}-12$ & 3.4 & 1 \\
\hline $54 F e(n, p)$ & $1.39 \mathrm{E}-12$ & 2 & $1.23 \mathrm{E}-12$ & 18.4 & 0.883 & $1.37 E-12$ & 3.6 & 0.99 \\
\hline 46Ti(n,p) & $1.80 \mathrm{E}-13$ & 2 & $1.56 \mathrm{E}-13$ & 21.9 & 0.865 & $1.80 \mathrm{E}-13$ & 5.2 & 1 \\
\hline $63 \mathrm{Cu}(\mathrm{n}, \alpha)$ & $8.35 \mathrm{E}-15$ & 3 & $7.55 \mathrm{E}-15$ & 17.9 & 0.904 & $8.58 E-15$ & 4.8 & 1.03 \\
\hline 48Ti(n,p) & $4.49 \mathrm{E}-15$ & 2 & 3.77E-15 & 20.2 & 0.839 & $4.46 \mathrm{E}-15$ & 5.4 & 0.99 \\
\hline $27 \mathrm{Al}(\mathrm{n}, \alpha)$ & $1.04 \mathrm{E}-14$ & 5.6 & $9.54 \mathrm{E}-15$ & 18.7 & 0.918 & $1.03 E-14$ & 6.1 & 0.99 \\
\hline
\end{tabular}



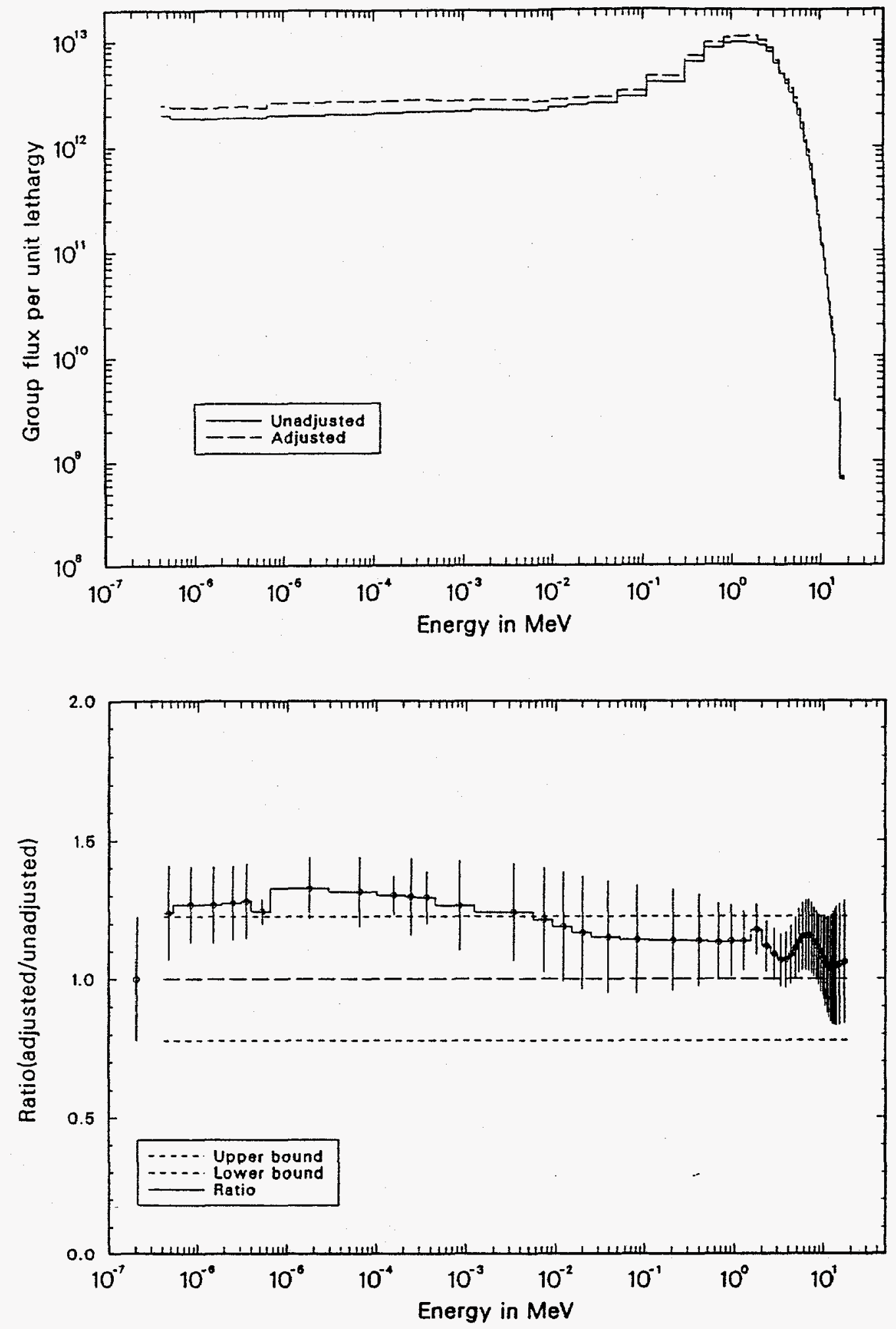

Figure H1. Upper part of figure compares adjusted and unadjusted (input) group fluence rates for $\mathrm{H}-2$ location and lower part displays the ratio of adjusted-to-unadjusted group values with input uncertainty bounds and final uncertainty error bars. 
Table H1. Adjusted group fluence rates for H-2 irradiation location.

\begin{tabular}{|c|c|c|c|c|c|c|c|}
\hline GROUP & EU & EL. & DU & PHA & UNCA & FRPHA & RPH \\
\hline 1 & $1.80 E+01$ & $1.60 \mathrm{E}+01$ & 0.118 & $8.38 E+07$ & 20.8 & 0 & 1.06 \\
\hline 2 & $1.60 E+01$ & $1.40 \mathrm{E}+01$ & 0.134 & $5.27 E+08$ & 20.6 & 0 & 1.05 \\
\hline 3 & $1.40 E+01$ & 1.35E+01 & 0.036 & $4.11 E+08$ & 20.4 & 0 & 1.05 \\
\hline 4 & 1.35E+01 & 1.30E+01 & 0.038 & $6.25 E+08$ & 20.2 & 0 & 1.04 \\
\hline 6 & $1.30 E+01$ & 1.25E+01 & 0.039 & $9.17 E+08$ & 19.8 & 0 & 1.04 \\
\hline 6 & $1.25 E+01$ & $1.20 E+01$ & 0.041 & $1.32 E+09$ & 19.2 & 0 & 1.04 \\
\hline 7 & $1.20 E+01$ & 1.15E+01 & 0.043 & $1.89 E+09$ & 18.5 & 0 & 1.04 \\
\hline 8 & $1.15 E+01$ & $1.10 E+01$ & 0.044 & $2.70 E+09$ & 17.6 & 0 & 1.04 \\
\hline 8 & $1.10 E+01$ & $1.05 E+01$ & 0.047 & $3.86 \mathrm{E}+09$ & 16.5 & 0 & 1.05 \\
\hline 10 & $1.05 E+01$ & $1.00 E+01$ & 0.049 & $5.63 E+09$ & 15.1 & 0.01 & 1.06 \\
\hline 11 & $1.00 E+01$ & $9.50 E+\infty$ & 0.051 & $8.40 E+09$ & 13.7 & 0.01 & 1.07 \\
\hline 12 & $9.50 E+\infty 0$ & $9.00 E+\infty$ & 0.054 & $1.27 E+10$ & 12.4 & 0.02 & 1.09 \\
\hline 13 & $9.00 E+\infty$ & 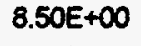 & 0.057 & $1.91 E+10$ & 11.5 & 0.02 & 1.1 \\
\hline 14 & $8.50 E+\infty$ & $8.00 E+\infty$ & 0.061 & $2.86 E+10$ & 11 & 0.04 & 1.12 \\
\hline 16 & $8.00 E+\infty 0$ & $7.50 E+\infty$ & 0.065 & $4.24 E+10$ & 11 & 0.05 & 1.13 \\
\hline 16 & $7.50 E+\infty 0$ & $7.00 E+\infty$ & 0.069 & $6.25 E+10$ & 11.1 & 0.08 & 1.15 \\
\hline 17 & $7.00 E+\infty 0$ & $6.50 E+\infty$ & 0.074 & $9.15 E+10$ & 11.1 & 0.11 & 1.16 \\
\hline 18 & $6.50 E+\infty 0$ & $6.00 E+\infty$ & 0.08 & $1.33 E+11$ & 10.9 & 0.17 & 1.15 \\
\hline 19 & $6.00 E+\infty 0$ & $5.50 E+\infty$ & 0.087 & $1.93 E+11$ & 10.5 & 0.24 & 1.15 \\
\hline 20 & $5.50 E+\infty 0$ & $5.00 E+\infty$ & 0.095 & $2.74 E+11$ & 10.1 & 0.34 & 1.14 \\
\hline 21 & $5.00 E+\infty 0$ & $4.50 E+\infty 0$ & 0.105 & $3.75 E+11$ & 9.9 & 0.47 & 1.11 \\
\hline 22 & $4.50 E+\infty 0$ & $4.00 E+\infty 0$ & 0.118 & $5.02 E+11$ & 9.7 & 0.63 & 1.09 \\
\hline 23 & $4.00 E+\infty 0$ & $3.50 E+\infty$ & 0.134 & $6.94 E+11$ & 9.4 & 0.87 & 1.07 \\
\hline 24 & $3.50 E+\infty 0$ & $3.00 E+\infty$ & 0.154 & $1.02 E+12$ & 8.9 & 1.28 & 1.07 \\
\hline 26 & $3.00 E+\infty 0$ & $2.50 E+\infty 0$ & 0.182 & $1.58 E+12$ & 8.6 & 1.98 & 1.09 \\
\hline 26 & $2.50 E+00$ & $2.00 E+\infty$ & 0.223 & $2.29 E+12$ & 8.2 & 2.87 & 1.12 \\
\hline 27 & $2.00 E+00$ & $1.50 E+\infty 0$ & 0.288 & $3.24 E+12$ & 7.7 & 4.06 & 1.18 \\
\hline 28 & $1.50 E+\infty 0$ & $1.00 E+\infty$ & 0.405 & $4.51 E+12$ & 9.4 & 5.65 & 1.14 \\
\hline 29 & $1.00 E+00$ & 8.21E-01 & 0.197 & $2.14 E+12$ & 11.4 & 2.68 & 1.14 \\
\hline 30 & 8.21E-01 & $4.98 E-01$ & 0.5 & $4.87 E+12$ & 12.2 & 6.1 & 1.13 \\
\hline 31 & 4.98E-01 & $3.02 E-01$ & 0.5 & $3.61 E+12$ & 14.6 & 4.52 & 1.14 \\
\hline 32 & $3.02 E-01$ & 1.11E-01 & 1 & $4.64 E+12$ & 16.1 & 5.82 & 1.14 \\
\hline 33 & 1.11E-01 & $5.25 \mathrm{E}-02$ & 0.75 & $2.53 E+12$ & 17.1 & 3.17 & 1.14 \\
\hline 34 & 5.25E-02 & 2.48E-02 & 0.75 & $2.20 \mathrm{E}+12$ & 17.6 & 2.75 & 1.15 \\
\hline 35 & $2.48 E-02$ & $1.50 E-02$ & 0.5 & $1.44 E+12$ & 17.5 & 1.8 & 1.17 \\
\hline 36 & $1.50 E-02$ & $9.12 E-03$ & 0.5 & $1.40 E+12$ & 16.6 & 1.76 & 1.19 \\
\hline 37 & $9.12 E-03$ & 5.53E-03 & 0.5 & $1.33 E+12$ & 15.5 & 1.66 & 1.21 \\
\hline 38 & $5.53 E-03$ & $1.23 E-03$ & 1.5 & $4.15 E+12$ & 14.2 & 5.2 & 1.24 \\
\hline 39 & 1.23E-03 & 4.54E-04 & 1 & $2.70 E+12$ & 12.8 & 3.38 & 1.26 \\
\hline 40 & $4.54 E-04$ & 2.75E-04 & 0.5 & $1.37 E+12$ & 7.3 & 1.72 & 1.29 \\
\hline 41 & 2.75E-04 & $2.14 E-04$ & 0.25 & $6.86 E+11$ & 10.6 & 0.86 & 1.3 \\
\hline 42 & 2.14E-04 & 1.01E-04 & 0.75 & $2.04 E+12$ & 5.4 & 2.55 & 1.3 \\
\hline 43 & $1.01 E-04$ & 2.90E-05 & 1.25 & $3.36 E+12$ & 9.5 & 4.21 & 1.31 \\
\hline 44 & 2.90E-05 & 6.48E-06 & 1.5 & $3.96 E+12$ & 8.3 & 4.97 & 1.33 \\
\hline 46 & $6.48 E-06$ & 3.93E-06 & 0.5 & $1.18 E+12$ & 3.7 & 1.48 & 1.24 \\
\hline 46 & 3.93E-06 & $3.06 E-06$ & 0.25 & $6.14 E+11$ & 10.6 & 0.77 & 1.28 \\
\hline 47 & $3.06 E-06$ & $1.86 E-06$ & 0.5 & $1.21 \mathrm{E}+12$ & 10.5 & 1.51 & 1.27 \\
\hline 48 & $1.86 E-06$ & $1.13 E-06$ & 0.5 & $1.19 E+12$ & 10.9 & 1.49 & 1.27 \\
\hline 49 & $1.13 E-06$ & 5.32E-07 & 0.75 & $1.79 E+12$ & 10.8 & 2.25 & 1.27 \\
\hline 50 & 5.32E-07 & 4.14E-07 & 0.25 & $6.18 E+11$ & 13.7 & 0.78 & 1.24 \\
\hline 51 & 4.14E-07 & $1.00 E-10$ & 8.328 & $1.57 \mathrm{E}+13$ & 22.4 & 19.65 & 1 \\
\hline
\end{tabular}


Table H2. Cumulative adjusted group fluence rates for $\mathrm{H}-2$ irradiation location.

\begin{tabular}{|c|c|c|c|c|c|c|}
\hline GROUP & EU & $\mathbf{E L}$ & CPHA & UNCA & FRCPHA & RCPH \\
\hline 1 & $1.80 E+01$ & $1.60 E+01$ & $8.38 E+07$ & 20.8 & 0 & 1.06 \\
\hline 2 & $1.60 E+01$ & 1.40E+01 & $6.11 E+08$ & 20.1 & 0 & 1.05 \\
\hline 3 & $1.40 E+01$ & 1.35E+01 & $1.02 E+\infty 9$ & 19.3 & 0 & 1.05 \\
\hline 4 & 1.35E+01 & $1.30 E+01$ & $1.65 E+09$ & 18.6 & 0 & 1.05 \\
\hline 5 & 1.30E+01 & $1.25 E+01$ & $2.56 E+09$ & 17.9 & 0 & 1.04 \\
\hline 6 & $1.25 E+01$ & $1.20 E+01$ & $3.88 E+09$ & 17.3 & 0 & 1.04 \\
\hline 7 & $1.20 E+01$ & $1.15 E+01$ & $5.77 E+09$ & 16.5 & 0.01 & 1.04 \\
\hline 8 & $1.15 E+01$ & $1.10 E+01$ & $8.47 E+09$ & 15.6 & 0.01 & 1.04 \\
\hline 8 & $1.10 E+01$ & $1.05 E+01$ & $1.23 E+10$ & 14.6 & 0.02 & 1.04 \\
\hline 10 & $1.05 E+01$ & $1.00 E+01$ & $1.80 E+10$ & 13.4 & 0.02 & 1.05 \\
\hline 11 & $1.00 E+01$ & $9.50 \mathrm{E}+\infty 0$ & $2.64 E+10$ & 11.9 & 0.03 & 1.06 \\
\hline 12 & $9.50 E+\infty 0$ & $9.00 E+\infty 0$ & $3.90 E+10$ & 10.3 & 0.05 & 1.07 \\
\hline 13 & $9.00 E+\infty 0$ & $8.50 E+\infty 0$ & $5.81 E+10$ & 8.7 & 0.07 & 1.08 \\
\hline 14 & $8.50 E+\infty 0$ & $8.00 E+\infty 0$ & 8.67E+10 & 7.2 & 0.11 & 1.09 \\
\hline 15 & $8.00 E+00$ & $7.50 \mathrm{E}+\infty 0$ & $1.29 E+11$ & 6.2 & 0.16 & 1.1 \\
\hline 16 & $7.50 E+\infty 0$ & $7.00 E+00$ & $1.92 E+11$ & 5.7 & 0.24 & 1.12 \\
\hline 17 & $7.00 E+\infty 0$ & $6.50 E+\infty 0$ & $2.83 E+11$ & 5.7 & 0.35 & 1.13 \\
\hline 18 & $6.50 \mathrm{E}+\infty 0$ & $6.00 E+\infty 0$ & $4.16 E+11$ & 5.8 & 0.52 & 1.14 \\
\hline 19 & $6.00 E+\infty$ & $5.50 E+\infty 0$ & $6.09 E+11$ & 5.8 & 0.76 & 1.14 \\
\hline 20 & $5.50 E+\infty$ & $5.00 E+00$ & $8.83 E+11$ & 5.5 & 1.11 & 1.14 \\
\hline 21 & $5.00 E+\infty$ & $4.50 E+\infty 0$ & $1.26 E+12$ & 5.2 & 1.58 & 1.13 \\
\hline 22 & $4.50 E+\infty 0$ & $4.00 E+\infty 0$ & $1.76 E+12$ & 4.8 & 2.21 & 1.12 \\
\hline 23 & $4.00 E+\infty 0$ & $3.50 E+\infty 0$ & 2.45E+12 & 4.4 & 3.08 & 1.1 \\
\hline 24 & $3.50 E+\infty 0$ & $3.00 E+\infty 0$ & $3.47 E+12$ & 4 & 4.35 & 1.09 \\
\hline 26 & $3.00 E+\infty$ & $2.50 E+\infty 0$ & $5.05 E+12$ & 3.5 & 6.33 & 1.09 \\
\hline 26 & $2.50 E+\infty 0$ & $2.00 E+\infty 0$ & $7.34 E+12$ & 3 & 9.2 & 1.1 \\
\hline 27 & $2.00 E+00$ & $1.50 E+\infty 0$ & $1.06 E+13$ & 2.4 & 13.26 & 1.12 \\
\hline 28 & $1.50 E+\infty 0$ & $1.00 E+00$ & $1.51 E+13$ & 3.1 & 18.91 & 1.13 \\
\hline 29 & $1.00 E+\infty 0$ & 8.21E-01 & $1.72 E+13$ & 3.3 & 21.59 & 1.13 \\
\hline 30 & 8.21E-01 & 4.98E-01 & $2.21 E+13$ & 4.2 & 27.69 & 1.13 \\
\hline 31 & 4.98E-01 & $3.02 E-01$ & $2.57 E+13$ & 4.9 & 32.22 & 1.13 \\
\hline 32 & $3.02 E-01$ & $1.11 E-01$ & $3.03 E+13$ & 6 & 38.04 & 1.13 \\
\hline 33 & 1.11E-01 & $5.25 E-02$ & $3.29 E+13$ & 6.4 & 41.21 & 1.13 \\
\hline 34 & 5.25E-02 & 2.48E-02 & $3.51 E+13$ & 6.8 & 43.96 & 1.13 \\
\hline 36 & $2.48 E-02$ & $1.50 E-02$ & $3.65 E+13$ & 7 & 45.77 & 1.13 \\
\hline 36 & $1.50 E-02$ & $9.12 E-03$ & $3.79 E+13$ & 7 & 47.53 & 1.14 \\
\hline 37 & $9.12 E-03$ & 5.53E-03 & $3.92 E+13$ & 7.1 & 49.19 & 1.14 \\
\hline 38 & 5.53E-03 & $1.23 E-03$ & $4.34 E+13$ & 7 & 54.39 & 1.15 \\
\hline 38 & $1.23 E-03$ & 4.54E-04 & $4.61 E+13$ & 6.8 & 57.77 & 1.15 \\
\hline 40 & 4.54E-04 & 2.75E-04 & $4.75 E+13$ & 6.7 & 59.49 & 1.16 \\
\hline 41 & $2.75 E-04$ & 2.14E-04 & $4.81 E+13$ & 6.6 & 60.35 & 1.16 \\
\hline 42 & 2.14E-04 & 1.01E-04 & $5.02 E+13$ & 6.3 & 62.9 & 1.16 \\
\hline 43 & $1.01 E-04$ & 2.90E-05 & $5.35 E+13$ & 5.9 & 67.11 & 1.17 \\
\hline 44 & 2.90E-05 & $6.48 E-06$ & $5.75 E+13$ & 5.4 & 72.08 & 1.18 \\
\hline 48 & $6.48 E-06$ & 3.93E-06 & $5.87 E+13$ & 5.3 & 73.56 & 1.18 \\
\hline 46 & 3.93E-06 & $3.06 E-06$ & $5.93 E+13$ & 5.2 & 74.33 & 1.18 \\
\hline 47 & $3.06 E-06$ & $1.86 E-06$ & $6.05 E+13$ & 5.1 & 75.84 & 1.19 \\
\hline 48 & $1.86 E-06$ & 1.13E-06 & $6.17 E+13$ & 5 & 77.33 & 1.19 \\
\hline 49 & 1.13E-06 & 5.32E-07 & $6.35 E+13$ & 4.8 & 79.57 & 1.19 \\
\hline 50 & 5.32E-07 & 4.14E-07 & $6.41 E+13$ & 4.8 & 80.35 & 1.19 \\
\hline 61 & 4.14E-07 & 1.00E-10 & $7.98 E+13$ & 5.8 & 100 & 1.15 \\
\hline
\end{tabular}



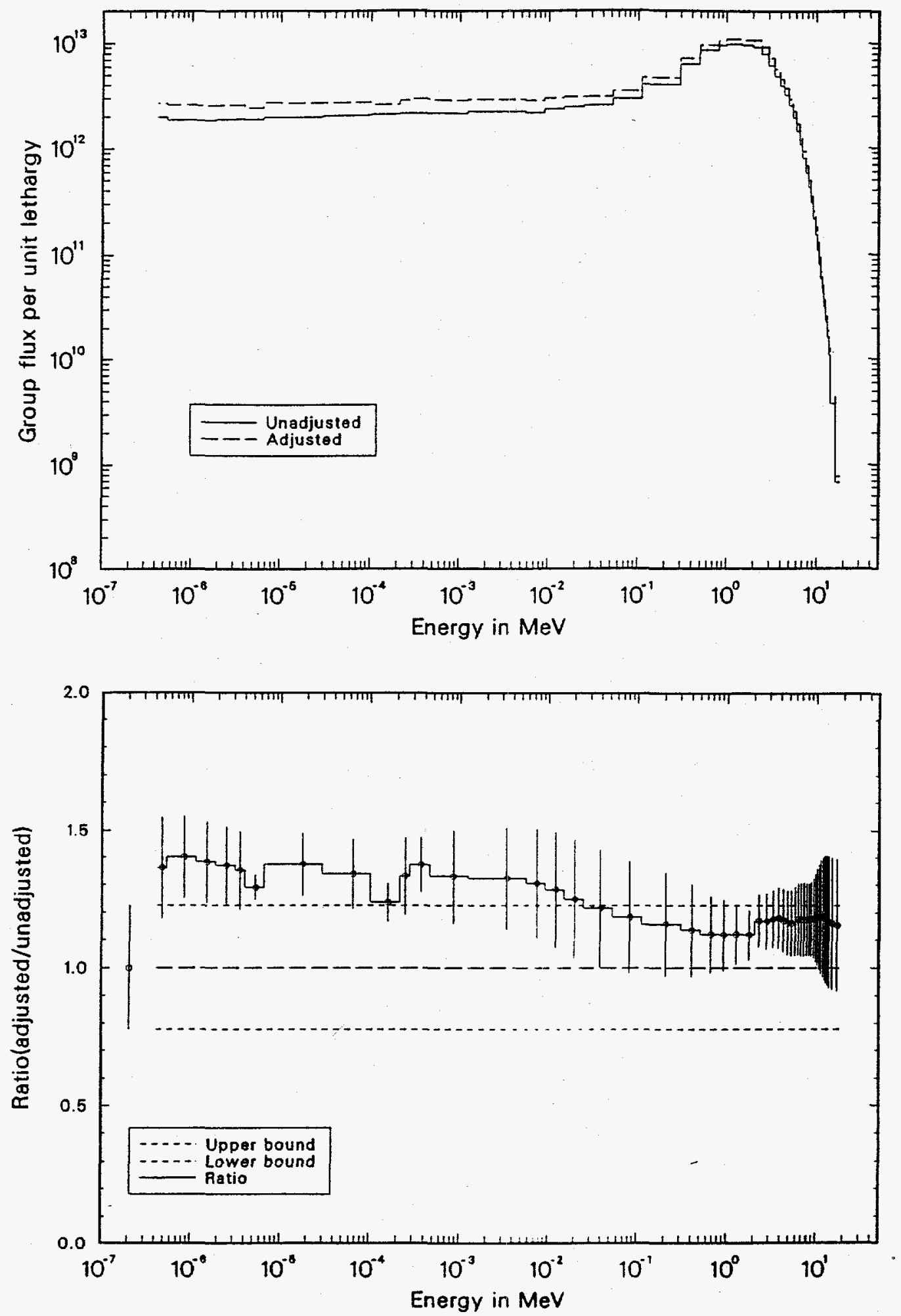

Figure H2. Upper part of figure compares adjusted and unadjusted (input) group fluence rates for H-10 location and lower part displays the ratio of adjusted-to-unadjusted group values with input uncertainty bounds and final uncertainty error bars. 
Table H3. Adjusted group fluence rates for $\mathrm{H}-10$ irradiation location.

\begin{tabular}{|c|c|c|c|c|c|c|c|}
\hline GROUP & EU & EL & DU & PHA & UNCA & FRPHA & RPH \\
\hline 1 & $1.80 E+01$ & $1.60 \mathrm{E}+01$ & 0.118 & $9.11 E+07$ & 20.8 & 0 & 1.15 \\
\hline 2 & $1.60 E+01$ & $1.40 E+01$ & 0.134 & $5.80 E+08$ & 20.6 & 0 & 1.16 \\
\hline 3 & $1.40 E+01$ & $1.35 E+01$ & 0.036 & $4.57 E+08$ & 20.4 & 0 & 1.16 \\
\hline 4 & 1.35E+01 & $1.30 E+01$ & 0.038 & $7.03 E+08$ & 20.1 & 0 & 1.17 \\
\hline 5 & 1.30E+01 & $1.25 E+01$ & 0.039 & $1.04 E+\infty 9$ & 19.7 & 0 & 1.17 \\
\hline 6 & $1.25 E+01$ & $1.20 E+01$ & 0.041 & $1.50 E+\infty 9$ & 19.1 & 0 & 1.18 \\
\hline 7 & $1.20 E+01$ & 1.15E+01 & 0.043 & $2.15 E+\infty 9$ & 18.4 & 0 & 1.18 \\
\hline 8 & $1.15 E+01$ & $1.10 E+01$ & 0.044 & $3.06 \mathrm{E}+09$ & 17.4 & 0 & 1.18 \\
\hline 9 & $1.10 E+01$ & $1.05 E+01$ & 0.047 & $4.36 E+\infty 9$ & 16.2 & 0.01 & 1.18 \\
\hline 10 & $1.05 E+01$ & $1.00 E+01$ & 0.049 & $6.28 E+09$ & 14.9 & 0.01 & 1.18 \\
\hline 11 & $1.00 E+01$ & $9.50 E+\infty 0$ & 0.051 & $9.25 E+09$ & 13.5 & 0.01 & 1.18 \\
\hline 12 & $9.50 E+\infty 0$ & $9.00 E+\infty 0$ & 0.054 & $1.37 E+10$ & 12.3 & 0.02 & 1.18 \\
\hline 13 & $9.00 E+\infty 0$ & $8.50 E+\infty 0$ & 0.057 & $2.03 E+10$ & 11.4 & 0.02 & 1.18 \\
\hline 14 & $8.50 E+\infty 0$ & $8.00 E+\infty$ & 0.061 & $3.01 E+10$ & 11.1 & 0.04 & 1.17 \\
\hline 15 & $8.00 E+\infty 0$ & $7.50 E+\infty 0$ & 0.065 & $4.40 \mathrm{E}+10$ & 11.1 & 0.05 & 1.17 \\
\hline 16 & $7.50 E+\infty 0$ & $7.00 E+\infty 0$ & 0.069 & $6.40 E+10$ & 11.3 & 0.08 & 1.17 \\
\hline 17 & $7.00 E+00$ & $6.50 E+\infty 0$ & 0.074 & $9.29 E+10$ & 11.3 & 0.11 & 1.17 \\
\hline 18 & $6.50 E+\infty 0$ & $6.00 E+\infty 0$ & 0.08 & $1.35 E+11$ & 11 & 0.17 & 1.17 \\
\hline 19 & $6.00 E+\infty 0$ & $5.50 E+\infty 0$ & 0.087 & $1.96 \mathrm{E}+11$ & 10.6 & 0.24 & 1.17 \\
\hline 20 & $5.50 E+\infty 0$ & $5.00 E+\infty$ & 0.095 & $2.80 E+11$ & 10.2 & 0.34 & 1.16 \\
\hline 21 & $5.00 E+\infty$ & $4.50 E+\infty$ & 0.105 & $3.92 E+11$ & 9.9 & 0.48 & 1.16 \\
\hline 22 & $4.50 E+\infty 0$ & $4.00 E+\infty$ & 0.118 & $5.41 E+11$ & 9.7 & 0.66 & 1.17 \\
\hline 23 & $4.00 E+\infty$ & $3.50 E+\infty$ & 0.134 & $7.65 E+11$ & 9.4 & 0.94 & 1.18 \\
\hline 24 & $3.50 E+\infty$ & $3.00 E+\infty$ & 0.154 & $1.12 E+12$ & 8.8 & 1.37 & 1.18 \\
\hline 26 & $3.00 E+\infty$ & $2.50 E+\infty 0$ & 0.182 & 1.69E+12 & 8.6 & 2.07 & 1.17 \\
\hline 26 & $2.50 E+\infty 0$ & $2.00 E+\infty 0$ & 0.223 & $2.40 E+12$ & 8.1 & 2.93 & 1.17 \\
\hline 27 & $2.00 E+\infty 0$ & $1.50 E+\infty$ & 0.288 & 3.07E+12 & 8 & 3.76 & 1.12 \\
\hline 28 & $1.50 E+\infty 0$ & $1.00 E+\infty$ & 0.405 & $4.45 E+12$ & 9.5 & 5.44 & 1.12 \\
\hline 29 & $1.00 E+\infty$ & 8.21E-01 & 0.197 & $2.10 E+12$ & 11.5 & 2.57 & 1.12 \\
\hline 30 & 8.21E-01 & 4.98E-01 & 0.5 & $4.81 E+12$ & 12.3 & 5.89 & 1.12 \\
\hline 31 & 4.98E-01 & $3.02 E-01$ & 0.5 & $3.60 \mathrm{E}+12$ & 14.7 & 4.41 & 1.14 \\
\hline 32 & $3.02 E-01$ & $1.11 E-01$ & 1 & $4.71 E+12$ & 16.1 & 5.77 & 1.16 \\
\hline 33 & 1.11E-01 & 5.25E-02 & 0.75 & $2.62 E+12$ & 17.1 & 3.21 & 1.18 \\
\hline 34 & 5.25E-02 & $2.48 E-02$ & 0.75 & $2.32 E+12$ & 17.6 & 2.84 & 1.22 \\
\hline 35 & 2.48E-02 & $1.50 E-02$ & 0.5 & $1.54 E+12$ & 17.5 & 1.88 & 1.25 \\
\hline 36 & $1.50 E-02$ & $9.12 E-03$ & 0.5 & $1.51 E+12$ & 16.6 & 1.85 & 1.28 \\
\hline 37 & $9.12 E-03$ & 5.53E-03 & 0.5 & $1.43 E+12$ & 15.5 & 1.75 & 1.3 \\
\hline 38 & 5.53E-03 & $1.23 E-03$ & 1.5 & $4.42 E+12$ & 14.2 & 5.42 & 1.32 \\
\hline 30 & 1.23E-03 & 4.54E-04 & 1 & $2.84 E+12$ & 12.8 & 3.48 & 1.33 \\
\hline 40 & 4.54E-04 & 2.75E-04 & 0.5 & $1.45 E+12$ & 7.3 & 1.78 & 1.37 \\
\hline 41 & 2.75E-04 & $2.14 E-04$ & 0.25 & $7.05 E+11$ & 10.6 & 0.86 & 1.33 \\
\hline 42 & $2.14 E-04$ & $1.01 E-04$ & 0.75 & $1.94 E+12$ & 5.5 & 2.37 & 1.24 \\
\hline 43 & $1.01 E-04$ & 2.90E-05 & 1.25 & 3.42E+12 & 9.5 & 4.19 & 1.34 \\
\hline 4 & 2.90E-05 & $6.48 E-06$ & 1.5 & 4.11E+12 & 8.4 & 5.03 & 1.37 \\
\hline 46 & $6.48 E-06$ & $3.93 E-06$ & 0.5 & $1.22 E+12$ & 3.7 & 1.5 & 1.29 \\
\hline 46 & $3.93 E-06$ & $3.06 \mathrm{E}-06$ & 0.25 & $6.49 E+11$ & 10.6 & 0.79 & 1.35 \\
\hline 47 & $3.06 E-06$ & $1.86 E-06$ & 0.5 & $1.30 E+12$ & 10.5 & 1.59 & 1.37 \\
\hline 48 & $1.86 E-06$ & $1.13 E-06$ & 0.5 & $1.30 E+12$ & 10.8 & 1.59 & 1.38 \\
\hline 49 & 1.13E-06 & 5.32E-07 & 0.75 & $1.98 E+12$ & 10.7 & 2.43 & 1.4 \\
\hline 60 & 5.32E-07 & 4.14E-07 & 0.25 & $6.81 E+11$ & 13.6 & 0.83 & 1.36 \\
\hline 51 & 4.14E-07 & $1.00 \mathrm{E}-10$ & 8.328 & $1.57 E+13$ & 22.4 & 19.2 & 1 \\
\hline
\end{tabular}


Table H4. Cumulative adjusted group fluence rates for H-10 irradiation location.

\begin{tabular}{|c|c|c|c|c|c|c|}
\hline GROUP & EU & EL & CPHA & UNCA & FRCPHA & RCPH \\
\hline 1 & $1.80 E+01$ & $1.60 E+01$ & $9.11 E+07$ & 20.8 & 0 & 1.15 \\
\hline 2 & $1.60 E+01$ & $1.40 E+01$ & $6.71 E+08$ & 20.1 & 0 & 1.16 \\
\hline 3 & $1.40 \mathrm{E}+01$ & 1.35E+01 & $1.13 E+09$ & 19.2 & 0 & 1.16 \\
\hline 4 & 1.35E+01 & $1.30 E+01$ & $1.83 E+09$ & 18.5 & 0 & 1.16 \\
\hline 5 & 1.30E+01 & $1.25 E+01$ & $2.87 E+09$ & 17.9 & 0 & 1.17 \\
\hline 6 & $1.25 E+01$ & $1.20 E+01$ & $4.37 E+\infty 9$ & 17.2 & 0.01 & 1.17 \\
\hline 7 & $1.20 E+01$ & $1.15 E+01$ & $6.52 E+09$ & 16.4 & 0.01 & 1.18 \\
\hline 8 & 1.15E+01 & $1.10 E+01$ & $9.58 E+09$ & 15.5 & 0.01 & 1.18 \\
\hline 9 & $1.10 E+01$ & $1.05 E+01$ & $1.39 E+10$ & 14.4 & 0.02 & 1.18 \\
\hline 10 & $1.05 E+01$ & $1.00 E+01$ & $2.02 E+10$ & 13.2 & 0.02 & 1.18 \\
\hline 11 & $1.00 E+01$ & $9.50 E+\infty 0$ & $2.95 E+10$ & 11.7 & 0.04 & 1.18 \\
\hline 12 & $9.50 E+\infty 0$ & $9.00 E+\infty 0$ & $4.32 E+10$ & 10.1 & 0.05 & 1.18 \\
\hline 13 & $9.00 E+\infty$ & $8.50 E+\infty 0$ & $6.35 E+10$ & 8.5 & 0.08 & 1.18 \\
\hline 14 & $8.50 E+\infty$ & $8.00 E+\infty 0$ & $9.36 E+10$ & 7.1 & 0.11 & 1.18 \\
\hline 16 & $8.00 E+\infty$ & $7.50 E+\infty 0$ & $1.38 E+11$ & 6.1 & 0.17 & 1.18 \\
\hline 16 & $7.50 E+\infty 0$ & $7.00 E+\infty 0$ & $2.02 E+11$ & 5.7 & 0.25 & 1.18 \\
\hline 17 & $7.00 E+\infty$ & $6.50 E+00$ & $2.95 E+11$ & 5.7 & 0.36 & 1.18 \\
\hline 18 & $6.50 E+\infty 0$ & $6.00 E+\infty 0$ & $4.30 E+11$ & 5.8 & 0.53 & 1.18 \\
\hline 19 & $6.00 E+\infty$ & $5.50 E+\infty 0$ & $6.25 E+11$ & 5.8 & 0.77 & 1.17 \\
\hline 20 & $5.50 E+\infty 0$ & $5.00 E+\infty 0$ & $9.05 E+11$ & 5.6 & 1.11 & 1.17 \\
\hline 21 & $5.00 E+\infty$ & $4.50 E+\infty 0$ & $1.30 E+12$ & 5.2 & 1.59 & 1.17 \\
\hline 22 & $4.50 E+\infty$ & $4.00 E+\infty 0$ & $1.84 E+12$ & 4.8 & 2.25 & 1.17 \\
\hline 23 & $4.00 E+\infty$ & $3.50 E+\infty 0$ & $2.60 E+12$ & 4.5 & 3.19 & 1.17 \\
\hline 24 & $3.50 E+\infty$ & $3.00 E+\infty 0$ & $3.73 E+12$ & 4 & 4.56 & 1.17 \\
\hline 25 & $3.00 E+\infty 0$ & $2.50 E+\infty 0$ & $5.42 E+12$ & 3.4 & 6.63 & 1.17 \\
\hline 26 & $2.50 E+\infty$ & $2.00 E+\infty$ & $7.81 E+12$ & 2.9 & 9.57 & 1.17 \\
\hline 27 & $2.00 E+\infty$ & $1.50 E+\infty$ & $1.09 E+13$ & 2.3 & 13.33 & 1.15 \\
\hline 28 & $1.50 E+\infty$ & $1.00 E+\infty 0$ & $1.53 E+13$ & 3 & 18.77 & 1.14 \\
\hline 29 & $1.00 E+\infty$ & 8.21E-01 & $1.74 E+13$ & 3.2 & 21.34 & 1.14 \\
\hline 30 & 8.21E-01 & $4.98 E-01$ & $2.22 \mathrm{E}+13$ & 4.2 & 27.24 & 1.14 \\
\hline 31 & 4.98E-01 & $3.02 E-01$ & $2.58 E+13$ & 4.9 & 31.65 & 1.14 \\
\hline 32 & $3.02 E-01$ & 1.11E-01 & $3.06 E+13$ & 6 & 37.42 & 1.14 \\
\hline 33 & $1.11 E-01$ & $5.25 E-02$ & $3.32 E+13$ & 6.5 & 40.63 & 1.14 \\
\hline 34 & 5.25E-02 & 2.48E-02 & $3.55 E+13$ & 6.8 & 43.47 & 1.15 \\
\hline 35 & 2.48E-02 & $1.50 E-02$ & $3.70 E+13$ & 7 & 45.35 & 1.15 \\
\hline 36 & $1.50 \mathrm{E}-02$ & $9.12 E-03$ & $3.86 E+13$ & 7.1 & 47.2 & 1.16 \\
\hline 37 & 9.12E-03 & 5.53E-03 & $4.00 E+13$ & 7.1 & 48.95 & 1.16 \\
\hline 38 & 5.53E-03 & $1.23 E-03$ & $4.44 E+13$ & 7.1 & 54.37 & 1.17 \\
\hline 39 & $1.23 E-03$ & 4.54E-04 & $4.72 E+13$ & 6.9 & 57.84 & 1.18 \\
\hline 40 & $4.54 E-04$ & $2.75 E-04$ & $4.87 E+13$ & 6.7 & 59.62 & 1.19 \\
\hline 41 & 2.75E-04 & $2.14 E-04$ & $4.94 E+13$ & 6.6 & 60.49 & 1.19 \\
\hline 42 & 2.14E-04 & $1.01 E-04$ & $5.13 E+13$ & 6.4 & 62.86 & 1.19 \\
\hline 43 & $1.01 E-04$ & 2.90E-05 & $5.48 E+13$ & 6 & 67.04 & 1.2 \\
\hline 4 & 2.90E-05 & $6.48 E-06$ & $5.89 E+13$ & 5.5 & 72.07 & 1.21 \\
\hline 46 & $6.48 E-06$ & 3.93E-06 & $6.01 E+13$ & 5.3 & 73.57 & 1.21 \\
\hline 46 & 3.93E-06 & $3.06 E-06$ & $6.07 E+13$ & 5.3 & 74.37 & 1.21 \\
\hline 47 & $3.06 E-06$ & $1.86 E-06$ & $6.20 E+13$ & 5.1 & 75.96 & 1.22 \\
\hline 48 & $1.86 E-06$ & $1.13 E-06$ & $6.33 E+13$ & 5 & 77.54 & 1.22 \\
\hline 49 & 1.13E-06 & 5.32E-07 & $6.53 E+13$ & 4.8 & 79.97 & 1.22 \\
\hline 50 & 5.32E-07 & 4.14E-07 & $6.60 E+13$ & 4.8 & 80.8 & 1.23 \\
\hline 51 & 4.14E-07 & $1.00 \mathrm{E}-10$ & 8.17E+13 & 5.8 & 100 & 1.17 \\
\hline
\end{tabular}



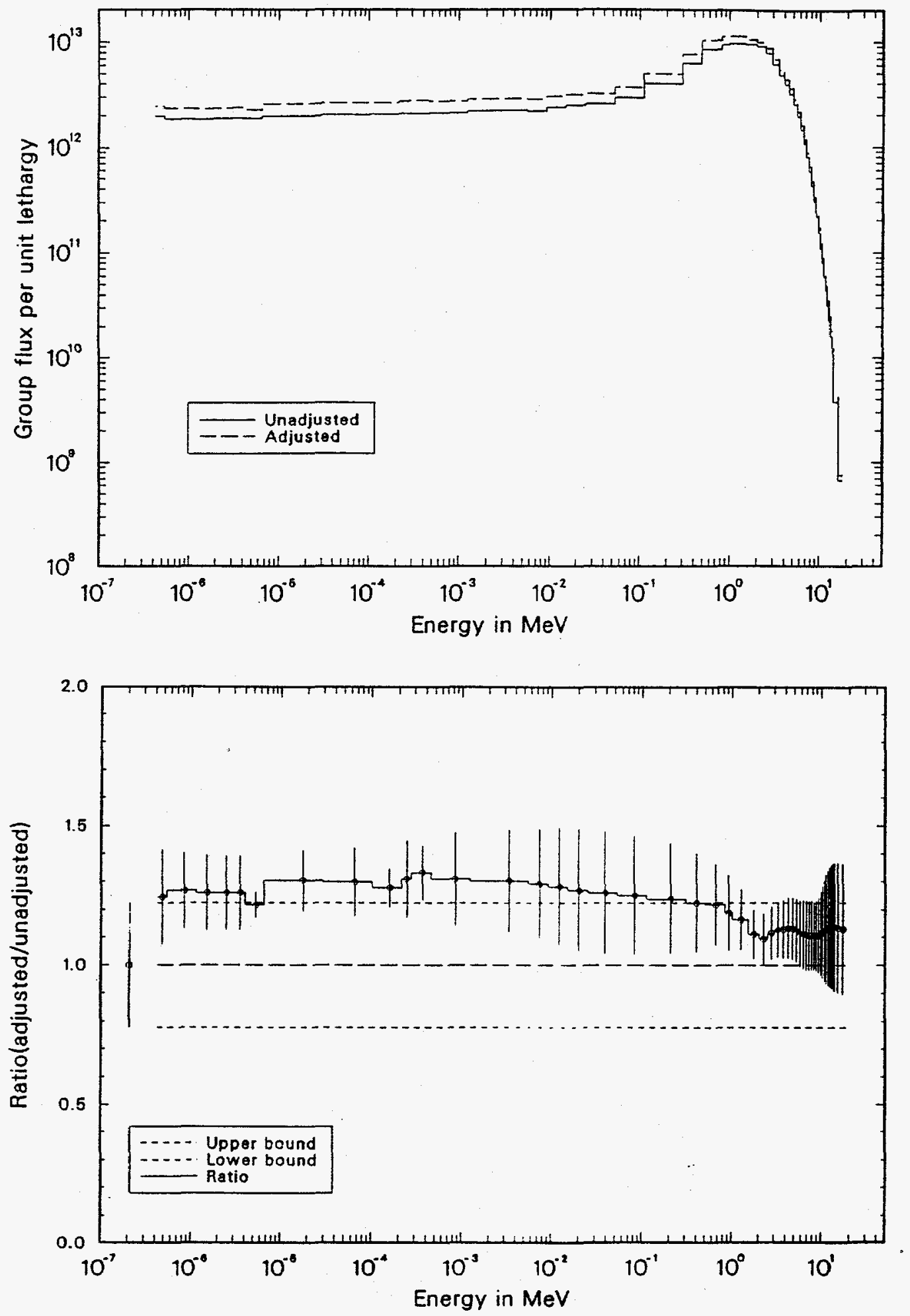

Figure H3. Upper part of figure compares adjusted and unadjusted (input) group fluence rates for H-14 location and lower part displays the ratio of adjusted-to-unadjusted group values with input uncertainty bounds and final uncertainty error bars. 
Table H5. Adjusted group fluence rates for H-14 irradiation location.

\begin{tabular}{|c|c|c|c|c|c|c|c|}
\hline GROUP & $\mathbf{E U}$ & EL & $\overline{D U}$ & PHA & UNCA & FRPHA & RPH \\
\hline 1 & $1.80 E+01$ & $1.60 E+01$ & 0.118 & $8.92 E+07$ & 20.8 & 0 & 1.13 \\
\hline 2 & $1.60 E+01$ & $1.40 E+01$ & 0.134 & $5.67 E+08$ & 20.6 & 0 & 1.13 \\
\hline 3 & $1.40 E+01$ & $1.35 E+01$ & 0.036 & $4.45 E+08$ & 20.4 & 0 & 1.14 \\
\hline 4 & 1.35E+01 & $1.30 E+01$ & 0.038 & $6.83 E+08$ & 20.1 & 0 & 1.14 \\
\hline 5 & $1.30 E+01$ & $1.25 E+01$ & 0.039 & $1.01 E+09$ & 19.6 & 0 & 1.14 \\
\hline 6 & $1.25 E+01$ & $1.20 \mathrm{E}+01$ & 0.041 & $1.45 E+09$ & 19.1 & 0 & 1.14 \\
\hline 7 & $1.20 E+01$ & $1.15 E+01$ & 0.043 & $2.06 E+09$ & 18.3 & 0 & 1.13 \\
\hline 8 & $1.15 E+01$ & $1.10 E+01$ & 0.044 & $2.92 E+09$ & 17.4 & 0 & 1.13 \\
\hline 9 & $1.10 E+01$ & $1.05 E+01$ & 0.047 & $4.14 E+09$ & 16.2 & 0.01 & 1.12 \\
\hline 10 & $1.05 E+01$ & $1.00 E+01$ & 0.049 & $5.94 E+09$ & 14.9 & 0.01 & 1.12 \\
\hline 11 & $1.00 E+01$ & $9.50 \mathrm{E}+\infty 0$ & 0.051 & $8.72 E+09$ & 13.5 & 0.01 & 1.11 \\
\hline 12 & $9.50 E+\infty 0$ & $9.00 E+00$ & 0.054 & $1.29 E+10$ & 12.3 & 0.02 & 1.11 \\
\hline 13 & $9.00 E+\infty$ & $8.50 E+\infty$ & 0.057 & $1.91 E+10$ & 11.4 & 0.02 & 1.11 \\
\hline 14 & $8.50 E+\infty 0$ & $8.00 E+\infty$ & 0.061 & $2.83 E+10$ & 11.1 & 0.03 & 1.11 \\
\hline 15 & $8.00 E+\infty 0$ & $7.50 \mathrm{E}+\infty$ & 0.065 & $4.15 E+10$ & 11.2 & 0.05 & 1.11 \\
\hline 16 & $7.50 E+\infty 0$ & $7.00 E+\infty$ & 0.069 & $6.03 E+10$ & 11.3 & 0.07 & 1.11 \\
\hline 17 & $7.00 E+\infty$ & $6.50 E+\infty$ & 0.074 & $8.76 E+10$ & 11.3 & 0.11 & 1.11 \\
\hline 18 & $6.50 E+\infty$ & $6.00 E+\infty$ & 0.08 & $1.28 E+11$ & 11 & 0.16 & 1.11 \\
\hline 19 & $6.00 E+\infty 0$ & $5.50 E+\infty$ & 0.087 & $1.87 E+11$ & 10.6 & 0.23 & 1.11 \\
\hline 20 & $5.50 E+\infty$ & $5.00 E+\infty$ & 0.095 & $2.71 E+11$ & 10.1 & 0.33 & 1.12 \\
\hline 21 & $5.00 E+\infty$ & $4.50 E+\infty 0$ & 0.105 & $3.81 E+11$ & 9.9 & 0.47 & 1.13 \\
\hline 22 & $4.50 E+\infty$ & $4.00 E+\infty 0$ & 0.118 & $5.24 E+11$ & 9.7 & 0.64 & 1.13 \\
\hline 23 & $4.00 E+\infty$ & $3.50 E+\infty$ & 0.134 & $7.33 E+11$ & 9.3 & 0.9 & 1.13 \\
\hline 24 & $3.50 E+\infty 0$ & $3.00 E+\infty$ & 0.154 & $1.07 E+12$ & 8.8 & 1.31 & 1.13 \\
\hline 25 & $3.00 E+\infty$ & $2.50 E+\infty$ & 0.182 & $1.62 \mathrm{E}+12$ & 8.6 & 1.98 & 1.12 \\
\hline 26 & $2.50 E+\infty 0$ & $2.00 E+\infty 0$ & 0.223 & $2.24 E+12$ & 8.2 & 2.74 & 1.09 \\
\hline 27 & $2.00 E+\infty 0$ & $1.50 E+\infty$ & 0.288 & $3.05 E+12$ & 7.9 & 3.73 & 1.11 \\
\hline 28 & $1.50 E+\infty 0$ & $1.00 E+\infty$ & 0.405 & $4.62 E+12$ & 9.4 & 5.65 & 1.16 \\
\hline 29 & $1.00 E+\infty 0$ & 8.21E-01 & 0.197 & $2.23 E+12$ & 11.3 & 2.73 & 1.19 \\
\hline 30 & 8.21E-01 & 4.98E-01 & 0.5 & $5.24 E+12$ & 12 & 6.4 & 1.22 \\
\hline 31 & $4.98 E-01$ & $3.02 E-01$ & 0.5 & $3.88 E+12$ & 14.4 & 4.74 & 1.22 \\
\hline 32 & $3.02 E-01$ & $1.11 E-01$ & 1 & $5.05 E+12$ & 15.9 & 6.17 & 1.24 \\
\hline 33 & 1.11E-01 & $5.25 E-02$ & 0.75 & $2.77 E+12$ & 17 & 3.38 & 1.25 \\
\hline 34 & $5.25 E-02$ & $2.48 E-02$ & 0.75 & $2.41 E+12$ & 17.5 & 2.94 & 1.26 \\
\hline 36 & $2.48 E-02$ & 1.50E-02 & 0.5 & $1.57 E+12$ & 17.4 & 1.91 & 1.27 \\
\hline 36 & 1.50E-02 & $9.12 E-03$ & 0.5 & $1.51 E+12$ & 16.5 & 1.85 & 1.28 \\
\hline 37 & $9.12 E-03$ & 5.53E-03 & 0.5 & $1.41 E+12$ & 15.4 & 1.72 & 1.29 \\
\hline 38 & 5.53E-03 & $1.23 E-03$ & 1.5 & $4.35 E+12$ & 14.1 & 5.32 & 1.3 \\
\hline 39 & $1.23 E-03$ & 4.54E-04 & 1 & $2.79 E+12$ & 12.8 & 3.41 & 1.31 \\
\hline 40 & 4.54E-04 & 2.75E-04 & 0.5 & $1.41 \mathrm{E}+12$ & 7.2 & 1.72 & 1.33 \\
\hline 41 & 2.75E-04 & $2.14 E-04$ & 0.25 & $6.92 E+11$ & 10.6 & 0.85 & 1.31 \\
\hline 42 & $2.14 E-04$ & $1.01 E-04$ & 0.75 & $2.00 E+12$ & 5.4 & 2.44 & 1.28 \\
\hline 43 & 1.01E-04 & 2.90E-05 & 1.25 & $3.32 E+12$ & 9.5 & 4.05 & 1.3 \\
\hline 44 & 2.90E-05 & $6.48 E-06$ & 1.5 & $3.89 E+12$ & 8.4 & 4.76 & 1.3 \\
\hline 46 & $6.48 E-06$ & $3.93 E-06$ & 0.5 & $1.16 E+12$ & 3.7 & 1.41 & 1.22 \\
\hline 46 & 3.93E-06 & $3.06 E-06$ & 0.25 & $6.04 E+11$ & 10.6 & 0.74 & 1.26 \\
\hline 47 & $3.06 \mathrm{E}-06$ & $1.86 E-06$ & 0.5 & $1.19 E+12$ & 10.5 & 1.46 & 1.26 \\
\hline 48 & $1.86 E-06$ & 1.13E-06 & 0.5 & $1.18 \mathrm{E}+12$ & 10.8 & 1.44 & 1.26 \\
\hline 49 & $1.13 E-06$ & 5.32E-07 & 0.75 & $1.79 \mathrm{E}+12$ & 10.8 & 2.19 & 1.27 \\
\hline 80 & 5.32E-07 & 4.14E-07 & 0.25 & $6.22 \mathrm{E}+11$ & 13.7 & 0.76 & 1.25 \\
\hline 51 & $4.14 E-07$ & $1.00 E-10$ & 8.328 & $1.57 E+13$ & 22.4 & 19.15 & 1 \\
\hline
\end{tabular}


Table H6. Cumulative Adjusted group fluence rates for $\mathrm{H}-14$ irradiation location.

\begin{tabular}{|c|c|c|c|c|c|c|}
\hline GROUP & $\overline{E U}$ & EL & CPHA & UNCA & FRCPHA & RCPH \\
\hline 1 & $1.80 \mathrm{E}+01$ & $1.60 \mathrm{E}+01$ & $8.92 E+07$ & 20.8 & 0 & 1.13 \\
\hline 2 & $1.60 \mathrm{E}+01$ & $1.40 \mathrm{E}+01$ & $6.57 E+08$ & 20.1 & 0 & 1.13 \\
\hline 3 & $1.40 E+01$ & $1.35 E+01$ & $1.10 E+09$ & 19.2 & 0 & 1.13 \\
\hline 4 & $1.35 \mathrm{E}+01$ & $1.30 \mathrm{E}+01$ & $1.79 E+09$ & 18.5 & 0 & 1.14 \\
\hline 5 & $1.30 E+01$ & $1.25 E+01$ & $2.79 E+09$ & 17.8 & 0 & 1.14 \\
\hline 6 & $1.25 \mathrm{E}+01$ & $1.20 \mathrm{E}+01$ & $4.24 E+09$ & 17.1 & 0.01 & 1.14 \\
\hline 7 & $1.20 \mathrm{E}+04$ & $1.15 E+01$ & $6.30 E+09$ & 16.3 & 0.01 & 1.14 \\
\hline 8 & $1.15 E+01$ & $1.10 E+01$ & $9.22 \mathrm{E}+09$ & 15.4 & 0.01 & 1.13 \\
\hline 9 & $1.10 \mathrm{E}+01$ & $1.05 E+01$ & $1.34 E+10$ & 14.4 & 0.02 & 1.13 \\
\hline 10 & $1.05 E+01$ & $1.00 E+01$ & $1.93 E+10$ & 13.1 & 0.02 & 1.13 \\
\hline 11 & $1.00 E+01$ & $9.50 E+\infty 0$ & $2.80 E+10$ & 11.7 & 0.03 & 1.12 \\
\hline 12 & $9.50 E+\infty$ & $9.00 E+\infty$ & $4.09 E+10$ & 10.1 & 0.05 & 1.12 \\
\hline 13. & $9.00 E+\infty$ & $8.50 E+\infty$ & $6.00 E+10$ & 8.5 & 0.07 & 1.11 \\
\hline 14 & $8.50 E+\infty$ & $8.00 E+\infty 0$ & $8.83 E+10$ & 7.1 & 0.11 & 1.11 \\
\hline 16 & $8.00 E+\infty$ & $7.50 E+00$ & $1.30 E+11$ & 6.1 & 0.16 & 1.11 \\
\hline 16 & $7.50 \mathrm{E}+\infty$ & $7.00 E+\infty$ & $1.90 \mathrm{E}+11$ & 5.7 & 0.23 & 1.11 \\
\hline 17 & $7.00 E+\infty$ & $6.50 E+\infty 0$ & $2.78 E+11$ & 5.7 & 0.34 & 1.11 \\
\hline 18 & $6.50 E+\infty$ & $6.00 E+\infty 0$ & $4.05 E+11$ & 5.8 & 0.5 & 1.11 \\
\hline 19 & $6.00 E+\infty$ & $5.50 E+\infty 0$ & $5.92 E+11$ & 5.8 & 0.72 & 1.11 \\
\hline 20 & $5.50 E+\infty$ & $5.00 E+\infty 0$ & $8.63 E+11$ & 5.6 & 1.05 & 1.11 \\
\hline 21 & $5.00 \mathrm{E}+\infty$ & $4.50 E+\infty 0$ & $1.25 \mathrm{E}+12$ & 5.2 & 1.52 & 1.12 \\
\hline 22 & $4.50 \mathrm{E}+\infty$ & $4.00 E+\infty$ & 1.77E+12 & 4.8 & 2.16 & 1.12 \\
\hline 23 & $4.00 E+\infty$ & $3.50 E+\infty$ & $2.50 E+12$ & 4.5 & 3.06 & 1.13 \\
\hline 24 & $3.50 E+\infty$ & $3.00 E+\infty$ & $3.58 E+12$ & 4 & 4.37 & 1.13 \\
\hline 26 & $3.00 E+\infty$ & $2.50 E+\infty 0$ & $5.19 E+12$ & 3.4 & 6.34 & 1.12 . \\
\hline 26 & $2.50 E+\infty$ & $2.00 E+00$ & $7.43 E+12$ & 2.9 & 9.08 & 1.11 \\
\hline 27 & $2.00 E+\infty 0$ & $1.50 \mathrm{E}+\infty 0$ & $1.05 E+13$ & 2.3 & 12.81 & 1.11 \\
\hline 28 & $1.50 \mathrm{E}+\infty$ & $1.00 E+\infty$ & $1.51 E+13$ & 3.1 & 18.46 & 1.13 \\
\hline 29 & $1.00 E+\infty 0$ & 8.21E-01 & $1.73 E+13$ & 3.3 & 21.18 & 1.14 \\
\hline 30 & 8.21E-01 & 4.98E-01 & $2.26 E+13$ & 4.2 & 27.58 & 1.15 \\
\hline 31 & $4.98 E-01$ & $3.02 E-01$ & $2.65 E+13$ & 5 & 32.33 & 1.16 \\
\hline 32 & $3.02 E-01$ & 1.11E-01 & $3.15 E+13$ & 6 & 38.5 & 1.17 \\
\hline 33 & 1.11E-01 & $5.25 E-02$ & $3.43 E+13$ & 6.5 & 41.88 & 1.18 \\
\hline 34 & $5.25 E-02$ & 2.48E-02 & $3.67 E+13$ & 6.9 & 44.82 & 1.19 \\
\hline 36 & 2.48E-02 & $1.50 \mathrm{E}-02$ & $3.83 E+13$ & 7 & 46.73 & 1.19 \\
\hline 36 & $1.50 E-02$ & $9.12 E-03$ & $3.98 E+13$ & 7.1 & 48.58 & 1.19 \\
\hline 37 & $9.12 E-03$ & $5.53 E-03$ & $4.12 E+13$ & 7.1 & 50.3 & 1.2 \\
\hline 38 & $5.53 E-03$ & 1.23E-03 & $4.55 E+13$ & 7.1 & 55.62 & 1.2 \\
\hline 39 & $1.23 E-03$ & 4.54E-04 & $4.83 E+13$ & 6.9 & 59.03 & 1.21 \\
\hline 40 & 4.54E-04 & $2.75 E-04$ & $4.97 E+13$ & 6.7 & 60.75 & 1.21 \\
\hline 41 & 2.75E-04 & $2.14 E-04$ & $5.04 E+13$ & 6.6 & 61.6 & 1.21 \\
\hline 42 & $2.14 E-04$ & 1.01E-04 & $5.24 E+13$ & 6.4 & 64.04 & 1.22 \\
\hline 43 & 1.01E-04 & 2.90E-05 & $5.57 E+13$ & 6 & 68.1 & 1.22 \\
\hline 4 & $2.90 E-05$ & $6.48 E-06$ & $5.96 E+13$ & 5.5 & 72.85 & 1.23 \\
\hline 46 & $6.48 E-06$ & 3.93E-06 & $6.08 E+13$ & 5.4 & 74.26 & 1.23 \\
\hline 46 & $3.93 E-06$ & $3.06 E-06$ & $6.14 E+13$ & 5.3 & 75 & 1.23 \\
\hline 47 & $3.06 E-06$ & $1.86 \mathrm{E}-06$ & $6.26 \mathrm{E}+13$ & 5.2 & 76.46 & 1.23 \\
\hline 48 & $1.86 E-06$ & $1.13 E-06$ & $6.38 E+13$ & 5.1 & 77.9 & 1.23 \\
\hline 49 & 1.13E-06 & $5.32 E-07$ & $6.56 E+13$ & 4.9 & 80.09 & 1.23 \\
\hline 50 & $5.32 E-07$ & 4.14E-07 & $6.62 E+13$ & 4.9 & 80.85 & 1.23 \\
\hline 51 & 4.14E-07 & $1.00 E-10$ & $8.19 E+13$ & 5.8 & 100 & 1.18 \\
\hline
\end{tabular}

61 
Table I. FERRET analysis summary for ATR I positions.

\begin{tabular}{|c|c|c|c|c|c|c|c|c|}
\hline $\begin{array}{l}\text { Dosimeter } \\
\text { Reaction }\end{array}$ & $\begin{array}{c}\text { Measured } \\
\text { Rate } \\
\text { (Bq/atom) } \\
\end{array}$ & $\begin{array}{c}\sigma \\
(\%)\end{array}$ & $\begin{array}{c}\text { Calculated } \\
\text { Rate } \\
\text { (Bq/atom) }\end{array}$ & $\begin{array}{c}\sigma \\
(\%)\end{array}$ & $\mathbf{C} / \mathbf{M}$ & $\begin{array}{c}\text { FERRET-Fit } \\
\text { Rate } \\
\text { (Bq/atom) } \\
\end{array}$ & $\begin{array}{c}\sigma \\
(\%)\end{array}$ & FF/M \\
\hline $45 \operatorname{Sc}(n, \gamma)$ & $1.79 \mathrm{E}-12$ & 2.2 & $\begin{array}{c}\mathrm{I}-6 \\
1.35 \mathrm{E}-12\end{array}$ & 19.4 & 0.752 & $1.77 \mathrm{E}-12$ & 5.5 & 0.99 \\
\hline $197 \mathrm{Au}(\mathrm{n}, \gamma)$ & $1.86 \mathrm{E}-10$ & 2 & $1.79 \mathrm{E}-10$ & 21.8 & 0.963 & $1.87 \mathrm{E}-10$ & 4.3 & 1 \\
\hline $235 \mathrm{U}(\mathrm{n}, \mathbf{f})$ & $3.71 \mathrm{E}-11$ & 2.2 & $3.40 \mathrm{E}-11$ & 17.3 & 0.918 & $3.69 \mathrm{E}-11$ & 3.1 & 0.99 \\
\hline $59 \mathrm{Co}(\mathrm{n}, \gamma)$ & $8.29 \mathrm{E}-12$ & 2.5 & 8.91 E-12 & 20.9 & 1.075 & $8.35 \mathrm{E}-12$ & 5.3 & 1.01 \\
\hline $\operatorname{s8Fe}(n, \gamma)$ & $1.71 \mathrm{E}-13$ & 2.5 & $1.56 \mathrm{E}-13$ & 18 & 0.913 & $1.69 \mathrm{E}-13$ & 5 & 0.99 \\
\hline $237 \mathrm{~Np}(\mathrm{n}, \mathrm{f})$ & $5.32 \mathrm{E}-13$ & 2 & $1.80 \mathrm{E}-12$ & 20.4 & 3.38 & $5.31 \mathrm{E}-13$ & 5.5 & 1 \\
\hline $238 \mathrm{U}(\mathrm{n}, \mathbf{n})$ & $7.13 \mathrm{E}-14$ & 2.3 & $3.24 E-13$ & 18.6 & 4.549 & $7.19 \mathrm{E}-14$ & 2.7 & 1.01 \\
\hline $47 \operatorname{Ti}(n, p)$ & $3.49 \mathrm{E}-15$ & 3.1 & $2.14 \mathrm{E}-14$ & 21.1 & 6.125 & $3.57 \mathrm{E}-15$ & 3.4 & 1.02 \\
\hline $58 \mathrm{Ni}(\mathrm{n}, \mathrm{p})$ & $1.94 \mathrm{E}-14$ & 2 & $9.68 \mathrm{E}-14$ & 19.1 & 4.991 & $1.93 \mathrm{E}-14$ & 3.7 & 1 \\
\hline $54 F e(n, p)$ & $1.36 \mathrm{E}-14$ & 3.5 & $7.36 \mathrm{E}-14$ & 18.4 & 5.412 & $1.41 \mathrm{E}-14$ & 3.9 & 1.03 \\
\hline 46Ti(n,p) & $2.34 E-15$ & 2.6 & $9.34 \mathrm{E}-15$ & 21.9 & 3.991 & $2.33 \mathrm{E}-15$ & 5.7 & 1 \\
\hline $63 \mathrm{Cu}(\mathrm{n}, \alpha)$ & $1.34 \mathrm{E}-16$ & 2.4 & $4.53 \mathrm{E}-16$ & 17.9 & 3.379 & $1.31 \mathrm{E}-16$ & 5.9 & 0.98 \\
\hline $48 T i(n, p)$ & $7.43 \mathrm{E}-17$ & 7.3 & $2.26 \mathrm{E}-16$ & 20.2 & 3.042 & $7.05 \mathrm{E}-17$ & 6.6 & 0.95 \\
\hline $27 \mathrm{Al}(\mathrm{n}, \alpha)$ & $1.51 \mathrm{E}-16$ & 3.3 & $\begin{array}{c}5.73 E-16 \\
\text { I-8 }\end{array}$ & 18.7 & 3.792 & 1.57E-16 & 6.1 & 1.04 \\
\hline $45 S c(n, \gamma)$ & $2.13 \mathrm{E}-12$ & 2.2 & $1.79 \mathrm{E}-12$ & 19.4 & 0.842 & $2.13 \mathrm{E}-12$ & 5.5 & 1 \\
\hline 197Au(n,y) & $2.47 \mathrm{E}-10$ & 2 & 2.39E-10 & 21.8 & 0.967 & $2.47 \mathrm{E}-10$ & 4.3 & 1 \\
\hline $235 U(n, f)$ & $4.78 \mathrm{E}-11$ & 2.2 & $4.54 \mathrm{E}-11$ & 17.3 & 0.95 & $4.72 \mathrm{E}-11$ & 3.1 & 0.99 \\
\hline $59 \mathrm{Co}(\mathrm{n}, \gamma)$ & $1.12 \mathrm{E}-11$ & 2.5 & $1.19 \mathrm{E}-11$ & 20.9 & 1.06 & $1.12 \mathrm{E}-11$ & 5.5 & 1 \\
\hline $\operatorname{s8Fe}(n, \gamma)$ & $2.11 \mathrm{E}-13$ & 2.5 & $2.08 \mathrm{E}-13$ & 18 & 0.987 & $2.10 \mathrm{E}-13$ & 5.2 & 1 \\
\hline $237 \mathrm{~Np}(\mathrm{n}, \mathbb{1})$ & 7.33E-13 & 2 & $2.40 \mathrm{E}-12$ & 20.4 & 3.27 & $7.34 \mathrm{E}-13$ & 5.5 & 1 \\
\hline $238 \mathrm{U}(\mathrm{n}, \mathrm{n})$ & $1.02 \mathrm{E}-13$ & 2.3 & 4.32E-13 & 18.6 & 4.239 & $1.02 \mathrm{E}-13$ & 2.7 & 1 \\
\hline 47Ti(n,p) & $4.90 \mathrm{E}-15$ & 3.1 & $2.85 E-14$ & 21.1 & 5.817 & 4.92E-15 & 3.5 & 1 \\
\hline $58 \mathrm{Ni}(\mathrm{n}, \mathrm{p})$ & $2.60 \mathrm{E}-14$ & 2 & $1.29 \mathrm{E}-13$ & 19.1 & 4.996 & $2.63 \mathrm{E}-14$ & 3.7 & 1.01 \\
\hline $54 F e(n, p)$ & $1.88 \mathrm{E}-14$ & 3.5 & $9.81 E-14$ & 18.4 & 5.22 & $1.90 \mathrm{E}-14$ & 3.9 & 1.01 \\
\hline 46Ti(n,p) & $3.01 E-15$ & 2.6 & $1.25 \mathrm{E}-14$ & 21.9 & 4.137 & $3.02 \mathrm{E}-15$ & 5.7 & 1 \\
\hline $63 \mathrm{Cu}(\mathrm{n}, \alpha)$ & $2.14 \mathrm{E}-16$ & 2.4 & $6.04 E-16$ & 18.2 & 2.281 & $1.71 \mathrm{E}-16$ & 5.9 & 0.8 \\
\hline 48Ti(n,p) & 8.72E-17 & 7.3 & $3.01 E-16$ & 20.2 & 3.456 & $9.27 E-17$ & 6.6 & 1.06 \\
\hline $27 \mathrm{Al}(n, \alpha)$ & $2.03 \mathrm{E}-16$ & 3.3 & $\begin{array}{c}7.63 \mathrm{E}-16 \\
\mathrm{I}-22\end{array}$ & 18.7 & 3.761 & $2.07 E-16$ & 6.1 & 1.02 \\
\hline $4 \operatorname{SSc}(n, \gamma)$ & $2.96 \mathrm{E}-12$ & 2.2 & $2.24 \mathrm{E}-12$ & 19.4 & 0.758 & $2.95 \mathrm{E}-12$ & 5.5 & 1 \\
\hline 197Au(n,y) & $3.25 \mathrm{E}-10$ & 2 & $2.98 \mathrm{E}-10$ & 21.8 & 0.918 & $3.26 \mathrm{E}-10$ & 4.3 & 1 \\
\hline $235 \mathrm{U}(\mathrm{n}, \mathrm{f})$ & $6.59 \mathrm{E}-11$ & 2.2 & $5.67 \mathrm{E}-11$ & 17.3 & 0.861 & $6.47 \mathrm{E}-11$ & 3.1 & 0.98 \\
\hline $59 \mathrm{Co}(\mathrm{n}, \gamma)$ & $1.48 \mathrm{E}-11$ & 2.5 & $1.48 \mathrm{E}-11$ & 20.9 & 1.003 & $1.49 \mathrm{E}-11$ & 5.4 & 1.01 \\
\hline $58 F e(n, \gamma)$ & $2.76 \mathrm{E}-13$ & 2.5 & $2.60 \mathrm{E}-13$ & 18 & 0.943 & $2.76 \mathrm{E}-13$ & 5 & 1 \\
\hline $237 \mathrm{~Np}(\mathrm{n}, \mathrm{n})$ & $9.30 \mathrm{E}-13$ & 2 & $3.00 \mathrm{E}-12$ & 20.4 & 3.222 & $9.30 \mathrm{E}-13$ & 5.5 & 1 \\
\hline $238 \mathrm{U}(\mathrm{n}, \mathrm{f})$ & $1.27 \mathrm{E}-13$ & 2.3 & $5.41 \mathrm{E}-13$ & 18.6 & 4.256 & $1.28 \mathrm{E}-13$ & 2.7 & 1.01 \\
\hline 47Ti(n,p) & $6.28 \mathrm{E}-15$ & 3.1 & $3.56 \mathrm{E}-14$ & 21.1 & 5.674 & $6.22 \mathrm{E}-15$ & 3.4 & 0.99 \\
\hline 58Ni(n,p) & 3.33E-14 & 2 & $1.61 \mathrm{E}-13$ & 19.1 & 4.846 & 3.33E-14 & 3.7 & 1 \\
\hline $54 F e(n, p)$ & $2.29 \mathrm{E}-14$ & 3.5 & $1.23 \mathrm{E}-13$ & 18.4 & 5.357 & $2.41 E-14$ & 3.9 & 1.05 \\
\hline $46 \mathrm{Ti}(\mathrm{n}, \mathrm{p})$ & 3.84E-15 & 2.6 & $1.56 \mathrm{E}-14$ & 21.9 & 4.053 & $3.84 \mathrm{E}-15$ & 5.7 & 1 \\
\hline $63 \operatorname{Cu}(n, \alpha)$ & $1.65 \mathrm{E}-16$ & 12.4 & $7.55 \mathrm{E}-16$ & 17.9 & 4.573 & $2.19 \mathrm{E}-16$ & 5.9 & 1.33 \\
\hline 48Ti(n,p) & 1.19E-16 & 7.3 & $3.77 \mathrm{E}-16$ & 20.2 & 3.166 & $1.19 \mathrm{E}-16$ & 6.6 & 1 \\
\hline $27 A \mid(n, \alpha)$ & $2.66 \mathrm{E}-16$ & 3.3 & $9.54 \mathrm{E}-16$ & 18.7 & 3.588 & $2.68 \mathrm{E}-16$ & 6.1 & 1.01 \\
\hline
\end{tabular}



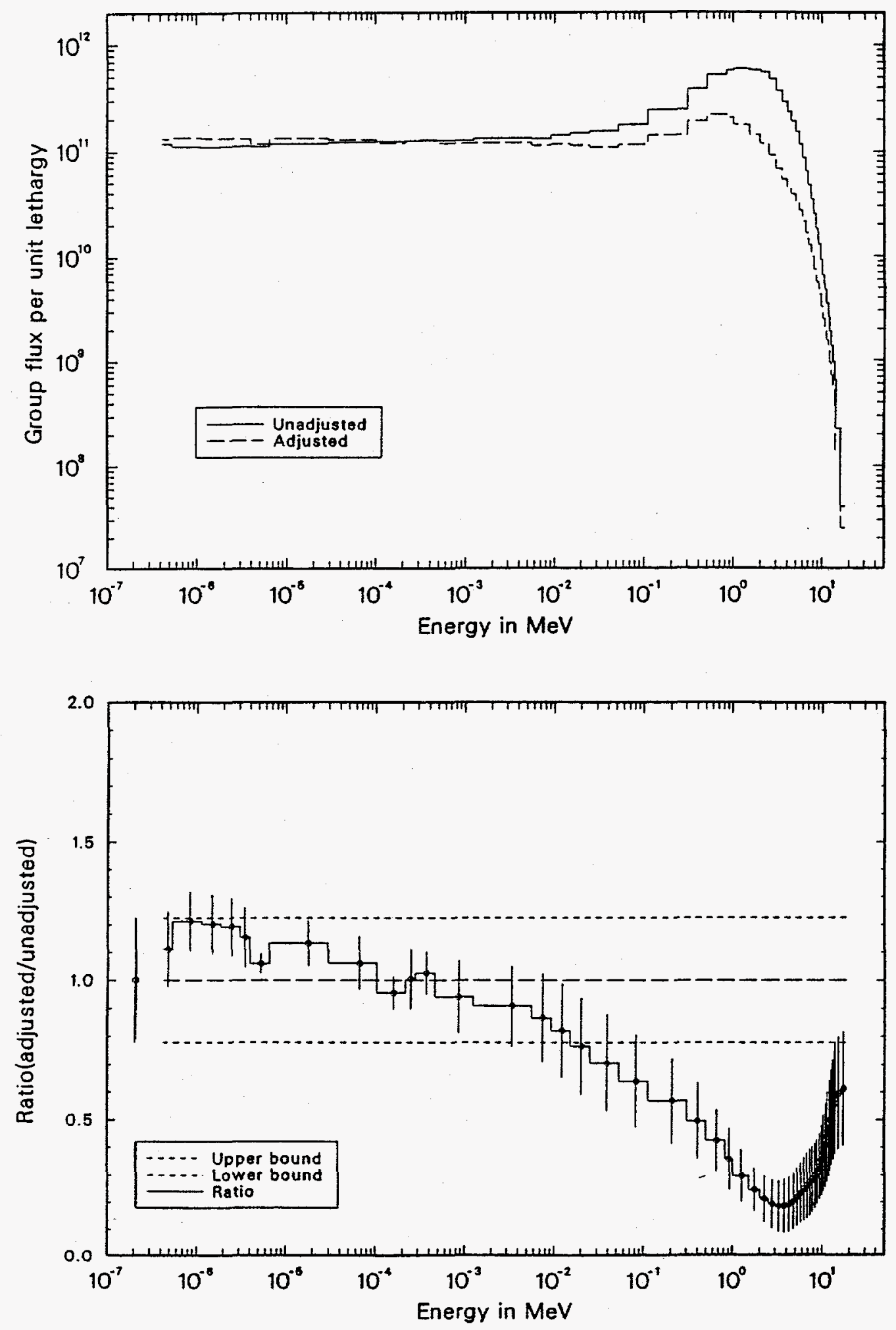

Figure I1. Upper part of figure compares adjusted and unadjusted (input) group fluence rates for I-6 location and lower part displays the ratio of adjusted-to-unadjusted group values with input uncertainty bounds and final uncertainty error bars. 
Table 11. Adjusted group fluence rates for 1-6 irradiation location.

\begin{tabular}{|c|c|c|c|c|c|c|c|}
\hline GROUP & $\mathbf{E U}$ & EL & DU & PHA & UNCA & FRPHA & RPH \\
\hline 1 & $1.80 E+01$ & $1.60 E+01$ & 0.118 & $2.90 E+06$ & 20.6 & 0 & 0.61 \\
\hline 2 & $1.60 E+01$ & $1.40 E+01$ & 0.134 & $1.79 E+07$ & 20.4 & 0 & 0.59 \\
\hline 3 & $1.40 E+01$ & 1.35E+01 & 0.036 & 1.35E+07 & 20.1 & 0 & 0.58 \\
\hline 4 & $1.35 E+01$ & $1.30 \mathrm{E}+01$ & 0.038 & $1.99 E+07$ & 19.7 & 0 & 0.55 \\
\hline 5 & $1.30 E+01$ & $1.25 E+01$ & 0.039 & $2.79 E+07$ & 19.1 & 0 & 0.53 \\
\hline 6 & $1.25 E+01$ & $1.20 E+01$ & 0.041 & $3.81 E+07$ & 18.4 & 0 & 0.5 \\
\hline 7 & $1.20 E+01$ & $1.15 E+01$ & 0.043 & $5.12 E+07$ & 17.5 & 0 & 0.47 \\
\hline 8 & $1.15 E+01$ & 1.10E+01 & 0.044 & $6.80 E+07$ & 16.4 & 0 & 0.44 \\
\hline 9 & $1.10 E+01$ & $1.05 E+01$ & 0.047 & $9.01 E+07$ & 15.2 & 0 & 0.41 \\
\hline 10 & $1.05 E+01$ & $1.00 E+01$ & 0.049 & $1.21 E+08$ & 14 & 0 & 0.38 \\
\hline 11 & $1,00 E+01$ & $9.50 E+\infty 0$ & 0.051 & $1.66 E+08$ & 12.9 & 0.01 & 0.35 \\
\hline 12 & $9.50 E+\infty$ & $9.00 E+\infty$ & 0.054 & $2.31 E+08$ & 12 & 0.01 & 0.33 \\
\hline 13 & $9.00 E+\infty$ & $8.50 E+\infty 0$ & 0.057 & $3.23 E+08$ & 11.7 & 0.01 & 0.31 \\
\hline 14 & $8.50 E+\infty 0$ & $8.00 E+\infty 0$ & 0.061 & $4.54 E+08$ & 11.8 & 0.01 & 0.3 \\
\hline 16 & $8.00 E+\infty$ & $7.50 E+\infty 0$ & 0.065 & $6.37 E+08$ & 12 & 0.02 & 0.28 \\
\hline 16 & $7.50 E+\infty 0$ & $7.00 E+00$ & 0.069 & $8.90 E+08$ & 12.1 & 0.03 & 0.27 \\
\hline 17 & $7.00 E+\infty 0$ & $6.50 E+00$ & 0.074 & $1.24 E+09$ & 12 & 0.04 & 0.26 \\
\hline 18 & $6.50 \mathrm{E}+\infty$ & $6.00 E+\infty 0$ & 0.08 & $1.72 E+\infty 9$ & 11.5 & 0.06 & 0.25 \\
\hline 19 & $6.00 E+\infty$ & $5.50 E+\infty 0$ & 0.087 & $2.36 E+09$ & 11 & 0.08 & 0.23 \\
\hline 20 & $5.50 E+\infty$ & $5.00 E+\infty$ & 0.095 & $3.15 E+09$ & 10.6 & 0.1 & 0.22 \\
\hline 21 & $5.00 E+\infty$ & $4.50 E+\infty$ & 0.105 & 4.11E+09 & 10.3 & 0.13 & 0.2 \\
\hline 22 & $4.50 E+\infty$ & $4.00 E+\infty$ & 0.118 & $5.31 E+09$ & 10.1 & 0.17 & 0.19 \\
\hline 23 & $4.00 E+\infty$ & $3.50 E+\infty$ & 0.134 & 7.20E+09 & 9.9 & 0.23 & 0.18 \\
\hline 24 & $3.50 E+\infty$ & $3.00 E+\infty$ & 0.154 & $1.05 E+10$ & 9.4 & 0.34 & 0.18 \\
\hline 25 & $3.00 E+\infty$ & $2.50 E+\infty$ & 0.182 & $1.68 E+10$ & 9 & 0.55 & 0.19 \\
\hline 26 & $2.50 E+\infty$ & $2.00 E+\infty$ & 0.223 & $2.60 E+10$ & 8.5 & 0.85 & 0.21 \\
\hline 27 & $2.00 E+\infty$ & $1.50 E+\infty$ & 0.288 & $4.04 E+10$ & 7.9 & 1.31 & 0.24 \\
\hline 28 & $1.50 E+\infty$ & $1.00 E+\infty$ & 0.405 & $7.06 E+10$ & 9.4 & 2.3 & 0.3 \\
\hline 29 & $1.00 E+\infty$ & 8.21E-01 & 0.197 & $4.02 E+10$ & 11 & 1.31 & 0.36 \\
\hline 30 & $8.21 E-01$ & 4.98E-01 & 0.5 & $1.09 E+11$ & 11.2 & 3.56 & 0.42 \\
\hline 31 & 4.98E-01 & $3.02 E-01$ & 0.5 & $9.41 E+10$ & 13.9 & 3.06 & 0.49 \\
\hline 32 & 3.02E-01 & 1.11E-01 & 1 & $1.39 E+11$ & 15.5 & 4.52 & 0.57 \\
\hline 33 & 1.11E-01 & $5.25 E-02$ & 0.75 & $8.49 E+10$ & 16.7 & 2.76 & 0.64 \\
\hline 34 & 5.25E-02 & $2.48 E-02$ & 0.75 & 8.07E+10 & 17.4 & 2.62 & 0.7 \\
\hline 36 & $2.48 E-02$ & $1.50 \mathrm{E}-02$ & 0.5 & $5.65 E+10$ & 17.4 & 1.84 & 0.76 \\
\hline 36 & $1.50 E-02$ & $9.12 E-03$ & 0.5 & $5.82 E+10$ & 16.7 & 1.89 & 0.82 \\
\hline 37 & $9.12 E-03$ & $5.53 E-03$ & 0.5 & $5.69 E+10$ & 15.7 & 1.85 & 0.87 \\
\hline 38 & 5.53E-03 & $1.23 E-03$ & 1.5 & $1.82 E+11$ & 14.4 & 5.93 & 0.91 \\
\hline 39 & $1.23 E-03$ & 4.54E-04 & 1 & $1.21 E+11$ & 13 & 3.92 & 0.94 \\
\hline 40 & 4.54E-04 & $2.75 E-04$ & 0.5 & $6.52 E+10$ & 7.7 & 2.12 & 1.03 \\
\hline 41 & $2.75 E-04$ & 2.14E-04 & 0.25 & $3.19 E+10$ & 10.7 & 1.04 & 1 \\
\hline 42 & 2.14E-04 & $1.01 E-04$ & 0.75 & $8.98 E+10$ & 5.8 & 2.92 & 0.96 \\
\hline 43 & 1.01E-04 & 2.90E-05 & 1.25 & $1.63 E+11$ & 9.5 & 5.29 & 1.06 \\
\hline 4 & 2.90E-05 & $6.48 E-06$ & 1.5 & $2.03 E+11$ & 8.2 & 6.61 & 1.13 \\
\hline 46 & $6.48 E-06$ & $3.93 E-06$ & 0.5 & $6.04 E+10$ & 3.7 & 1.97 & 1.06 \\
\hline 46 & 3.93E-06 & $3.06 E-06$ & 0.25 & 3.32E+10 & 10.6 & 1.08 & 1.15 \\
\hline 47 & $3.06 E-06$ & $1.86 \mathrm{E}-06$ & 0.5 & $6.77 E+10$ & 10.4 & 2.2 & 1.19 \\
\hline 48 & $1.86 E-06$ & 1.13E-06 & 0.5 & $6.76 E+10$ & 10.7 & 2.2 & 1.2 \\
\hline 49 & $1.13 E-06$ & $5.32 E-07$ & 0.75 & $1.03 E+11$ & 10.6 & 3.35 & 1.21 \\
\hline 60 & 5.32E-07 & 4.14E-07 & 0.25 & $3.33 E+10$ & 13.6 & 1.08 & 1.11 \\
\hline 51 & 4.14E-07 & $1.00 \mathrm{E}-10$ & 8.328 & $9.41 E+11$ & 22.4 & 30.62 & 1 \\
\hline
\end{tabular}


Table 12. Cumulative adjusted group fluence rates for 1-6 irradiation location.

\begin{tabular}{|c|c|c|c|c|c|c|}
\hline GROUP & EU & EL & CPHA & UNCA & FRCPHA & RCPH \\
\hline 1 & $1.80 E+01$ & $1.60 E+01$ & $2.90 E+06$ & 20.6 & 0 & 0.61 \\
\hline 2 & $1.60 E+01$ & $1.40 E+01$ & $2.08 E+07$ & 19.9 & 0 & 0.6 \\
\hline 3 & $1.40 E+01$ & $1.35 E+01$ & $3.43 E+07$ & 19 & 0 & 0.59 \\
\hline 4 & $1.35 E+01$ & $1.30 E+01$ & $5.42 E+07$ & 18.2 & 0 & 0.57 \\
\hline 5 & $1.30 E+01$ & $1.25 E+01$ & 8.21E+07 & 17.4 & 0 & 0.56 \\
\hline 6 & $1.25 E+01$ & $1.20 \mathrm{E}+01$ & $1.20 E+08$ & 16.6 & 0 & 0.54 \\
\hline 7 & $1.20 E+01$ & $1.15 E+01$ & $1.71 E+08$ & 15.7 & 0.01 & 0.51 \\
\hline 8 & 1.15E+01 & $1.10 E+01$ & $2.39 E+08$ & 14.6 & 0.01 & 0.49 \\
\hline 9 & $1.10 E+01$ & $1.05 E+01$ & $3.29 E+08$ & 13.4 & 0.01 & 0.46 \\
\hline 10 & 1.05E+01 & $1.00 E+01$ & $4.50 \mathrm{E}+08$ & 12.1 & 0.01 & 0.44 \\
\hline 11 & $1.00 E+01$ & $9.50 E+\infty$ & $6.16 E+08$ & 10.6 & 0.02 & 0.41 \\
\hline 12 & $9.50 E+\infty$ & $9.00 E+\infty$ & 8.47E+08 & 9 & 0.03 & 0.39 \\
\hline 13 & $9.00 E+\infty$ & $8.50 E+\infty$ & 1.17E+09 & 7.6 & 0.04 & 0.36 \\
\hline 14 & $8.50 E+\infty$ & $8.00 E+\infty 0$ & $1.62 E+\infty 9$ & 6.5 & 0.05 & 0.34 \\
\hline 16 & $8.00 E+\infty 0$ & $7.50 \mathrm{E}+\infty$ & $2.26 E+\infty 9$ & 6 & 0.07 & 0.32 \\
\hline 16 & $7.50 E+\infty 0$ & $7.00 E+\infty$ & $3.15 E+\infty 9$ & 6 & 0.1 & 0.31 \\
\hline 17 & $7.00 E+\infty$ & $6.50 E+\infty 0$ & $4.39 E+09$ & 6.2 & 0.14 & 0.29 \\
\hline 18 & $6.50 E+\infty$ & $6.00 E+\infty$ & $6.11 E+09$ & 6.3 & 0.2 & 0.28 \\
\hline 19 & $6.00 E+\infty$ & $5.50 E+\infty$ & $8.47 E+09$ & 6.2 & 0.28 & 0.26 \\
\hline 20 & $5.50 E+\infty$ & $5.00 E+\infty$ & $1.16 E+10$ & 5.9 & 0.38 & 0.25 \\
\hline 21 & $5.00 E+\infty$ & $4.50 E+\infty 0$ & $1.57 E+10$ & 5.4 & 0.51 & 0.24 \\
\hline 22 & $4.50 E+\infty 0$ & $4.00 E+\infty$ & $2.10 E+10$ & 5 & 0.68 & 0.22 \\
\hline 23 & $4.00 E+\infty$ & $3.50 E+\infty 0$ & $2.82 E+10$ & 4.6 & 0.92 & 0.21 \\
\hline 24 & $3.50 E+\infty 0$ & $3.00 E+\infty$ & $3.88 E+10$ & 4.2 & 1.26 & 0.2 \\
\hline 26 & $3.00 E+\infty$ & $2.50 E+\infty 0$ & $5.56 \mathrm{E}+10$ & 3.8 & 1.81 & 0.2 \\
\hline 26 & $2.50 E+\infty$ & $2.00 E+00$ & $8.15 E+10$ & 3.4 & 2.65 & 0.2 \\
\hline 27 & $2.00 E+\infty$ & $1.50 E+\infty 0$ & $1.22 E+11$ & 2.7 & 3.97 & 0.22 \\
\hline 28 & $1.50 E+\infty$ & $1.00 E+\infty 0$ & 1.93E+11 & 3.6 & 6.26 & 0.24 \\
\hline 29 & $1.00 E+\infty$ & 8.21E-01 & $2.33 E+11$ & 3.8 & 7.57 & 0.25 \\
\hline 30 & 8.21E-01 & 4.98E-01 & $3.42 E+11$ & 4.9 & 11.13 & 0.29 \\
\hline 31 & 4.98E-01 & $3.02 E-01$ & $4.36 E+11$ & 5.8 & 14.19 & 0.32 \\
\hline 32 & $3.02 E-01$ & 1.11E-01 & $5.75 E+11$ & 7.3 & 18.71 & 0.36 \\
\hline 33 & 1.11E-01 & $5.25 E-02$ & $6.60 E+11$ & 7.9 & 21.47 & 0.38 \\
\hline 34 & 5.25E-02 & 2.48E-02 & $7.41 E+11$ & 8.4 & 24.09 & 0.4 \\
\hline 36 & 2.48E-02 & $1.50 E-02$ & $7.97 E+11$ & 8.7 & 25.93 & 0.41 \\
\hline 36 & $1.50 E-02$ & $9.12 E-03$ & 8.55E+11 & 8.8 & 27.83 & 0.43 \\
\hline 37 & $9.12 E-03$ & $5.53 E-03$ & $9.12 E+11$ & 8.8 & 29.67 & 0.44 \\
\hline 38 & 5.53E-03 & 1.23E-03 & $1.09 E+12$ & 8.7 & 35.6 & 0.48 \\
\hline 39 & $1.23 E-03$ & 4.54E-04 & $1.22 E+12$ & 8.4 & 39.52 & 0.51 \\
\hline 40 & 4.54E-04 & 2.75E-04 & $1.28 \mathrm{E}+12$ & 8 & 41.64 & 0.52 \\
\hline 41 & 2.75E-04 & 2.14E-04 & $1.31 E+12$ & 7.9 & 42.68 & 0.53 \\
\hline 42 & $2.14 E-04$ & $1.01 E-04$ & $1.40 E+12$ & 7.4 & 45.6 & 0.54 \\
\hline 43 & $1.01 E-04$ & $2.90 E-05$ & $1.57 E+12$ & 6.6 & 50.9 & 0.57 \\
\hline 4 & $2.90 \mathrm{E}-05$ & $6.48 E-06$ & 1.77E+12 & 5.8 & 57.5 & 0.61 \\
\hline 45 & $6.48 E-06$ & $3.93 E-06$ & $1.83 E+12$ & 5.6 & 59.47 & 0.61 \\
\hline 46 & 3.93E-06 & $3.06 E-06$ & $1.86 E+12$ & 5.4 & 60.55 & 0.62 \\
\hline 47 & $3.06 E-06$ & $1.86 E-06$ & $1.93 E+12$ & 5.2 & 62.75 & 0.63 \\
\hline 48 & $1.86 E-06$ & 1.13E-O6 & $2.00 E+12$ & 5 & 64.95 & 0.64 \\
\hline 49 & $1.13 E-06$ & 5.32E-07 & $2.10 E+12$ & 4.7 & 68.3 & 0.66 \\
\hline 60 & $5.32 E-07$ & 4.14E-07 & $2.13 E+12$ & 4.6 & 69.38 & 0.66 \\
\hline 51 & 4.14E-07 & 1.00E-10 & $3.07 E+12$ & 7.6 & 100 & 0.74 \\
\hline
\end{tabular}



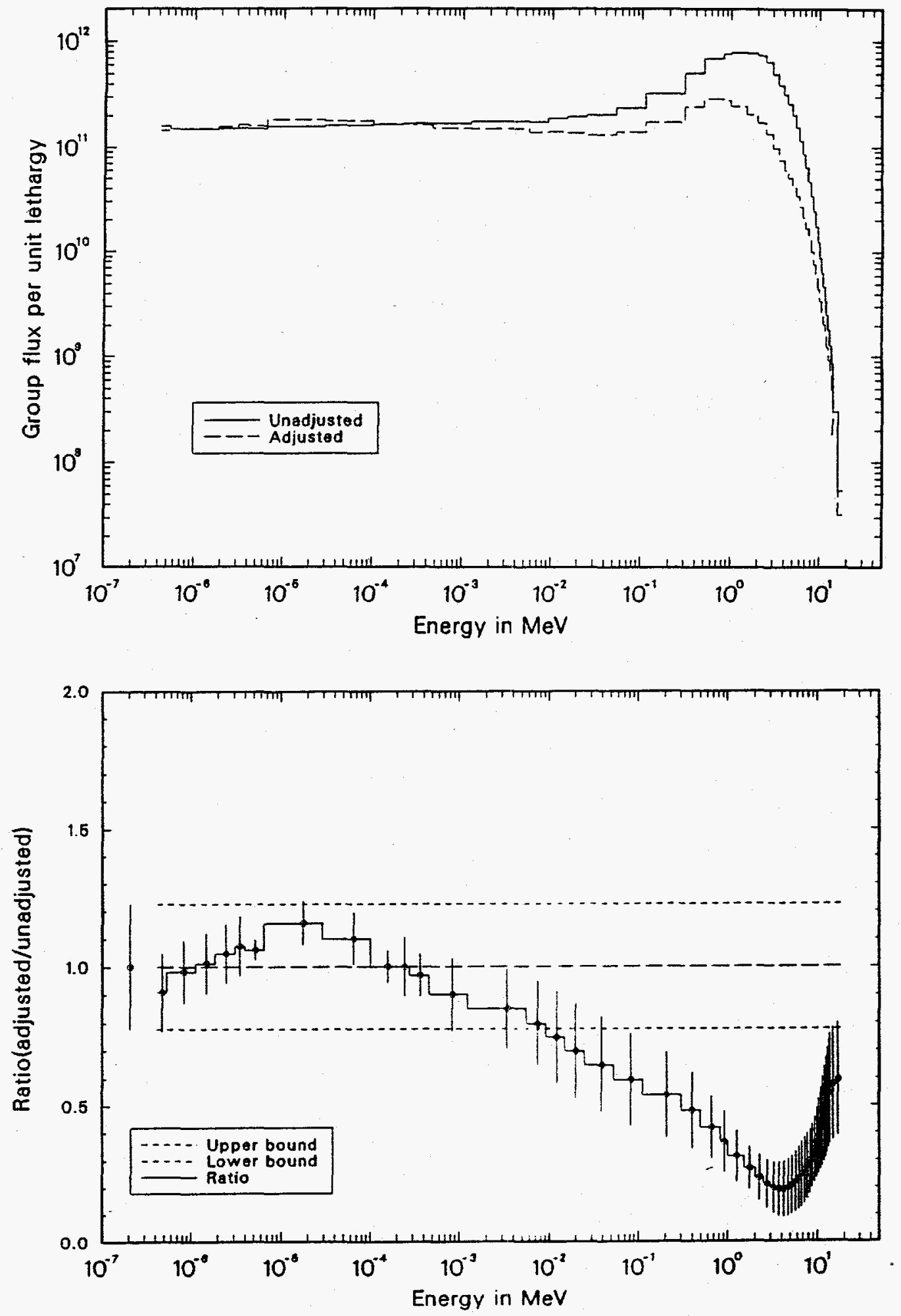

Figure I2. Upper part of figure compares adjusted and unadjusted (input) group fluence rates for I-8 location and lower part displays the ratio of adjusted-to-unadjusted group values with input uncertainty bounds and final uncertainty error bars. 
Table 13. Adjusted group fluence rates for 1-8 irradiation location.

\begin{tabular}{|c|c|c|c|c|c|c|c|}
\hline GROUP & $\mathbf{E U}$ & EL & DU & PHA & UNCA & FRPHA & RPH \\
\hline 1 & $1.80 E+01$ & $1.60 E+01$ & 0.118 & $3.75 E+06$ & 20.6 & 0 & 0.59 \\
\hline 2 & $1.60 E+01$ & $1.40 E+01$ & 0.134 & $2.31 E+07$ & 20.4 & 0 & 0.58 \\
\hline 3 & $1.40 \mathrm{E}+01$ & $1.35 E+01$ & 0.036 & $1.76 E+07$ & 20.1 & 0 & 0.56 \\
\hline 4 & $1.35 E+01$ & $1.30 E+01$ & 0.038 & $2.59 E+07$ & 19.7 & 0 & 0.54 \\
\hline 5 & $1.30 E+01$ & $1.25 E+01$ & 0.039 & $3.65 E+07$ & 19.1 & 0 & 0.52 \\
\hline 6 & $1.25 E+01$ & $1.20 E+01$ & 0.041 & $5.02 E+07$ & 18.4 & 0 & 0.49 \\
\hline 7 & $1.20 E+01$ & $1.15 E+01$ & 0.043 & $6.81 E+07$ & 17.5 & 0 & 0.47 \\
\hline 8 & 1.15E+01 & $1.10 E+01$ & 0.044 & $9.13 E+07$ & 16.4 & 0 & 0.44 \\
\hline 8 & $1.10 E+01$ & 1.05E+01 & 0.047 & $1.22 \mathrm{E}+08$ & 15.1 & 0 & 0.41 \\
\hline 10 & $1.05 E+01$ & $1.00 E+01$ & 0.040 & $1.65 E+08$ & 13.9 & 0 & 0.39 \\
\hline 11 & $1.00 E+01$ & $9.50 E+\infty 0$ & 0.051 & $2.27 E+08$ & 12.7 & 0.01 & 0.36 \\
\hline 12 & $9.50 E+\infty 0$ & $9.00 E+\infty$ & 0.054 & $3.14 E+08$ & 12 & 0.01 & 0.34 \\
\hline 13 & $9.00 E+\infty 0$ & $8.50 E+\infty$ & 0.057 & $4.36 E+08$ & 11.7 & 0.01 & 0.32 \\
\hline 14 & $8.50 E+\infty 0$ & $8.00 E+\infty$ & 0.061 & $6.04 E+08$ & 11.8 & 0.02 & 0.3 \\
\hline 16 & $8.00 E+\infty 0$ & $7.50 E+\infty$ & 0.065 & $8.31 E+08$ & 12.1 & 0.02 & 0.28 \\
\hline 16 & $7.50 E+\infty 0$ & $7.00 E+\infty$ & 0.069 & $1.14 E+09$ & 12.2 & 0.03 & 0.26 \\
\hline 17 & $7.00 E+\infty$ & $6.50 E+\infty 0$ & 0.074 & $1.56 E+09$ & 12 & 0.04 & 0.25 \\
\hline 18 & $6.50 E+\infty 0$ & $6.00 E+\infty 0$ & 0.08 & $2.14 E+09$ & 11.6 & 0.05 & 0.23 \\
\hline 19 & $6.00 E+\infty 0$ & $5.50 E+\infty 0$ & 0.087 & $2.94 E+09$ & 11.1 & 0.07 & 0.22 \\
\hline 20 & $5.50 E+\infty$ & $5.00 E+\infty$ & 0.095 & $3.99 E+09$ & 10.7 & 0.1 & 0.21 \\
\hline 21 & $5.00 E+\infty$ & $4.50 E+\infty 0$ & 0.105 & $5.32 E+09$ & 10.4 & 0.13 & 0.2 \\
\hline 22 & $4.50 E+\infty 0$ & $4.00 E+\infty 0$ & 0.118 & $7.08 E+09$ & 10.2 & 0.18 & 0.19 \\
\hline 23 & $4.00 E+\infty 0$ & $3.50 E+\infty 0$ & 0.134 & $9.93 E+09$ & 9.9 & 0.25 & 0.19 \\
\hline 24 & $3.50 \mathrm{E}+\infty 0$ & $3.00 E+\infty$ & 0.154 & $1.50 E+10$ & 9.4 & 0.38 & 0.2 \\
\hline 26 & $3.00 E+\infty 0$ & $2.50 E+\infty 0$ & 0.182 & $2.44 E+10$ & 9 & 0.61 & 0.21 \\
\hline 26 & $2.50 \mathrm{E}+\infty 0$ & $2.00 E+\infty$ & 0.223 & $3.84 E+10$ & 8.4 & 0.96 & 0.23 \\
\hline 27 & $2.00 E+\infty 0$ & $1.50 E+\infty$ & 0.288 & $5.93 E+10$ & 7.8 & 1.48 & 0.27 \\
\hline 28 & $1.50 E+\infty 0$ & $1.00 \mathrm{E}+\infty$ & 0.405 & $9.93 E+10$ & 9.4 & 2.49 & 0.31 \\
\hline 29 & $1.00 E+\infty$ & 8.21E-01 & 0.197 & $5.49 E+10$ & 11.1 & 1.37 & 0.36 \\
\hline 30 & 8.21E-01 & 4.98E-01 & 0.5 & $1.44 E+11$ & 11.5 & 3.61 & 0.42 \\
\hline 31 & 4.98E-01 & $3.02 E-01$ & 0.5 & $1.22 \mathrm{E}+11$ & 14.1 & 3.04 & 0.48 \\
\hline 32 & $3.02 E-01$ & $1.11 E-01$ & 1 & $1.75 E+11$ & 15.7 & 4.39 & 0.54 \\
\hline 33 & 1.11E-01 & $5.25 E-02$ & 0.75 & $1.05 E+11$ & 16.8 & 2.63 & 0.59 \\
\hline 34 & $5.25 E-02$ & $2.48 E-02$ & 0.75 & $9.86 E+10$ & 17.5 & 2.47 & 0.65 \\
\hline 36 & $2.48 E-02$ & $1.50 E-02$ & 0.5 & $6.87 E+10$ & 17.5 & 1.72 & 0.7 \\
\hline 36 & $1.50 \mathrm{E}-02$ & $9.12 E-03$ & 0.5 & $7.05 E+10$ & 16.8 & 1.77 & 0.75 \\
\hline 37 & $9.12 E-03$ & 5.53E-03 & 0.5 & $6.95 E+10$ & 15.7 & 1.74 & 0.79 \\
\hline 38 & 5.53E-03 & $1.23 E-03$ & 1.5 & $2.27 E+11$ & 14.4 & 5.68 & 0.85 \\
\hline 39 & $1.23 E-03$ & 4.54E-04 & 1 & $1.54 E+11$ & 13 & 3.85 & 0.9 \\
\hline 40 & 4.54E-04 & $2.75 E-0.4$ & 0.5 & $8.21 E+10$ & 7.7 & 2.06 & 0.97 \\
\hline 41 & 2.75E-04 & $2.14 E-04$ & 0.25 & $4.23 E+10$ & 10.6 & 1.06 & 1 \\
\hline 42 & 2.14E-04 & $1.01 E-04$ & 0.75 & $1.25 E+11$ & 5.7 & 3.14 & 1 \\
\hline 43 & 1.01E-04 & 2.90E-05 & 1.25 & $2.25 E+11$ & 9.3 & 5.63 & 1.1 \\
\hline 44 & $2.90 E-05$ & 6.48E-06 & 1.5 & $2.77 E+11$ & 7.9 & 6.93 & 1.16 \\
\hline 46 & $6.48 E-06$ & 3.93E-06 & 0.5 & $8.06 E+10$ & 3.6 & 2.02 & 1.06 \\
\hline 46 & $3.93 E-06$ & $3.06 \mathrm{E}-06$ & 0.25 & $4.12 E+10$ & 10.6 & 1.03 & 1.07 \\
\hline 47 & $3.06 E-06$ & $1.86 E-06$ & 0.5 & $7.94 E+10$ & 10.5 & 1.99 & 1.05 \\
\hline 48 & $1.86 \mathrm{E}-06$ & 1.13E-06 & 0.5 & $7.59 E+10$ & 11 & 1.9 & 1.01 \\
\hline 49 & 1.13E-06 & 5.32E-07 & 0.75 & $1.11 E+11$ & 11.2 & 2.78 & 0.98 \\
\hline 50 & 5.32E-07 & 4.14E-07 & 0.25 & $3.63 E+10$ & 14 & 0.91 & 0.91 \\
\hline 51 & 4.14E-07 & $1.00 E-10$ & 8.328 & $1.26 E+12$ & 22.4 & 31.42 & 1 \\
\hline
\end{tabular}


Table 14. Cumulative adjusted group fluence rates for 1-8 irradiation location.

\begin{tabular}{|c|c|c|c|c|c|c|}
\hline GROUP & EU & EL & CPHA & UNCA & FRCPHA & RCPH \\
\hline 1 & $1.80 \mathrm{E}+01$ & $1.60 E+01$ & $3.75 E+06$ & 20.6 & 0 & 0.59 \\
\hline 2 & $1.60 \mathrm{E}+01$ & $1.40 E+01$ & $2.69 E+07$ & 19.9 & 0 & 0.58 \\
\hline 3 & $1.40 E+01$ & 1.35E+01 & $4.44 E+07$ & 19 & 0 & 0.57 \\
\hline 4 & $1.35 E+01$ & $1.30 E+01$ & $7.03 E+07$ & 18.2 & 0 & 0.56 \\
\hline 5 & $1.30 E+01$ & $1.25 E+01$ & $1.07 E+08$ & 17.4 & 0 & 0.54 \\
\hline 6 & $1.25 E+01$ & $1.20 E+01$ & $1.57 E+08$ & 16.6 & 0 & 0.53 \\
\hline 7 & $1.20 \mathrm{E}+01$ & 1.15E+01 & $2.25 E+08$ & 15.7 & 0.01 & 0.51 \\
\hline 8 & $1.15 E+01$ & $1.10 E+01$ & $3.16 E+08$ & 14.6 & 0.01 & 0.49 \\
\hline 8 & $1.10 \mathrm{E}+01$ & $1.05 E+01$ & $4.39 E+08$ & 13.4 & 0.01 & 0.46 \\
\hline 10 & $1.05 E+01$ & $1.00 E+01$ & $6.03 E+08$ & 12 & 0.02 & 0.44 \\
\hline 11 & $1.00 E+01$ & $9.50 E+\infty 0$ & $8.30 E+08$ & 10.5 & 0.02 & 0.42 \\
\hline 12 & $9.50 E+\infty$ & $9.00 E+\infty 0$ & $1.15 E+\infty$ & 8.9 & 0.03 & 0.39 \\
\hline 13 & $9.00 E+\infty$ & $8.50 E+\infty$ & $1.58 \mathrm{E}+\infty$ & 7.5 & 0.04 & 0.37 \\
\hline 14 & $8.50 E+\infty 0$ & $8.00 E+\infty$ & $2.19 E+\infty 9$ & 6.5 & 0.05 & 0.34 \\
\hline 16 & $8.00 E+\infty$ & $7.50 E+\infty$ & $3.02 E+\infty 9$ & 6 & 0.08 & 0.32 \\
\hline 16 & $7.50 E+\infty 0$ & $7.00 E+\infty$ & $4.16 E+\infty 9$ & 6 & 0.1 & 0.3 \\
\hline 17 & $7.00 E+\infty$ & $6.50 E+\infty$ & $5.72 E+\infty 9$ & 6.2 & 0.14 & 0.29 \\
\hline 18 & $6.50 E+\infty$ & $6.00 E+\infty 0$ & $7.86 E+\infty$ & 6.3 & 0.2 & 0.27 \\
\hline 19 & $6.00 E+\infty$ & $5.50 E+\infty$ & $1.08 E+10$ & 6.2 & 0.27 & 0.25 \\
\hline 20 & $5.50 E+\infty$ & $5.00 E+\infty 0$ & $1.48 E+10$ & 5.9 & 0.37 & 0.24 \\
\hline 21 & $5.00 E+\infty$ & $4.50 E+\infty 0$ & $2.01 E+10$ & 5.5 & 0.5 & 0.23 \\
\hline 22 & $4.50 E+\infty 0$ & $4.00 E+\infty 0$ & $2.72 E+10$ & 5.1 & 0.68 & 0.22 \\
\hline 23 & $4.00 E+\infty$ & $3.50 E+\infty 0$ & $3.71 E+10$ & 4.7 & 0.93 & 0.21 \\
\hline 24 & $3.50 E+\infty 0$ & $3.00 E+\infty 0$ & $5.21 E+10$ & 4.3 & 1.31 & 0.21 \\
\hline 25 & $3.00 E+\infty$ & $2.50 E+\infty 0$ & $7.65 E+10$ & 3.9 & 1.92 & 0.21 \\
\hline 26 & $2.50 \mathrm{E}+\infty$ & $2.00 E+\infty 0$ & $1.15 E+11$ & 3.4 & 2.88 & 0.22 \\
\hline 27 & $2.00 E+\infty$ & $1.50 E+\infty 0$ & $1.74 E+11$ & 2.7 & 4.36 & 0.23 \\
\hline 28 & $1.50 E+00$ & $1.00 E+\infty$ & $2.74 E+11$ & 3.6 & 6.85 & 0.26 \\
\hline 29 & $1.00 E+\infty 0$ & $8.21 E-01$ & $3.28 E+11$ & 3.8 & 8.22 & 0.27 \\
\hline 30 & $8.21 E-01$ & 4.98E-01 & $4.73 E+11$ & 4.9 & 11.84 & 0.3 \\
\hline 31 & 4.98E-01 & $3.02 E-01$ & $5.94 E+11$ & 5.8 & 14.88 & 0.33 \\
\hline 32 & $3.02 E-01$ & 1.11E-01 & $7.70 E+11$ & 7.2 & 19.27 & 0.36 \\
\hline 33 & 1.11E-01 & $5.25 \mathrm{E}-02$ & $8.75 E+11$ & 7.8 & 21.9 & 0.38 \\
\hline 34 & 5.25E-02 & 2.48E-02. & $9.73 E+11$ & 8.3 & 24.37 & 0.39 \\
\hline 35 & $2.48 E-02$ & 1.50E-02 & $1.04 E+12$ & 8.5 & 26.09 & 0.4 \\
\hline 36 & $1.50 \mathrm{E}-02$ & $9.12 E-03$ & $1.11 E+12$ & 8.7 & 27.86 & 0.42 \\
\hline 37 & $9.12 E-03$ & $5.53 E-03$ & $1.18 E+12$ & 8.7 & 29.6 & 0.43 \\
\hline 38 & $5.53 E-03$ & 1.23E-03 & $1.41 E+12$ & 8.5 & 35.27 & 0.47 \\
\hline 39 & $1.23 E-03$ & 4.54E-04 & $1.56 \mathrm{E}+12$ & 8.3 & 39.12 & 0.49 \\
\hline 40 & 4.54E-0.4 & $2.75 E-04$ & $1.64 E+12$ & 7.9 & 41.18 & 0.5 \\
\hline 41 & 2.75E-04 & $2.14 E-0.4$ & $1.69 E+12$ & 7.7 & 42.24 & 0.51 \\
\hline 42 & 2.14E-04 & $1.01 E-04$ & $1.81 E+12$ & 7.2 & 45.38 & 0.53 \\
\hline 43 & $1.01 E-04$ & $2.90 E-05$ & $2.04 E+12$ & 6.4 & 51.01 & 0.56 \\
\hline 4 & 2.90E-05 & $6.48 E-06$ & $2.31 E+12$ & 5.6 & 57.94 & 0.59 \\
\hline 46 & $6.48 E-06$ & $3.93 E-06$ & $2.40 E+12$ & 5.4 & 59.96 & 0.6 \\
\hline 46 & $3.93 E-06$ & $3.06 E-06$ & $2.44 E+12$ & 5.3 & 61 & 0.61 \\
\hline 47 & $3.06 E-06$ & 1.86E-06 & $2.52 E+12$ & 5.1 & 62.98 & 0.62 \\
\hline 48 & $1.86 \mathrm{E}-06$ & $1.13 E-06$ & $2.59 E+12$ & 4.9 & 64.88 & 0.62 \\
\hline 40 & 1.13E-06 & 5.32E-07 & $2.70 E+12$ & 4.6 & 67.67 & 0.63 \\
\hline 80 & 5.32E-07 & $4.14 E-07$ & $2.74 E+12$ & 4.6 & 68.58 & 0.64 \\
\hline 51 & 4.14E-07 & $1.00 E-10$ & $3.99 E+12$ & 7.7 & 100 & 0.72 \\
\hline
\end{tabular}



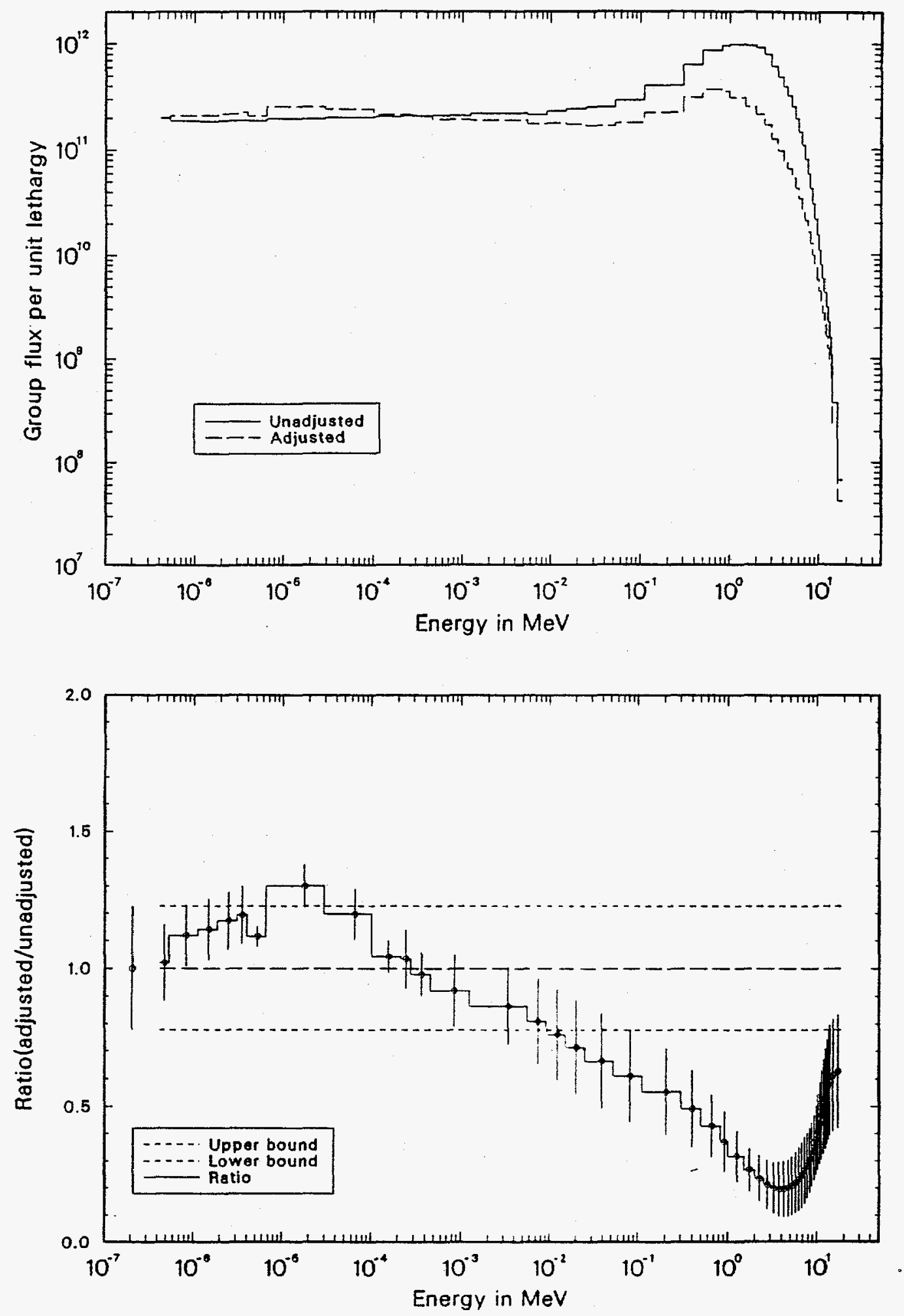

Figure I3. Upper part of figure compares adjusted and unadjusted (input) group fluence rates for I-22 location and lower part displays the ratio of adjusted-to-unadjusted group values with input uncertainty bounds and final uncertainty error bars. 
Table 15. Adjusted group fluence rates for 1-22 irradiation location.

\begin{tabular}{|c|c|c|c|c|c|c|c|}
\hline GROUP & EU & EL & DU & PHA & UNCA & FRPHA & RPH \\
\hline 1 & $1.80 E+01$ & $1.60 E+01$ & 0.118 & $4.95 E+06$ & 20.6 & 0 & 0.63 \\
\hline 2 & $1.60 E+01$ & $1.40 E+01$ & 0.134 & $3.06 E+07$ & 20.4 & 0 & 0.61 \\
\hline 3 & $1.40 E+01$ & 1.35E+01 & 0.036 & 2.33E+07 & 20.1 & 0 & 0.6 \\
\hline 4 & 1.35E+01 & $1.30 E+01$ & 0.038 & $3.45 E+07$ & 19.6 & 0 & 0.58 \\
\hline 6 & 1.30E+01 & $1.25 E+01$ & 0.039 & $4.88 E+07$ & 19.1 & 0 & 0.55 \\
\hline 6 & 1.25E+04 & $1.20 \mathrm{E}+01$ & 0.041 & $6.70 E+07$ & 18.3 & 0 & 0.53 \\
\hline 7 & $1.20 E+01$ & $1.15 E+01$ & 0.043 & $9.05 E+07$ & 17.4 & 0 & 0.5 \\
\hline 8 & 1.15E+01 & $1.10 E+01$ & 0.044 & $1.21 E+08$ & 16.3 & 0 & 0.47 \\
\hline 9 & $1.10 E+01$ & $1.05 E+01$ & 0.047 & $1.61 E+\infty 8$ & 15 & 0 & 0.44 \\
\hline 10 & $1.05 E+01$ & $1.00 E+01$ & 0.049 & $2.16 E+08$ & 13.8 & 0 & 0.41 \\
\hline 11 & $1.00 E+01$ & $9.50 E+\infty 0$ & 0.051 & $2.96 \mathrm{E}+08$ & 12.7 & 0.01 & 0.38 \\
\hline 12 & $9.50 E+\infty 0$ & $9.00 E+\infty 0$ & 0.054 & $4.07 E+08$ & 11.9 & 0.01 & 0.35 \\
\hline 13 & $9.00 E+\infty 0$ & $8.50 E+\infty$ & 0.057 & $5.62 E+08$ & 11.7 & 0.01 & 0.32 \\
\hline 14 & $8.50 E+\infty 0$ & $8.00 E+\infty 0$ & 0.061 & $7.74 E+08$ & 11.8 & 0.01 & 0.3 \\
\hline 15 & $8.00 E+00$ & $7.50 E+\infty 0$ & 0.065 & $1.06 E+\infty 9$ & 12.1 & 0.02 & 0.28 \\
\hline 16 & $7.50 E+\infty 0$ & $7.00 E+\infty 0$ & 0.069 & $1.44 E+\infty 9$ & 12.3 & 0.03 & 0.26 \\
\hline 17 & $7.00 E+\infty 0$ & $6.50 E+00$ & 0.074 & $1.96 E+09$ & 12.1 & 0.04 & 0.25 \\
\hline 18 & $6.50 E+\infty 0$ & $6.00 E+\infty$ & 0.08 & $2.68 E+09$ & 11.7 & 0.05 & 0.23 \\
\hline 19 & $6.00 E+00$ & $5.50 \mathrm{E}+00$ & 0.087 & $3.69 E+\infty 9$ & 11.1 & 0.07 & 0.22 \\
\hline 20 & $5.50 E+\infty$ & $5.00 E+00$ & 0.095 & $5.03 E+\infty 9$ & 10.7 & 0.1 & 0.21 \\
\hline 21 & $5.00 E+\infty 0$ & $4.50 E+\infty 0$ & 0.105 & $6.75 E+\infty 9$ & 10.4 & 0.13 & 0.2 \\
\hline 22 & $4.50 E+\infty 0$ & $4.00 E+\infty 0$ & 0.118 & $9.04 E+\infty 9$ & 10.2 & 0.17 & 0.2 \\
\hline 23 & $4.00 E+\infty 0$ & $3.50 E+\infty 0$ & 0.134 & $1.27 E+10$ & 9.9 & 0.25 & 0.2 \\
\hline 24 & $3.50 E+\infty 0$ & $3.00 E+\infty 0$ & 0.154 & $1.90 E+10$ & 9.4 & 0.37 & 0.2 \\
\hline 26 & $3.00 E+\infty 0$ & $2.50 E+00$ & 0.182 & $3.08 E+10$ & 8.9 & 0.6 & 0.21 \\
\hline 26 & $2.50 E+00$ & $2.00 E+\infty 0$ & 0.223 & $4.82 E+10$ & 8.4 & 0.93 & 0.24 \\
\hline 27 & $2.00 E+\infty 0$ & $1.50 E+\infty$ & 0.288 & $7.33 E+10$ & 7.8 & 1.42 & 0.27 \\
\hline 28 & $1.50 E+\infty 0$ & $1.00 \mathrm{E}+00$ & 0.405 & $1.25 E+11$ & 9.4 & 2.42 & 0.32 \\
\hline 29 & $1.00 E+\infty 0$ & 8.21E-01 & 0.197 & $6.96 E+10$ & 11.1 & 1.35 & 0.37 \\
\hline 30 & 8.21E-01 & 4.98E-01 & 0.5 & $1.84 \mathrm{E}+11$ & 11.4 & 3.57 & 0.43 \\
\hline 31 & 4.98E-01 & $3.02 \mathrm{E}-01$ & 0.5 & $1.56 \mathrm{E}+11$ & 14 & 3.01 & 0.49 \\
\hline 32 & $3.02 E-01$ & $1.11 E-01$ & 1 & $2.25 E+11$ & 15.6 & 4.36 & 0.55 \\
\hline 33 & 1.11E-01 & $5.25 E-02$ & 0.75 & $1.35 E+11$ & 16.8 & 2.62 & 0.61 \\
\hline 34 & 5.25E-02 & $2.48 E-02$ & 0.75 & $1.27 \mathrm{E}+11$ & 17.5 & 2.45 & 0.66 \\
\hline 36 & $2.48 E-02$ & $1.50 E-02$ & 0.5 & $8.80 E+10$ & 17.5 & 1.7 & 0.71 \\
\hline 36 & $1.50 \mathrm{E}-02$ & $9.12 E-03$ & 0.5 & $8.98 E+10$ & 16.8 & 1.74 & 0.76 \\
\hline 37 & $9.12 E-03$ & 5.53E-03 & 0.5 & $8.84 E+10$ & 15.8 & 1.71 & 0.81 \\
\hline 38 & $5.53 E-03$ & 1.23E-03 & 1.5 & $2.89 E+11$ & 14.5 & 5.59 & 0.86 \\
\hline 39 & $1.23 E-03$ & 4.54E-04 & 1 & $1.96 \mathrm{E}+11$ & 13.1 & 3.8 & 0.92 \\
\hline 40 & 4.54E-04 & 2.75E-04 & 0.5 & $1.04 E+11$ & 7.8 & 2.01 & 0.98 \\
\hline 41 & 2.75E-04 & 2.14E-04 & 0.25 & $5.48 \mathrm{E}+10$ & 10.7 & 1.06 & 1.03 \\
\hline 42 & 2.14E-04 & $1.01 E-04$ & 0.75 & $1.63 E+11$ & 5.8 & 3.16 & 1.04 \\
\hline 43 & $1.01 E-04$ & 2.90E-05 & 1.25 & $3.06 E+11$ & 9.4 & 5.91 & 1.2 \\
\hline 4 & 2.90E-05 & $6.48 E-06$ & 1.5 & $3.88 E+11$ & 7.8 & 7.52 & 1.3 \\
\hline 46 & $6.48 E-06$ & $3.93 E-06$ & 0.5 & $1.06 E+11$ & 3.7 & 2.05 & 1.12 \\
\hline 46 & 3.93E-06 & $3.06 E-06$ & 0.25 & $5.72 E+10$ & 10.6 & 1.11 & 1.19 \\
\hline 47 & $3.06 E-06$ & $1.86 E-\infty 6$ & 0.5 & $1.11 E+11$ & 10.5 & 2.15 & 1.17 \\
\hline 48 & $1.86 E-06$ & 1.13E-06 & 0.5 & $1.07 E+11$ & 10.9 & 2.07 & 1.14 \\
\hline 49 & 1.13E-06 & 5.32E-07 & 0.75 & $1.58 \mathrm{E}+11$ & 11.1 & 3.06 & 1.12 \\
\hline 60 & 5.32E-07 & 4.14E-07 & 0.25 & $5.10 E+10$ & 13.9 & 0.99 & 1.02 \\
\hline 51 & 4.14E-07 & 1.00E-10 & 8.328 & $1.57 E+12$ & 22.4 & 30.37 & 1 \\
\hline
\end{tabular}


Table 16. Cumulative Adjusted group fluence rates for 1-22 irradiation location.

\begin{tabular}{|c|c|c|c|c|c|c|}
\hline GROUP & $\mathbf{E U}$ & EL & CPHA & UNCA & FRCPHA & RCPH \\
\hline 1 & $1.80 E+01$ & $1.60 E+01$ & $4.95 E+06$ & 20.6 & 0 & 0.63 \\
\hline 2 & $1.60 \mathrm{E}+01$ & $1.40 E+01$ & $3.56 E+07$ & 19.9 & 0 & 0.61 \\
\hline 3 & $1.40 E+01$ & 1.35E+01 & $5.89 E+07$ & 18.9 & 0 & 0.61 \\
\hline 4 & $1.35 E+01$ & $1.30 E+01$ & $9.35 E+07$ & 18.2 & 0 & 0.59 \\
\hline 5 & $1.30 E+01$ & $1.25 E+01$ & $1.42 E+08$ & 17.4 & 0 & 0.58 \\
\hline 6 & $1.25 E+01$ & $1.20 E+01$ & $2.09 E+08$ & 16.5 & 0 & 0.56 \\
\hline 7 & $1.20 E+01$ & $1.15 E+01$ & $3.00 E+08$ & 15.6 & 0.01 & 0.54 \\
\hline 8 & $1.15 E+01$ & $1.10 E+01$ & $4.21 E+08$ & 14.5 & 0.01 & 0.52 \\
\hline 9 & $1.10 E+01$ & $1.05 E+01$ & $5.81 E+08$ & 13.3 & 0.01 & 0.49 \\
\hline 10 & $1.05 E+01$ & $1.00 E+01$ & 7.97E+08 & 11.9 & 0.02 & 0.47 \\
\hline 11 & $1.00 E+01$ & $9.50 E+\infty$ & $1.09 E+09$ & 10.4 & 0.02 & 0.44 \\
\hline 12 & $9.50 E+\infty 0$ & $9.00 E+\infty$ & $1.50 E+09$ & 8.8 & 0.03 & 0.41 \\
\hline 13 & $9.00 E+00$ & $8.50 E+00$ & $2.06 E+09$ & 7.4 & 0.04 & 0.38 \\
\hline 14 & $8.50 E+\infty$ & $8.00 E+\infty 0$ & $2.84 E+09$ & 6.4 & 0.05 & 0.36 \\
\hline 15 & $8.00 E+00$ & $7.50 E+\infty 0$ & $3.89 \mathrm{E}+09$ & 5.9 & 0.08 & 0.33 \\
\hline 16 & $7.50 E+\infty 0$ & $7.00 E+\infty$ & $5.33 E+09$ & 6 & 0.1 & 0.31 \\
\hline 17 & $7.00 E+\infty$ & $6.50 E+\infty 0$ & $7.29 E+09$ & 6.2 & 0.14 & 0.29 \\
\hline 18 & $6.50 E+\infty 0$ & $6.00 E+\infty$ & $9.98 E+09$ & 6.3 & 0.19 & 0.27 \\
\hline 19 & $6.00 E+\infty 0$ & $5.50 E+\infty$ & $1.37 E+10$ & 6.2 & 0.26 & 0.26 \\
\hline 20 & $5.50 E+\infty 0$ & $5.00 E+00$ & $1.87 E+10$ & 5.9 & 0.36 & 0.24 \\
\hline 21 & $5.00 E+\infty 0$ & $4.50 E+\infty$ & $2.54 E+10$ & 5.5 & 0.49 & 0.23 \\
\hline 22 & $4.50 E+\infty 0$ & $4.00 E+\infty 0$ & $3.45 E+10$ & 5.1 & 0.67 & 0.22 \\
\hline 23 & $4.00 E+\infty 0$ & $3.50 E+\infty 0$ & $4.72 E+10$ & 4.7 & 0.91 & 0.21 \\
\hline 24 & $3.50 E+\infty 0$ & $3.00 E+\infty$ & $6.62 E+10$ & 4.3 & 1.28 & 0.21 \\
\hline 26 & $3.00 E+\infty 0$ & $2.50 E+\infty 0$ & $9.70 E+10$ & 3.9 & 1.88 & 0.21 \\
\hline 26 & $2.50 E+\infty 0$ & $2.00 E+\infty 0$ & $1.45 E+11$ & 3.4 & 2.81 & 0.22 \\
\hline 27 & $2.00 E+\infty 0$ & $1.50 E+\infty$ & $2.19 E+11$ & 2.7 & 4.23 & 0.23 \\
\hline 28 & $1.50 E+\infty 0$ & $1.00 E+\infty$ & $3.44 E+11$ & 3.6 & 6.65 & 0.26 \\
\hline 29 & $1.00 E+\infty 0$ & 8.21E-01 & $4.13 E+11$ & 3.8 & 8 & 0.27 \\
\hline 30 & $8.21 E-01$ & $4.98 E-01$ & $5.98 E+11$ & 4.9 & 11.56 & 0.31 \\
\hline 31 & 4.98E-01 & $3.02 E-01$ & $7.53 E+11$ & 5.8 & 14.58 & 0.33 \\
\hline 32 & $3.02 E-01$ & 1.11E-01 & $9.79 E+11$ & 7.2 & 18.94 & 0.36 \\
\hline 33 & 1.11E-01 & $5.25 E-02$ & $1.11 E+12$ & 7.8 & 21.56 & 0.38 \\
\hline 34 & 5.25E-02 & $2.48 E-02$ & $1.24 E+12$ & 8.3 & 24.01 & 0.4 \\
\hline 36 & 2.48E-02 & $1.50 \mathrm{E}-02$ & $1.33 E+12$ & 8.6 & 25.71 & 0.41 \\
\hline 36 & $1.50 E-02$ & $9.12 E-03$ & $1.42 E+12$ & 8.7 & 27.45 & 0.43 \\
\hline 37 & $9.12 E-03$ & 5.53E-03 & $1.51 E+12$ & 8.7 & 29.16 & 0.44 \\
\hline 38 & 5.53E-03 & $1.23 E-03$ & $1.80 E+12$ & 8.6 & 34.75 & 0.48 \\
\hline 39 & 1.23E-03 & 4.54E-04 & $1.99 E+12$ & 8.3 & 38.55 & 0.5 \\
\hline 40 & $4.54 E-04$ & 2.75E-04 & $2.10 E+12$ & 8 & 40.56 & 0.51 \\
\hline 41 & 2.75E-04 & $2.14 E-04$ & $2.15 E+12$ & 7.8 & 41.62 & 0.52 \\
\hline 42 & $2.14 E-04$ & $1.01 E-04$ & $2.31 E+12$ & 7.3 & 44.78 & 0.54 \\
\hline 43 & $1.01 E-04$ & $2.90 E-05$ & $2.62 E+12$ & 6.4 & 50.69 & 0.57 \\
\hline 44 & 2.90E-05 & $6.48 E-06$ & $3.01 E+12$ & 5.5 & 58.21 & 0.62 \\
\hline 46 & $6.48 E-06$ & $3.93 E-06$ & $3.11 E+12$ & 5.3 & 60.26 & 0.63 \\
\hline 46 & $3.93 E-06$ & $3.06 E-06$ & 3.17E+12 & 5.2 & 61.37 & 0.63 \\
\hline 47 & $3.06 E-06$ & $1.86 \mathrm{E}-06$ & $3.28 E+12$ & 5 & 63.52 & 0.64 \\
\hline 48 & $1.86 E-06$ & 1.13E-06 & $3.39 E+12$ & 4.8 & 65.58 & 0.65 \\
\hline 49 & $1.13 E-06$ & 5.32E-07 & $3.55 E+12$ & 4.5 & 68.65 & 0.66 \\
\hline 50 & 5.32E-07 & 4.14E-07 & $3.60 E+12$ & 4.5 & 69.63 & 0.67 \\
\hline 51 & 4.14E-07 & $1.00 E-10$ & $5.17 E+12$ & 7.5 & 100 & 0.74 \\
\hline
\end{tabular}


Table OS. FERRET analysis summary for ATR OS-5 position.

\begin{tabular}{|c|c|c|c|c|c|c|c|c|}
\hline $\begin{array}{c}\text { Dosimeter } \\
\text { Reaction }\end{array}$ & $\begin{array}{c}\text { Measured } \\
\text { Rate } \\
\text { (Bq/atom) }\end{array}$ & $\begin{array}{c}\sigma \\
(\%) \\
\end{array}$ & $\begin{array}{l}\text { Calculated Rate } \\
\text { (Bq/atom) }\end{array}$ & $\begin{array}{c}\sigma \\
(\%) \\
\end{array}$ & $\mathrm{C} / \mathrm{M}$ & $\begin{array}{c}\text { FERRET-Fit } \\
\text { Rate (Bq/atom) }\end{array}$ & $\begin{array}{c}\sigma \\
(\%) \\
\end{array}$ & FF/M \\
\hline $45 \operatorname{Sc}(\mathrm{n}, \gamma)$ & $1.80 \mathrm{E}-13$ & 2.2 & $1.34 \mathrm{E}-13$ & 19.4 & 0.748 & $1.78 \mathrm{E}-13$ & 7.2 & 0.99 \\
\hline $197 \mathrm{Au}(\mathrm{n}, \gamma)$ & 2.05E-11 & 2 & $1.79 \mathrm{E}-11$ & 21.8 & 0.873 & $2.05 \mathrm{E}-11$ & 4.5 & 1 \\
\hline $235 U(n, f)$ & $3.78 \mathrm{E}-12$ & 2.3 & $3.40 \mathrm{E}-12$ & 17.3 & 0.901 & $3.75 \mathrm{E}-12$ & 3.2 & 0.99 \\
\hline $59 \mathrm{Co}(\mathrm{n}, \gamma)$ & $8.50 \mathrm{E}-13$ & 5 & 8.91E-13 & 20.9 & 1.048 & $8.81 \mathrm{E}-13$ & 6.8 & 1.04 \\
\hline $\operatorname{s8Fe}(n, \gamma)$ & $1.76 \mathrm{E}-14$ & 4.5 & $1.56 \mathrm{E}-14$ & 18 & 0.887 & $1.70 \mathrm{E}-14$ & 6.2 & 0.97 \\
\hline $237 \mathrm{~Np}(\mathrm{n}, \mathrm{f})$ & $5.01 \mathrm{E}-14$ & 2 & $1.80 \mathrm{E}-13$ & 20.4 & 3.589 & $5.01 E-14$ & 7.8 & 1 \\
\hline $238 \mathrm{U}(\mathrm{n}, \mathrm{f})$ & $6.60 \mathrm{E}-15$ & 2.3 & $3.24 \mathrm{E}-14$ & 18.6 & 4.914 & $6.54 \mathrm{E}-15$ & 2.9 & 0.99 \\
\hline $47 T i(n, p)$ & $1.95 \mathrm{E}-16$ & 2.9 & $2.14 \mathrm{E}-15$ & 21.1 & 0.963 & $2.04 \mathrm{E}-16$ & 5.2 & 1.05 \\
\hline $58 \mathrm{Ni}(\mathrm{n}, \mathrm{p})$ & $1.55 \mathrm{E}-15$ & 2 & $9.68 \mathrm{E}-15$ & 19.1 & 6.247 & $1.57 \mathrm{E}-15$ & 5.7 & 1.01 \\
\hline $\operatorname{S4Fe}(n, p)$ & $1.41 E-15$ & 16 & $7.36 \mathrm{E}-15$ & 18.4 & 5.22 & $1.35 \mathrm{E}-15$ & 5.6 & 0.96 \\
\hline $46 \operatorname{Ti}(n, p)$ & $2.01 \mathrm{E}-16$ & 4.1 & $9.34 \mathrm{E}-16$ & 21.9 & 4.646 & $2.01 \mathrm{E}-16$ & 9 & 1 \\
\hline $63 \mathrm{Cu}(\mathrm{n}, \alpha)$ & $7.20 \mathrm{E}-17$ & 27 & $4.53 \mathrm{E}-17$ & 17.9 & 0.629 & $1.44 \mathrm{E}-17$ & 7.6 & 0.2 \\
\hline 48Ti(n,p) & $6.25 \mathrm{E}-18$ & 15 & $2.26 \mathrm{E}-17$ & 20.2 & 3.617 & $6.73 \mathrm{E}-18$ & 10.5 & 1.08 \\
\hline $27 \mathrm{Al}(\mathrm{n}, \alpha)$ & $1.22 \mathrm{E}-17$ & 6.2 & $5.73 \mathrm{E}-17$ & 18.7 & 4.694 & $1.55 \mathrm{E}-17$ & 8.1 & 1.27 \\
\hline
\end{tabular}



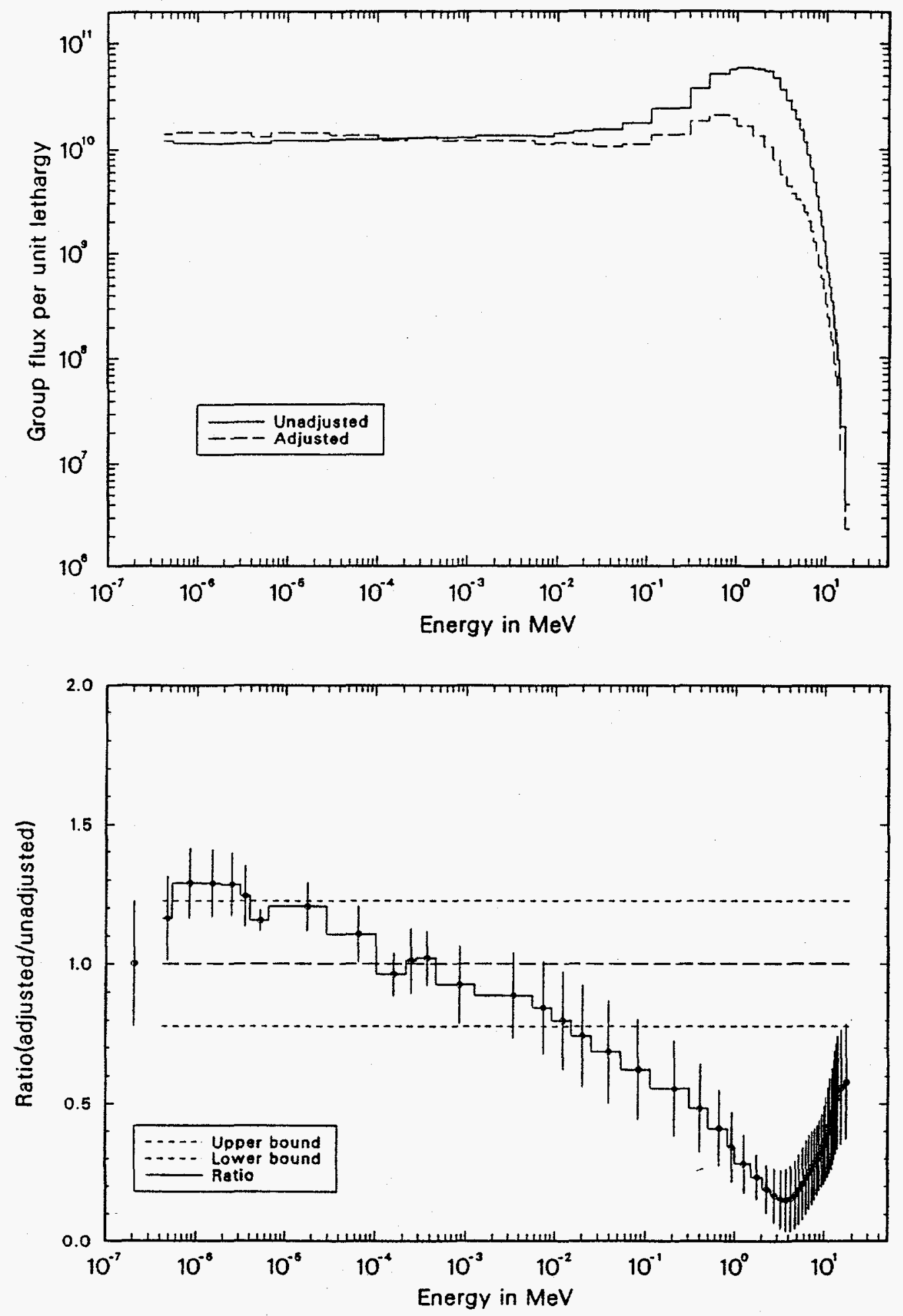

Figure OS1. Upper part of figure compares adjusted and unadjusted (input) group fluence rates for OS-5 location and lower part displays the ratio of adjusted-to-unadjusted group values with input uncertainty bounds and final uncertainty error bars. 
Table OS1. Adjusted group fluence rates for OS-5 irradiation location.

\begin{tabular}{|c|c|c|c|c|c|c|c|}
\hline GROUP & $E \mathbf{E U}$ & EL & $\mathrm{DU}$ & PHA & UNCA & FRPHA & RPH \\
\hline 1 & $1.80 E+01$ & $1.60 E+01$ & 0.118 & $2.75 E+05$ & 20.8 & 0 & 0.58 \\
\hline 2 & $1.60 E+01$ & $1.40 E+01$ & 0.134 & $1.68 E+06$ & 20.6 & 0 & 0.56 \\
\hline 3 & $1.40 \mathrm{E}+01$ & 1.35E+01 & 0.036 & $1.27 E+\infty 6$ & 20.4 & 0 & 0.54 \\
\hline 4 & $1.35 E+01$ & $1.30 E+01$ & 0.038 & $1.86 \mathrm{E}+06$ & 20.1 & 0 & 0.52 \\
\hline 5 & 1.30E+01 & $1.25 E+01$ & 0.039 & $2.61 E+\infty 6$ & 19.6 & 0 & 0.49 \\
\hline 6 & $1.25 E+01$ & $1.20 E+01$ & 0.041 & $3.58 E+06$ & 19.1 & 0 & 0.47 \\
\hline 7 & $1.20 E+01$ & $1.15 E+01$ & 0.043 & $4.85 E+06$ & 18.4 & 0 & 0.44 \\
\hline 8 & $1.15 E+01$ & $1.10 E+01$ & 0.044 & $6.51 E+06$ & 17.5 & 0 & 0.42 \\
\hline 9 & $1.10 E+01$ & $1.05 E+01$ & 0.047 & $8.73 E+06$ & 16.4 & 0 & 0.4 \\
\hline 10 & $1.05 E+01$ & $1.00 E+01$ & 0.049 & $1.18 E+07$ & 15.3 & 0 & 0.37 \\
\hline 11 & $1.00 E+01$ & $9.50 E+00$ & 0.051 & $1.64 E+07$ & 14.2 & 0.01 & 0.35 \\
\hline 12 & $9.50 E+\infty$ & $9.00 E+\infty 0$ & 0.054 & $2.30 E+07$ & 13.4 & 0.01 & 0.33 \\
\hline 13 & $9.00 E+\infty 0$ & $8.50 E+\infty 0$ & 0.057 & $3.23 E+07$ & 12.9 & 0.01 & 0.31 \\
\hline 14 & $8.50 E+\infty$ & $8.00 E+\infty 0$ & 0.061 & $4.53 E+07$ & 12.8 & 0.01 & 0.29 \\
\hline 16 & $8.00 E+\infty$ & $7.50 E+\infty$ & 0.065 & $6.30 E+07$ & 13.1 & 0.02 & 0.28 \\
\hline 16 & $7.50 E+\infty$ & $7.00 E+\infty$ & 0.009 & $8.72 E+07$ & 13.4 & 0.03 & 0.27 \\
\hline 17 & $7.00 E+\infty$ & $6.50 E+\infty$ & 0.074 & $1.19 E+08$ & 13.5 & 0.04 & 0.25 \\
\hline 18 & $6.50 E+\infty$ & $6.00 \mathrm{E}+\infty$ & 0.08 & $1.61 E+08$ & 13.4 & 0.05 & 0.23 \\
\hline 19 & $6.00 E+\infty$ & $5.50 E+\infty$ & 0.087 & $2.12 E+08$ & 13.1 & 0.07 & 0.21 \\
\hline 20 & $5.50 \mathrm{E}+\infty$ & $5.00 E+\infty 0$ & 0.095 & $2.72 E+08$ & 12.6 & 0.09 & 0.19 \\
\hline 21 & $5.00 E+\infty$ & $4.50 E+\infty$ & 0.105 & $3.42 E+08$ & 12.2 & 0.11 & 0.17 \\
\hline 22 & $4.50 E+\infty 0$ & $4.00 E+\infty$ & 0.118 & $4.34 E+08$ & 11.8 & 0.14 & 0.16 \\
\hline 23 & $4.00 E+\infty 0$ & $3.50 E+\infty 0$ & 0.134 & $5.88 E+08$ & 11.3 & 0.19 & 0.15 \\
\hline 24 & $3.50 E+\infty$ & $3.00 E+\infty$ & 0.154 & 8.77E+08 & 10.7 & 0.28 & 0.15 \\
\hline 26 & $3.00 E+\infty 0$ & $2.50 E+\infty 0$ & 0.182 & $1.44 E+\infty 9$ & 9.8 & 0.47 & 0.17 \\
\hline 26 & $2.50 E+\infty 0$ & $2.00 E+\infty 0$ & 0.223 & $2.33 E+\infty 9$ & 8.8 & 0.76 & 0.19 \\
\hline 27 & $2.00 E+00$ & $1.50 E+\infty 0$ & 0.288 & $3.84 E+\infty 9$ & 8.1 & 1.25 & 0.23 \\
\hline 28 & $1.50 E+\infty$ & $1.00 E+\infty 0$ & 0.405 & $6.69 E+09$ & 10.6 & 2.17 & 0.28 \\
\hline 29 & $1.00 E+\infty 0$ & 8.21E-01 & 0.197 & $3.87 E+09$ & 12.8 & 1.26 & 0.34 \\
\hline 30 & 8.21E-01 & 4.98E-01 & 0.5 & $1.06 E+10$ & 13.9 & 3.44 & 0.41 \\
\hline 31 & 4.98E-01 & 3.02E-01 & 0.5 & $9.19 E+\infty 9$ & 15.9 & 2.99 & 0.48 \\
\hline 32 & $3.02 E-01$ & 1.11E-01 & 1 & $1.36 E+10$ & 17.2 & 4.41 & 0.56 \\
\hline 33 & 1.11E-01 & 5.25E-02 & 0.75 & $8.28 E+09$ & 18.1 & 2.69 & 0.62 \\
\hline 34 & 5.25E-02 & 2.48E-02 & 0.75 & $7.85 E+09$ & 18.4 & 2.55 & 0.69 \\
\hline 36 & $2.48 E-02$ & $1.50 E-02$ & 0.5 & $5.50 E+\infty 9$ & 18.3 & 1.78 & 0.74 \\
\hline 36 & $1.50 E-02$ & $9.12 E-03$ & 0.5 & $5.66 E+09$ & 17.5 & 1.84 & 0.8 \\
\hline 37 & $9.12 E-03$ & $5.53 E-03$ & 0.5 & $5.54 E+09$ & 16.5 & 1.8 & 0.84 \\
\hline 38 & 5.53E-03 & $1.23 E-03$ & 1.5 & $1.78 E+10$ & 15.3 & 5.79 & 0.89 \\
\hline 39 & $1.23 E-03$ & $4.54 E-04$ & 1 & $1.19 E+10$ & 13.9 & 3.85 & 0.93 \\
\hline 40 & 4.54E-04 & 2.75E-04 & 0.5 & $6.48 E+09$ & 9.9 & 2.11 & 1.02 \\
\hline 41 & 2.75E-04 & $2.14 E-04$ & 0.25 & $3.21 E+09$ & 11.6 & 1.04 & 1.01 \\
\hline 42 & 2.14E-04 & $1.01 E-04$ & 0.75 & $9.05 E+09$ & 7.8 & 2.94 & 0.96 \\
\hline 43 & $1.01 E-04$ & 2.90E-05 & 1.25 & $1.70 E+10$ & 10.1 & 5.51 & 1.11 \\
\hline 44 & 2.90E-05 & $6.48 E-06$ & 1.5 & $2.16 E+10$ & 8.6 & 7.02 & 1.2 \\
\hline 46 & $6.48 E-06$ & $3.93 E-06$ & 0.5 & $6.59 E+09$ & 3.8 & 2.14 & 1.16 \\
\hline 48 & $3.93 E-06$ & $3.06 E-06$ & 0.25 & $3.57 E+09$ & 10.8 & 1.16 & 1.24 \\
\hline 47 & $3.06 E-06$ & $1.86 E-06$ & 0.5 & $7.29 \mathrm{E}+\infty$ & 11.3 & 2.37 & 1.28 \\
\hline 48 & $1.86 E-06$ & $1.13 E-06$ & 0.5 & $7.23 E+\infty 9$ & 12.1 & 2.35 & 1.29 \\
\hline 49 & 1.13E-06 & 5.32E-07 & 0.75 & $1.09 E+10$ & 12.5 & 3.55 & 1.29 \\
\hline 50 & 5.32E-07 & 4.14E-07 & 0.25 & $3.49 E+\infty 9$ & 15 & 1.13 & 1.16 \\
\hline 51 & 4.14E-07 & $1.00 \mathrm{E}-10$ & 8.328 & $9.41 E+10$ & 22.4 & 30.57 & 1 \\
\hline
\end{tabular}


Table OS2. Cumulative adjusted group fluence rates for OS-5 irradiation location.

\begin{tabular}{|c|c|c|c|c|c|c|}
\hline GROUP & EU & EL & CPHA & UNCA & FRCPHA & $\overline{\text { RCPH }}$ \\
\hline 1 & $1.80 \mathrm{E}+01$ & $1.60 \mathrm{E}+01$ & $2.75 E+05$ & 20.8 & 0 & 0.58 \\
\hline 2 & $1.60 E+01$ & $1.40 E+01$ & $1.95 E+\infty 6$ & 20.1 & 0 & 0.56 \\
\hline 3 & $1.40 E+01$ & 1.35E+01 & $3.22 E+\infty 6$ & 19.2 & 0 & 0.55 \\
\hline 4 & $1.35 E+01$ & $1.30 \mathrm{E}+01$ & $5.08 \mathrm{E}+06$ & 18.5 & 0 & 0.54 \\
\hline 6 & $1.30 E+01$ & $1.25 E+01$ & $7.69 E+06$ & 17.8 & 0 & 0.52 \\
\hline 6 & $1.25 E+01$ & $1.20 \mathrm{E}+01$ & $1.13 E+07$ & 17.1 & 0 & 0.5 \\
\hline 7 & $1.20 E+01$ & 1.15E+01 & $1.61 E+07$ & 16.3 & 0.01 & 0.48 \\
\hline 8 & $1.15 E+01$ & 1.10E+01 & $2.26 E+07$ & 15.4 & 0.01 & 0.46 \\
\hline 9 & $1.10 E+01$ & $1.05 E+01$ & $3.14 E+07$ & 14.4 & 0.01 & 0.44 \\
\hline 10 & $1.05 E+01$ & $1.00 \mathrm{E}+01$ & $4.32 E+07$ & 13.3 & 0.01 & 0.42 \\
\hline 11 & $1.00 E+01$ & $9.50 E+\infty 0$ & 5.97E+07 & 12 & 0.02 & 0.4 \\
\hline 12 & $9.50 \mathrm{E}+\infty 0$ & $9.00 E+\infty 0$ & $8.26 E+07$ & 10.7 & 0.03 & 0.38 \\
\hline 13 & $9.00 E+\infty 0$ & $8.50 E+\infty 0$ & $1.15 E+08$ & 9.4 & 0.04 & 0.36 \\
\hline 14 & $8.50 E+\infty 0$ & $8.00 E+\infty 0$ & $1.60 E+08$ & 8.3 & 0.05 & 0.34 \\
\hline 16 & $8.00 E+00$ & $7.50 E+\infty 0$ & $2.23 E+08$ & 7.7 & 0.07 & 0.32 \\
\hline 16 & $7.50 E+\infty 0$ & $7.00 E+\infty 0$ & $3.10 E+08$ & 7.6 & 0.1 & 0.3 \\
\hline 17 & $7.00 E+00$ & $6.50 E+\infty 0$ & $4.30 E+08$ & 7.7 & 0.14 & 0.29 \\
\hline 18 & $6.50 \mathrm{E}+\infty 0$ & $6.00 E+\infty 0$ & $5.91 E+08$ & 7.9 & 0.19 & 0.27 \\
\hline 19 & $6.00 E+\infty 0$ & $5.50 E+\infty 0$ & $8.02 E+08$ & 8 & 0.26 & 0.25 \\
\hline 20 & $5.50 \mathrm{E}+\infty 0$ & $5.00 E+\infty 0$ & $1.07 E+09$ & 7.8 & 0.35 & 0.23 \\
\hline 21 & $5.00 E+\infty 0$ & $4.50 E+\infty$ & $1.42 E+\infty 9$ & 7.5 & 0.46 & 0.21 \\
\hline 22 & $4.50 E+00$ & $4.00 E+\infty 0$ & $1.85 E+09$ & 7.1 & 0.6 & 0.2 \\
\hline 23 & $4.00 E+\infty 0$ & $3.50 E+00$ & $2.44 E+\infty 9$ & 6.5 & 0.79 & 0.18 \\
\hline 24 & $3.50 E+00$ & $3.00 E+\infty 0$ & $3.32 E+09$ & 6 & 1.08 & 0.17 \\
\hline 26 & $3.00 E+\infty 0$ & $2.50 E+00$ & 4.75E+09 & 5.2 & 1.54 & 0.17 \\
\hline 26 & $2.50 E+\infty 0$ & $2.00 E+\infty$ & $7.08 E+09$ & 4.3 & 2.3 & 0.18 \\
\hline 27 & $2.00 E+00$ & $1.50 E+00$ & $1.09 E+10$ & 3 & 3.55 & 0.19 \\
\hline 28 & $1.50 E+00$ & $1.00 E+\infty 0$ & $1.76 E+10$ & 4.2 & 5.72 & 0.22 \\
\hline 29 & $1.00 E+\infty 0$ & 8.21E-01 & $2.15 E+10$ & 4.8 & 6.98 & 0.23 \\
\hline 30 & 8.21E-01 & 4.98E-01 & $3.21 E+10$ & 6.7 & 10.42 & 0.27 \\
\hline 31 & $4.98 \mathrm{E}-01$ & $3.02 E-01$ & $4.13 E+10$ & 7.9 & 13.4 & 0.3 \\
\hline 32 & $3.02 E-01$ & $1.11 E-01$ & $5.48 E+10$ & 9.4 & 17.81 & 0.34 \\
\hline 33 & 1.11E-01 & 5.25E-02 & $6.31 E+10$ & 10 & 20.5 & 0.36 \\
\hline 34 & 5.25E-02 & 2.48E-02 & $7.10 E+10$ & 10.4 & 23.05 & 0.38 \\
\hline 36 & $2.48 E-02$ & $1.50 E-02$ & $7.65 E+10$ & 10.6 & 24.84 & 0.4 \\
\hline 36 & $1.50 \mathrm{E}-02$ & $9.12 E-03$ & $8.21 E+10$ & 10.6 & 26.67 & 0.41 \\
\hline 37 & $9.12 E-03$ & $5.53 E-03$ & 8.77E+10 & 10.5 & 28.47 & 0.42 \\
\hline 38 & $5.53 E-03$ & $1.23 E-03$ & $1.06 \mathrm{E}+11$ & 10.1 & 34.26 & 0.47 \\
\hline 39 & 1.23E-03 & 4.54E-04 & 1.17E+11 & 9.7 & 38.11 & 0.49 \\
\hline 40 & 4.54E-04 & 2.75E-04 & $1.24 E+11$ & 9.3 & 40.22 & 0.5 \\
\hline 41 & 2.75E-04 & $2.14 E-04$ & $1.27 E+11$ & 9.2 & 41.26 & 0.51 \\
\hline 42 & 2.14E-04 & $1.01 E-04$ & $1.36 E+11$ & 8.6 & 44.2 & 0.53 \\
\hline 43 & 1.01E-04 & $2.90 E-05$ & $1.53 E+11$ & 7.7 & 49.71 & 0.56 \\
\hline 4 & 2.90E-05 & $6.48 E-06$ & $1.75 E+11$ & 6.7 & 56.73 & 0.6 \\
\hline 46 & $6.48 E-06$ & $3.93 E-06$ & $1.81 E+11$ & 6.4 & 58.87 & 0.61 \\
\hline 46 & $3.93 E-06$ & $3.06 \mathrm{E}-06$ & $1.85 E+11$ & 6.3 & 60.03 & 0.62 \\
\hline 47 & $3.06 \mathrm{E}-06$ & $1.86 \mathrm{E}-06$ & $1.92 E+11$ & 6 & 62.4 & 0.63 \\
\hline 48 & $1.86 \mathrm{E}-06$ & 1.13E-06 & $1.99 E+11$ & 5.7 & 64.74 & 0.64 \\
\hline 49 & $1.13 E-06$ & 5.32E-07 & $2.10 E+11$ & 5.3 & 68.29 & 0.66 \\
\hline 60 & 5.32E-07 & $4.14 E-07$ & $2.14 E+11$ & 5.2 & 69.43 & 0.66 \\
\hline 61 & 4.14E-07 & $1.00 \mathrm{E}-10$ & $3.08 \mathrm{E}+11$ & 7.7 & 100 & 0.74 \\
\hline
\end{tabular}


Table SE. FERRET analysis summary for ATR SE positions.

\begin{tabular}{|c|c|c|c|c|c|c|c|c|}
\hline $\begin{array}{c}\text { Dosimeter } \\
\text { Reaction }\end{array}$ & $\begin{array}{c}\text { Measured } \\
\text { Rate } \\
\text { (Bq/atom) }\end{array}$ & $\begin{array}{c}\sigma \\
(\%)\end{array}$ & $\begin{array}{c}\text { Calculated Rate } \\
\text { (Bq/atom) }\end{array}$ & $\begin{array}{c}\sigma \\
(\%) \\
\end{array}$ & $\mathbf{C} / \mathbf{M}$ & $\begin{array}{c}\text { FERRET-Fit } \\
\text { Rate (Bq/atom) }\end{array}$ & $\begin{array}{c}\sigma \\
(\%)\end{array}$ & FF/M \\
\hline $\operatorname{45Sc}(n, \gamma)$ & $2.82 \mathrm{E}-11$ & 2 & $\begin{array}{c}\text { SE-1 } \\
2.24 E-11\end{array}$ & 19.4 & 0.795 & $2.81 \mathrm{E}-11$ & 6 & 1 \\
\hline $197 \mathrm{Au}(\mathrm{n}, \gamma)$ & $3.25 \mathrm{E}-09$ & 2 & $2.98 \mathrm{E}-09$ & 21.8 & 0.918 & $3.26 \mathrm{E}-09$ & 4.4 & 1 \\
\hline $235 U(n, f)$ & $6.64 \mathrm{E}-10$ & 2 & $5.67 \mathrm{E}-10$ & 17.3 & 0.854 & $6.62 \mathrm{E}-10$ & 3 & 1 \\
\hline $59 \mathrm{Co}(\mathrm{n}, \gamma)$ & $1.61 \mathrm{E}-10$ & 2.2 & $1.48 \mathrm{E}-10$ & 20.9 & 0.922 & $1.61 \mathrm{E}-10$ & 5.7 & 1 \\
\hline $\operatorname{s8Fe}(\mathrm{n}, \gamma)$ & $3.15 \mathrm{E}-12$ & 2.2 & $2.60 \mathrm{E}-12$ & 18 & 0.826 & $3.14 \mathrm{E}-12$ & 5.2 & 1 \\
\hline $237 \mathrm{~Np}(\mathrm{n}, \mathbf{n})$ & $2.96 \mathrm{E}-11$ & 2 & $3.00 \mathrm{E}-11$ & 20.4 & 1.012 & $2.96 \mathrm{E}-11$ & 5.6 & 1 \\
\hline $238 U(n, f)$ & $5.36 \mathrm{E}-12$ & 2.2 & $5.41 \mathrm{E}-12$ & 18.6 & 1.008 & $5.34 \mathrm{E}-12$ & 2.5 & 1 \\
\hline 47Ti(n,p) & $3.08 \mathrm{E}-13$ & 2.2 & $3.56 \mathrm{E}-13$ & 21.1 & 1.157 & $3.07 \mathrm{E}-13$ & 3.4 & 1 \\
\hline $58 \mathrm{Ni}(\mathrm{n}, \mathrm{p})$ & $1.67 \mathrm{E}-12$ & 2 & $1.61 \mathrm{E}-12$ & 19.1 & 0.966 & $1.67 \mathrm{E}-12$ & 3.7 & 1 \\
\hline $54 \mathrm{Fe}(\mathrm{n}, \mathrm{p})$ & $1.20 \mathrm{E}-12$ & 2.3 & $1.23 \mathrm{E}-12$ & 18.4 & 1.022 & $1.22 \mathrm{E}-12$ & 3.9 & 1.01 \\
\hline 46Ti(n,p) & $1.63 \mathrm{E}-13$ & 2.1 & $1.56 \mathrm{E}-13$ & 21.9 & 0.955 & $1.63 \mathrm{E}-13$ & 5.7 & 1 \\
\hline $63 \mathrm{Cu}(\mathrm{n}, \alpha)$ & $8.03 E-15$ & 3 & $7.55 \mathrm{E}-15$ & 17.9 & 0.94 & $7.75 \mathrm{E}-15$ & 5.1 & 0.97 \\
\hline 48Ti(n,p) & $4.14 \mathrm{E}-15$ & 2.8 & $3.77 \mathrm{E}-15$ & 20.2 & 0.91 & $4.16 \mathrm{E}-15$ & 5.9 & 1 \\
\hline $27 \mathrm{Al}(n, \alpha)$ & $8.53 \mathrm{E}-15$ & 5 & $\begin{array}{l}\text { 9.54E-15 } \\
\text { SE-3 }\end{array}$ & 18.7 & 1.119 & $9.07 E-15$ & 6.4 & 1.06 \\
\hline $\operatorname{45Sc}(n, \gamma)$ & $3.08 \mathrm{E}-11$ & 2 & $2.24 \mathrm{E}-11$ & 19.4 & 0.728 & $3.07 \mathrm{E}-11$ & 6 & 1 \\
\hline 197Au(n,y) & $3.63 \mathrm{E}-09$ & 2 & $2.98 \mathrm{E}-09$ & 21.8 & 0.822 & $3.64 \mathrm{E}-09$ & 4.4 & 1 \\
\hline $235 \mathrm{U}(\mathbf{n}, \mathbf{f})$ & $7.34 \mathrm{E}-10$ & 2 & 5.67E-10 & 17.3 & 0.773 & 7.30E-10 & 3 & 1 \\
\hline $59 \mathrm{Co}(\mathrm{n}, \gamma)$ & $1.76 \mathrm{E}-10$ & 2.3 & $1.48 \mathrm{E}-10$ & 20.9 & 0.844 & $1.77 \mathrm{E}-10$ & 5.7 & 1 \\
\hline $\operatorname{s8Fe}(n, \gamma)$ & $3.42 \mathrm{E}-12$ & 2.2 & $2.60 \mathrm{E}-12$ & 18 & 0.761 & $3.41 \mathrm{E}-12$ & 5.2 & 1 \\
\hline $237 N p(n, f)$ & $3.36 \mathrm{E}-11$ & 2 & $3.00 \mathrm{E}-11$ & 20.4 & 0.892 & $3.36 \mathrm{E}-11$ & 5.6 & 1 \\
\hline $238 U(n, f)$ & $6.09 \mathrm{E}-12$ & 2.2 & $5.41 \mathrm{E}-12$ & 18.6 & 0.888 & $6.10 \mathrm{E}-12$ & 2.5 & 1 \\
\hline 47Ti(n,p) & $3.45 \mathrm{E}-13$ & 2.2 & $3.56 \mathrm{E}-13$ & 21.1 & 1.033 & $3.48 E-13$ & 3.4 & 1.01 \\
\hline $58 \mathrm{Ni}(\mathrm{n}, \mathrm{p})$ & $1.89 \mathrm{E}-12$ & 2 & $1.61 \mathrm{E}-12$ & 19.1 & 0.854 & $1.89 \mathrm{E}-12$ & 3.8 & 1 \\
\hline $54 \mathrm{Fe}(\mathrm{n}, \mathrm{p})$ & $1.39 \mathrm{E}-12$ & 2.3 & $1.23 \mathrm{E}-12$ & 18.4 & 0.883 & $1.37 \mathrm{E}-12$ & 3.9 & 0.99 \\
\hline 46Ti(n,p) & $1.79 \mathrm{E}-13$ & 2.1 & $1.56 \mathrm{E}-13$ & 21.9 & 0.87 & $1.79 \mathrm{E}-13$ & 5.7 & 1 \\
\hline $63 \mathrm{Cu}(n, \alpha)$ & $8.36 \mathrm{E}-15$ & 3 & $7.55 \mathrm{E}-15$ & 17.9 & 0.903 & $8.63 \mathrm{E}-15$ & 5.1 & 1.03 \\
\hline 48Ti(n,p) & $4.76 \mathrm{E}-15$ & 2.8 & $3.77 \mathrm{E}-15$ & 20.2 & 0.791 & 4.70E-15 & 5.8 & 0.99 \\
\hline $27 \mathrm{Al}(\mathrm{n}, \alpha)$ & $1.07 \mathrm{E}-14$ & 5 & $9.54 \mathrm{E}-15$ & 18.7 & 0.892 & $1.04 \mathrm{E}-14$ & 6.4 & 0.97 \\
\hline
\end{tabular}



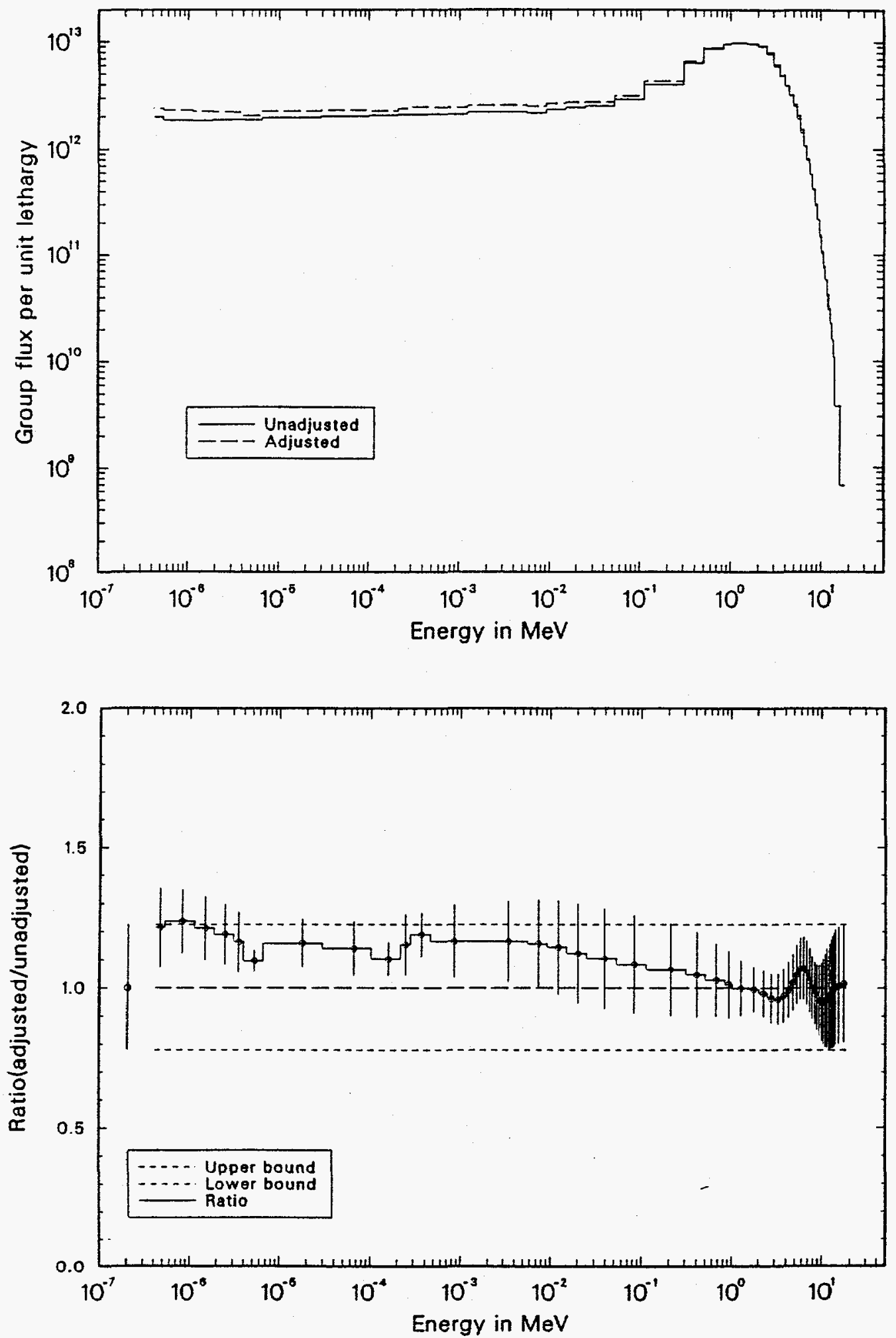

Figure SE1. Upper part of figure compares adjusted and unadjusted (input) group fluence rates for SE-1 location and lower part displays the ratio of adjusted-to-unadjusted group values with input uncertainty bounds and final uncertainty error bars. 
Table SE1. Adjusted group fluence rates for SE-1 irradiation location.

\begin{tabular}{|c|c|c|c|c|c|c|c|}
\hline GROUP & EU & $\mathbf{E L}$ & DU & PHA & UNCA & FRPHA & RPH \\
\hline 1 & $1.80 E+01$ & $1.60 E+01$ & 0.118 & $8.02 E+07$ & 20.8 & 0 & 1.02 \\
\hline 2 & $1.60 E+01$ & $1.40 \mathrm{E}+01$ & 0.134 & $5.05 E+08$ & 20.7 & 0 & 1.01 \\
\hline 3 & $1.40 E+01$ & 1.35E+01 & 0.036 & $3.93 E+08$ & 20.5 & 0 & 1 \\
\hline 4 & 1.35E+01 & $1.30 E+01$ & 0.038 & $5.97 E+08$ & 20.3 & 0 & 0.99 \\
\hline 5 & $1.30 E+01$ & 1.25E+01 & 0.039 & 8.71E+08 & 19.9 & 0 & 0.99 \\
\hline 6 & $1.25 E+01$ & $1.20 \mathrm{E}+01$ & 0.041 & $1.25 \mathrm{E}+09$ & 19.4 & 0 & 0.98 \\
\hline 7 & $1.20 E+01$ & $1.15 E+01$ & 0.043 & $1.76 \mathrm{E}+09$ & 18.7 & 0 & 0.97 \\
\hline 8 & $1.15 E+01$ & $1.10 E+01$ & 0.044 & $2.49 E+\infty 9$ & 17.8 & 0 & 0.96 \\
\hline 8 & 1.10E+01 & $1.05 E+01$ & 0.047 & $3.52 E+09$ & 16.7 & 0 & 0.96 \\
\hline 10 & $1.05 E+01$ & $1.00 E+01$ & 0.049 & $5.05 E+09$ & 15.4 & 0.01 & 0.95 \\
\hline 11 & $1.00 E+01$ & $9.50 E+\infty 0$ & 0.051 & $7.44 E+09$ & 14 & 0.01 & 0.95 \\
\hline 12 & $9.50 E+\infty 0$ & $9.00 E+\infty 0$ & 0.054 & $1.11 E+10$ & 12.7 & 0.02 & 0.95 \\
\hline 13 & $9.00 E+00$ & $8.50 E+00$ & 0.057 & $1.67 E+10$ & 11.7 & 0.02 & 0.97 \\
\hline 14 & $8.50 E+\infty 0$ & $8.00 E+\infty 0$ & 0.061 & $2.51 E+10$ & 11.2 & 0.03 & 0.98 \\
\hline 15 & $8.00 E+\infty 0$ & $7.50 E+\infty 0$ & 0.065 & $3.75 E+10$ & 11.2 & 0.05 & 1 \\
\hline 16 & $7.50 E+\infty 0$ & $7.00 E+\infty 0$ & 0.009 & $5.60 E+10$ & 11.3 & 0.08 & 1.03 \\
\hline 17 & $7.00 E+00$ & $6.50 E+\infty 0$ & 0.074 & $8.34 E+10$ & 11.4 & 0.11 & 1.05 \\
\hline 18 & $6.50 E+\infty 0$ & $6.00 E+\infty 0$ & 0.08 & $1.23 E+11$ & 11.2 & .17 & 1.07 \\
\hline 19 & $6.00 E+\infty 0$ & $5.50 E+\infty 0$ & 0.087 & $1.79 E+11$ & 10.8 & 0.24 & 1.07 \\
\hline 20 & $5.50 E+\infty$ & $5.00 E+\infty 0$ & 0.095 & $2.53 E+11$ & 10.4 & 0.34 & 1.05 \\
\hline 21 & $5.00 E+\infty$ & $4.50 E+\infty 0$ & 0.105 & $3.44 E+11$ & 10.1 & 0.46 & 1.02 \\
\hline 22 & $4.50 E+\infty 0$ & $4.00 E+00$ & 0.118 & $4.59 E+11$ & 9.9 & 0.62 & 0.99 \\
\hline 23 & $4.00 E+\infty 0$ & $3.50 E+\infty 0$ & 0.134 & $6.32 E+11$ & 9.6 & 0.85 & 0.97 \\
\hline 24 & $3.50 E+\infty 0$ & $3.00 E+\infty 0$ & 0.154 & $9.15 E+11$ & 9.1 & 1.24 & 0.96 \\
\hline 26 & $3.00 E+\infty 0$ & $2.50 E+\infty 0$ & 0.182 & $1.40 E+12$ & 8.8 & 1.88 & 0.96 \\
\hline 26 & $2.50 \mathrm{E}+\infty 0$ & $2.00 E+\infty 0$ & 0.223 & $2.01 E+12$ & 8.3 & 2.71 & 0.98 \\
\hline 27 & $2.00 E+\infty 0$ & $1.50 E+\infty 0$ & 0.288 & $2.74 E+12$ & 8.1 & 3.7 & 1 \\
\hline 28 & $1.50 E+\infty 0$ & $1.00 E+\infty$ & 0.405 & $3.97 E+12$ & 9.9 & 5.36 & 1 \\
\hline 29 & $1.00 E+\infty 0$ & 8.21E-01 & 0.197 & $1.90 E+12$ & 12 & 2.57 & 1.01 \\
\hline 30 & 8.21E-01 & 4.98E-01 & 0.5 & $4.42 E+12$ & 12.9 & 5.97 & 1.03 \\
\hline 31 & 4.98E-01 & 3.02E-01 & 0.5 & $3.32 E+12$ & 15.1 & 4.49 & 1.05 \\
\hline 32 & $3.02 E-01$ & 1.11E-01 & 1 & $4.34 E+12$ & 16.5 & 5.87 & 1.07 \\
\hline 33 & $1.11 E-01$ & $5.25 E-02$ & 0.75 & $2.40 E+12$ & 17.4 & 3.24 & 1.08 \\
\hline 34 & 5.25E-02 & 2.48E-02 & 0.75 & $2.11 E+12$ & 17.8 & 2.85 & 1.1 \\
\hline 35 & 2.48E-02 & $1.50 \mathrm{E}-02$ & 0.5 & $1.39 E+12$ & 17.6 & 1.87 & 1.12 \\
\hline 36 & $1.50 E-02$ & 9.12E-03 & 0.5 & $1.35 E+12$ & 16.7 & 1.83 & 1.14 \\
\hline 37 & $9.12 E-03$ & $5.53 E-03$ & 0.5 & $1.27 E+12$ & 15.6 & 1.71 & 1.16 \\
\hline 38 & 5.53E-03 & $1.23 E-03$ & 1.5 & $3.90 E+12$ & 14.3 & 5.26 & 1.17 \\
\hline 39 & $1.23 E-03$ & 4.54E-04 & 1 & $2.49 E+12$ & 12.9 & 3.36 & 1.16 \\
\hline 40 & 4.54E-04 & 2.75E-04 & 0.5 & $1.26 E+12$ & 7.8 & 1.7 & 1.19 \\
\hline 41 & 2.75E-04 & 2.14E-04 & 0.25 & $6.10 E+11$ & 10.8 & 0.82 & 1.15 \\
\hline 42 & 2.14E-04 & $1.01 E-04$ & 0.75 & $1.73 E+12$ & 5.9 & 2.33 & 1.1 \\
\hline 43 & $1.01 E-04$ & 2.90E-05 & 1.25 & $2.91 E+12$ & 9.6 & 3.94 & 1.14 \\
\hline 44 & 2.90E-05 & 6.48E-06 & 1.5 & $3.46 E+12$ & 8.4 & 4.68 & 1.16 \\
\hline 46 & $6.48 E-06$ & $3.93 E-06$ & 0.5 & $1.04 E+12$ & 3.7 & 1.41 & 1.1 \\
\hline 46 & 3.93E-06 & $3.06 E-06$ & 0.25 & $5.58 E+11$ & 10.7 & 0.75 & 1.16 \\
\hline 47 & $3.06 E-06$ & $1.86 E-06$ & 0.5 & $1.13 E+12$ & 10.8 & 1.52 & 1.19 \\
\hline 48 & $1.86 \mathrm{E}-06$ & $1.13 E-06$ & 0.5 & $1.13 E+12$ & 11.3 & 1.53 & 1.21 \\
\hline 49 & 1.13E-06 & 5.32E-07 & 0.75 & $1.75 E+12$ & 11.3 & 2.36 & 1.24 \\
\hline 50 & 5.32E-07 & 4.14E-07 & 0.25 & $6.07 E+11$ & 14.1 & 0.82 & 1.21 \\
\hline 51 & 4.14E-07 & $1.00 \mathrm{E}-10$ & 8.328 & $1.57 E+13$ & 22.4 & 21.18 & 1 \\
\hline
\end{tabular}


Table SE2. Cumulative adjusted group fluence rates for SE-1 irradiation location.

\begin{tabular}{|c|c|c|c|c|c|c|}
\hline GROUP & EU & $\mathbf{E L}$ & CPHA & UNCA & FRCPHA & RCPH \\
\hline 1 & $1.80 \mathrm{E}+01$ & $1.60 \mathrm{E}+01$ & $8.02 E+07$ & 20.8 & 0 & 1.02 \\
\hline 2 & $1.60 E+01$ & $1.40 E+01$ & $5.85 E+08$ & 20.2 & 0 & 1.01 \\
\hline 3 & $1.40 \mathrm{E}+01$ & 1.35E+01 & $9.78 E+08$ & 19.3 & 0 & 1.01 \\
\hline 4 & $1.35 E+01$ & $1.30 \mathrm{E}+01$ & $1.57 E+\infty 9$ & 18.7 & 0 & 1 \\
\hline 5 & $1.30 \mathrm{E}+01$ & $1.25 E+01$ & $2.45 E+09$ & 18 & 0 & 1 \\
\hline 6 & $1.25 E+01$ & $1.20 E+01$ & $3.69 E+09$ & 17.4 & 0 & 0.99 \\
\hline 7 & $1.20 E+01$ & $1.15 E+01$ & $5.45 E+09$ & 16.7 & 0.01 & 0.98 \\
\hline 8 & $1.15 E+01$ & $1.10 E+01$ & $7.94 E+09$ & 15.8 & 0.01 & 0.98 \\
\hline 9 & $1.10 \mathrm{E}+01$ & $1.05 E+01$ & $1.15 E+10$ & 14.8 & 0.02 & 0.97 \\
\hline 10 & $1.05 E+01$ & $1.00 E+01$ & $1.65 E+10$ & 13.7 & 0.02 & 0.96 \\
\hline 11 & $1.00 E+01$ & $9.50 E+\infty$ & $2.40 E+10$ & 12.3 & 0.03 & 0.96 \\
\hline 12 & $9.50 E+\infty$ & $9.00 E+\infty$ & $3.51 E+10$ & 10.7 & 0.05 & 0.96 \\
\hline 13 & $9.00 E+\infty$ & $8.50 E+\infty 0$ & $5.18 E+10$ & 9.1 & 0.07 & 0.96 \\
\hline 14 & $8.50 E+\infty 0$ & $8.00 E+\infty$ & $7.68 E+10$ & 7.6 & 0.1 & 0.97 \\
\hline 15 & $8.00 E+\infty$ & $7.50 E+\infty 0$ & $1.14 E+11$ & 6.5 & 0.15 & 0.98 \\
\hline 16 & $7.50 E+\infty$ & $7.00 E+\infty$ & $1.70 E+11$ & 6 & 0.23 & 0.99 \\
\hline 17 & $7.00 E+\infty$ & $6.50 E+\infty 0$ & $2.54 E+11$ & 5.9 & 0.34 & 1.01 \\
\hline 18 & $6.50 E+\infty$ & $6.00 E+\infty$ & $3.77 E+11$ & 6 & 0.51 & 1.03 \\
\hline 19 & $6.00 E+\infty 0$ & $5.50 E+\infty 0$ & $5.56 E+11$ & 6.1 & 0.75 & 1.04 \\
\hline 20 & $5.50 E+\infty$ & $5.00 \mathrm{E}+\infty 0$ & 8.09E+11 & 5.9 & 1.09 & 1.04 \\
\hline 21 & $5.00 E+\infty$ & $4.50 E+\infty 0$ & 1.15E+12 & 5.5 & 1.56 & 1.04 \\
\hline 22 & $4.50 E+\infty 0$ & $4.00 E+\infty 0$ & $1.61 E+12$ & 5.1 & 2.18 & 1.02 \\
\hline 23 & $4.00 E+\infty$ & $3.50 E+\infty$ & $2.24 E+12$ & 4.6 & 3.03 & 1.01 \\
\hline 24 & $3.50 E+\infty$ & $3.00 E+\infty$ & $3.16 E+12$ & 4.1 & 4.27 & 0.99 \\
\hline 26 & $3.00 E+\infty$ & $2.50 E+00$ & $4.55 E+12$ & 3.6 & 6.15 & 0.98 \\
\hline 26 & $2.50 \mathrm{E}+\infty 0$ & $2.00 E+\infty$ & $6.56 E+12$ & 3.1 & 8.86 & 0.98 \\
\hline 27 & $2.00 E+\infty 0$ & $1.50 E+\infty$ & $9.30 E+12$ & 2.5 & 12.56 & 0.99 \\
\hline 28 & $1.50 E+\infty$ & $1.00 E+\infty 0$ & $1.33 E+13$ & 3.3 & 17.92 & 0.99 \\
\hline 29 & $1.00 E+\infty$ & 8.21E-01 & $1.52 E+13$ & 3.6 & 20.49 & 0.99 \\
\hline 30 & 8.21E-01 & 4.98E-01 & $1.96 E+13$ & 4.7 & 26.46 & 1 \\
\hline 31 & 4.98E-01 & $3.02 \mathrm{E}-01$ & $2.29 E+13$ & 5.5 & 30.95 & 1.01 \\
\hline 32 & $3.02 E-01$ & 1.11E-01 & $2.73 E+13$ & 6.6 & 36.82 & 1.02 \\
\hline 33 & 1.11E-01 & $5.25 E-02$ & $2.97 E+13$ & 7.1 & 40.06 & 1.02 \\
\hline 34 & 5.25E-02 & $2.48 E-02$ & $3.18 E+13$ & 7.4 & 42.91 & 1.03 \\
\hline 36 & $2.48 E-02$ & $1,50 E-02$ & $3.31 E+13$ & 7.6 & 44.78 & 1.03 \\
\hline 36 & $1.50 \mathrm{E}-02$ & $9.12 E-03$ & $3.45 E+13$ & 7.6 & 46.61 & 1.03 \\
\hline 37 & $9.12 E-03$ & $5.53 E-03$ & $3.58 E+13$ & 7.6 & 48.32 & 1.04 \\
\hline 38 & 5.53E-03 & $1.23 E-03$ & $3.97 E+13$ & 7.5 & 53.58 & 1.05 \\
\hline 39 & $1.23 E-03$ & 4.54E-04 & $4.21 E+13$ & 73 & 56.94 & 1.06 \\
\hline 40 & 4.54E-04 & $2.75 E-04$ & $4.34 E+13$ & 7.1 & 58.64 & 1.06 \\
\hline 41 & $2.75 E-04$ & 2.14E-04 & $4.40 E+13$ & 7 & 59.47 & 1.06 \\
\hline 42 & 2.14E-04 & $1.01 E-04$ & $4.57 E+13$ & 6.8 & 61.8 & 1.06 \\
\hline 43 & 1.01E-04 & 2.90E-05 & $4.87 E+13$ & 6.3 & 65.74 & 1.07 \\
\hline 4 & 2.90E-05 & $6.48 E-06$ & $5.21 E+13$ & 5.8 & 70.42 & 1.07 \\
\hline 45 & $6.48 E-06$ & 3.93E-06 & $5.32 E+13$ & 5.7 & 71.83 & 1.07 \\
\hline 46 & $3.93 E-06$ & $3.06 E-06$ & $5.37 E+13$ & 5.6 & 72.58 & 1.07 \\
\hline 47 & 3.06E-06 & $1.86 E-06$ & $5.48 E+13$ & 5.5 & 74.1 & 1.08 \\
\hline 48 & $1.86 E-06$ & $1.13 E-06$ & $5.60 E+13$ & 5.4 & 75.64 & 1.08 \\
\hline 40 & $1.13 E-06$ & 5.32E-07 & $5.77 E+13$ & 5.2 & 78 & 1.08 \\
\hline 60 & 5.32E-07 & 4.14E-07 & $5.83 E+13$ & 5.1 & 78.82 & 1.08 \\
\hline 51 & 4.14E-07 & $1.00 E-10$ & $7.40 E+13$ & 6.2 & 100 & 1.06 \\
\hline
\end{tabular}



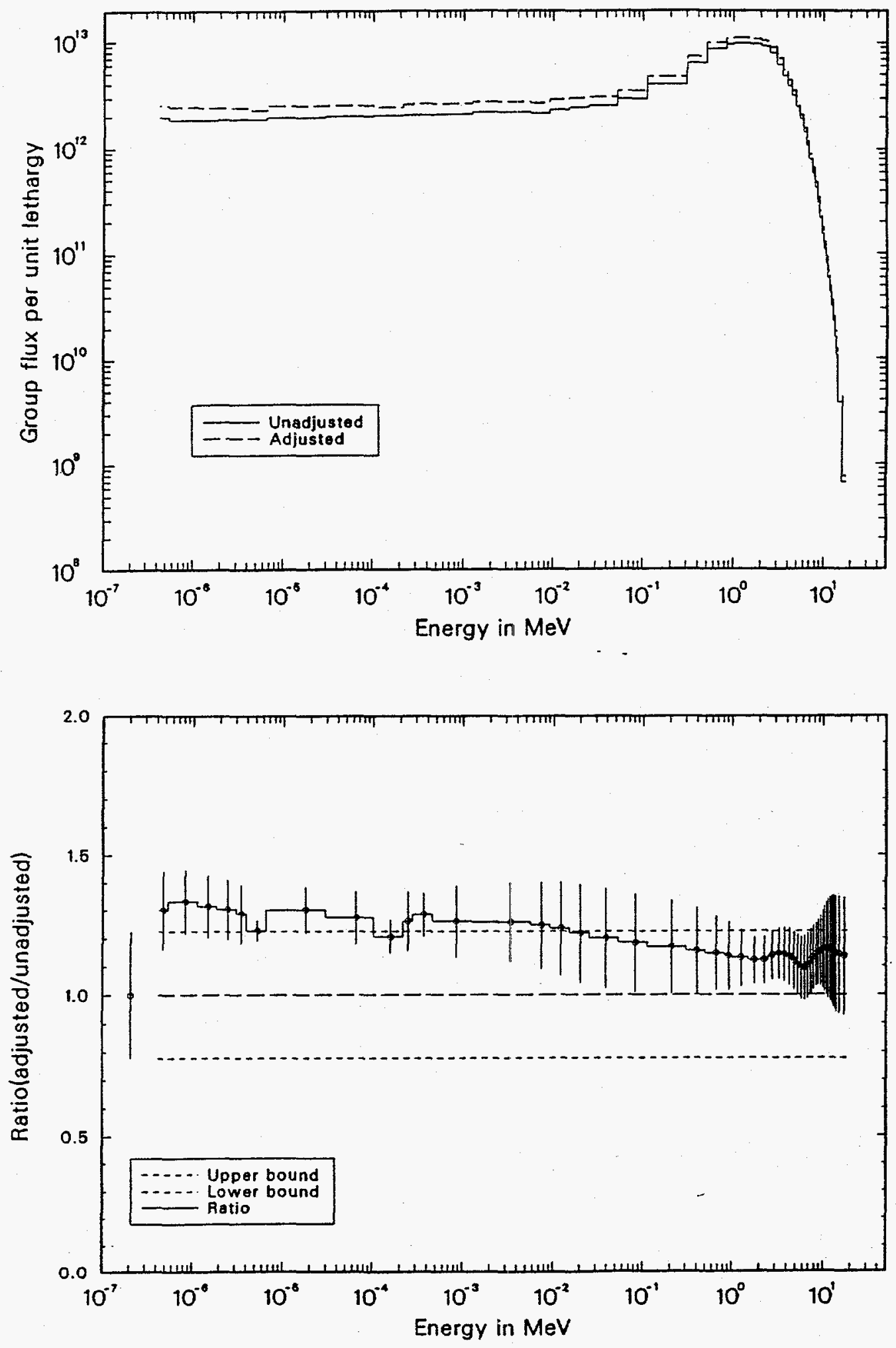

Figure SE2. Upper part of figure compares adjusted and unadjusted (input) group fluence rates for SE-3 location and lower part displays the ratio of adjusted-to-unadjusted group values with input uncertainty bounds and final uncertainty error bars. 
Table SE3. Adjusted group fluence rates for SE-3 irradiation location.

\begin{tabular}{|c|c|c|c|c|c|c|c|}
\hline GROUP & $\mathbf{E U}$ & EL & DU & PHA & UNCA & FRPHA & RPH \\
\hline 1 & $1.80 E+01$ & $1.60 E+01$ & 0.118 & $8.96 E+07$ & 20.8 & 0 & 1.13 \\
\hline 2 & $1.60 E+01$ & $1.40 E+01$ & 0.134 & $5.71 E+08$ & 20.7 & 0 & 1.14 \\
\hline 3 & $1.40 E+01$ & $1.35 E+01$ & 0.036 & $4.49 E+08$ & 20.5 & 0 & 1.15 \\
\hline 4 & $1.35 E+01$ & $1.30 \mathrm{E}+01$ & 0.038 & $6.91 E+08$ & 20.2 & 0 & 1.15 \\
\hline 6 & 1.30E+01 & $1.25 E+01$ & 0.039 & $1.02 \mathrm{E}+09$ & 19.8 & 0 & 1.16 \\
\hline 6 & $1.25 E+01$ & $1.20 \mathrm{E}+01$ & 0.041 & $1.48 E+09$ & 19.3 & 0 & 1.16 \\
\hline$T$ & $1.20 E+01$ & 1.15E+01 & 0.043 & $2.11 E+09$ & 18.6 & 0 & 1.16 \\
\hline 8 & 1.15E+0t & $1.10 E+01$ & 0.044 & $3.01 E+09$ & 17.6 & 0 & 1.16 \\
\hline 9 & $1.10 E+01$ & $1.05 E+01$ & 0.047 & $4.28 E+09$ & 16.5 & 0.01 & 1.16 \\
\hline 10 & 1.05E+01 & $1.00 E+01$ & 0.049 & $6.18 E+\infty 9$ & 15.1 & 0.01 & 1.16 \\
\hline 11 & $1.00 E+01$ & $9.50 E+\infty$ & 0.051 & $9.09 E+09$ & 13.7 & 0.01 & 1.16 \\
\hline 12 & $9.50 E+\infty$ & $9.00 E+\infty$ & 0.054 & $1.35 \mathrm{E}+10$ & 12.4 & 0.02 & 1.16 \\
\hline 13 & $9.00 E+\infty$ & $8.50 E+\infty$ & 0.057 & $1.99 E+10$ & 11.5 & 0.02 & 1.15 \\
\hline 14 & $8.50 E+\infty$ & $8.00 E+\infty$ & 0.061 & $2.92 E+10$ & 11.2 & 0.04 & 1.14 \\
\hline 16 & $8.00 E+\infty$ & $7.50 E+\infty$ & 0.065 & $4.24 E+10$ & 11.3 & 0.05 & 1.13 \\
\hline 16 & $7.50 \mathrm{E}+00$ & $7.00 E+\infty$ & 0.069 & $6.09 E+10$ & 11.5 & 0.08 & 1.12 \\
\hline 17 & $7.00 E+\infty$ & $6.50 E+\infty$ & 0.074 & $8.73 E+10$ & 11.6 & 0.11 & 1.1 \\
\hline 18 & $6.50 E+\infty 0$ & $6.00 E+\infty$ & 0.08 & $1.26 \mathrm{E}+11$ & 11.4 & 0.16 & 1.1 \\
\hline 19 & $6.00 E+\infty$ & $5.50 E+\infty$ & 0.087 & $1.84 E+11$ & 11 & 0.23 & 1.09 \\
\hline 20 & $5.50 E+\infty$ & $5.00 E+\infty 0$ & 0.095 & $2.66 E+11$ & 10.5 & 0.33 & 1.11 \\
\hline 21 & $5.00 E+\infty$ & $4.50 E+\infty$ & 0.105 & $3.78 E+11$ & 10.2 & 0.47 & 1.12 \\
\hline 22 & $4.50 E+\infty 0$ & $4.00 E+\infty$ & 0.118 & $5.24 E+11$ & 9.9 & 0.65 & 1.13 \\
\hline 23 & $4.00 E+\infty$ & $3.50 E+\infty$ & 0.134 & $7.41 E+11$ & 9.5 & 0.92 & 1.14 \\
\hline 24 & $3.50 E+\infty$ & $3.00 E+\infty 0$ & 0.154 & $1.09 E+12$ & 9 & 1.36 & 1.15 \\
\hline 26 & $3.00 E+\infty$ & $2.50 E+\infty 0$ & 0.182 & $1.65 E+12$ & 8.7 & 2.06 & 1.14 \\
\hline 26 & $2.50 E+\infty$ & $2.00 E+\infty 0$ & 0.223 & $2.30 E+12$ & 8.3 & 2.86 & 1.12 \\
\hline 27 & $2.00 E+\infty$ & $1.50 E+\infty$ & 0.288 & $3.08 E+12$ & 8.1 & 3.84 & 1.12 \\
\hline 28 & $1.50 E+\infty$ & $1.00 E+\infty$ & 0.405 & $4.49 E+12$ & 10 & 5.59 & 1.13 \\
\hline 29 & $1.00 \mathrm{E}+\infty 0$ & 8.21E-01 & 0.197 & $2.14 E+12$ & 12 & 2.66 & 1.14 \\
\hline 30 & 8.21E-01 & 4.98E-01 & 0.5 & $4.93 E+12$ & 13 & 6.14 & 1.15 \\
\hline 31 & 4.98E-01 & $3.02 E-01$ & 0.5 & $3.66 E+12$ & 15.2 & 4.56 & 1.15 \\
\hline 32 & $3.02 E-01$ & $1.11 E-01$ & 1 & $4.76 E+12$ & 16.6 & 5.94 & 1.17 \\
\hline 33 & $1.11 E-01$ & $5.25 E-02$ & 0.75 & $2.62 E+12$ & 17.5 & 3.27 & 1.18 \\
\hline 34 & 5.25E-02 & $2.48 \mathrm{E}-02$ & 0.75 & $2.29 E+12$ & 17.9 & 2.86 & 1.2 \\
\hline 36 & 2.48E-02 & $1.50 \mathrm{E}-02$ & 0.5 & $1.50 E+12$ & 17.7 & 1.87 & 1.22 \\
\hline 36 & $1.50 E-02$ & $9.12 E-03$ & 0.5 & $1.46 E+12$ & 16.7 & 1.82 & 1.23 \\
\hline 37 & $9.12 E-03$ & $5.53 E-03$ & 0.5 & $1.36 E+12$ & 15.6 & 1.7 & 1.25 \\
\hline 38 & $5.53 E-03$ & $1.23 E-03$ & 1.5 & $4.20 E+12$ & 14.3 & 5.24 & 1.26 \\
\hline 39 & $1.23 E-03$ & 4.54E-04 & 1 & $2.69 E+12$ & 13 & 3.35 & 1.26 \\
\hline 40 & 4.54E-04 & 2.75E-04 & 0.5 & $1.36 \mathrm{E}+12$ & 7.8 & 1.69 & 1.28 \\
\hline 41 & 2.75E-04 & $2.14 E-04$ & 0.25 & $6.67 E+11$ & 10.8 & 0.83 & 1.26 \\
\hline 42 & 2.14E-04 & 1.01E-04 & 0.75 & $1.89 E+12$ & 6 & 2.35 & 1.2 \\
\hline 43 & 1.01E-04 & $2.90 E-05$ & 1.25 & $3.25 E+12$ & 9.6 & 4.05 & 1.27 \\
\hline 44 & 2.90E-05 & $6.48 E-06$ & 1.5 & $3.89 E+12$ & 8.4 & 4.85 & 1.3 \\
\hline 45 & $6.48 E-06$ & $3.93 E-06$ & 0.5 & $1.17 E+12$ & 3.7 & 1.45 & 1.23 \\
\hline 46 & 3.93E-06 & $3.06 E-06$ & 0.25 & $6.17 E+11$ & 10.7 & 0.77 & 1.29 \\
\hline 47 & $3.06 E-06$ & $1.86 \mathrm{E}-06$ & 0.5 & $1.23 E+12$ & 10.8 & 1.54 & 1.3 \\
\hline 48 & $1.86 E-06$ & $1.13 E-06$ & 0.5 & $1.23 E+12$ & 11.3 & 1.53 & 1.31 \\
\hline 49 & 1.13E-06 & $5.32 E-07$ & 0.75 & $1.88 E+12$ & 11.4 & 2.34 & 1.33 \\
\hline 60 & $5.32 E-07$ & 4.14E-07 & 0.25 & $6.50 E+11$ & 14.1 & 0.81 & 1.3 \\
\hline 51 & 4.14E-07 & $1.00 \mathrm{E}-10$ & 8.328 & $1.57 E+13$ & 22.4 & 19.54 & 1 \\
\hline
\end{tabular}


Table SE4. Cumulative adjusted group fluence rates for SE-3 irradiation location.

\begin{tabular}{|c|c|c|c|c|c|c|}
\hline GROUP & EU & EL & CPHA & UNCA & FRCPHA & RCPH \\
\hline 1 & $1.80 E+01$ & $1.60 \mathrm{E}+01$ & $8.96 E+07$ & 20.8 & 0 & 1.13 \\
\hline 2 & $1.60 E+01$ & $1.40 E+01$ & $6.61 E+08$ & 20.2 & 0 & 1.14 \\
\hline 3 & $1.40 E+01$ & $1.35 E+01$ & $1.11 E+09$ & 19.3 & 0 & 1.14 \\
\hline 4 & 1.35E+01 & $1.30 E+01$ & $1.80 E+09$ & 18.6 & 0 & 1.15 \\
\hline 5 & $1.30 \mathrm{E}+01$ & $1.25 E+01$ & $2.82 E+09$ & 18 & 0 & 1.15 \\
\hline 6 & $1.25 E+01$ & $1.20 E+01$ & 4.30E+09 & 17.3 & 0.01 & 1.15 \\
\hline 7 & $1.20 E+01$ & $1.15 E+01$ & $6.41 E+09$ & 16.6 & 0.01 & 1.16 \\
\hline 8 & 1.15E+01 & $1.10 E+01$ & $9.42 E+09$ & 15.7 & 0.01 & 1.16 \\
\hline 8 & $1.10 E+01$ & $1.05 E+01$ & 1.37E+10 & 14.7 & 0.02 & 1.16 \\
\hline 10 & $1.05 E+01$ & $1.00 E+01$ & 1.99E+10 & 13.4 & 0.02 & 1.16 \\
\hline 11 & $1.00 E+01$ & $9.50 E+\infty 0$ & $2.90 E+10$ & 12 & 0.04 & 1.16 \\
\hline 12 & $9.50 E+\infty 0$ & $9.00 E+\infty 0$ & $4.24 E+10$ & 10.4 & 0.05 & 1.16 \\
\hline 13 & $9.00 E+\infty 0$ & $8.50 E+\infty$ & $6.23 E+10$ & 8.7 & 0.08 & 1.16 \\
\hline 14 & $8.50 E+\infty 0$ & $8.00 E+\infty 0$ & $9.15 E+10$ & 7.3 & 0.11 & 1.15 \\
\hline 15 & $8.00 E+\infty$ & $7.50 E+\infty 0$ & $1.34 E+11$ & 6.3 & 0.17 & 1.14 \\
\hline 16 & $7.50 E+\infty$ & $7.00 E+\infty 0$ & 1.95E+11 & 5.8 & 0.24 & 1.14 \\
\hline 17 & $7.00 \mathrm{E}+\infty$ & $6.50 E+\infty 0$ & $2.82 E+11$ & 5.9 & 0.35 & 1.13 \\
\hline 18 & $6.50 E+\infty 0$ & $6.00 E+\infty 0$ & 4.08E+11 & 6 & 0.51 & 1.12 \\
\hline 19 & $6.00 E+\infty 0$ & $5.50 E+\infty 0$ & $5.92 E+11$ & 6.1 & 0.74 & 1.11 \\
\hline 20 & $5.50 E+\infty$ & $5.00 E+\infty 0$ & $8.58 E+11$ & 5.9 & 1.07 & 1.11 \\
\hline 21 & $5.00 E+\infty 0$ & $4.50 E+\infty 0$ & 1.24E+12 & 5.6 & 1.54 & 1.11 \\
\hline 22 & $4.50 E+\infty$ & $4.00 E+\infty$ & $1.76 E+12$ & 5.2 & 2.19 & 1.12 \\
\hline 23 & 4.00E $+\infty$ & $3.50 E+\infty 0$ & $2.50 \mathrm{E}+12$ & 4.7 & 3.12 & 1.12 \\
\hline 24 & $3.50 E+\infty$ & $3.00 E+\infty 0$ & $3.59 E+12$ & 4.2 & 4.48 & 1.13 \\
\hline 25 & $3.00 E+\infty 0$ & $2.50 E+\infty 0$ & $5.24 E+12$ & 3.6 & 6.53 & 1.13 \\
\hline 26 & $2.50 E+\infty 0$ & $2.00 E+\infty$ & $7.54 E+12$ & 3.1 & 9.4 & 1.13 \\
\hline 27 & $2.00 E+\infty 0$ & $1.50 E+\infty 0$ & $1.06 E+13$ & 2.5 & 13.24 & 1.13 \\
\hline 28 & $1.50 E+\infty$ & $1.00 E+\infty$ & $1.51 E+13$ & 3.3 & 18.83 & 1.13 \\
\hline 29 & $1.00 E+\infty$ & $8.21 E-01$ & $1.73 E+13$ & 3.6 & 21.49 & 1.13 \\
\hline 30 & $8.21 E-01$ & $4.98 E-01$ & $2.22 E+13$ & 4.7 & 27.63 & 1.13 \\
\hline 31 & 4.98E-01 & $3.02 E-01$ & $2.58 E+13$ & 5.5 & 32.2 & 1.14 \\
\hline 32 & $3.02 E-01$ & $1.11 E-01$ & $3.06 E+13$ & 6.6 & 38.13 & 1.14 \\
\hline 33 & 1.11E-01 & $5.25 E-02$ & $3.32 E+13$ & 7 & 41.4 & 1.14 \\
\hline 34 & 5.25E-02 & $2.48 E-02$ & $3.55 \mathrm{E}+13$ & 7.4 & 44.26 & 1.15 \\
\hline 35 & $2.48 E-02$ & $1.50 E-02$ & $3.70 E+13$ & 7.5 & 46.13 & 1.15 \\
\hline 36 & 1.50E-02 & $9.12 E-03$ & $3.85 E+13$ & 7.6 & 47.95 & 1.15 \\
\hline 37 & $9.12 E-03$ & $5.53 E-03$ & $3.98 E+13$ & 7.6 & 49.65 & 1.16 \\
\hline 38 & $5.53 E-03$ & $1.23 E-03$ & 4. $40 E+13$ & 7.4 & 54.89 & 1.17 \\
\hline 39 & $1.23 E-03$ & $4.54 E-04$ & $4.67 E+13$ & 7.3 & 58.24 & 1.17 \\
\hline 40 & $4.54 E-04$ & $2.75 E-04$ & $4.81 E+13$ & 7.1 & 59.93 & 1.17 \\
\hline 41 & 2.75E-04 & 2.14E-04 & $4.88 E+13$ & 7 & 60.76 & 1.17 \\
\hline 42 & 2.14E-04 & $1.01 E-04$ & $5.06 E+13$ & 6.7 & 63.12 & 1.18 \\
\hline 43 & $1.01 E-04$ & 2.90E-05 & $5.39 E+13$ & 6.3 & 67.17 & 1.18 \\
\hline 4 & 2.90E-05 & $6.48 E-06$ & $5.78 E+13$ & 5.8 & 72.01 & 1.19 \\
\hline 46 & $6.48 E-06$ & $3.93 E-06$ & $5.90 E+13$ & 5.7 & 73.47 & 1.19 \\
\hline 46 & 3.93E-06 & $3.06 E-06$ & $5.96 \mathrm{E}+13$ & 5.6 & 74.24 & 1.19 \\
\hline 47 & $3.06 E-06$ & $1.86 E-06$ & $6.08 E+13$ & 5.5 & 75.77 & 1.19 \\
\hline 48 & $1.86 E-06$ & $1.13 E-06$ & $6.20 E+13$ & 5.3 & 77.31 & 1.19 \\
\hline 49 & $1.13 E-06$ & 5.32E-07 & $6.39 E+13$ & 5.1 & 79.65 & 1.2 \\
\hline 50 & 5.32E-07 & 4.14E-07 & $6.46 \mathrm{E}+13$ & 5.1 & 80.46 & 1.2 \\
\hline 51 & 4.14E-07 & $1.00 E-10$ & $8.02 E+13$ & 6 & 100 & 1.15 \\
\hline
\end{tabular}

